Florida International University FIU Digital Commons

\title{
Using Introduced Species of Anolis Lizards to Test Adaptive Radiation Theory
}

James T. Stroud

Florida International University, jstro014@fiu.edu

DOI: 10.25148 /etd.FIDC006576

Follow this and additional works at: https:// digitalcommons.fiu.edu/etd

Part of the Behavior and Ethology Commons, Evolution Commons, and the Other Ecology and Evolutionary Biology Commons

\section{Recommended Citation}

Stroud, James T., "Using Introduced Species of Anolis Lizards to Test Adaptive Radiation Theory" (2018). FIU Electronic Theses and Dissertations. 3695.

https://digitalcommons.fiu.edu/etd/3695 


\title{
FLORIDA INTERNATIONAL UNIVERSITY
}

\author{
Miami, Florida
}

\section{USING INTRODUCED SPECIES OF ANOLIS LIZARDS TO TEST ADAPTIVE RADIATION THEORY}

A dissertation in partial fulfillment of the

Requirements for the degree of

DOCTOR OF PHILOSOPHY

In

BIOLOGY

By

James T. Stroud 
To: $\quad$ Dean Michael R. Heithaus

College of Arts, Sciences, and Education

This dissertation, written by James T. Stroud, and entitled Using Introduced Species of Anolis Lizards to Test Adaptive Radiation Theory, having been approved in respect to style and intellectual content, is referred to you for judgment.

We have read this dissertation and recommend that it be approved.

Maureen A. Donnelly

Christopher Baraloto

Hong Liu

Jonathan B. Losos

Kenneth J. Feeley, Major Professor

Date of Defense: March 2, 2018

The dissertation of James T. Stroud is approved.

Dean Michael R. Heithaus College of Arts, Sciences, and Education

Andrés G. Gil

Vice President for Research and Economic Development and Dean of the University Graduate School

Florida International University, 2018 


\section{COPYRIGHT PAGE}

The chapter listed below have been published in peer-reviewed journals. The journal "Annual Review of Ecology, Evolution, and Systematics" states that authors do not need to obtain permission to reuse the material in their review (Chapter II). Specifically, the copyright transfer agreement provides “...the nonexclusive right to use, reproduce, distribute, perform, update, create derivatives, and make copies of the work (electronically or in print) in connection with the author's teaching, conference presentations, lectures, and publications, provided proper attribution is given.” The journal “Biological Invasions” is published by Springer and has granted Copright Clearance (order no. 4201361412484) to publish Chapter V in this dissertation. Chapter III has been formatted for submission to "Proceedings of the National Academy of Sciences". Chapter IV has been formatted for submission to "Ecology Letters".

\section{CHAPTER II}

Stroud JT and Losos JB (2016) Ecological opportunity and adaptive radiation. Annual Review of Ecology, Evolution, and Systematics, 47: 507-532

\section{CHAPTER V}

Stroud JT, Giery ST, and Outerbridge ME (2017) Establishment of Anolis sagrei on Bermuda represents a novel ecological threat to Critically Endangered Bermuda skinks (Plestiodon longirostris). Biological Invasions 19: 1723-1731

All other materials (C) Copyright 2018 by James T. Stroud

All rights reserved 


\section{DEDICATION}

To my parents, Mark and Teresa.

For everything, and more. 


\section{ACKNOWLEDGMENTS}

The fact that this Acknowledgments section is so long is testament to the many wonderful, caring, intelligent, and marvellous people that I have had the absolute pleasure of coming across during my doctoral studies. Thank you, you are all beautiful. This list is presented in no particular order of importance, and I have attempted to be as exhaustive as my [exhausted] mind will let me however, due to those reasons, there is a chance that some of you may have escaped this list. If so, I apologise in advance, and please do not hesitate in reminding me. I will be extraordinarily embarrassed and buy you lunch.

First of all, I must thank my family. I was so incredibly moved that all of you made the $>4,000$ mile trip from London to watch my defence. The fact that that act itself only represents a tiny example of your support is a testament to how truly important you were in this dissertation being a success. I hope you all know that I would do anything to reciprocate. This dissertation is dedicated wholeheartedly to my parents: the best people I know in the world. Thank you for always encouraging me to be curious, be successful, and for setting the standards of how hard you should work if it's something you are truly passionate about. The tireless, and all-too-often (and ashamedly) thankless, effort and care you put in to ensuring that we would always have access to the best education available is humbling. I am so, so proud to call you my parents. My sisters, Jessica and Olivia, are the most unfathomably supportive siblings imaginable. I am prouder of you than you could ever possibly believe. The strongest, most caring, and most intelligent women. Thank you for taking your spare time - where you could have gone anywhere in the world (!) - to come and visit me during my PhD studies, it means so much. I owe a special thank you to my Nan and Grandad. I am sorry I couldn’t finish earlier. I tried. I know how proud you always are of all of us.

To Ken, thank you so much for the past 5 years. Most obviously and primarily for doing all the things a great advisor would (and should) do, but also for the trust and freedom that you 
afforded me when I fled on a totally different research tangent to the rest of the lab. I can say, with confidence, that I never studied anything in my PhD that I did not find truly exciting and enjoyable. For that, I thank you deeply. Prior to joining the lab I had resigned myself to a life outside of academia; my many failed applications to graduate school lead me to believe I was not strong or smart enough to study the things I was most interested in - those topics were destined for others. You allowed me to find out if I could. Any advisor that supports that is invaluable.

To my committee members, thank you. Mo, you never hesitated in offering advice, were extremely generous - especially with providing housing at the annual JMIH conferences, and frequently took me in as an adopted lab member. You were always available to me for help, thank you! Thank you to Hong Liu and John Withey, who were both valuable committee members, and to Chris Baraloto for stepping in after John Withey left FIU. Jonathan, you were a continual source of advice and support throughout my $\mathrm{PhD}$. Thank you for gently guiding me with your advice, and for nonchalantly dropping questions in conversations which led to years of thinking. Having the opportunity to write the Annual Review (Chapter II) together was incredible; I learnt an awful lot about evolutionary theory, but (most importantly) it was also a wonderfully insightful internship in scientific writing.

Fairchild Tropical Botanic Gardens were - and continue to be - overwhelmingly supportive of my lizard research in the gardens. I am incredibly proud of the research system on the anole community at FTBG that I have been able to develop over the past 5 years, and most especially proud of our "Lizards On The Loose” outreach project with the Fairchild Challenge (thanks to their whole team, especially Amanda Noble and Barbara Martinez). The director of the garden, Carl Lewis, has never refused any of my (many) requests, and Amy Padolf - the director of education at Fairchild - has always been wonderfully supportive throughout (and always excited about science!). Special thank you to the administrative staff for always helping, most of all Rose Ricks - you are an angel! 
Thank you to all of the people and agencies that provided my $\mathrm{PhD}$ research with financial support; FIU Dissertation Evidence Acquisition [DEA] Fellowship, FIU Dissertation Year Fellowship [DYF], FIU Judith Evans Parker International Travel Fellowship, FIU Kimberly Green Latin American and Caribbean Center (LACC) Tinker Research Grant, Fairchild Tropical Botanic Garden (Graduate Student Research Grant), American Society of Naturalists (Graduate Research Award), National Science Foundation (NSF) Doctoral Dissertation Improvement Grant (DDIG), Bermuda Zoological Association’s Eric Clee Research Award. And thank you to the following for sponsoring travel to conferences for me to present my dissertation research: FIU Dept. of Biology, CASE, UGS, and FCE/LTER, American Society of Naturalists, and the American Society of Ichthyologists and Herpetologists. Additionally, thank you to FIU's College of Arts and Science’s for awarding my Chapter II ("Ecological Opportunity and Adaptive Radiation”) as FIU’s 2017 Outstanding Graduate Student Manuscript in STEM. And thank you to FIU's Outstanding Student Life Awards for awarding me with the 2017 Outstanding Graduate Scholar Award.

Thank you to all of my Feeley labmates past and present: Brian Machovina, Catherina Bravo-Avila, Belen Fadrique, and Christine Pardo, but special thanks goes to Tim Perez. As soon as you started you impressed me with your passion for botany and natural inquisitiveness (but probably most with your collection of mind-blowing shirts - as I write this you are wearing your shirt with zebras on. Classic.). My dissertation writing was definitely helped by having you around to bounce ideas off, however lizards are still > plants. I must also afford great thanks to my former lab-mate Evan Rehm. Evan you really supported me and guided me through the early stages of my $\mathrm{PhD}$, probably more than you realized. You were a great mentor. Thank you.

Thank you to all of the FIU undergraduate students that have helped me throughout my doctorate research. Veronica Vargas, your help with toepad analysis was priceless. Oliver Ljustina, you're a rock star. Keep going at it. Thank you for working tirelessly and 
enthusiastically in whatever crazy project we dreamed up. Nick Palermo, I am incredibly proud to have watched you graduate from undergrad and now develop into an established and successful $\mathrm{PhD}$ student - thanks for helping me out in my early days! Same goes to Marie Colom, you really pioneered our early ethological work in Miami anoles. Thank you!

Mark Ladd - in my first week here, when I knew no one in the country and found myself in a couple of sticky situations, you made sure to take me under your wing. Little did I know how big that wing was or how important it would become. Your friendship was invaluable to so many personal and professional aspects of me succeeding in graduate school. Thank you, mate! While recognising Mark it would be hard not to also recognise his conjoined-twin Dr. Andy Shantz. Some of their antics would occasionally make it hard for me to remind myself what brilliant, hardworking, and articulate scientists they are. The pair of you facilitated some truly great times in Miami and I am indebted to you both. p.s. I'm still backing myself to make a 40 yard field goal. Sabrina, thank you for (time and time again...!) looking after us so well! On that note, the entire Schneider family have always been fabulously welcoming from the moment we met. Beautiful people and I am grateful for everything they have done to make Miami feel like home. Thanksgiving will never be the same!

Brett Pierce and Geoffrey Shideler (and their wonderful wives, Jess and Allison) have become incredibly close and treasured friends over the past couple of years. You truly are one of the biggest reasons I (and we) are sad to be leaving Miami. On that note, thank you to the Pierce family, Ron and Susan, for providing accommodation in Troy, Alabama, where we sought refuge following our evacuation from Florida due to Hurricane Irma in the autumn of 2017.

Throughout my PhD I have frequently deferred difficult questions to, and requested advice from, Sean Giery, who is a brilliant scientist and an even better naturalist. I look forward to (and hope for) a long career of friendship and collaboration. Hopefully one that includes annual trips Bermuda! Michelle Thompson, thank you for hosting during my trips to Costa Rica, but 
most especially for being both a reliable outlet to vent about graduate school and a perpetual avenue of support as we - at times, blindly - made our way through our PhDs. Mike Bush, thanks for always being there. You're the man. Special thanks to all of my other Miami friends that truly made my time here enjoyable; Sean Charles, Jenn Sweatman, Lela Schlenker, Winter Beckles, Nathan Lemoine, Greg Hill, Ben Wilson, Luke Linhoff, and Mike Britton.

England isn’t famous for producing lizard scientists - in part due to only having 3 species of native lizards, one of which has no legs, and one of which is restricted to sandy dunes, not a feature for which the British Isles are necessarily known for. However, Rob Heathcote is one. Thank you, mate, for always being there to support me with whatever crazy, inaccurate, and (probably) impossible idea I was excitedly telling you about at any given time. Hopefully you'll come back from the dark side (fish) soon. On that note, thank you Alex Pigot for being one of the most articulate minds I know - your feedback on my work is always insightful, and conversations about any aspect of ecology and evolution always enlightening.

Thank you to my lifelong friends back home; Steve Cronin, Matthew Silley, Jimmy Spence, Tom Stacey, and Liam Whelan (it's alphabetical order, chill out) for always making me realise that even in the grand scheme of things in the real non-PhD-student world - babies, mortgages, etc - I still had the most difficult, stressful, and important career, and they recognised and respected that. Jokes aside, thanks for always being there. Jim, Steve \& Helen, and Matt \& Lauren thanks for coming to visit! Sam Lander, you were a consistent source of counsel for all things, thank you for that and for coming over! Superhoops. Tom Flanagan, thanks for coming over so much in the first couple of years of my $\mathrm{PhD}$ - it really meant a lot, and I loved spending that time together. Most importantly, thanks for never bringing Patty back.

It is important for me to also generously thank Anne and Jon Flanagan, my aunt and uncle. You have encouraged and supported me a lot throughout my life, not just in the past 5 years, and I can't put into words how important that is. Laura, you are a sister to me, and all of 
the things I said about Jess and Liv unreservedly apply to you too. Same with Trish, thank you so much for supporting my love of nature. I am so extremely lucky to have the family that I do. Similarly, special thank you to Sharon and Joe Lewin for making it all the way out here as part of my extended family to watch my defence! I also owe great thanks to Alejandro and Arlim Belisario for all of their love and support throughout the latter stages of my doctoral studies. They are amazingly beautiful people, fed me with more punta trasera and paella than I ever thought possible, and never faltered in welcoming me into their family. Thank you, from the bottom of my heart.

I owe great thanks to Jason Kolbe, as you were the one truly responsible for introducing me to the world of Florida anoles. You have helped me through almost all stages of this dissertation, right from its early inception (and editing my dreadful first year grant proposals...) through to research projects which we are still working on together. You were the most important advisor to me outside of my committee. Thank you! Also thank you (and Jonathan) for bringing me over to Abaco in my first year of my $\mathrm{PhD}$ to assist with your Bahamian fieldwork. That trip was important to me as a first year graduate student, and it really helped broaden my perspectives on anole ecology, evolution, and fieldwork. And while I was there, thank you to Tom Schoener and Dave Spiller for intellectually stimulating science conversations throughout the trip which undoubtedly influenced the direction of my doctoral studies.

Thank you Kenny Krysko - you were instrumental in me getting my first ever publication, a Herpetological Review natural history note. I recorded Mexican spiny tailed iguanas (Ctenosaura similis) eating baybean (Canavalia rosea) flowers on the beach of Crandon Park, Key Biscayne in Miami (Thanks for taking the photo, Mum). I had never published before, and it was an important moment in my professional career.

Mark Outerbridge and his partner Simieon were great hosts and tremendous facilitators of my research in Bermuda. Mark’s parents, Thad and Evan Outerbridge, kindly provided me and 
Sean Giery with accommodation during our Bermuda fieldwork. I have become especially fond of the island, and look forwad to continuing to work there in the future. On that note, Joe Macedonia - a pioneer of Bermudian anole ecology - was nothing but helpful and excited by my research on anoles in Bermuda, a trait not always common in the highly competitive world of science. Your advice and feedback on Chapter III was important. Thank you, I really appreciated that.

Thank you Yoel Stuart, you have been brilliantly supportive throughout all of our research discussions on anoles and character displacement, and provided unexpected and invaluable help with my NSF DDIG applications. My subsequent success in getting a DDIG was in no small part due to your advice. Thanks to all other anolologists who provided me with intelligent and stimulating conversations about various aspects of anole behaviour, ecology, and evolution: Alex Gunderson, Michele Johnson, Anthony Geneva, Martha Muñoz, Kristin Winchell, Ambika Kamath, Sofia Prado-Irwin, Pavitra Malhotra, Colin Donihue, Adam Algar, Kirsten Nicholson, Thom Sanger, Manuel Leal, Dan Warner, Josh Hall, Tim Mitchell, and Neil Losin. You're all talented scientists and great people. Thank you to Peter and Rosemary Grant for interesting conversations about character displacement when I was fortunate enough to interact with you during your visit to the Miami. Those helped shape some of my interpretations within Chapter IV.

Finally, and most importantly, I thank you, Alex Belisario. You inspired me when I was down, praised me when I was high, motivated me when I was tired, and reigned me in when I was pushing too hard. You played the most important role in me finishing this whole thing, and were instrumental in me completing this dissertation while maintaining a sound, healthy mind (-ish). You mean the world to me, thank you. 


\section{ABSTRACT OF THE DISSERTATION \\ USING INTRODUCED SPECIES OF ANOLIS LIZARDS TO TEST \\ ADAPTIVE RADIATION THEORY \\ by}

James T. Stroud

Florida Interantional University, 2018

Miami, Florida

\section{Professor Kenneth J. Feeley, Major Professor}

Adaptive radiation - the proliferation of species from a single ancestor and diversification into many ecologically different forms - has long been heralded as an important process in the generation of phenotypic diversity. However, the early stages of adaptive radiation are notoriously elusive to observe and study. In this dissertation, I capitalize on communities of introduced non-native Anolis lizards as analogues of early stage adaptive radiations. In Chapter II, I begin by reviewing the concept of "ecological opportunity" - a classic hypothesis put forward as a potential key to understanding when and how adaptive radiation occurs. In Chapter III, I investigate the mechanisms which allow for coexistence and community assembly among ecologically-similar species. To do this I investigate range dynamics and assembly patterns of introduced anoles on the oceanic island of Bermuda. I discover that interspecific partitioning of the structural environment facilitates species coexistence, however the order of species assembly was an important predictor of final community composition. In Chapter IV, I then investigate how interspecific interactions between coexisting species may drive phenotypic divergence. This is the process of character displacement, which has been widely hypothesized to be an important mechanism driving phenotypic divergence in adaptive radiations. To do this I investigate 
sympatric and allopatric populations of introduced Cuban brown anoles (Anolis sagrei) and Puerto Rican crested anoles (A. cristatellus) in Miami FL, USA. I identify morphological shifts in sympatry, driven by divergence in habitat use and decreases in abundance. This study provides evidence of how selection on both ecologically and sexually-important traits can both drive phenotypic divergence during character displacement. Finally, in Chapter V, after taking advantage of non-native species as model eco-evolutionary systems in previous chapters, I investigate the potentially harmful effects that their presence may have on vulnerable native biodiversity. To do this I investigate the conservation risk posed by newly-discovered populations of A. sagrei on Bermuda to Critically Endangered endemic Bermuda skinks (Plestiodon longirostris). Through a detailed analysis of habitat use, diet, population size, and morphology of A. sagrei on Bermuda, we conclude it likely poses a high conservation threat to P. longirostris through interspecific competition. 


\section{TABLE OF CONTENTS}

\section{CHAPTER}

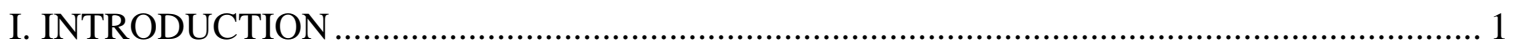

Anolis lizards: A model system of adaptive radiation.................................................................. 3

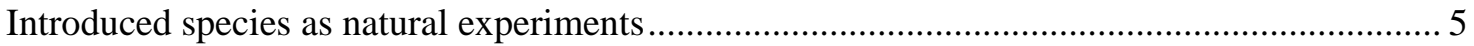

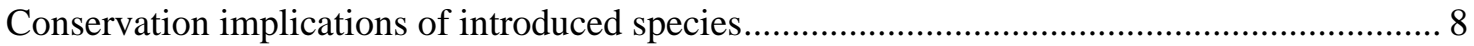

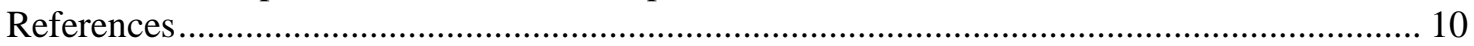

II. ECOLOGICAL OPPORTUNITY AND ADAPTIVE RADIATION ….................................. 11

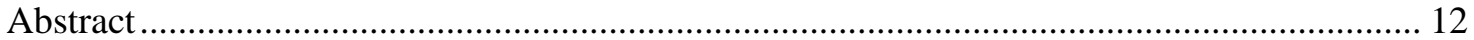

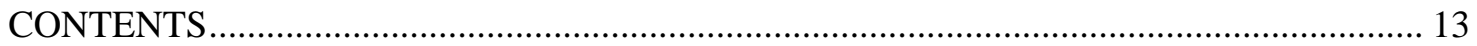

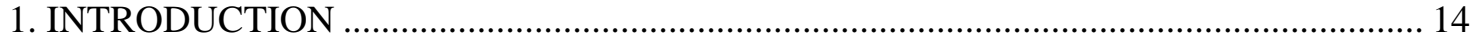

1.1. A historical perspective: From conception to modern utilization .............................. 14

2. WHAT IS THE EVIDENCE THAT ECOLOGICAL OPPORTUNITY PROMOTES

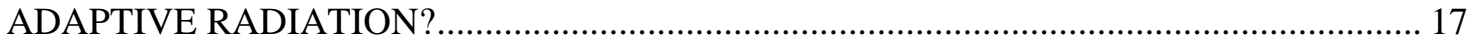

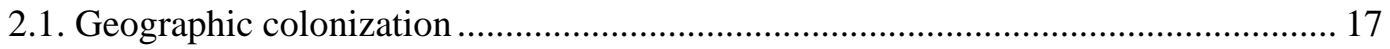

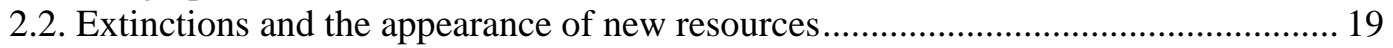

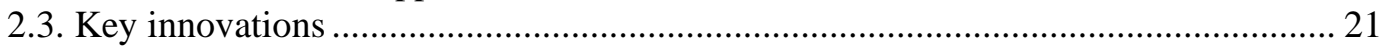

2.4. Testing the ecological opportunity hypothesis with phylogenies .............................. 24

3. HOW MECHANICSTICALLY DOES ECOLOGICAL OPPORTUNITY LEAD TO

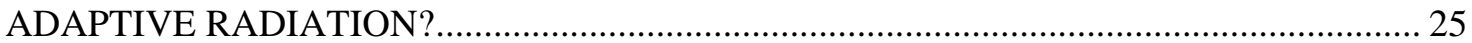

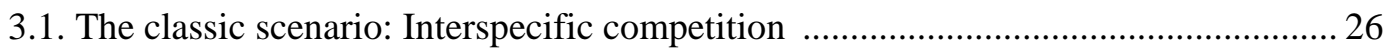

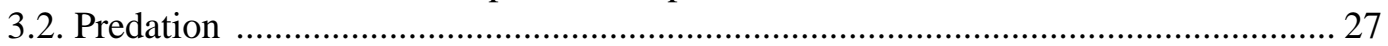

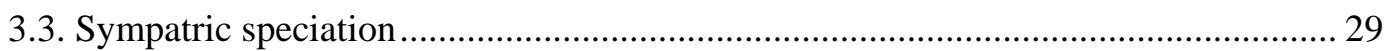

4. IS ECOLOGICAL OPPORTUNITY NECESSARY FOR ADAPTIVE RADIATION? ...... 31

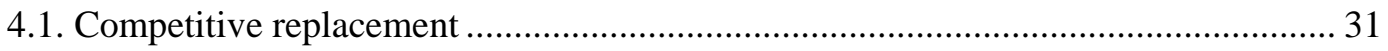

4.2. Self-propagating radiations: Niche construction.................................................... 32

5. WHY DOES ECOLOGICAL OPPORTUNITY NOT ALWAYS RESULT IN

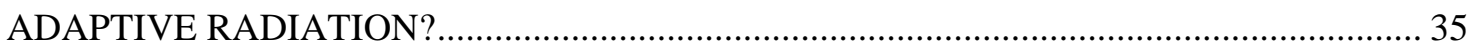

6. CAN ECOLOGICAL OPPORTUNITY BE QUANTIFIED A PRIORI, OR IS IT ONLY

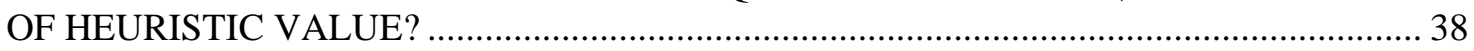

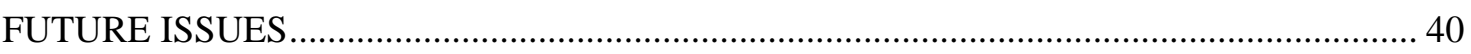

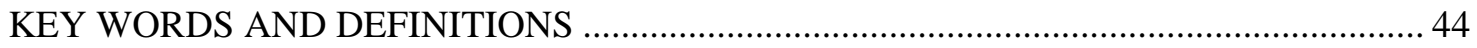

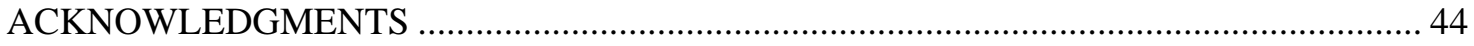

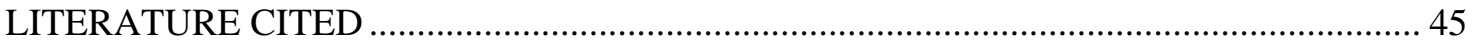

III. PRIORITY EFFECTS INFLUENCE ASYMMETRICAL ASSEMBLY PATTERNS OF

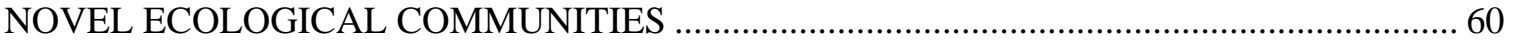

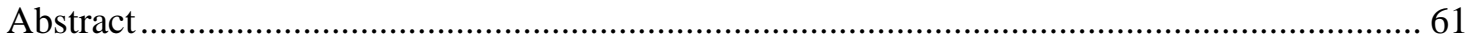

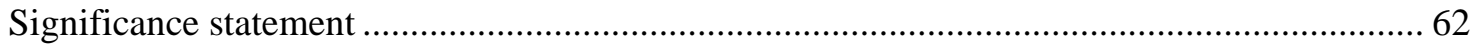

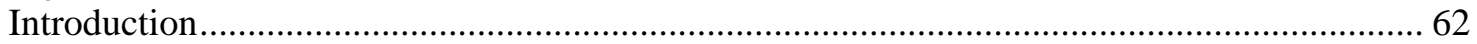

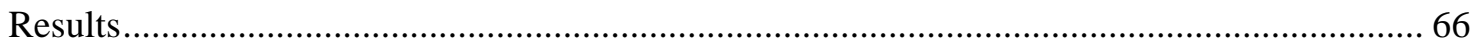

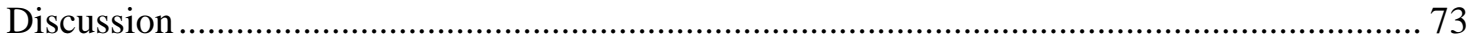




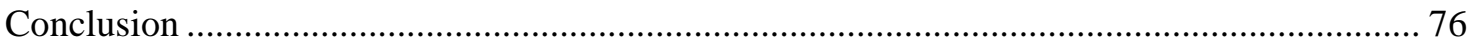

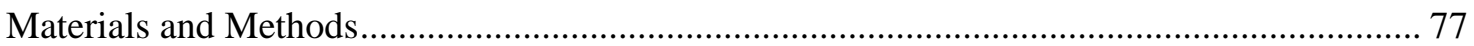

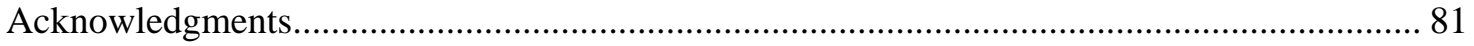

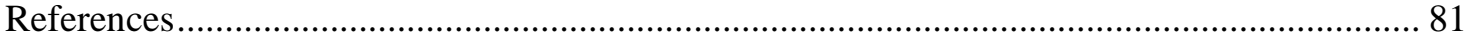

IV. COMPLEX CHARACTER DISPLACEMENT DRIVEN SIMULTANEOUSLY BY

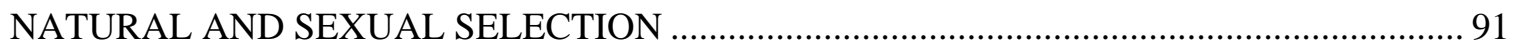

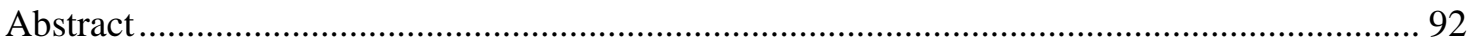

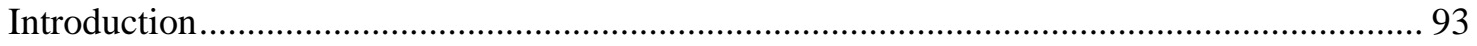

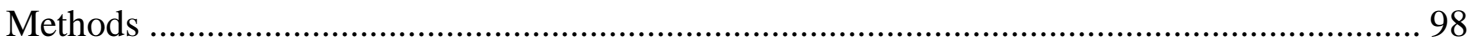

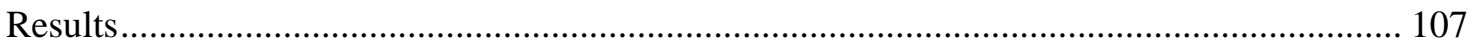

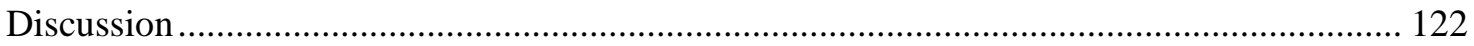

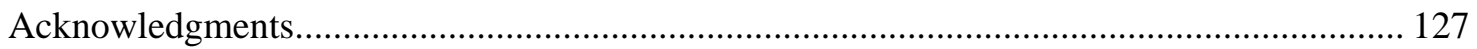

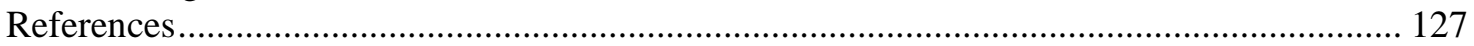

V. ESTABLISHMENT OF ANOLIS SAGREI ON BERMUDA REPRESENTS A NOVEL
ECOLOGICAL THREAT TO CRITICALLY ENDANGERED BERMUDA SKINKS
(PLESTIODON LONGIROSTRIS)

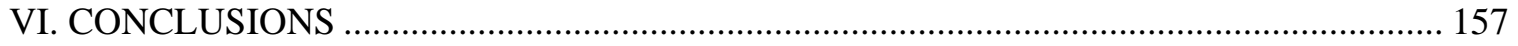

Non-native species: Eco-evolutionary experiments in the Anthropocene .............................. 159

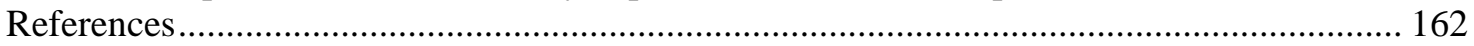

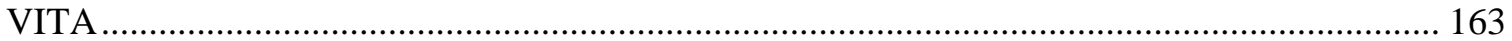




\section{LIST OF TABLES}

TABLE

PAGE

\section{CHAPTER III}

S3.1 Structural habitat selection (perch use height and diameter) of all non-native Bermuda Anolis lizards. Microhabitat use (mean $+/-1$ S.E.) by four introduced Anolis species on Bermuda. Communities are: $\mathrm{GL}=A$. grahami/A. leachii, $\mathrm{GE}=A$. grahami/A. extremus, GEL = A. grahami/A. leachii/A. extremus. Community level means are combined for sexes and replicate sites. Sample sizes are sometimes lower for perch diameter

S3.2 Interspecific pairwise comparisons of three ecological axes; (i) prey item size, (ii) perch height, and (iii) perch diameter. In each community, each pair of species is using a significantly different part of the resource spectrum for at least one ecological variable.

S3.3 Body size (snout-vent length [mm] and mass [g]) comparisons of anoles on Bermuda... 88

S3.4 Identifying accessible ecological space by assessing interspecific differences of invader vs. resident species of anoles on Bermuda.

S3.5 Intraspecific niche variation on three ecological axes; (i) prey item size, (ii) perch height, and (iii) perch diameter. Intraspecific variation was high for A. graham (significant differences among all three axes), intermediate for A. leachii (significant difference in one axis; perch height), and non-existent for $A$. extremus (no difference in ecology between A. extremus regardless of the community).

\section{CHAPTER IV}

4.1 Site location details of all allopatric and sympatric populations in this study

4.2 Component matrix for the first 3 principal components (PC1:PC3) of aggressive behaviors observed during interspecific behavioral trials.

4.3 Morphological trait shifts between allopatry and sympatry in A. sagrei and A. cristatellus. All results are from Linear Mixed Effects Models, with model coefficient ( \pm 1 SEM), $t$ value with degrees of freedom (note: ${ }^{a} t_{4,197}{ }^{b} t_{4,186}$ ), and significance value $(p)$ given. To assess differences in traits relative to body size, all models include snout-vent length as a fixed effect, except for the snout-vent length model. Anolis sagrei have longer limbs and fewer toepad lamellae in sympatry with A. cristatellus, while A. cristatellus have smaller and narrower heads, and smaller hindfeet when sympatric with $A$. sagrei. All models in bold are significant at $\alpha=0.05 .{ }^{\dagger} p<0.06$.......

4.4 Comparisons of movement behavior between sympatric and allopatric populations of $A$. sagrei and A. cristatellus. Data represent mean of site means of behavior rate 
per hour ${ }^{-1}$. N represents number of lizards observed (and cumulative minutes of observation). Results in bold indicate model significance at $\alpha=0.05 .{ }^{\dagger} P<0.1$.

4.5 Repeated measures GLMs investigating the effect of interspecific interactions on intraspecific sociality. In sympatry, interspecific interactions significantly predict the frequency of conspecific interactions in A. cristatellus $(p<0.001)$ but not in A. sagrei $(p=0.181)$.

4.6 Comparisons of morphological traits which have diverged in each species between sympatry and allopatry, alongside estimates of evolutionary divergence in Haldanes .. 121

SM4.1 Perch height and morphology. Sample sizes and basic summary statistics by site (and per treatment) for perch height and morphological analyses and allopatric vs. sympatric A. sagrei and A. cristatellus

SM4.2 Diet. Sample sizes of number of lizards (and number of resulting prey items) by site (and per treatment) in allopatric vs. sympatric A. sagrei and A. cristatellus

SM4.3 Movement behavior. Sample sizes and basic summary statistics of number of lizards and length of observation by site (and per treatment) in allopatric vs. sympatric A. sagrei and A. cristatellus

SM4.4 Maximal model estimates of repeated measures GLM investigating the effect of interspecific interactions on intraspecific sociality. Only $p$-values obtained from permutations of observed coefficients against 10,000 randomized coefficients from optimal models are shown (see Methods for details of model optimization)

\section{CHAPTER V}

5.1 Stomach contents analysis of two independent populations of Cuban brown anoles (A. sagrei) (Site A, Site B) and a combined species total. Data are presented as raw stomach contents and as proportion of total stomach contents. Taxonomic Orders are highlighted in gray, with a breakdown to family where possible highlighted underneath in italics. Orders known to be consumed by Bermudian skinks ( $P$. longirostris) are marked with an ' $\mathrm{X}$ ' in the final column 


\section{LIST OF FIGURES}

FIGURE

PAGE

\section{CHAPTER I}

1.1 A primary mechanism of communication in anoles is achieved through visual displays of an elaborate extendable throat fan called a dewlap. (left) Here, a male Puerto Rican crested anole (A. cristatellus) performs dewlap displays at a conspecific male. (right) Enlarged subdigital toepads are filled with adhesive scales called lamellae, which increase clinging performance on vertical surfaces and facilitate an arboreal lifestyle. This is the toepad of an arboreal specialist, the Cuban knight anole (A. equestris) Photos: J.Stroud

1.2 The progression of an aggressive male-male social interaction between Puerto Rican crested anoles (A. cristatellus). Male-male combat likely has direct fitness consequences through territory maintenance and access to females. Increased head size, which corresponds with increased bite force - an important predictor of success in aggressive combat, might be favored in populations with high levels of intraspecific social interactions. Photo: J. Stroud (Miami, FL).....

1.3 The Critically Endangered Bermuda skink (Plestiodon longirostris), endemic to the Bermuda archipelago and one of the rarest lizards in the world with a total global population of ca. 3,500 individuals. Photo: J.Stroud (Nonsuch Island, Bermuda).....

\section{CHAPTER II}

2.1 Trends in research on ecological opportunity as reflected in the number of articles published annually. The literature search was conducted using the Google Scholar database on January 20, 2016. To find articles that include "ecological opportunity," the following specifications were used: Find articles with the exact phrases "ecological opportunity" and "adaptive radiation" and with at least one of the words "ecology" or “evolution.” Searches were run individually for every year 1950-2015; owing to a lack of studies before 1985, data from only 1985-2015 are shown

2.2 (a) The colonization of an isolated area (e.g., an island or lake) can provide a release from competition and predation pressures, allowing a clade to diversify into a variety of ecological niches from which they were previously blocked. For example, the colonization of Madagascar resulted in a spectacular adaptive radiation of vangid birds (Yamagishi et al. 2001, Jønsson et al. 2012). Additional examples include Galapagos finches (Grant \& Grant 2008), Hawaiian lobeliads (Givnish et al. 2009), African Rift Lake cichlids (Seehausen 2006), ' Hawaiian spiders (Gillespie 2004, 2015), Sulawesi silversides (Pfaender et al. 2010), and Caribbean Anolis lizards (Losos 2009). (b) Lineages able to survive extinction events may be presented with access to ecological space previously occupied by members of their own clade or by other competitors. For example, following the Cretaceous-Paleogene mass extinction of the nonavian dinosaurs 
and other archosaurs, ancestral birds and placental mammals gained access to previously unavailable ecological space and rapidly radiated (Hull 2015); mammals did exist, and some groups originated, prior to the extinction event, but this is simplified for heuristic purposes. An additional example is the Permian-Triassic radiation of ammonoids (McGowan 2004). (c) The appearance of new resources may provide ecological opportunities for species that can utilize them. For example, the emergence of the Andean mountains in the tropics provided new cool, high-elevation habitats that spurred adaptive radiations when colonized by ancestral Espeletia and Lupinus species (Monasterio \& Sarmiento 1991, Hughes \& Eastwood 2006). Additional examples include flowering plants and phytophagous insects (Labandeira \& Sepkoski 1993, Bronstein et al. 2006) and the appearance of grasses and grazing horses (MacFadden 2005). (d ) The evolution of a feature that allows a lineage to interact with the environment in a novel way may provide the ability to utilize formerly unavailable resources. The evolution of the pharyngeal jaw, for example, allowed African Rift Lake cichlids to diversify into a wide range of trophic specialists (Liem 1973, Mabuchi et al. 2007), although this has recently been debated (Seehausen 2006). Additional examples include the evolution of flight in bats and birds (Cracraft 1990, Sears et al. 2006, Simmons et al. 2008), phytophagy in insects (Farrell 1998), nectar spurs in Aquilegia columbines (Hodges \& Arnold 1995, Ree 2005), and toepads in lizards (Williams \& Peterson 1982). It should be noted that in all panels (a-d ) the structures of all radiating groups are not meant to accurately reflect true phylogenetic relationships

\section{CHAPTER III}

3.1 Conceptual representation of mechanisms through which different ecological communities can be formed from the same species pool: a) All species occupy independent niches; b) An incumbent species blocks an ecologically-similar species from joining the community through priority effects by niche pre-emption (i.e. competitive exclusion); c) An incumbent species blocks niche access to an ecologicallysimilar species through priority effects, but niche lability facilitates species coexistence and community assembly as each species utilizes independent ecological space. Symbol colors indicate different species. Symbol shapes denote the general ecological niche which that species occupies and dashed symbols represent vacant niches. Figure modified from Fukami (2015).

3.2 Community assembly patterns at the contact zone between two species ([B] A. leachii; green, and [C] A. extremus; blue) which both underwent rapid directional dispersal from original geographically-distinct locations on Bermuda (G). In 1964, only A. grahami [A; red] existed on Sandy's Parish, which was ubiquitous across the island except for the extreme northwestern tip where A. extremus established. By 1991, A. extremus had dispersed from its original site of introduction to form multiple 2 species communities with A. grahami, while A. leachii had dispersed through Southampton to the edge of the A. extremus range creating a contact zone (D; dotted line, arrows represent direction of dispersal). In 2015 (E), A. leachii had invaded Sandy’s Parish to form 3 species 
communities, while A. extremus had failed to invade through the original contact zone with A. leachii in Southampton. Native islands from which each species originated are indicated under A-C. The geographic location of Bermuda is shown in F. Dashed lines represent range edges. Anole illustrations are used with permission from Schwartz \& Henderson (1987)

3.3 Community assembly and ecological niche organization of non-native Anolis lizards in Bermuda. Plots represent ecological niches of each species, here described through the axes along which divergence most commonly occurred to facilitate coexistence; structural habitat use (points represent species mean +/- 1 S.E.). (A) Anolis extremus blocks ecological access to leachii attempting to join grahami-extremus communities through priority effects and niche-preemption. However, leachii responds by shifting its niche into unoccupied ecological space (i.e. assembly mechanism shown in Fig 1c). In response, grahami returns to colonize ecological space made vacant by the shift of extremus, which corresponds with niche space it occupies when coexisting with only leachii. (B) However, extremus is unsuccessful in invading grahami-leachii communities (either before ${ }^{1}$ or after $^{2}$ the invasion of leachii) as priority effects from leachii blocks access to the preferred ecological space of extremus (i.e. assembly mechanism shown in Fig 1b). The invading species (in both A \& B) always significantly overlaps with the incumbent species in both axes of ecological space

3.4 Body size differences of the introduced anoles of Bermuda; A. grahami (left), A. extremus (center), A. leachii (right). Body size is represented by PC1 of a principal components analysis of 10 size-related morphological traits which explained $96.7 \%$ of variation between species, with factor loadings ranging from $22 \%$ for snout-vent length to $71.1 \%$ for mass. Bold lines represent median values, error bars are 95\% C.I ... 71

3.5 The phylogenetic distribution of non-native Bermudian Anolis lizards investigated in this study (colored arrows), alongside the communities from which they originate (circled). Each species established on Bermuda have different levels of evolutionary experience of interspecific interactions. Anolis extremus, endemic to Barbados, has had no contact with a congener for $\sim 6.1 \mathrm{my}$ (estimate of divergence from $A$. roquet [Thorpe et al. 2005], which coexists with A. lividus on Martinique). Anolis leachii coexists with 1 congener, A. wattsi, on the Barbuda Bank (Antigua \& Barbuda); Anolis grahami coexists with 4 congeners of high ecomorphological diversity on Jamaica. Phylogeny drawn from Gamble et al. (2012)................................................................... 73

\section{CHAPTER IV}

4.1 (Left) Cuban brown anole (Anolis sagrei) and (right) Puerto Rican crested anole (A. cristatellus). Photo: JStroud.

4.2 Behavioral aggression (mean +- 1 SE) of (A) A. sagrei and (B) A. cristatellus towards sympatric heterospecifics in experimental trials. (C) Conceptual representation of ecomorphological similarity among established Anolis lizards in Florida following "ecomorph" categorizations (from Losos 2009). Symbol colors identify each species; $A$. cristatellus (blue; “trunk-ground”, Puerto Rico), A. sagrei (red; “trunk-ground”, 
Cuba/Bahamas), A. distichus (grey; "trunk", Hispaniola), and A. carolinensis (green; "trunk-crown”, USA). ${ }^{*} p<0.05,{ }^{* *} p<0.001,{ }^{* * *} p<0.0001$. Figure (C) reproduced with permission from Losos (2009)

4.3 Brown anoles (A. sagrei) and crested anoles (A. cristatellus) interact strongly in sympatry, resulting in (A) symmetric decreases in relative abundances, and (B) ecological character displacement through divergence in perch height

4.4 Ecological character displacement in sympatry. (A) In allopatry, A. sagrei and A. cristatellus do not differ in the distributions of observed perch height $(p=0.739)$, however diverge in sympatry (B; $p<0.0001)$, such that (C) A. sagrei are more commonly found on the ground, and A. cristatellus increase in arboreality. Figure $\mathrm{C}$ reproduced with permission from Losos (2009).

4.5 Morphological divergence in sympatry. Anolis sagrei (A-E) had longer limbs and hindfeet, as well as fewer toepad lamellae, when sympatric with A. cristatellus than when allopatric. Anolis cristatellus (F-I) had a smaller heads and shorter hindfeet when sympatric with $A$. sagrei than when allopatric

4.6 Condition dependence of morphological traits that experienced population-level shifts from allopatry to sympatry in A. sagrei (A-C) and A. cristatellus (D-F). Regression lines are only shown for significant relationships (at $\alpha=0.05$ ). Anolis sagrei exhibit positive condition-dependence in hindlimb $(p=0.005)$ and forelimb length $(p=0.016)$ in sympatry with $A$. cristatellus, but not in allopatry (see text for details). Anolis cristatellus exhibit positive condition dependence of head size in both sympatry and allopatry, however only positive condition-dependence in hindfoot when in allopatry $(p<0.001)$. All traits are relative to body size (residuals derived from ordinary least squares regressions of each trait independently against snout-vent length) and body condition represents residuals of mass against svl. Trendlines are only shown for significant relationships $(\alpha=0.05)$

4.7 There is a strong positive relationship between head size (A. Head length, B. Jaw length, C. Head width) and bite force, and hindfoot length and clinging force (D), in A. cristatellus 116

4.8 Dietary analysis of prey size and source in allopatric vs. sympatric populations of $A$. sagrei and $A$. cristatellus. (a) Neither $A$. sagrei ( $p=0.249$; points represent mean of site means \pm 1 S.E.) or $A$. cristatellus ( $p=0.347$ ) ate different sized prey items when in allopatry or sympatry. However, in concordance which shifts in perch height, (b) A. sagrei consumed significantly more terrestrial prey and significantly less arboreal prey when sympatric with A. cristatellus ( $p<0.0001$ ), and A. cristatellus consumed significantly more arboreal prey and less terrestrial prey in sympatry $(p<0.001)$

4.9 (A) When in sympatry with A. sagrei, male A. cristatellus interact with conspecific males significantly less than when allopatric $(p<0.001)$. Frequency of interactions represent residuals from a regression of weighted conspecific male associations against cumulative associations. Points represent mean values \pm 1 S.E. (B) Social isolation of $A$. cristatellus 
from conspecific males is driven by interactions with heterospecific A. sagrei males (blue solid line, $p<0.001$ ). This conspecific vs. heterospecific interaction relationship does not exist for sympatric $A$. sagrei $(p=0.161)$. Only significant trendlines shown. Each point represents an individual adult male lizard. Interaction data represent weighted association coefficients (see Methods for details).

SM4.1 Phylogenetic relationship of Anolis sagrei (red arrow) and A. cristatellus (blue arrow); A. sagrei and A. cristatellus are diverged by ca. 45-50my. Phylogeny produced from Gamble et al. 2014

\section{CHAPTER V}

5.1 Adult male Cuban brown anole (A. sagrei) in Bermuda with an extended dewlap during a signal display: this species is easily distinguishable from other established Anolis lizards on Bermuda by a brown dorsal pattern and red coloration of the dewlap. Photo: JStroud

5.2 The current distribution of Bermuda skinks ( $P$. longirostris: black circles) and the recently discovered Cuban brown anole (A. sagrei: white circles) populations. All islands labelled in the inset have established $P$. longirostris populations. Skink population data are the most up-to-date available from the Bermuda Department of Environment and Natural Resources

5.3 Proportional habitat use of Anolis lizards established on Bermuda. Grey areas indicated high terrestriality (lizards observed $0-10 \mathrm{~cm}$ from the ground) which Bermudian skinks (Plestiodon longirostris) solely utilize. Data are combined for all mature individuals of both sexes.

5.4 General body size overlap between $P$. longirostris (juveniles $n=20$, subadults $n=32$, adults $\mathrm{n}=33$ ) and $A$. sagrei (males $\mathrm{n}=52$, female $\mathrm{n}=36$ ). Circled area indicates body size overlap. $P$. longirostris snout-vent length and mass data taken from Raine (1998)

\section{CHAPTER VI}

6.1 An adult male Cuban brown anole (Anolis sagrei) in Miami, FL. Photo: JStroud... 161 
CHAPTER I

INTRODUCTION 
Adaptive radiation - the evolutionary divergence of members of a single phylogenetic lineage into a variety of different adaptive forms (Futuyma 1998) - has long been heralded by evolutionary biologists as one of the most important processes in the generation of phenotypic diversity. Indeed, much of the diversity on earth may have arisen from numerous independent episodes of adaptive radiation (Schluter 2000). Classic examples include the Galápagos finches Darwin's eponymous birds, cichlid fishes of the African Great Rift Lakes, and the extravagantly diverse radiations of Hawaiian honeycreepers and silverswords. But what actually triggers an adaptive radiation? And, if speciation in the early stages of adaptive radiation produces a collection of similar species, what processes allow for their coexistence? And what processes lead to the remarkable diversity of phenotypes observed among species? In this dissertation, I review the conditions that may lead to adaptive radiation - specifically 'ecological opportunity', and investigate the ecological and evolutionary processes which allow for coexistence of ecologically similar species, and which lead to phenotypic divergence.

Simpson (1953) was the first to identify and suggest ‘ecological opportunity’ as a prerequisite for adaptive radiation. Ecological opportunity - broadly defined as the availability of ecologically accessible resources that may be evolutionarily exploited, but often simply describing a species or clade finding itself in the absence of ecologically-similar competitors has since been widely invoked as a potential key to understanding when and how adaptive radiation occurs. In Chapter II, I review the relationship between ecological opportunity and adaptive radiation. I first present a historical review of the 'ecological opportunity' hypothesis as it relates to adaptive radiation. I then review evidence that ecological opportunity actually promotes adaptive radiation, how ecological opportunity might mechanistically lead to adaptive radiation, and explore evidence for alternative mechanisms in order to determine if ecological opportunity can be considered a necessary prerequisite for adaptive radiation. I then explore those species (and clades) that have failed to radiate in the presence of an apparent ecological 
opportunity, and suggest reasons for those ‘failures'. Finally, I conclude by discussing whether ecological opportunity has any predictive power - in other words, can ecological opportunity be identified and quantified a priori, or is it only of heuristic value?

Anolis lizards: A model system of adaptive radiation

One model system classically used in the research of adaptive radiation are Anolis lizards. The most species rich amniote tetrapod genus in the world with $>400$ species (and counting), Anolis lizards, or anoles, are widely distributed throughout the Neotropics (Losos 2009). Anoles are small to medium sized lizards, diurnal, generally insectivorous, possess sticky scales on enlarged toepads which aid with clinging to vertical surfaces - a trait fairly unique among nongecko lizards, and possess one of the most extravagant ornaments of visual communication of all lizards, the dewlap, an extendable throat fan (Fig. 1.1). However, despite these commonalities, there exists great variation among species in other aspects of their ecology and behavior. As a result of these differences, anoles exhibit a variety of phenotypic forms as species have evolved to specialize on particular features of the environment.

One reason that there has been such sustained scientific interest in anoles among evolutionary biologists is that they are not famous for just a single adaptive radiation, but for many. Anoline adaptive radiations on each of the four islands of the Caribbean Greater Antilles Cuba, Hispaniola, Jamaica, and Puerto Rico - have independently produced the same set of habitat specialists, with species grouped into categories termed "ecomorphs" due to the ecomorphological similarity of the species each group contains (Williams 1972, 1983, Losos 2009). Greater Antillean anoles represent one of the few robust examples of replicated adaptive radiations. 

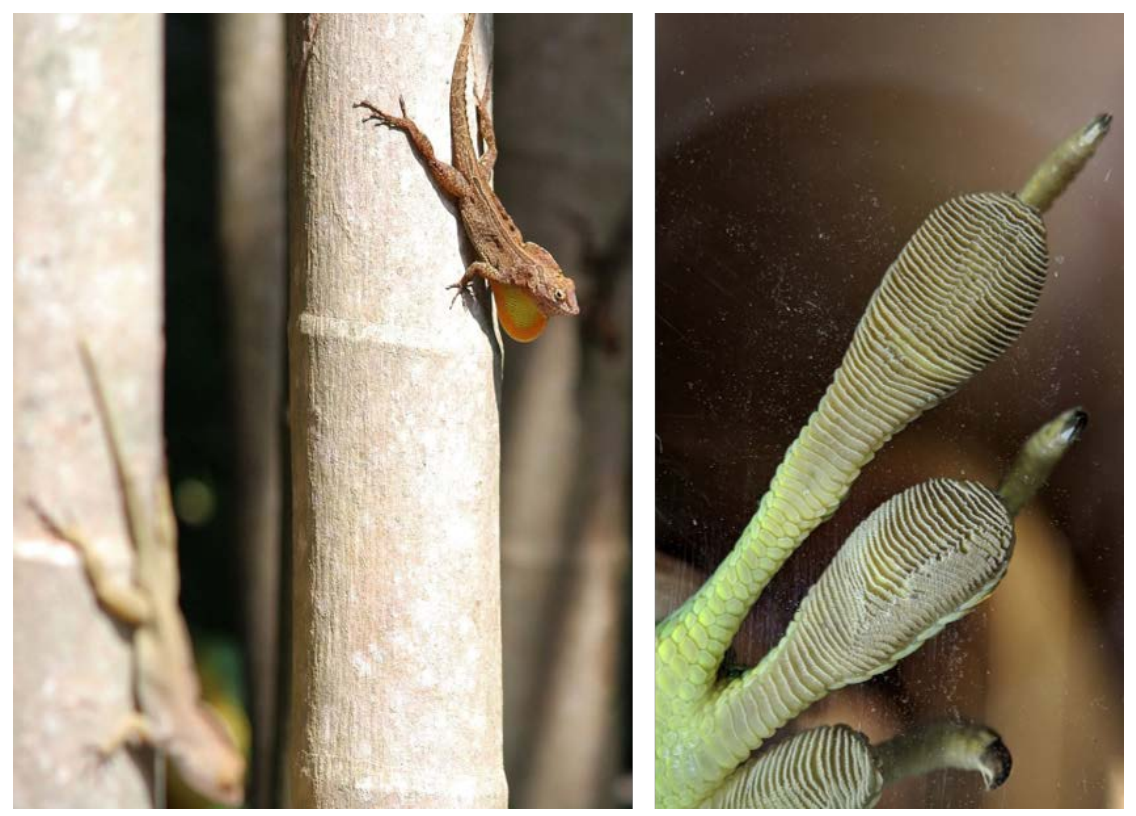

Figure 1.1. A primary mechanism of communication in anoles is achieved through visual displays of an elaborate extendable throat fan called a dewlap. (left) Here, a male Puerto Rican crested anole (A. cristatellus) performs dewlap displays at a conspecific male. (right) Enlarged subdigital toepads are filled with adhesive scales called lamellae, which increase clinging performance on vertical surfaces and facilitate an arboreal lifestyle. This is the toepad of an arboreal specialist, the Cuban knight anole (A. equestris) Photos: J.Stroud.

However, much of our understanding about the mechanisms that generated anole diversity has relied on inferring process from pattern. In particular, given the historical nature of evolutionary biology - one must collect evidence in the present to test hypotheses about the past (Cleland 2001, Mayr 2004), understanding the processes driving the early stages of adaptive radiation has remained particularly elusive. If these stages are observable, for example in a young adaptive radiation presently diversifying, they can be notoriously difficult to identify. Recent advances in the availability of detailed, time-calibrated molecular phylogenies has allowed for hypotheses about the pace and catalysts of these elusive early stages to be tested. However, these investigations rely on inferring the history of species coexistence, extent of interspecific interactions, and the proximate causes of adaptive divergence, from phylogenetic estimates of 
divergence times. Therefore, understanding the behavioral, ecological, and evolutionary processes that occur during these early stages remains a major challenge.

Introduced species as natural experiments

Over the past century, concomitant with the rapid increase in the connectivity of human societies, anoles have been extensively introduced - both intentionally and unintentionally - into areas outside of their native range (Helmus et al. 2014). This has created many novel communities of anoles whose constituent species originate from different Caribbean islands and often have no, or only a very faint, history of evolutionary interactions. These recently assembled, evolutionarily-novel anole communities are analogous to those elusive early-stages of adaptive radiation. I take advantage of this for Chapters III and IV to test key predictions of community assembly and adaptive radiation theory.

In Chapter III, I capitalize on a 100 year old natural experiment in community assembly theory presented by the introduction of three species of Caribbean anoles to the oceanic island of Bermuda, where no anole has ever naturally existed. I conduct the first island-wide distribution census of all species in $>25$ years, and explore the ecological and behavioural mechanisms that have facilitated species coexistence and community assembly. I discover that range expansion in two species - the Antiguan anole (A. leachii) and the Barbadian anole (A. extremus) - has been asymmetrical where their distributions come into contact, which has resulted in the formation of different ecological communities despite the same available species pool. In allopatry on Bermuda, A. leachii and A. extremus occupy identical ecological niches. To achieve successful invasion into the range of A. extremus, A. leachii demonstrated a shift in perch height, using arboreal habitat not used by any other species. Throughout all of the communities in Bermuda, $A$. extremus exhibited no variation in multiple aspects of its ecology. This lack of ecological 
flexibility likely facilitated its failure to invade communities that already contained A. leachii, which had occupied the preferred ecological conditions of A. extremus through priority effects. I suggest some general hypotheses for why differences in ecological flexibility of $A$. leachii for $A$. extremus may exist.

I then build from understanding how ecological divergence facilitates novel species coexistence, to investigating how it might also drive adaptive diversification. To do this I take advantage of a different community of introduced anoles, those found in Miami FL, USA. In Chapter IV, I investigate the morphological consequences of ecological divergence generated when two similar species - the Cuban brown anole (A. sagrei) and the Puerto Rican crested anole (A. cristatellus) - coexist in sympatry. Anolis sagrei and A. cristatellus originate from independent island radiations yet are a classic example of parallel evolution. Both species are classified as “trunk-ground” ecomorphs and are exceptionally similar in ecology and morphology. This situation is analogous to the early stages of adaptive radiation, whereby nascent species that are ecologically-similar and have evolved reproductive isolation in allopatry are reacquainted in sympatry. Upon contact, and in the absence of competitive exclusion, species diverge in resource use to minimize interspecific interactions. Natural selection then favors those individuals that are able to use a region of resource space not already used by the other species, which in turn results in phenotypic adaptation to the new realized resource spectrum. This is the process of ecological character displacement, and is widely recognized as an important mechanism driving phenotypic divergence in adaptive radiations.

I discover that allopatric populations of A. sagrei and A. cristatellus in Miami, FL, occupy identical ecological niches. However when in sympatry, coexistence in facilitated by a divergence in perch height; $A$. sagrei becomesmore terrestrial, and A. cristatellus becomes more arboreal. I recorded that sympatric populations of A. sagrei had relatively longer limbs and fewer 
adhesive toepad scales (lamellae) than allopatric populations, which is in accord with our understanding of the morphology-habitat relationship in anoles. Longer limbs allow lizards to run faster on large, broad surfaces, such as the ground, and toepad lamellae are directly proportional to a species' degree of arboreality, with more aboreal species more reliant on lamellae for maintaining themselves in aboreal environments. However, I record that sympatric A. cristatellus have smaller heads, a trait not expected to be under selection as a result of increased arboreality. I reveal how increased arboreality in sympatric $A$. crisatellus, likely reinforced by agonistic interspecific interactions from terrestrial $A$. sagrei, has led to the fragmentation of intra-specific social networks and increased social isolation of males. I hypothesize that this has relaxed selection on sexually-important traits associated with male-male interactions, principally bite force and head size (Fig. 1.2). This research reveals how simple ecological character displacement may asymmetrically lead to morphological shifts through a combination of both natural and sexual selection, and therefore be responsible for the evolution of a far greater extent of adaptive diversity than previously appreciated.
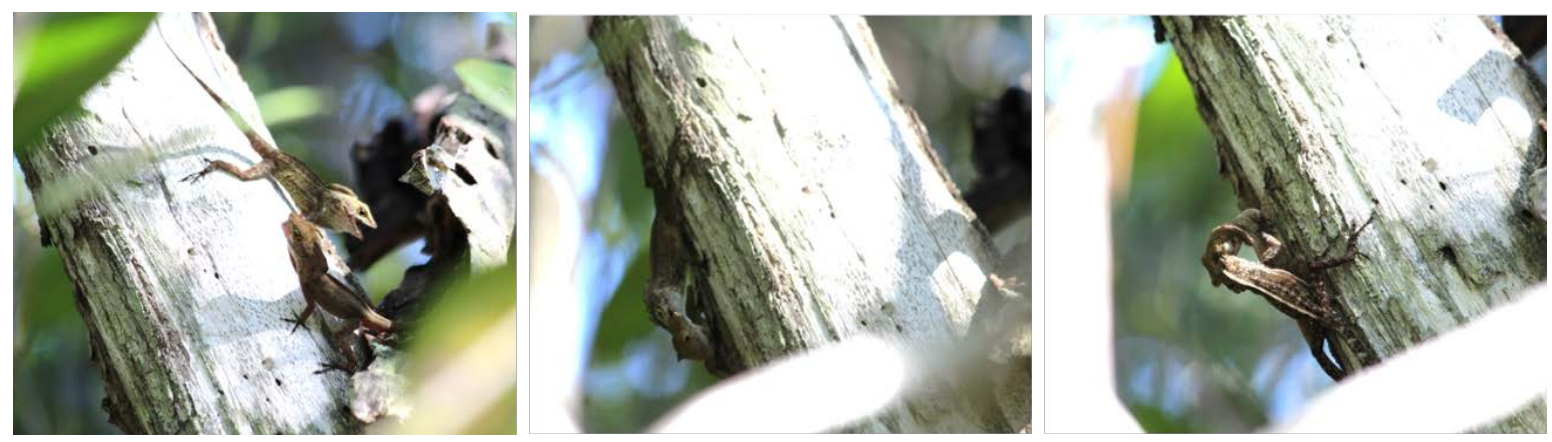

Figure 1.2. The progression of an aggressive male-male social interaction between Puerto Rican crested anoles (A. cristatellus). Male-male combat likely has direct fitness consequences through territory maintenance and access to females. Increased head size, which corresponds with increased bite force - an important predictor of success in aggressive combat, might be favored in populations with high levels of intraspecific social interactions. Photo: J. Stroud (Miami, FL). 


\section{Conservation implications of introduced species}

As an unexpected result of my research studying community assembly of anoles in Chapter III, my colleagues and I inadvertently discovered Cuban brown anoles (A. sagrei) in Bermuda. Chapter V represents the first official documentation of A. sagrei in Bermuda. It would have been unwise and irresponsible of me to write an entire dissertation about how introduced species may be capitalized for science without also recognizing the many direct, and indirect, threats that they can pose to native flora and fauna (Clavero \& Garcia-Berthou 2005, Young et al. 2016). Few species are considered more vulnerable than oceanic island endemics since those species have often evolved in depauperate insular communities and are presumed to be both competitively weaker relative to species from more diverse communities and naïve to many other harmful biotic interactions (Simberloff 1995).

Bermuda has only one endemic lizard, the Critically Endangered Bermuda skink (Plestiodon [Eumeces] longirostris) (Wingate 1965, Conyers \& Wingate 1996; Fig. 1.3). Bermuda skinks are terrestrial, leaf-litter specialists, and are similar in size and ecology to $A$. sagrei, and are restricted to a handful of locations in Bermuda comprising a total global population of ca. 3,500 lizards. I discovered A. sagrei at two geographically distinct locations, neither of which currently support Bermuda skinks. Through detailed assessments of habitat use, diet, population size, and morphology, I evaluate the conservation threat that $A$. sagrei may present to Bermuda skinks through ecological overlap if (or, more likely, when) they are to come into contact. I conclude by suggesting that $A$. sagrei likely pose a significant conservation threat to Bermuda skinks via ecological resource competition. These findings strongly highlight the importance to conservation management of Bermuda skinks of continuing to monitor the distribution and ecology of A. sagrei on Bermuda. 


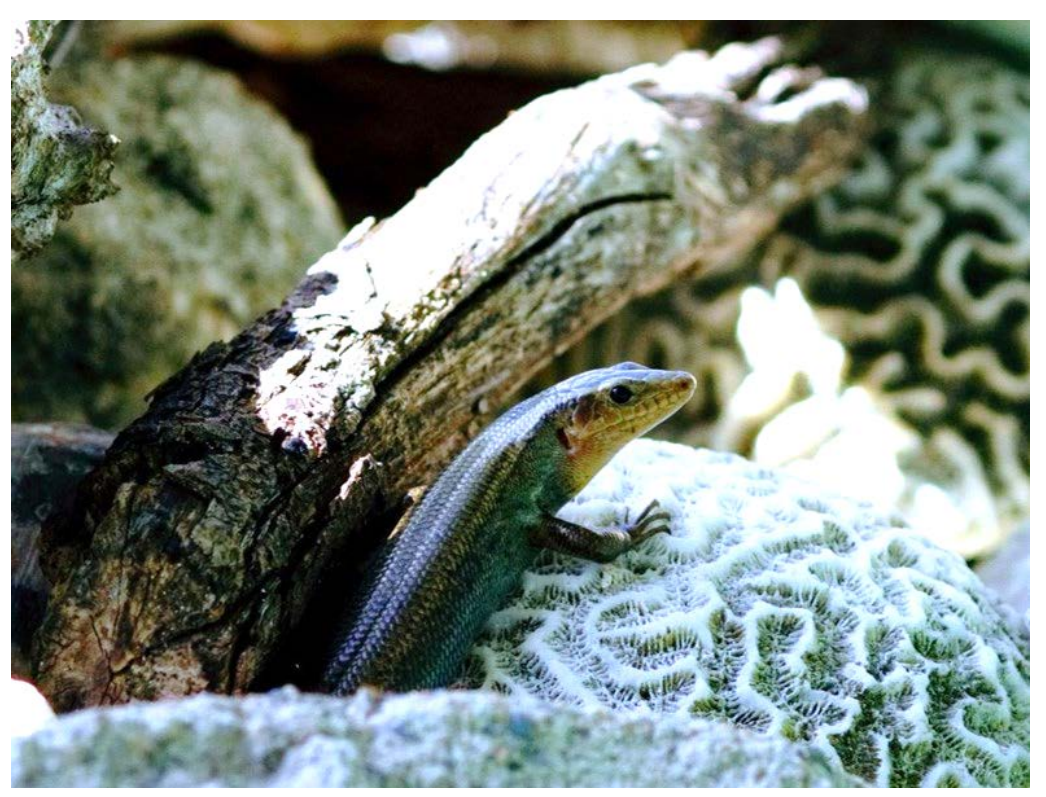

Figure 1.3. The Critically Endangered Bermuda skink (Plestiodon longirostris), endemic to the Bermuda archipelago and one of the rarest lizards in the world with a total global population of ca. 3,500 individuals. Photo: J.Stroud (Nonsuch Island, Bermuda).

In conclusion, this dissertation advances our knowledge of several fundamental areas surrounding the ecological and evolutionary processes involved in adaptive radiation. I provide evidence from two independent natural experiments of introduced anole communities that species coexistence can be facilitated by rapid ecological divergence, principally through partitioning of structural habitat. In turn, I provide evidence that this divergence in habitat can lead to shifts in morphology consistent with natural selection, and that interspecific interactions can significantly disrupt social networks, driving shifts in morphology consistent with sexual selection. I conclude by recognizing the ecological threat that introduced species can present to vulnerable native biodiversity and ecosystems. 


\section{References}

Clavero, M. and García-Berthou, E., 2005. Invasive species are a leading cause of animal extinctions. Trends in Ecology \& Evolution, 20(3): 110.

Cleland, C.E., 2001. Historical science, experimental science, and the scientific method. Geology, 29(11): 987-990.

Conyers, J. \& Wingate, D. 1996. Plestiodon longirostris. The IUCN Red List of Threatened Species 1996: e.T8218A12900393. http://dx.doi.org/10.2305/IUCN.UK.1996.RLTS.T8218A12900393.en

Edgar P, Kitson L, Glasspool AF, Sarkis S (2010) Recovery plan for the Bermuda skink, Eumeces longirostris. Department of Conservation Services, Government of Bermuda, Crawl

Futuyma DJ. 1998. Evolutionary Biology. Sunderland, MA: Sinauer. 3rd ed.

Helmus, M.R., Mahler, D.L. and Losos, J.B., 2014. Island biogeography of the Anthropocene. Nature, 513(7519): 543-546.

Losos, J.B., 2011. Lizards in an evolutionary tree: ecology and adaptive radiation of anoles (Vol. 10). Univ of California Press.

Mayr E. 2004. What Makes Biology Unique? Cambridge (United Kingdom): Cambridge University Press.

Schluter D. 2000. The Ecology of Adaptive Radiation. Oxford, UK: Oxford Univ. Press

Simberloff D (1995) Why do introduced species appear to devastate islands more than mainland areas? Pacific Science, 49(1):87-97.

Simpson GG. 1953. The Major Features of Evolution. New York: Columbia Univ. Press

Williams, E.E., 1972. The origin of faunas: Evolution of lizard congeners in a complex island fauna: a trial analysis. In Evolutionary biology (pp. 47-89). Springer, Boston, MA.

Williams, E.E., 1983. Ecomorphs, faunas, island size, and diverse end points in island radiations of Anolis. In Lizard ecology: studies of a model organism, pp.327-370.

Wingate DB (1965) Terrestrial herpetofauna of Bermuda. Herpetologica, 21:202-218

Young, H.S., McCauley, D.J., Galetti, M. and Dirzo, R., 2016. Patterns, causes, and consequences of anthropocene defaunation. Annual Review of Ecology, Evolution, and Systematics, 47: 333-358. 


\section{CHAPTER II}

\section{ECOLOGICAL OPPORTUNITY AND ADAPTIVE RADIATION}

Stroud, J.T., \& Losos, J.B. (2016) Ecological Opportunity and Adaptive Radiation. Annual Review of Ecology, Evolution \& Systematics, 47: 507-532 


\begin{abstract}
The process of adaptive radiation - the proliferation of species from a single ancestor and diversification into many ecologically-different forms - has been of great interest to evolutionary biologists since Darwin. Since the middle of the last century, “ecological opportunity” has been invoked as a potential key to understanding when and how adaptive radiation occurs. Interest in the topic of ecological opportunity has accelerated as research on adaptive radiation has experienced a resurgence, fueled in part by advances in phylogenetic approaches to studying evolutionary diversification. Nonetheless, what the term actually means, much less how it mechanistically leads to adaptive diversification, is currently debated; whether the term has any predictive value or is a heuristic useful only for post hoc explanation also remains unclear. Recent recognition that evolutionary change can occur rapidly and on a timescale commensurate with ecological processes suggests that it is time to synthesize ecological and evolutionary approaches to the study of community assembly and evolutionary diversification.
\end{abstract}




\section{CONTENTS}

\section{INTRODUCTION}

1.1. A historical perspective: from conception to modern utilization

2. WHAT IS THE EVIDENCE THAT ECOLOGICAL OPPORTUNITY PROMOTES ADAPTIVE RADIATION?

2.1. Geographic colonization

2.2. Extinctions and the appearance of new resources

2.3. Key innovations

2.4. Testing the ecological opportunity hypothesis with phylogenies

3. HOW MECHANISTICALLY DOES ECOLOGICAL OPPORTUNITY LEAD TO ADAPTIVE RADIATION?

3.1. The classic scenario: Interspecific competition

3.2. Predation

3.3. Sympatric speciation

4. IS ECOLOGICAL OPPORTUNITY NECESSARY FOR ADAPTIVE RADIATION?

4.1. Competitive replacement

4.2. Self-propagating radiations: Niche construction

5. WHY DOES ECOLOGICAL OPPORTUNITY NOT ALWAYS RESULT IN ADAPTIVE RADIATION?

6. CAN ECOLOGICAL OPPORTUNITY BE IDENTIFIED AND QUANTIFIED A PRIORI, OR IS IT ONLY OF HEURISTIC VALUE?

FUTURE ISSUES

KEY WORDS AND DEFINITIONS

LITERATURE CITED 


\section{INTRODUCTION}

Ecological opportunity, "loosely defined as a wealth of evolutionarily accessible resources little used by competing taxa” (Schluter 2000), has long been thought to be an important - perhaps necessary - prerequisite for adaptive radiation. This view can be traced back to Darwin and was canonized by Simpson (1953); more recently, Schluter (2000) highlighted it as the centerpiece of understanding when and how adaptive radiation occurs. Certainly, the importance of ecological opportunity - as recognized by the absence of ecologically-similar species - seems indisputable given the widespread occurrence of adaptive radiations after mass extinction events and on islands, lakes, and mountaintops.

But what actually is ecological opportunity? How is it identified and quantified? How mechanistically does it lead to evolutionary radiation, and why in some cases and not others? And, in cases where radiation has not occurred, can one assess whether the cause was lack of opportunity or some other explanation?

\subsection{A historical perspective: From conception to modern utilization}

The notion of ecological opportunity as a prerequisite for adaptive radiation stems from the pioneering work of George G. Simpson, in which he defined ecological opportunity as an environment experienced by an ancestral species that was previously “occupied by organisms for some reason competitively inferior to the entering group or must be empty” (1953, p. 207). Other prominent evolutionary biologists of the time - notably David Lack (1947) and Ernst Mayr (1942) - held similar views; namely they supported the idea that a release from the biotic constraints of competing taxa in depauperate environments allows for the proliferation of species, increased ecological specialization and associated phenotypic diversification. 
Simpson (1953) suggested that ecological opportunity could become available in a number of ways. The geographic colonization of isolated areas lacking in competitors provides ample examples of producing adaptive radiations. Indeed, many classic examples of adaptive radiation, spurred by the ecological opportunity of colonization, are from islands (see Section II). The absence of mainland species on islands provides opportunities for increased ecological specialization into niches not filled by competing taxa. A similar adaptive landscape may be encountered in a post-mass extinction environment, where ecologically-similar competitors may again be absent. Conversely, the appearance of new resources rather than the absence of other species may be the source of opportunity. Finally, Simpson (1953) attached great importance to the evolution of unique phenotypes that allowed a species to interact with the environment in a novel way (i.e., "key innovations”; Miller 1949; Liem 1974). Such traits have the potential, Simpson suggested, to allow a species to diversify into a variety of niches not previously accessible and not occupied by competitor species.

Interest in the role of ecological opportunity in adaptive radiation has erupted in the last two decades (Figure 1). The term “ecological opportunity”, which in an evolutionary sense refers to the availability of ecologically accessible resources that may be evolutionarily exploited, was rarely used in the literature prior to 1995, but since then its use has increased almost exponentially. Certainly, a major cause of this increasing interest in ecological opportunity was Schluter's book (2000) emphasizing the importance of ecological radiation as a major contributor to evolutionary diversification. Of particular importance to the study of both adaptive radiation and ecological opportunity has been the explosion of molecular phylogenetic studies, a trend that began shortly before Schluter’s book was published (e.g., Givnish \& Sytsma 1997). The proliferation of densely-sampled, time-calibrated phylogenies of many groups has not only set the stage for modern investigation of the causes of evolutionary diversification, but also has revealed 
macroevolutionary patterns (discussed in Section II) consistent with a determinative role for ecological opportunity.

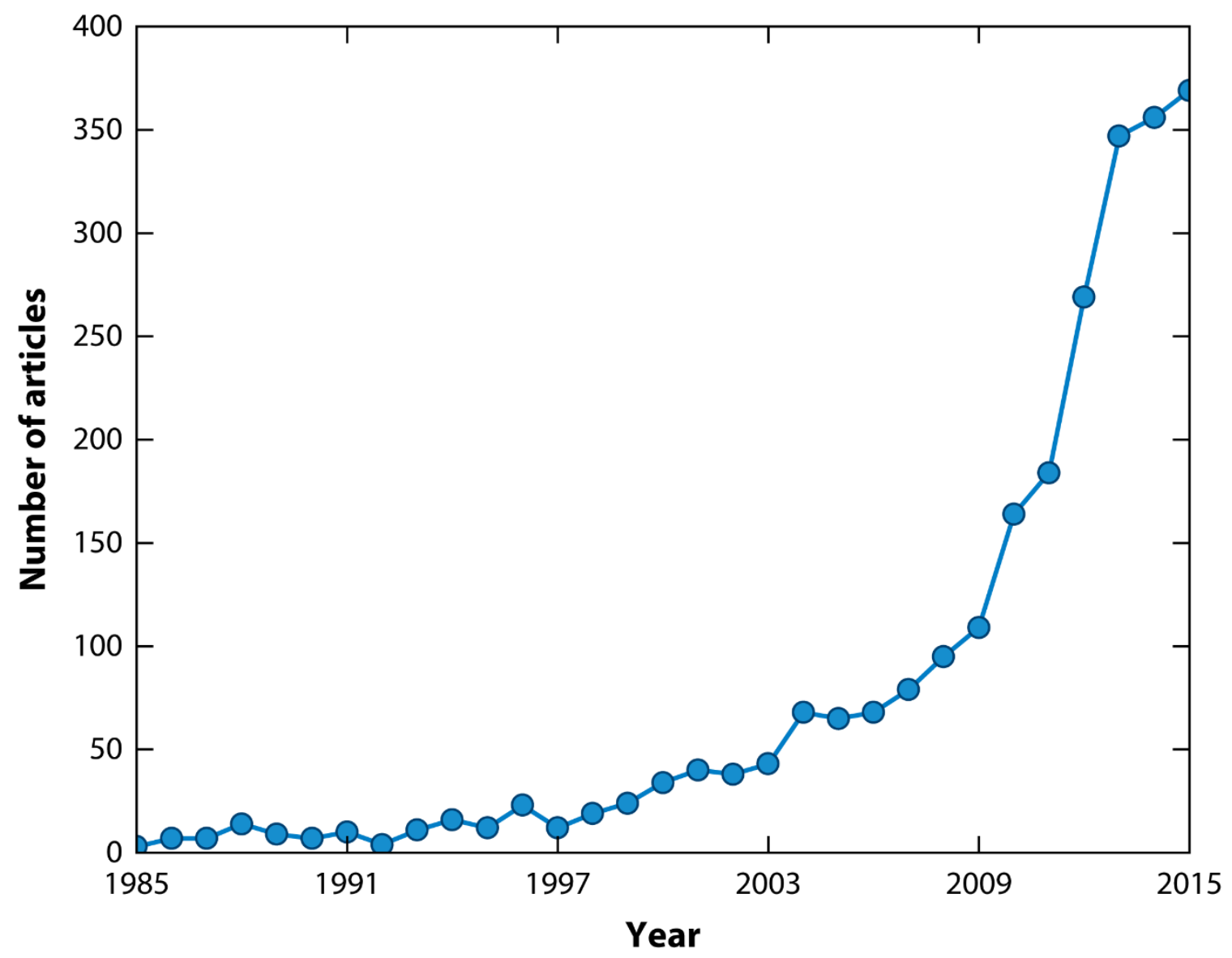

Figure 2.1. Trends in research on ecological opportunity as reflected in the number of articles published annually. The literature search was conducted using the Google Scholar database on January 20, 2016. To find articles that include "ecological opportunity," the following specifications were used: Find articles with the exact phrases "ecological opportunity" and "adaptive radiation" and with at least one of the words "ecology" or "evolution." Searches were run individually for every year 1950-2015; owing to a lack of studies before 1985, data from only 1985-2015 are shown. 


\section{WHAT IS THE EVIDENCE THAT ECOLOGICAL OPPORTUNITY PROMOTES ADAPTIVE RADIATION?}

Simpson (1953) suggested that for an adaptive radiation to occur, an ancestral species must have geographical, ecological, and evolutionary access to ecological opportunity. By geographical access, he meant simply that a species must find itself in a location where ecological opportunity occurs. Ecological access requires the availability of resources not usurped by competitively superior species, and evolutionary access means that a species has the ability to utilize the resources. In Simpson's view, adaptive radiation results when the ancestral species already has access along two of these axes and then an event occurs that provides access for the third. For example, adaptive radiation might ensue when a species colonizes an area in which resources are available and it has the evolutionary capability of diversifying to take advantage of them. Alternatively, it may also result when the species is already present in an area, but an extinction event removes an ecologically dominant incumbent (see Figure 2.2).

\subsection{Geographic colonization}

The fact that many textbook examples of adaptive radiation occur on islands is testament to the importance of geographical access as a precursor of adaptive radiation. The remote Hawaiian archipelago has been particularly fruitful, generating exceptional radiations of birds (Lovette et al. 2002), plants (Givnish et al. 2009), insects (Roderick \& Gillespie 1998), and arachnids (Gillespie 2004, 2015). In landlocked lakes, the aquatic equivalent of islands, the same patterns can be observed; the African Rift Lakes have produced multiple spectacular radiations of cichlid fishes (Brawand et al. 2014, Seehausen 2014, Sturmbauer et al. 2011); on the Indonesian island of Sulawesi, an adaptive radiation of silversides in Lake Matano has produced exceptional morphological diversity (Pfaender et al. 2010, 2016). One common trait that both emergent islands and lakes have in common is the absence of competitors, such as those that may be 

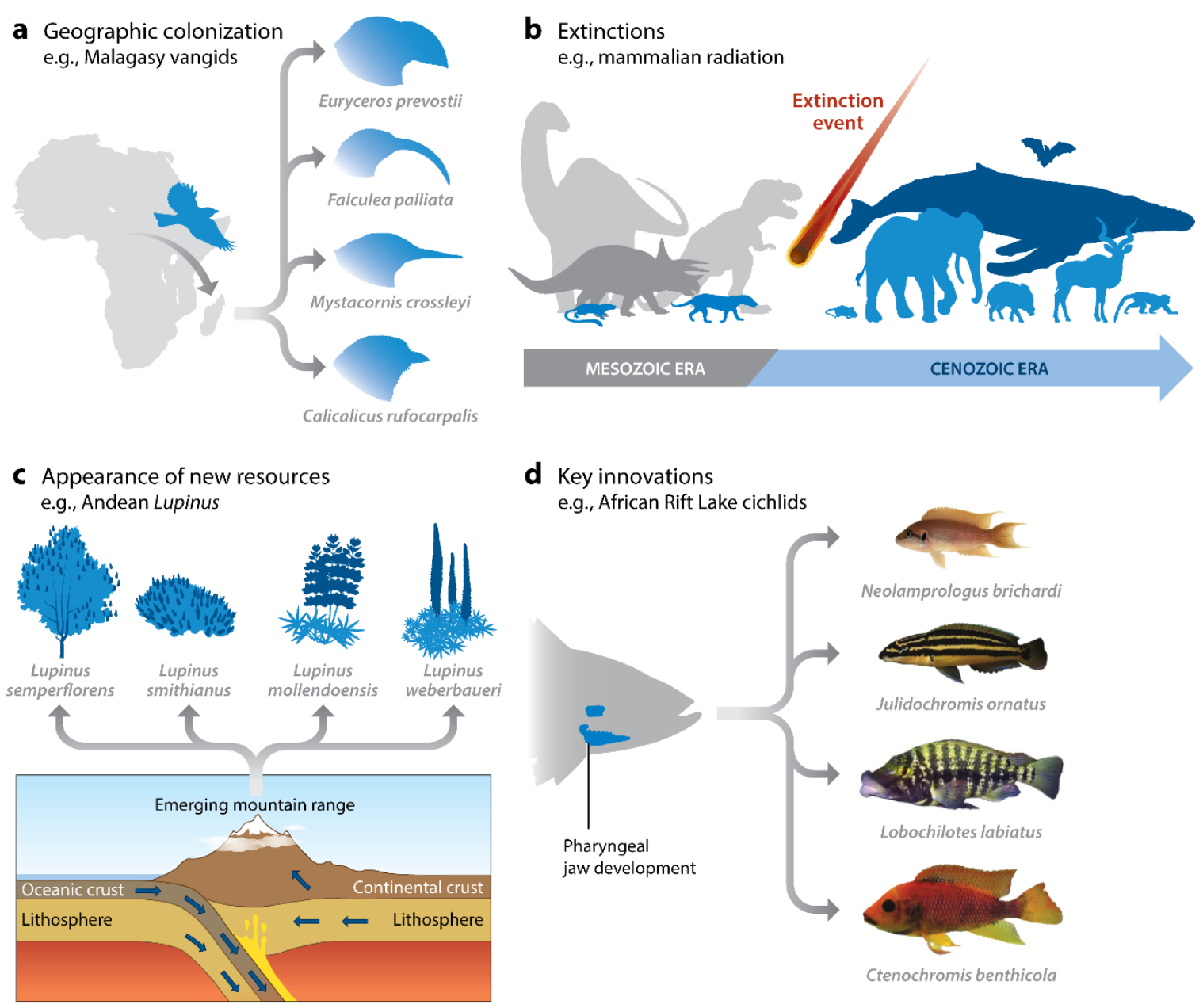

d Key innovations
e.g., African Rift Lake cichlids

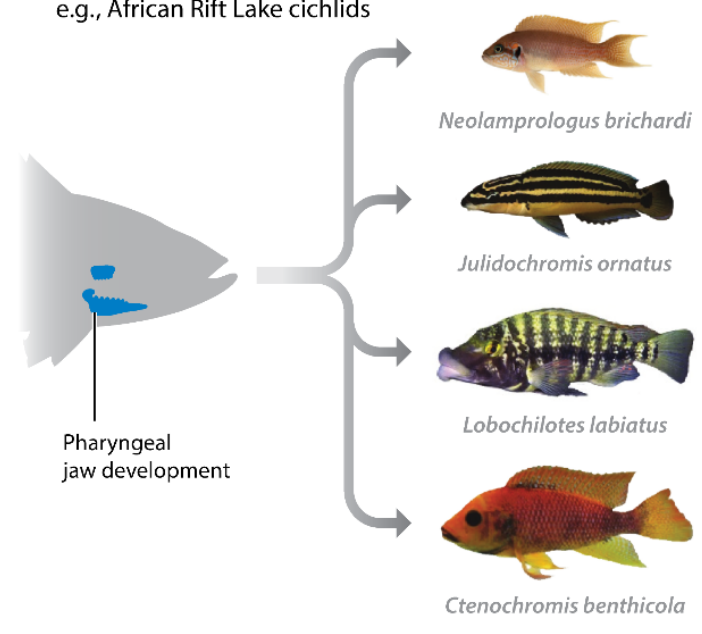

Figure 2.2. (a) The colonization of an isolated area (e.g., an island or lake) can provide a release from competition and predation pressures, allowing a clade to diversify into a variety of ecological niches from which they were previously blocked. For example, the colonization of Madagascar resulted in a spectacular adaptive radiation of vangid birds (Yamagishi et al. 2001, Jønsson et al. 2012). Additional examples include Galapagos finches (Grant \& Grant 2008), Hawaiian lobeliads (Givnish et al. 2009), African Rift Lake cichlids (Seehausen 2006), Hawaiian spiders (Gillespie 2004, 2015), Sulawesi silversides (Pfaender et al. 2010), and Caribbean Anolis lizards (Losos 2009). (b) Lineages able to survive extinction events may be presented with access to ecological space previously occupied by members of their own clade or by other competitors. For example, following the Cretaceous-Paleogene mass extinction of the nonavian dinosaurs and other archosaurs, ancestral birds and placental mammals gained access to previously unavailable ecological space and rapidly radiated (Hull 2015); mammals did exist, and some groups originated, prior to the extinction event, but this is simplified for heuristic purposes. An additional example is the Permian-Triassic radiation of ammonoids (McGowan 2004). (c) The appearance of new resources may provide ecological opportunities for species that can utilize them. For example, the emergence of the Andean mountains in the tropics provided new cool, highelevation habitats that spurred adaptive radiations when colonized by ancestral Espeletia and 
Lupinus species (Monasterio \& Sarmiento 1991, Hughes \& Eastwood 2006). Additional examples include flowering plants and phytophagous insects (Labandeira \& Sepkoski 1993, Bronstein et al. 2006) and the appearance of grasses and grazing horses (MacFadden 2005). (d ) The evolution of a feature that allows a lineage to interact with the environment in a novel way may provide the ability to utilize formerly unavailable resources. The evolution of the pharyngeal jaw, for example, allowed African Rift Lake cichlids to diversify into a wide range of trophic specialists (Liem 1973, Mabuchi et al. 2007), although this has recently been debated (Seehausen 2006). Additional examples include the evolution of flight in bats and birds (Cracraft 1990, Sears et al. 2006, Simmons et al. 2008), phytophagy in insects (Farrell 1998), nectar spurs in Aquilegia columbines (Hodges \& Arnold 1995, Ree 2005), and toepads in lizards (Williams \& Peterson 1982). It should be noted that in all panels (a-d ) the structures of all radiating groups are not meant to accurately reflect true phylogenetic relationships.

present in areas from which an ancestral species has arrived (Carlquist 1974, Givnish 1997a, Leigh et al. 2007). A release from competitors provides the opportunity for radiating species to utilize ecological niches from which they were previously blocked. Similarly, a release from predators may also allow the use of habitats or resources previously inaccessible, thus spurring adaptive diversification (Benkman 1991, Heinen et al. 2013, Runemark et al. 2014, Schluter 1988). As a result of the release from the biotic pressures experienced on the mainland, island radiations often have much higher ecological and phenotypic diversity than their mainland sister clades (Lovette et al. 2002, Schluter 2000). Some have argued that adaptive radiation may primarily be an island phenomena (Webb et al. 2006); however many extensive evolutionary radiations have also occurred in mainland situations when ecological circumstances have permitted (Mouton \& Van Wyk 1997, Tanentzap et al. 2015).

\subsection{Extinctions and the appearance of new resources}

In some cases, ancestral species encounter ecological opportunity within the ancestral range. Two ways in which this may occur are in the aftermath of an extinction event or following the appearance of new habitats or resources. 
The presence of an incumbent clade usually prevents another clade from diversifying (Rosenzweig \& McCord 1991), just as an incumbent species often prevents colonization of an ecologically-similar species (the “priority effect” [MacArthur 1972, Chase 2007]). The evolutionary inhibition of incumbents has been demonstrated experimentally in laboratory microbial experiments in which the extent of adaptive radiation was significantly constrained when ecologically similar species were present (Brockhurst et al. 2007). Given the inhibitory role of incumbents, it is not surprising that the elimination of competing taxa presents an ecological opportunity for those lineages able to survive an extinction event (Chen \& Benton 2012, Erwin 2007, 2015). The paleontological record abounds with examples of surviving taxa rapidly radiating after extinction events, so much so that the ensuing morphological disparity matches, or even exceeds, that observed in their extinct predecessors (Hull 2015). Surviving lineages may radiate into niches occupied by members of the radiating clade prior to the extinction event (Ciampaglio 2002, Foote 1996), such as the rapid recovery of ammonoid diversity following the Permian-Triassic mass extinction (McGowan 2004), or as is the case more commonly, may radiate into niches previously filled by competitors that succumbed to extinction (Foote 1999, Friedman 2010).

Mass extinction events, which remove entire or large proportions of taxonomic groups, provide ample evidence for the ecological opportunity hypothesis. For example, the CretaceousPaleogene mass extinction of the non-avian dinosaurs and other archosaurs resulted in an explosive radiation of birds and placental mammals (Erwin 2015, Smith et al. 2010; see Hull 2015 for a comprehensive review). In contrast to active clade replacement, in which a competitively-dominant radiating clade supplants a previously incumbent clade (see Section IV below), this large-scale release from competitive and predatory pressure resulted in a classic example of passive clade replacement (Alroy 1999, Archibald 2011), whereby a clade is able to radiate into ecological space previously occupied by the extinct taxa. 
Access to new ecological opportunity can also occur in situ if new resources appear within an area. The evolution of flowering plants, for example, may have spurred the diversification of phytophagus insects (Bronstein et al. 2006, Labandeira \& Sepkoski 1993; however see McKenna et al. 2009). Similarly, soon after the Miocene appearance of grasslands in North America, horses (family Equidae) radiated rapidly, diversifying in body size, limb morphology and dentition suitable for grazing on abrasive vegetation (MacFadden 2005). Alternatively the appearance of novel environmental conditions, such as the emergence of new mountain ranges, can be the catalyst for ecological opportunity. During the uplift of the Andean mountains, high-elevation paramo habitats formed as a type of above-treeline alpine tundra (Madrinan et al. 2013). Elevational tracking of this novel habitat zone by ancestral Espeletia and Lupinus plant species spurred their diverse radiations (Monasterio \& Sarmiento 1991, Rauscher 2002, Hughes \& Eastwood 2006, Hughes \& Atchinson 2015).

\subsection{Key innovations}

In addition to geographical and ecological access, for a clade to radiate, it must have the evolutionary capability to diversify to take advantage of the available resources. Discussion of this topic has focused on the evolution of so-called "key innovations" - features that allow a lineage to interact with the environment in a novel way and thus may provide the ability, hitherto unavailable, to utilize available resources (Galis 2001, Hunter 1998, Rabosky 2014). For example, the evolution of flight in birds, bats, and pterosaurs presumably provided access to aerial prey resources, leading to subsequent diversification to specialize to different aspects of the aerial realm (Wellborn \& Langerhans 2015). In other cases, the key innovation can provide access by minimizing the restricting effect of predators. For example, the evolution of brightly colored phenotypes to advertise toxicity in tropical dendrobatid poison frogs decreased the need 
for predator-induced "hiding” behavior and therefore allowed species to utilize habitats and resources that were previously inaccessible (Arbuckle \& Speed 2015, Santos et al. 2003, Summers 2003).

Many possible examples of a key innovation leading to adaptive radiation have been suggested, but making a compelling cause-and-effect relationship between the evolution of a trait and subsequent diversification is difficult in any particular instance. One solution is to investigate potential key innovations that have evolved several times to test for a general relationship between evolution of a trait and subsequent diversification (de Queiroz 2002, Mitter et al. 1988a); examples include hypocone dentition in mammals (Hunter \& Jernvall 1995), toepads in lizards (Larson \& Losos 1996, Williams et al. 1982), nectar spurs in Aquilegia columbines (Hodges \& Arnold 1995, Ree 2005), phytophagy in insects (Farrell 1998, Mitter et al. 1988b), and pharyngeal jaws in fish (Mabuchi et al. 2007). Of course, key innovations are often not a single trait, but a complex of several traits — the evolution of one trait may set the stage for subsequent evolution of other traits, the combination of which in turn trigger radiation (Cornwell et al. 2014, Donoghue 2005, Marazzi et al. 2012). For example, features that appeared during the evolution of wings in birds evolved across multiple nodes in the phylogeny, and thus the "wing” as a key innovation was not a singular evolutionary event, but the culmination of many evolutionary changes over millions of years (Cracraft 1990).

Two caveats must be kept in mind in evaluating claims of key innovations relative to adaptive radiation. First, key innovations may not lead to adaptive radiation. Many clades have evolved features allowing them to interact with the environment in a fundamentally different way, yet which have not diversified to an appreciable extent. For example, Archer fish (Toxotes sp.) have evolved the ability to shoot water from their mouths up to three meters to dislodge insects perched on overhanging vegetation (Burnette \& Ashley-Ross 2015, Schuster et al. 2006), yet the 
archer fish family (Toxotidae) is composed of only seven morphologically-similar species (Allen 2004). Similarly, Aneides salamanders evolved a novel foot structure providing great climbing ability, but Aneides contains only six very similar species (Baum \& Larson 1991). Among the mammals, the elongated digits evolved in parallel in the Madagascan aye-ayes (Daubentonia madagascariensis) and Papuan striped possums (Dactylopsila trivirgata) provide the ability to locate and extract prey from crevices in the manner of a woodpecker (Erickson 1991, Rawlins \& Handasyde 2002), yet each belongs to a monotypic genus. The possession of a key innovation may not lead to adaptive radiation either because ecological opportunity is not available - the innovation may provide access to a very narrow spectrum of resources—or because the clade does not have the evolutionary flexibility to diversify (see discussion of failure for adaptive radiation to occur in Section V).

The second caveat is that many studies have considered any trait that subsequently leads to species diversification to be a key innovation (e.g., von Hagen \& Kadereit 2003; Ree 2005; Erkens et al. 2012; Silvestro et al. 2014). However, the observation that a clade is species-rich does not indicate that it is adaptively diverse, much less that the trait allowed clade members to interact with the environment in a new way. More generally, some adaptive radiations contain few species, and some species-rich clades exhibit little diversity in ecological form (i.e. little adaptive disparity; Givnish 1997b, Losos \& Mahler 2010). Consequently, adaptive disparity and species richness are not necessarily related, and different terms are needed for traits that promote one type of diversification or the other (although in some cases, a trait may have both effects). “Key Innovations” (Miller 1949) refer to those traits that lead to interacting with the environment in a different way; another term is needed to refer to traits that increase the rate of species diversification. 


\subsection{Testing the ecological opportunity hypothesis with phylogenies}

In several ways, molecular phylogenetics has been instrumental in the resurgence of the study of adaptive radiation and the role that ecological opportunity plays (Glor 2010). For example, molecular studies have revealed that many biotas previously assumed to be composed of multiple ancestral lineages are the result of diversification of a single clade; notably those of the Malagasy vangids (Reddy et al. 2012, Yamagishi et al. 2001); Australian, African and global corvoids (Barker et al. 2004; Jønsson et al. 2011, 2015); Lake Victoria cichlids (Meyer et al. 1990); and Hawaiian lobeliads (Givnish et al. 2009). Molecular phylogenies have also proved useful in clarifying temporal patterns of diversification, which is important to understanding the pace of diversification (Rabosky 2009) and in recognizing potential catalysts for adaptive radiation (Donoghue 2005, Glor 2010).

In addition, molecular phylogenies have been used to directly test the hypothesis that rates of adaptive radiation are related to available ecological opportunity. Early studies simply looked at the rate of species proliferation through time as a clade diversified; assuming that as a clade became more species-rich, ecological opportunity would decrease, these studies tested the prediction that declining opportunity would lead to a slow-down in the pace of diversification through time (Freckleton \& Harvey 2006, Schluter 2000; note that adaptive radiation does not necessarily entail a burst of diversification at the outset; whether such a temporal pattern occurs as part of a radiation is a hypothesis to be tested, rather than part of the definition [Givnish, 2015]). More recently, researchers have directly tested the relationship between opportunity, estimated as the interspecific morphological variety inferred to have existed at a given time, and rate of ecomorphological diversification (Mahler et al. 2010). The prediction in these studies is that morphological diversification should decrease as clades became more ecomorphologically diverse (Arakaki et al. 2011, Burbrink et al. 2012, Hughes et al. 2013, Slater 2015, Svensson \& 
Calsbeek 2012). When applying this framework to Greater Antillean Anolis lizard radiations, for example, time-calibrated phylogenetic methods reveal both a rapid early accumulation of lineages and bursts of phenotypic evolution (Mahler et al. 2010); a pattern which is common across taxonomic groups and geographic regions (e.g. the fossil record, Foote 1997; birds, Rabosky \& Lovette 2008; plants, Agrawal et al. 2009; fishes, Near et al. 2012; mammals, Schenk et al. 2013).

\section{HOW MECHANISTICALLY DOES ECOLOGICAL OPPORTUNITY LEAD TO ADAPTIVE RADIATION?}

Picture a pregnant rodent washing ashore on a lush tropical island full of plant and arthropod life, but lacking herbivores, granivores and carnivores. The many available resources in the form of foods and habitats would constitute a wealth of ecological opportunity and with luck and avoidance of inbreeding depression, the resulting population would quickly become wellestablished. Scenarios such as this embody the first step in adaptive radiation, a population finding itself in the presence of great opportunity. But how does this ecological cornucopia translate into evolutionary diversification?

Adaptive radiation entails evolution in two dimensions: the proliferation of an initial ancestral species into multiple descendant species, and the divergence of these species to adapt to an array of different ecological conditions, which we henceforth refer to as niches (for discussion of this long-lived and contentious term, see Chase \& Leibold 2003). Whether speciation and adaptive divergence are a sequential or simultaneous process is an outstanding question in macroevolution. 


\subsection{The classic scenario: Interspecific competition}

The classic scenario postulates speciation occurring first, followed by subsequent divergence. The archipelago model—exemplified by adaptive radiation in Darwin’s finches (Grant \& Grant 2008, 2014)—is a prime example: an ancestral finch initially colonizes one of the Galápagos islands, and subsequently individuals from that population colonize another island. In allopatry, the two populations diverge to the extent that they are substantially or completely reproductively isolated (or would be were they to occur in sympatry); such reproductive isolation can evolve for many reasons including genetic drift or as an incidental by-product of divergence resulting from different adaptive or sexual selection pressures (Gittenberger 1991, Price 2008, Schluter 2000, Wagner et al. 2012). At the same time, some degree of adaptive divergence occurs as the two nascent species adapt to differences between the islands. Subsequently, colonization from one island to the other brings the two nascent species into sympatry. Once the populations reach their carrying capacities, they may compete for resources. Given the different types of available resources, the two populations may take advantage of this ecological opportunity and diverge in resource use; this resource partitioning permits the species to minimize interspecific competition. Assuming that the populations can coexist long enough (that is, that competitive exclusion does not lead to the extinction of one [Macarthur \& Levins 1967; Slatkin 1980; Gomulkiewicz \& Holt 1995]), natural selection may then cause the species to diverge phenotypically to adapt to their new resource utilization regime. This is the process of ecological character displacement (Brown \& Wilson 1956). Natural selection against hybrids can also lead to the perfection of reproductive isolation if it was incomplete prior to sympatry (the process of reinforcement; Blair 1955). Multiple cycles of such divergence in isolation followed by character displacement in sympatry can lead to a diverse adaptive radiation. 
Not too long ago, both character displacement and reinforcement were thought by some to be unlikely on both theoretical and empirical grounds, but in recent years, these concerns have diminished and both are now generally considered to occur commonly (Schluter 2000; Dayan \& Simberloff 2005; Grether et al. 2009; Pfennig \& Pfennig 2012a,b; Stuart \& Losos 2013). Evidence from both laboratory studies of microorganisms (Bailey \& Kassen 2012, Le Gac et al. 2012, Rainey \& Travisano 1998, Tyerman et al. 2008) and field studies of trait shifts in nature (Goldberg et al. 2012, Grant \& Grant 2006, Pfennig et al. 2006, Stuart et al. 2014) continue to provide compelling evidence for character displacement when ecological opportunity is present. Additionally, an increased movement of species to regions outside of their native range in the Anthropocene is providing ample opportunities to observe species in the early stages of secondary contact and coexistence, setting the stage for many new observational studies of character displacement (Strauss \& Weber 2016).

\subsection{Predation}

Traditionally, interspecific competition has been considered the driving force behind adaptive radiation in the presence of ecological opportunity, but other mechanisms may be important as well. In particular, predation (defined here as consumption of one individual by another, thus including herbivory and parasitism) can cause populations to shift their resource use; in the presence of ecological opportunity, predation, in theory, may be a potent force driving adaptive radiation (Langerhans 2007).

Predation can play a role at several different stages of adaptive radiation. On one hand, allopatric populations may diverge adaptively due not to differences in resource availability, but rather as a result of experiencing different predation pressures. Damselfly larvae, mosquitofish, sticklebacks and zooplankton, for example, exhibit divergence in behavior, habitat use, and 
morphology depending on the types of predators to which they are exposed (Giery \& Layman 2015, Giery et al. 2015, Marchinko 2009, Strobbe et al. 2011, Walsh \& Post 2011).

Alternatively, divergence can also occur between sympatric species as they adapt in different ways to predation by a common predator (Allen et al. 2013). Such predator-driven divergence can be particularly potent when it drives species into different niches and lifestyles that lead to differences in resource use as well. For example, the evolution of body armor can affect locomotion which in turn may alter how animals can forage and acquire resources (Broeckhoven et al. 2015, Langerhans 2009).

Predator-driven prey divergence can result in evolutionary patterns similar to those resulting from interspecific competition. When prey species share a predator, an increase in the population size of one prey species may lead to a larger population of the predator, which in turn would lead to a reduction in the population of the second prey species. The result is that the population sizes of the two species would be negatively related, just as occurs with interspecific competition (Holt 1977). And just as with interspecific competition, prey species may diverge in habitat or resource use to minimize vulnerability to the shared predator, leading to the same pattern of character displacement as produced by interspecific competition. The process by which predation may lead to the same types of ecological and evolutionary response as competition has been termed “competition for enemy free space” (Jeffries \& Lawton 1984) or “apparent competition” (Holt 1977).

In these ways, predation-driven divergent selection could lead to adaptive radiation in the presence of ecological opportunity. However, the extent to which predation drives adaptive radiation remains unresolved and few examples have been documented (Anderson \& Langerhans 2015, Langerhans 2007, Vamosi 2005). 
In addition to predation, other interspecific interactions may also be important in stimulating adaptive radiation. For example, mutualisms can promote the coexistence of closelyrelated species and may also lead to new ecological opportunities (Anacker \& Strauss 2014, Strauss \& Weber 2016).

\subsection{Sympatric speciation}

The archipelago model of adaptive radiation by allopatric speciation, as described earlier for Darwin's finches, is easy to envision. Speciation may occur on different islands, with species subsequently coming into contact via dispersal. However, any biogeographic or historical setting in which populations become geographically isolated may produce allopatric speciation and serve as the first stage in the adaptive radiation process. Allopatric speciation has historically been considered the predominant process by which speciation occurs, at least in animals if not plants, and is one reason that the traditional view of adaptive radiation invokes speciation in allopatry followed by divergence in sympatry.

The alternative view of the relationship between ecological opportunity and adaptive radiation envisions speciation and adaptive diversification occurring in concert in one place without an allopatric stage. In this view, the ancestral population first expands its resource use, taking advantage of the variety of available resources and/or the lack of predators (Parent \& Crespi 2009, Wellborn \& Langerhans 2015, Yoder et al. 2010). This niche expansion in the absence of other species is referred to as ecological release (Wellborn \& Langerhans 2015, Yoder

et al. 2010; it can occur in the classic allopatric scenario as well, but is not a necessary part of it). Subsequent to niche expansion, disruptive selection operates on the population, favoring individuals better-suited to utilize specific resources, but working against those intermediate individuals not well-adapted to any particular resource (Wellborn \& Langerhans 2015). As 
subpopulations become well-adapted to specific resources, the relative fitness of intermediate phenotypes decreases. As a result, strong selection favors individuals that mate assortatively, leading to increasing reproductive isolation between the subpopulations, which may eventually become different species (Dieckmann \& Doebeli 1999, Doebeli \& Dieckmann 2000, Kondrashov \& Kondrashov 1999). This is one model of sympatric speciation, now often studied under the rubric of ecological speciation (Nosil 2012).

For much of the latter half of the twentieth century, sympatric speciation was theorized to be very unlikely, the primary criticism being that interbreeding between diverging subpopulations would tend to homogenize the populations and prevent the establishment of assortative mating (Coyne \& Orr 2004, Coyne \& Price 2000, Felsenstein 1981, Mayr 1963). However, in recent years the development of new theoretical frameworks and the discovery of a slew of suggestive examples has caused the pendulum to swing in the opposite direction, and such sympatric ecological speciation is now considered a likely phenomenon by many (e.g., Bolnick \& Fitzpatrick 2007, Givnish 2010, Bird et al. 2012, Mullen \& Shaw 2014, Nosil 2012). In some respects, a model of adaptive radiation via sympatric speciation is more parsimonious than invoking the existence of an intermediate allopatric stage for speciation for which there often is no independent evidence. This argument has been made particularly forcefully for adaptive radiations occurring on smaller islands or lakes where the opportunity for allopatry is not obvious (Barluenga et al. 2006, Kautt et al. 2012, Martin \& Feinstein 2014, Schliewen et al. 1994; but see Martin et al. 2015). Nonetheless, whether adaptive radiation often proceeds by sympatric speciation remains highly debated (Henning \& Meyer 2014, Martin et al. 2015, Nosil 2012, Schluter 2009), and the number of putative cases of adaptive radiation via this mechanism of speciation remains low. 


\section{IS ECOLOGICAL OPPORTUNITY NECESSARY FOR ADAPTIVE RADIATION?}

Clearly, ecological opportunity often leads to adaptive radiation. But is it a necessary prerequisite? Can adaptive radiation occur in the absence of pre-existing ecological opportunity by members of a diversifying clade either wresting previously unavailable resources away from other taxa that had been using them or by creating their own opportunity?

\subsection{Competitive replacement}

The paleontological literature is replete with proposed examples of one clade diversifying at the expense of an existing clade, outcompeting the extant species and forcing the clade into evolutionary decline; a process known as active clade replacement (see discussions in Benton 1996, Jablonski 2008). The paleontological signal of such a situation would be negatively correlated species diversity patterns, one clade rising in diversity while the other diminishes. Perhaps the most convincing examples are those observed among post-Paleozoic cyclostome and cheilostome bryozoans (Lidgard et al. 1993, Sepkoski et al. 2000) and the multiple diversifying clades of canids and felids driving two canid subfamilies extinct in North America (Silvestro et al. 2015).

However, most purported examples of competitive clade replacement have fallen out of favor (Benton et al. 2014, Wilson et al. 2012), being replaced instead with a scenario whereby the incumbent taxon declined prior, and for reasons unrelated, to the diversification of a second group (Benton 1996, 2009; Brusatte et al. 2008, Rosenzweig \& McCord 1991, Valkenburgh 1999). Subsequent diversification of the second clade after extinction of the first exemplifies postextinction radiation driven by new ecological opportunities (passive clade replacement, discussed in Section II). For example, the idea that the rise of the dinosaurs came at the expense of other 
archosaurs has become increasingly disparaged, replaced by the idea that the process represented an extended passive replacement facilitated by dramatic changes in the global environment (Brusatte et al. 2008, 2010; Benton et al. 2014).

Moreover, the scenario of one clade competitively diversifying and eliminating a second clade is called into question by the rarity in which even a single species competitively eliminates another throughout its range today. The vast number of human introductions of species to areas outside their native ranges has brought together countless numbers of competitively similar species with no prior history of interaction (Sax et al. 2007). Nonetheless, few examples exist of one species causing the global (as opposed to local) extinction of another species as a result of interspecific competition (Davis 2013). By contrast, exposure to novel predation and disease from introduced species have led to the global extinction of many native species (Kraus 2015, Roy et al. 2012, Sax et al. 2007). Although novel competition can cause rapid reductions in population sizes of native species and may result in extinctions over a longer temporal scale than predation or disease (McCune et al. 2013), given the relative rarity of documented competition-caused extinctions of even single species, the possibility of an adaptively radiating clade eliminating an entire clade of established species by way of resource usurpation appears unlikely.

\subsection{Self-propagating radiations: Niche construction}

Ecological opportunity thus seems usually necessary as a pre-requisite for adaptive radiation. In most well-studied cases, such opportunity exists prior to adaptive radiation, but an alternative is that clades create their own opportunity as they radiate (see Odling-Smee et al. 2003, 2013 for extensive discussion). Ecological opportunity may be generated through the 
creation of novel niches, whereby the environment is modified in some way - either biotically or abiotically - such that access to newly-created resources results (Matthews et al. 2014).

This process of niche construction may occur in three ways. First, as a clade radiates, the presence of multiple species provides ecological opportunities that other clade members can exploit (which we term "intra-clade niche construction"). The traditional view is that as a clade diversifies, ecological resources become increasingly limited, and the rate of diversification slows down. But an alternative possibility is that the more species there are in a clade, the more opportunities there are for predators or mutualists (Erwin 2015, Tokeshi 2009, Wellborn \& Langerhans 2015, Whittaker 1977). Most ecological communities are comprised of species from many clades, but when members of a single radiation are extremely diverse ecologically (usually on islands or in lakes), then this accelerating effect of species richness may have an evolutionary component: as the clade radiates, it may create additional opportunities, spurring further radiation, thus creating further opportunities, and so on.

This scenario is most likely when adaptive radiations transcend trophic levels, producing radiation members that consume other members of the same clade (Schluter 2000). Indeed, the evolution of a species that preys on other members of a clade has been observed in a diversity of taxa. For example, freshwater fishes specialized to feed on the scales of other species in its clade has evolved in both Bahamanian pupfish (Cyprinodon sp., Martin \& Feinstein 2014, Martin \& Wainwright 2013) and African Rift Lake cichlid (Koblmüller et al. 2007, Seehausen 2014, Takahashi et al. 2007) radiations. Additionally, intra-clade niche construction has also been demonstrated experimentally in microbial laboratory systems. For example, by manipulating the spatial complexity of the structural environment available to an ancestral population of Escherichia coli, initial colonizers of uninhabited fragment patches modified the environment such that divergence occurred when subsequent colonizers were able to exploit a different, 
previously unavailable niche and adaptive radiation ensued (Habets et al. 2006). Similarly, several microbial studies have shown the evolution of a trophic specialist able to metabolize the waste product of an ancestral species (Kassen 2009, Losos \& Mahler 2010). Though these examples demonstrate that adaptive radiations may create additional opportunity during diversification, the general pattern in adaptive radiations of decreasing diversification and ecomorphological adaptation rates through time (e.g. Agrawal et al. 2009, Mahler et al. 2010; but see Slater 2015) suggests that the creation of additional ecological opportunities within a clade during radiation is rare.

Second, concurrent radiation of two clades may create opportunities for ecological diversification in one or both clades (which we term “inter-clade niche construction”). For example, a radiation driven by competition or predation may create new ecological opportunities for a co-existing clade that may adapt and use constituent members of the first as a resource. This may spur further complementary radiation of the first clade as members seek to avoid being exploited by the second. The diversification of apple maggot flies, for example, is paralleled by radiation of the parasites that prey upon them (Forbes 2009), much like the diversification of herbivorous weevils occurring in concert with that of flowering plants (McKenna et al. 2009). In some cases, co-evolutionary dynamics are more complicated, involving one clade escaping harmful biotic pressures of another and diversifying as selection is relaxed, providing the basis of the escape and radiation theory of plant-herbivore coevolution (Ehrlich \& Raven 1964) and Vermeij’s (1987) theory of “evolution and escalation”.

A third way in which radiations may create their own ecological opportunity is through the construction of new ecological opportunities via alterations to the physical environment; so called “ecosystem engineering” (Jones et al. 1994, 1997; Wright \& Jones 2006; Odling-Smee et al. 2013). Ecosystem engineers affect resource availability for other species by physically 
modifying the abiotic or biotic characteristics of an environment (Erwin 2008, Jones et al. 1994). Ecosystem engineering could lead to adaptive radiation if an ecosystem engineer (or clade of ecosystem engineers) creates new environments that prompt adaptive radiation in another clade. For example, the unique and complex habitat structure built by coral reefs provided ecological opportunities for specialization and subsequent diversification of tetraodontiform fishes (Alfaro et al. 2007), just as the evolution of burrowing led to increased bioturbation and subsequent diversification of marine animal lineages able to exploit the newly constructed habitat zone during the Cambrian explosion (Erwin 2008). These examples, of course, do not illustrate a clade creating its own ecological opportunities. However, the possibility exists that a radiating clade could take advantage of opportunities created by an ecosystem engineering clade member. One example may be the exceptional adaptive radiation of lobeliad plants in Hawaii. After initial radiation by a colonial species, the evolution of forest plants able to withstand hot, unshaded habitats may have acted as ecological engineers by subsequently providing suitable environmental conditions allowing for the evolution of shade-tolerant sub-canopy species (Givnish et al. 2004, 2009).

\section{WHY DOES ECOLOGICAL OPPORTUNITY NOT ALWAYS RESULT IN ADAPTIVE RADIATION?}

Although ecological opportunity is the usual stimulus for adaptive radiation, some clades fail to radiate in the presence of an apparent ecological opportunity (Losos 2010, Losos \& Mahler 2010, Wilson 1992; 'depauperons' sensu Donoghue \& Sanderson 2015, Strauss \& Weber 2016). For example, in the Galápagos, Darwin’s finches are the only clade of birds that radiated to any appreciable extent (Valente et al. 2015). Similarly, on Caribbean islands, Anolis lizards have repeatedly and independently diversified on separate islands, yet few other clades of lizards have 
followed suit, despite having had the same temporal opportunity to do so (Crother \& Guyer 1996, Thorpe et al. 2008). The presence of ecological opportunity, therefore, does not guarantee that a clade will radiate.

A clade might fail to radiate in the apparent presence of ecological opportunity for several reasons. One explanation is that ecological opportunity is not actually present. For example, the failure of some clades to radiate on islands may be because earlier arriving clades already usurped available resources. This can be observed in the muroid rodents, where in independent radiations around the world, early colonizers had inhibitory effects on the ultimate diversity of later colonizers (Schenk et al. 2013). Alternatively, ecological opportunity itself may have been misidentified. The spectrum of available resources that constitutes an ecological opportunity for one species may not be the same as that required by a different species. For example, the diversity of seed sizes and shapes available on the Galápagos may have constituted opportunity to an ancestral finch species, but the range of insects may not have provided diverse opportunities for insectivorous birds, thus explaining differences in evolutionary diversification among Galápagos birds (Arbogast et al. 2006, Grant \& Grant 2008, Rundell \& Price 2009, Valente et al. 2015).

Even in the presence of ecological opportunity, however, adaptive radiation may not occur for two reasons. First, as discussed previously, adaptive radiation requires both proliferation of species and diversification in resource use to fill different ecological niches. Consequently, if a species is unable to speciate, then adaptive radiation cannot occur (Wellborn \& Langerhans 2015). For example, many types of organisms—e.g., birds, lizards, snails and snakes—almost never speciate on islands smaller than a threshold size (Coyne \& Price 2000, Kisel \& Barraclough 2010, Losos \& Parent 2009, Losos \& Schluter 2000, Pyron \& Burbrink 2014). Failure of these species—such as Pinaroloxias inornata, the single species of Darwin finch 
on Cocos Island or Anolis in the Lesser Antilles_-to radiate on these ecologically diverse islands may be a result of their inability to speciate.

The second reason that a clade may fail to radiate in the presence of ecological opportunity is that it does not have the ability to evolve readily into diverse forms (Schluter 2000): clades that lack such evolvability will change more slowly or not at all, whereas those that can readily change will be capable of adapting to new circumstances (Adamowicz et al. 2008, Arbogast et al. 2006, Wellborn \& Langerhans 2015). Several factors could account for differences in evolvability. For example, species with greater modularity-i.e., in which different aspects of the phenotype can evolve independently—may be able to diversify to a greater extent than species in which phenotypic components are less independent (Clune et al. 2013, Kirschner et al. 1998, Rutherford \& Lindquist 1998, Vermeij 1973). Phenotypic and behavioral plasticity may also be important factors in determining levels of evolvability (Baldwin 1896, Draghi \& Whitlock 2012, Snell-Rood 2013). Plasticity may allow a species to exist in conditions that otherwise would be unsuitable, possibly providing sufficient time for subsequent genetic adaptations to the new ecological environment (reviewed in West-Eberhard 2003). However, identifying the evolutionary role of evolvability may be difficult. This is because evolvability itself may evolve rather than being characteristic of entire clades (Zaman et al. 2014), for example, hybridization events increased evolvability in populations of African Lake Malawi cichlids (Parsons et al. 2011).

The observation that some clades radiate more than others (Carlquist 1974) suggests that evolvability and propensity to speciate may be important in determining whether adaptive radiation occurs. Some clades appear to have high evolvability and propensity to radiate regardless of the environment, such as the Hawaiian honeycreepers and Darwin’s finches, which have both radiated extensively on their respective archipelagos, as have their sister taxa on the 
mainland (Burns et al. 2002, Lovette et al. 2002). By contrast, the Hawaiian thrushes and the Galápagos mockingbirds have not radiated on either islands or the mainland despite existing there for the same length of time (Arbogast et al. 2006, Grant \& Grant 2008, Lovette et al. 2002). Cichlid fish show a similar pattern, with some clades frequently radiating and others not (Seehausen 2014). These consistent differences across different contexts suggest either intrinsic differences in evolvability or speciation propensity may exist among taxa. On the other hand, some clades that appear to readily radiate on islands remain relatively depauperate elsewhere in their range. For example, the Tetragnatha spiders and aglycyderid weevils radiated to a greater extent on Hawaii than on the mainland (Gillespie 2015, Paulay 1994), and cichlid fish diversity in Africa is much higher in lakes than rivers (Genner et al. 2015). In these cases, extrinsic circumstances appear to be more important in determining whether radiation results.

\section{CAN ECOLOGICAL OPPORTUNITY BE IDENTIFIED AND QUANTIFIED A PRIORI OR IS IT ONLY OF HEURISTIC VALUE?}

Ecological opportunity is usually recognized after it has occurred: a clade that has experienced an adaptive radiation is identified and then its history is assessed to see whether ecological opportunity was present early on. Alternatively, an event that generates ecological opportunity—such as a mass extinction event or creation of a new island or mountain range — is identified and clades are studied to see if any have subsequently radiated. The consensus is clear that ecological opportunity usually precedes adaptive radiation.

Nonetheless, two key questions remain. First, as discussed in the previous section, in those cases in which a clade did not radiate, is a lack of ecological opportunity the explanation? Second, looking forward, can we identify species or clades currently experiencing ecological opportunity, those that we would expect to radiate in the future? In other words, can ecological 
opportunity be identified independently of the occurrence of adaptive radiation? Can ecological opportunity be measured? Does the concept have predictive value, or is it just a useful heuristic for explaining adaptive radiation after the fact (Losos 2010)?

Answering these questions requires a means of measuring ecological opportunity, which is not straightforward. In this respect, the concept of ecological opportunity is plagued by the same difficulties as the empty niche concept (Chase \& Leibold 2003, Losos \& Mahler 2010). Not only are both hard to identify in the absence of species that fill or take advantage of them, but it is also difficult to demonstrate that resources are ever truly underutilized by some member of a community, even if not by a member of a focal clade.

Ecological opportunity represents an adaptive landscape with many vacant peaks (Simpson 1953). An approach to testing for the existence of ecological opportunity might involve estimating selection on an adaptive landscape (Fear \& Price 1998; Schluter 2000; Arnold et al. 2001; the concept of adaptive landscapes is extensively reviewed in Svensson \& Calsbeek 2012). If it is possible (e.g., through hybridization) to generate a variety of phenotypes, it may be possible to detect unoccupied adaptive peaks, which suggest the existence of ecological opportunity; in other words there exists an alternative way of making a living which is awaiting the evolution of a species able to do so.

Of course, estimating the adaptive landscape, particularly in the context of evolutionary radiation, is fraught with difficulty. In particular, the presence of other species-e.g., competitors and predators—-will alter the shape of the landscape, potentially causing peaks to appear or vanish compared to a landscape estimated in their absence. Consequently, in the context of investigating whether ecological opportunity exists, the landscape will need to be investigated in the presence of other species. This approach, however, will only suffice to identify currently existing opportunity. Once speciation occurs, the landscape may shift as a result of the presence of a new 
species. Hence, estimating how long opportunity persists during the course of a radiation will be very difficult, and is beyond any work that has been conducted to date.

Only a few studies have quantified the adaptive landscape experienced by the constituent species of a given adaptive radiation (e.g., Case 1979; Schluter \& Grant 1984; Pfaender et al. 2016). For example, Martin and Wainwright (2013a) estimated the adaptive landscape by measuring selection on a variable population produced by hybridizing three sympatric pupfish species from San Salvador, Bahamas. Their study confirmed the existence of two peaks corresponding to the phenotype of two of the three species. Similarly, Arnegard et al. (2014) used isotopic signatures of hybrid threespine stickleback fish (Gasterosteus aculeatus) to identify independent adaptive peaks in a population where individuals forage across a gradient from limnetic to benthic diets. Extending this approach to test for the existence of unoccupied adaptive peaks available to species potentially experiencing ecological opportunity is a logical next step in this research direction.

\section{FUTURE ISSUES}

Simpson's (1953) suggestion that ecological opportunity is the impetus for adaptive radiation is well-supported. Now would seem to be the time for the field to move beyond documenting whether a relationship exists between ecological opportunity and adaptive radiation and to investigate the underlying mechanistic basis for the relationship. Additionally, investigations should assess when and why the two are sometimes uncoupled, either because adaptive radiation can occur without pre-existing opportunity or, conversely, because radiations sometimes fail to follow from the existence of opportunity. 
New tools - from comparative genomics to the ability to estimate adaptive landscapes and conduct evolutionary experiments in the field - now provide the means to further refine these questions. However, at the most fundamental level, a detailed understanding of the natural history of study organisms will remain crucially important to research development and interpretation (Greene 1986, Grant \& Grant 2008, 2014). We expect the study of ecological opportunity to continue to blossom in the near future.

1. Adaptive landscapes. Recent empirical studies have estimated the shape of adaptive landscapes with multiple coexisting species in an adaptive radiation. Further studies attempting to quantify ecological opportunity, i.e., the presence of multiple adaptive peaks on a landscape, will continue to develop our understanding of the nature of ecological opportunity and will allow us to see how opportunity varies among taxa, areas and through time. Further, a more detailed macroevolutionary theory of how the adaptive landscape itself evolves will be important to further bridge gaps between the pattern-process divide (Arnold et al. 2001, Svensson \& Calsbeek 2012, Wellborn \& Langerhans 2015).

2. Genomics. Investigations into the genomic structure of several well-studied adaptive radiations have already begun (e.g. Darwin’s finches, Almen et al. 2015; African Rift Lake cichlids, Brawand et al. 2014, Wagner et al. 2013; Heliconius butterflies, The Heliconius Genome Consortium et al. 2012; Supple et al. 2013). Studies that synthesize research on adaptive landscapes with genomics will have the potential to present a clearer understanding of the phenotype-fitness and genotype-phenotype relationship and will be instrumental in understanding the genetic basis of how and why ecological opportunity is exploited and adaptive radiation occurs. 
3. Niche construction. As a better understanding of eco-evolutionary feedback relationships continues to develop, opportunities will arise to provide empirical tests for hypotheses of niche construction. Although long-supported in the paleontological literature (Odling-Smee et al. 2013), and more recently from microbial laboratory studies (Habets et al. 2006, Rainey \& Travisano 1998), little evidence exists from contemporary ecological studies (although see Matthews et al. 2016). Advances in methods for studying food webs, for example using stable isotopes or DNA barcoding of fecal samples, may reveal previously undetected novel ecological pathways through which evolutionary divergence resulting from ecological opportunity may be facilitated.

4. Species introductions. The global movement of species in the Anthropocene has provided unparalleled opportunities to observe novel ecological and evolutionary scenarios (Wellborn \& Langerhans 2015, Strauss \& Weber 2016). For example, movement of species to areas with no, or few, ecological competitors may provide situations analogous to conditions first experienced by ancestral species in an adaptive radiation, potentially presenting the introduced species with ecological opportunity. It may be particularly valuable to compare introduced species from clades that have radiated elsewhere to those from clades that have failed to radiate to examine the role of inherent evolvability of a clade in responding to ecological opportunity. Advances in how to predict areas vulnerable to invasion may also provide opportunities to identify ecological opportunity a priori. For example, the identification of young diversifying clades- particularly those in areas strongly associated with the production of adaptive radiations such as islands - may suggest that ecological opportunity is still present and therefore more vulnerable to ecological and evolutionary exploitation by novel colonists.

5. Global extinctions. As we enter the "Sixth Mass Extinction" in the Anthropocene (Ceballos et al. 2015), we are being presented with the first large-scale opportunity to study ecological and evolutionary responses to biodiversity loss (Wellborn \& Langerhans 2015). 
Despite an undoubted catastrophe for global biodiversity, this evolutionary research opportunity is unprecedented. For example, current global amphibian rates of extinction are four orders of magnitude higher than expected background rates (Alroy 2015). The IUCN Red List currently classify $>30 \%$ of frogs and toads (Anura), and $>49 \%$ of newts and salamanders (Urodela) representing a wide range of ecological diversity - as either extinct or threatened with extinction (Catenazzi 2015). Their loss, or others like it, may present ecological opportunities for lineages able to exploit resources vacated by the loss of a large proportion of an entire taxonomic group.

6. Latitudinal diversity gradient. The latitudinal gradient in species diversity is well supported (Hillebrand 2004), however the underlying mechanisms which have led to it remain unclear. Given the existence of a positive relationship between ecological opportunity and speciation rates, one possibility in understanding the evolution of the latitudinal diversity gradient may be found in identifying a relationship between between ecological opportunity and latitude (Schluter 2016). A more comprehensive understanding of the geographic nature of ecological opportunity would help in understanding how it may be important in shaping global patterns of species diversity. 


\section{KEY WORDS AND DEFINITIONS}

Adaptive radiation: evolutionary divergence of members of a single phylogenetic lineage into a variety of different adaptive forms (Futuyma 1998)

Diversification: the evolution of phenotypically and reproductively distinct species in a clade

Ecological character displacement: the divergence of sympatric species to minimize ecological overlap

Ecological opportunity: the availability of ecologically accessible resources that may be evolutionarily exploited

Evolvability: the capacity to generate heritable phenotypic variation

Disparity: the difference among taxa of a phenotypic trait or traits

Key innovation: the evolution of a trait that allows a species to interact with the environment in a novel way

Reinforcement: the evolution of traits that minimize hybridization between species

\section{ACKNOWLEDGMENTS}

We would like to thank Kenneth Feeley, Sean Giery, Evan Rehm, Rachel Hillyer, Sterling Nesbitt, Timothy Perez, Marjorie Weber, Thomas Givnish, and Sally Otto for their thoughtful comments and discussions on previous drafts of this manuscript. JS was supported by a Florida International University Dissertation Evidence Acquisition Fellowship. 


\section{LITERATURE CITED}

Adamowicz SJ, Purvis A, Wills M a. 2008. Increasing morphological complexity in multiple parallel lineages of the Crustacea. Proc. Natl. Acad. Sci. U. S. A. 105(12):4786-91

Agrawal AA, Fishbein M, Haltschke R, Hastings AP, Rabosky DL, Rasmann S. 2009. Evidence for adaptive radiation from a phylogenetic study of plant defenses. Proc. Natl. Acad. Sci. 106(43):18067-72

Alfaro ME, Santini F, Brock CD. 2007. Do reefs drive diversification in marine teleosts? Evidence from the pufferfish and their allies (order tetraodontiformes). Evolution (N. Y). 61(9):2104-26

Allen GR. 2004. Toxotes kimberleyensis, a new species of archerfish (Pisces: Toxotidae) from fresh waters of Western Australia. Rec. Aust. Museum. 56:225-30

Allen WL, Baddeley R, Scott-Samuel NE, Cuthill IC. 2013. The evolution and function of pattern diversity in snakes. Behav. Ecol. 24(5):1237-50

Almen MS, Lamichhaney S, Berglund J, Grant BR, Grant PR, et al. 2015. Adaptive radiation of Darwin’s finches revisited using whole genome sequencing. BioEssays. 38(1):14-20

Alroy J. 1999. The Fossil Record of North American Mammals : Evidence for a Paleocene Evolutionary Radiation. Syst. Biol. 48(1):107-18

Alroy J. 2015. Current extinction rates of reptiles and amphibians. Proc. Natl. Acad. Sci. 112(42):13003-8

Anacker BL, Strauss SY. 2014. The geography and ecology of plant speciation: range overlap and niche divergence in sister species. Proceedings of the Royal Society B-Biological Sciences 281

Anderson CM, Langerhans RB. 2015. Origins of female genital diversity: Predation risk and lock-and-key explain rapid divergence during an adaptive radiation. Evolution (N. Y). 69(9):2452-67

Arakaki M, Christin P-A, Nyffeler R, Lendel A, Eggli U, et al. 2011. Contemporaneous and recent radiations of the world's major succulent plant lineages. Proc. Natl. Acad. Sci. U. S. A. 108(20):8379-84

Arbogast BS, Drovetski S V., Curry RL, Boag PT, Seutin G, et al. 2006. The Origin and Diversification of Galápagos Mockingbirds. Evolution (N. Y). 60(2):370-82

Arbuckle K, Speed MP. 2015. Antipredator defenses predict diversification rates. Proc. Natl. Acad. Sci. 2015:1-6

Archibald JD. 2011. Extinction and Radiation: How the Fall of Dinosaurs Led to the Rise of Mammals. JHU Press 
Arnold SJ, Pfrender ME, Jones AG. 2001. The adaptive landscape as a conceptual bridge between micro- and macroevolution. Genetica. 112-113:9-32

Bailey SF, Kassen R. 2012. Spatial Structure of Ecological Opportunity Drives Adaptation in a Bacterium. Am. Nat. 180(2):270-83

Baldwin JM. 1896. A new factor in evolution. Am. Nat. 30(354):441-51

Barker FK, Cibois A, Schikler P, Feinstein J, Cracraft J. 2004. Phylogeny and diversification of the largest avian radiation. Proc. Natl. Acad. Sci. U. S. A. 101(30):11040-45

Barluenga M, Stölting KN, Salzburger W, Muschick M, Meyer A. 2006. Sympatric speciation in Nicaraguan crater lake cichlid fish. Nature. 439(7077):719-23

Baum DA, Larson A. 1991. Adaptation Reviewed - A Phylogenetic Methodology for Studying Character Macroevolution. Syst. Zool. 40:1-18

Benkman CW. 1991. Predation, seed size partitioning and the evolution of body size in seedeating finches. Evol. Ecol. 5(2):118-27

Benton MJ. 1996. On the nonprevalence of competitive replacement in the evolution of tetrapods. In Evolutionary Paleobiology, eds. JW Valentine, D Jablonski, pp. 185-210. Chicago: University of Chicago Press

Benton MJ. 2009. The Red Queen and the Court Jester : and Abiotic Factors Through Time. Science (80-. ). 323(February):728-32

Benton MJ, Forth J, Langer MC. 2014. Models for the rise of the dinosaurs. Curr. Biol. 24(2):R87-95

Bird CE, Fernandez-Silva I, Skillings DJ, Toonen RJ. 2012. Sympatric Speciation in the Post “Modern Synthesis” Era of Evolutionary Biology. Evol. Biol. 39(2):158-80

Blair WF. 1955. Size differences as a possible isolating mechanism in Microhyla. Am. Nat. 89: 297-301

Bolnick DI, Fitzpatrick BM. 2007. Sympatric Speciation: Models and Empirical Evidence. Annu. Rev. Ecol. Evol. Syst. 38(1):459-87

Brawand D, Wagner CE, Li YI, Malinsky M, Keller I, et al. 2014. The genomic substrate for adaptive radiation in African cichlid fish. Nature. 513(18 September 2014):375 -

Brockhurst MA, Colegrave N, Hodgson DJ, Buckling A. 2007. Niche occupation limits adaptive radiation in experimental microcosms. PLoS One. 2(2):1-4

Broeckhoven C, Diedericks G, Mouton PLFN. 2015. What doesn’t kill you might make you stronger: functional basis for variation in body armour. J. Anim. Ecol. (JUNE 2015):n/a - n/a

Brown WL, Wilson EO. 1956. Character displacement. Syst. Zool. 5(2):49-64 
Brusatte SL, Benton MJ, Ruta M, Lloyd GT. 2008. Superiority, competition, and opportunism in the evolutionary radiation of dinosaurs. Science (80-. ). 321(5895):1485-88

Brusatte SL, Nesbitt SJ, Irmis RB, Butler RJ, Benton MJ, Norell MA. 2010. The origin and early radiation of dinosaurs. Earth-Science Rev. 101(1-2):68-100

Burbrink FT, Ruane S, Pyron RA. 2012. When are adaptive radiations replicated in areas? Ecological opportunity and unexceptional diversification in West Indian dipsadine snakes (Colubridae: Alsophiini). J. Biogeogr. 39(3):465-75

Burnette MF, Ashley-Ross MA. 2015. One shot, one kill: The forces delivered by archer fish shots to distant targets. Zoology. 118(5):302-11

Burns KJ, Hackett SJ, Klein NK. 2002. Phylogenetic relationships and morphological diversity in Darwin's finches and their relatives. Evolution. 56(6):1240-52

Carlquist S. 1974. Island Biology. Columbia University Press: New York \& London

Case TJ. 1979. Character displacement and coevolution in some Cnemidophorus lizards. Fortschr. Zool. 25:235-82

Catenazzi A. 2015. State of the World's Amphibians. Annu. Rev. Environ. Resour. 40(1):91-119

Ceballos G, Ehrlich PR, Barnosky AD, García A, Pringle RM, Palmer TM. 2015. Accelerated modern human - induced species losses: entering the sixth mass extinction. Sci. Adv.

1(e1400253):1-5

Chase JM. 2007. Drought mediates the importance of stochastic community assembly. Proc. Natl. Acad. Sci. U. S. A. 104(44):17430-34

Chase JM, Leibold MA. 2003. Ecological Niches: Linking Classical and Contemporary Approaches. University of Chicago Press

Chen Z-Q, Benton MJ. 2012. The timing and pattern of biotic recovery following the endPermian mass extinction. Nat. Geosci. 5(6):375-83

Ciampaglio CN. 2002. Determining the role that ecological and developmental constraints play in controlling disparity: Examples from the crinoid and blastozoan fossil record. Evol. Dev. 4(3):170-88

Clune J, Mouret J, Lipson H. 2013. The evolutionary origins of modularity. Proc. Biol. Sci. 280(1755):20122863

Cornwell WK, Sprent JI, Kattge J, Kiers ET, Werner GDA. 2014. A single evolutionary innovation drives the deep evolution of symbiotic N2-fixation in angiosperms. Nat. Commun. 5(May):1-9

Coyne JA, Orr HA. 2004. Speciation. Sinauer Associates Incorporated: Sunderland, MA 
Coyne JA, Price TD. 2000. Little evidence for sympatric speciation in island birds. Evolution (N. Y). 54(6):2166-71

Cracraft J. 1990. The origin of evolutionary novelties: pattern and process at different hierarchical levels. In Evolutionary Innovations, eds. MH Nitecki, D V. Nitecki, pp. 21-44. University of Chicago Press

Crother BI, Guyer C. 1996. Caribbean historical biogeography: was the dispersal-vicariance debate eliminated by an extraterrestrial bolide? Herpetologica. 52:440-65

Davis MA. 2013. Invasive Species. In, N MacLeod, ed. Grzimek's Animal Life Encyclopedia: Extinction, 1st Edition. Gale, 779-787)

Dayan T, Simberloff D. 2005. Ecological and community-wide character displacement: The next generation. Ecol. Lett. 8(8):875-94

de Queiroz A. 2002. Contingent predictability in evolution: key traits and diversification. Syst. Biol. 51(6):917-29

Dieckmann U, Doebeli M. 1999. On the origin of species by sympatric speciation. Nature, 400(6742): 354-357

Doebeli M, Dieckmann U. 2000. Evolutionary branching and sympatric speciation caused by different types of ecological interactions. Am. Nat. 156(4): 77-101

Donoghue MJ. 2005. Key innovations, convergence, and success: macroevolutionary lessons from plant phylogeny. Paleobiology. 31(sp5):77-93

Donoghue MJ, Sanderson MJ. 2015. Confluence, synnovation, and depauperons in plant diversification. New Phytol. 207: 260-74

Draghi JA, Whitlock MC. 2012. Phenotypic plasticity facilitates mutational variance, genetic variance, and evolvability along the major axis of environmental variation. Evolution (N. Y). 66(9):2891-2902

Ehrlich PR, Raven PH. 1964. Butterflies and Plants : A Study in Coevolution Author. Evolution (N. Y). 18(4):586-608

Erickson CJ. 1991. Percussive foraging in the aye-aye, Daubentonia madagascariensis. Anim. Behav. 41(5):793-801

Erkens RHJ, Chatrou LW, Couvreur TLP. 2012. Radiations and key innovations in an early branching angiosperm lineage (Annonaceae; Magnoliales). Bot. J. Linn. Soc. 169(1):117-34

Erwin DH. 2007. Increasing returns, ecological feedback and the Early Triassic recovery. Palaeoworld. 16(1-3):9-15

Erwin DH. 2008. Macroevolution of ecosystem engineering, niche construction and diversity. Trends Ecol. Evol. 23(6):304-10 
Erwin DH. 2015. Novelty and innovation in the history of life. Curr. Biol. 25(19):R930-40

Farrell BD. 1998. "Inordinate fondness” explained: why are there so many beetles? Science (80-. ). 281(July):555-59

Fear KK, Price T. 1998. The adaptive surface in ecology. Oikos. 82(3):440-48

Felsenstein J. 1981. Skepticism towards Santa Rosalia, or why are there so few kinds of animals? Evolution (N. Y). 35(1):124-38

Foote M. 1996. Ecological Controls on the Evolutionary Recovery of Post-Paleozoic Crinoids. Science (80-. ). 274(1993):1492-95

Foote M. 1999. Morphological diversity in the evolutionary radiation of Paleozoic and postPaleozoic crinoids. Paleobiology. 25(2):1-115

Forbes AA. 2009. Sequential Sympatric Speciation Across Tropic Levels. Science (80-. ). 323:776-79

Freckleton RP, Harvey PH. 2006. Detecting non-brownian trait evolution in adaptive radiations. PLoS Biol. 4(11):2104-11

Friedman M. 2010. Explosive morphological diversification of spiny-finned teleost fishes in the aftermath of the end-Cretaceous extinction. Proc. Biol. Sci. 277(1688):1675-83

Galis F. 2001. Key innovations and radiations. In The Character Concept in Evolutionary Biology, ed. GP Wagner, pp. 581-605. San Diego: Academic

Genner MJ, Ngatunga BP, Mzighani S, Smith A, Turner GF. 2015. Geographical ancestry of Lake Malawi’s cichlid fish diversity: Biol. Lett. 11(6):20150232

Giery ST, Layman C a. 2015. Interpopulation Variation in a Condition-Dependent Signal: Predation Regime Affects Signal Intensity and Reliability. Am. Nat. 186(2):000-000

Giery ST, Layman C a., Langerhans RB. 2015. Anthropogenic ecosystem fragmentation drives shared and unique patterns of sexual signal divergence among three species of Bahamian mosquitofish. Evol. Appl.

Gillespie RG. 2004. Community assembly through adaptive radiation in Hawaiian spiders. Science (80-. ). 303(January):356-59

Gillespie RG. 2015. Island time and the interplay between ecology and evolution in species diversification. Evol. Appl. 9(1): 53-73

Gittenberger E. 1991. What about non-adaptive radiation? Biol. J. Linn. Soc. 43(4):263-72

Givnish TJ. 2010. Ecology of plant speciation. Taxon. 59(5): 1326-1366

Givnish TJ. 2015. Adaptive radiation versus 'radiation' and 'explosive diversification': why conceptual distinctions are fundamental to understanding evolution. New Phytol. 207(2): 297-303 
Givnish TJ. 1997a. Adaptive plant evolution on islands: Classical patterns, molecular data, new insights. Molecular evolution and adaptive radiation (eds Givnish TJ, Systsma KJ), pp. 1-54. Oxford University Press, London.

Givnish TJ. 1997b. Adaptive radiation and molecular systematics: Issues and approaches. Molecular evolution and adaptive radiation (eds Givnish TJ, Systsma KJ), pp. 1-54. Oxford University Press, London.

Givnish TJ, Sytsma KJ. 1997. Molecular Evolution and Adaptive Radiation. Cambridge University Press

Givnish TJ, Montgomery RA, Goldstein G. 2004. Adaptive radiation of photosynthetic physiology in the Hawaiian lobeliads: Light regimes, static light responses, and whole-plant compensation points. American Journal of Botany. 91(2): 228-246

Givnish TJ, Millam KC, Mast AR, Paterson TB, Theim TJ, et al. 2009. Origin, adaptive radiation and diversification of the Hawaiian lobeliads (Asterales: Campanulaceae). Proc. R. Soc. B Biol. Sci. 276(1656):407-16

Glor RE. 2010. Phylogenetic Insights on Adaptive Radiation. Annu. Rev. Ecol. Evol. Syst. 41(1):251-70

Goldberg EE, Lande R, Price TD. 2012. Population regulation and character displacement in a seasonal environment. Am. Nat. 179(6):693-705

Gomulkiewicz R, Holt RD. 1995. When does evolution by natural selection prevent extinction? Evolution (N. Y). 49(1):201-7

Grant PR, Grant BR. 2008. How and Why Species Multiply. The Radiation of Darwin’s Finches. Princeton Series in Evolutionary Biology

Grant PR, Grant BR. 2014. 40 Years of Evolution: Darwin’s Finches on Daphne Major Island. Princeton University Press

Grant PR, Grant BR. 2006. Evolution of Character Displacement in Darwin 's Finches. Science (80-. ). 313(5784):224-26

Greene HW. 1986. Natural history and evolutionary biology. Predator-prey relationships: Perspectives and approaches from the study of lower vertebrates. (Feder ME, Lauder GV, eds). pp. 99-108, University of Chicago Press

Grether GF, Losin N, Anderson CN, Okamoto K. 2009. The role of interspecific interference competition in character displacement and the evolution of competitor recognition. Biol. Rev. 84(4):617-35

Habets MGJL, Rozen DE, Hoekstra RF, De Visser JAGM. 2006. The effect of population structure on the adaptive radiation of microbial populations evolving in spatially structured environments. Ecol. Lett. 9(9):1041-48 
Heinen JL, Coco MW, Marcuard MS, White DN, Peterson MN, et al. 2013. Environmental drivers of demographics, habitat use, and behavior during a post-Pleistocene radiation of Bahamas mosquitofish (Gambusia hubbsi). Evol. Ecol. 27(5):971-91

Henning F, Meyer A. 2014. The evolutionary genomics of cichlid fishes: explosive speciation and adaptation in the postgenomic era. Annu. Rev. Genomics Hum. Genet. 15:417-41

Hillebrand H. 2004. On the generality of the latitudinal diversity gradient. Am. Nat. 163(2): 192211

Hodges SA, Arnold ML. 1995. Spurring plant diversification: are floral nectar spurs a key innovation? Proc. R. Soc. B. 262(1365):343-48

Holt RD. 1977. Predation, apparent competition and the structure of prey communities. Theor. Popul. Biol. 12(2):197-229

Hughes CE, Eastwood R. 2006. Island radiation on a continental scale: exceptional rates of plant diversification after uplift of the Andes. Proc. Nat. Aca. Sci. 103(27): 10334-10339

Hughes CE, Atchinson GW. 2015. The ubiquity of alpine plant radiations: from the Andes to the Hengduan Mountains. New Phytologist. 207(2): 275-285

Hughes M, Gerber S, Wills MA (2013) Clades reach highest morphological disparity early in their evolution. Proc. Natl. Acad. Sci. USA 110(34):13875-13879

Hull P. 2015. Life in the aftermath of mass extinctions. Curr. Biol. 25(19):R941-52

Hunter JP. 1998. Key innovations and the ecology of macroevolution. Trends Ecol. Evol. 13(1):31-36

Hunter JP, Jernvall J. 1995. The hypocone as a key innovation in mammalian evolution. Proc. Natl. Acad. Sci. U. S. A. 92(23):10718-22

Jablonski D. 2008. Biotic interactions and macroevolution: extensions and mismatches across scales and levels. Evolution. 62(4):715-39

Jeffries MJ, Lawton JH. 1984. Enemy free space and the structure of ecological communities. Biol. J. Linn. Soc. 23:269-86

Jones CG, Lawton JH, Shachak M. 1997. Positive and negative effects of organisms as physical ecosystem engineers. Ecology. 78(7):1946-57

Jones CG, Lawton JH, Shachak M, Jones CG, Lawton JH, Shachak M. 1994. Organisms as ecosystem engineers. Oikos. 69(3):373-86

Jønsson KA, Fabre P-H, Kennedy JD, Holt BG, Borregaard MK, et al. 2015. A supermatrix phylogeny of corvoid passerine birds (Aves: Corvides). Mol. Phylogenet. Evol. 94(Pt A):87-94

Jønsson KA, Fabre P-H, Ricklefs RE, Fjeldså J. 2011. Major global radiation of corvoid birds originated in the proto-Papuan archipelago. Proc. Natl. Acad. Sci. U. S. A. 108(6):2328-33 
Kassen R. 2009. Toward a general theory of adaptive radiation: insights from microbial experimental evolution. Ann. N. Y. Acad. Sci. 1168:3-22

Kautt AF, Elmer KR, Meyer A. 2012. Genomic signatures of divergent selection and speciation patterns in a "natural experiment", the young parallel radiations of Nicaraguan crater lake cichlid fishes. Mol. Ecol. 21(19):4770-86

Kirschner M, Kirschner M, Gerhart J, Gerhart J. 1998. Evolvability. Proc. Natl. Acad. Sci. 95(15):8420-27

Kisel Y, Barraclough TG. 2010. Speciation has a spatial scale that depends on levels of gene flow. Am. Nat. 175(3):316-34

Koblmüller S, Egger B, Sturmbauer C, Sefc KM. 2007. Evolutionary history of Lake Tanganyika’s scale-eating cichlid fishes. Mol. Phylogenet. Evol. 44(3):1295-1305

Kondrashov AS, Kondrashov FA. 1999. Interactions among quantitative traits in the course of sympatric speciation. Nature. 400(6742): 351-354

Kraus F. 2015. Impacts from Invasive Reptiles and Amphibians. Annu. Rev. Ecol. Evol. Syst. 46(1):75-97

Langerhans RB. 2007. Evolutionary consequences of predation: Avoidance, escape, reproduction, and diversification. Predation Org. A Distinct Phenom. 177-220

Langerhans RB. 2009. Trade-off between steady and unsteady swimming underlies predatordriven divergence in Gambusia affinis. J. Evol. Biol. 22(5):1057-75

Larson A, Losos JB. 1996. Phylogenetic systematics of adaptation. In Adaptation, eds. MR Rose, G V. Lauder, pp. 187-220. Academic Press, San Diego

Le Gac M, Plucain J, Hindre T, Lenski RE, Schneider D. 2012. Ecological and evolutionary dynamics of coexisting lineages during a long-term experiment with Escherichia coli. Proc. Natl. Acad. Sci. 109(24):9487-92

Leigh EG, Hladik A, Hladik CM, Jolly A, Leigh EG, et al. 2007. The biogeography of large islands, or how does the size of the ecological theater affect the evolutionary play. Rev. E'cole (Terre Vie). 62(February):105-68

Lidgard S, McKinney FK, Taylor PD. 1993. Competition, clade replacement, and a history of cyclostome and cheilostome bryozoan diversity. Paleobiology. 19(3):352-71

Liem KF. 1974. Evolutionary strategies and morphological innovations: Cichlid pharyngeal jaws. Syst. Zool. 22:425-41

Losos JB. 2010. Adaptive radiation, ecological opportunity, and evolutionary determinism. American Society of Naturalists E. O. Wilson award address. Am. Nat. 175(6):623-39

Losos JB, Mahler DL. 2010. Adaptive Radiation: The Interaction of Ecological Opportunity, Adaptation, and Speciation. In Evolution since Darwin: The First 150 Years, eds. MA Bell, DJ 
Futuyma, WF Eanes, JS Levinton, pp. 381-420. Sinauer Associates Incorporated: Sunderland, MA

Losos JB, Parent CE. 2009. The speciation-area relationship. In The Theory of Island Biogeography Revisited, eds. JB Losos, RE Ricklefs, pp. 415-38. Princeton, NJ: Princeton University Press

Losos JB, Schluter D. 2000. Analysis of an evolutionary species-area relationship. Nature. 408(6814):847-50

Lovette IJ, Bermingham E, Ricklefs RE. 2002. Clade-specific morphological diversification and adaptive radiation in Hawaiian songbirds. Proc. Biol. Sci. 269(1486):37-42

Mabuchi K, Miya M, Azuma Y, Nishida M. 2007. Independent evolution of the specialized pharyngeal jaw apparatus in cichlid and labrid fishes. BMC Evol. Biol. 7:10

Macarthur R, Levins R. 1967. The Limiting Similarity, Convergence, and Divergence of Coexisting Species. Am. Nat. 101(921):377

MacArthur RH. 1972. Geographical Ecology. Harper \& Row: New York, NY

Mahler DL, Revell LJ, Glor RE, Losos JB. 2010. Ecological opportunity and the rate of morphological evolution in the diversification of Greater Antillean anoles. Evolution (N. Y). 64(9):2731-45

Marazzi B, Ané C, Simon MF, Delgado-Salinas A, Luckow M, Sanderson MJ. 2012. Locating evolutionary precursors on a phylogenetic tree. Evolution (N. Y). 66(12):3918-30

Marchinko KB. 2009. Predation's role in repeated phenotypic and genetic divergence of armor in threespine stickleback. Evolution (N. Y). 63(1):127-38

Martin CH, Cutler JS, Friel JP, Touokong CD, Coop G, Wainwright PC. 2015. Complex histories of repeated gene flow in Cameroon crater lake cichlids cast doubt on one of the clearest examples of sympatric speciation. Evolution (N. Y). 69(6):1406-22

Martin CH, Feinstein LC. 2014. Novel trophic niches drive variable progress towards ecological speciation within an adaptive radiation of pupfishes. Mol. Ecol. 23(7):1846-62

Martin CH, Wainwright PC. 2013a. On the measurement of ecological novelty: scale-eating pupfish are separated by 168 my from other scale-eating fishes. PLoS One. 8(8):e71164

Martin CH, Wainwright PC. 2013b. Multiple fitness peaks on the adaptive landscape drive adaptive radiation in the wild. Science. 339(6116):208-11

Matthews B, Aebischer T, Sullam KE, Seehausen O. 2016. Experimental Evidence of an Ecoevolutionary Feedback during Adaptive Divergence. Curr. Biol. 26:1-7

Matthews B, De Meester L, Jones CG, Ibelings BW, Bouma TJ, et al. 2014. Under niche construction: an operational bridge between ecology, evolution, and ecosystem science. Ecol. Monogr. 84(2):245-63 
Mayr. 1963. Animal Species and Evolution. Belknap Press of Harvard University Press

McCune JL, Harrower WL, Avery-Gomm S, Brogan JM, Csergő AM, Davidson LN, Garani A, Halpin LR, Lipsen LP, Lee C, Nelson JC. 2013. Threats to Canadian species at risk: An analysis of finalized recovery strategies. Biol. Cons. 166: 254-265

McGowan AJ. 2004. Ammonoid taxonomic and morphologic recovery patterns after the Permian Triassic. Geology. 32(8):665-68

Meyer A, Kocher TD, Basasibwaki P, Wilson AC. 1990. Monophyletic origin of Lake Victoria cichlid fishes suggested by mitochondrial DNA sequences. Nature. 34: 550-553

Miller AH. 1949. Some ecologic and morphologic considerations in the evolution of higher taxonomic categories. In Ornithologie Als Biologische Wissenschaft, eds. E Mayr, E Schuz, pp. 84-88. Heidelberg: Carl Winter

Mitter C, Farrell B, Wiegmann B. 1988a. The Phylogenetic Study of Adaptive Zones: Has Phytophagy Promoted Insect Diversification? Am. Nat. 132(1):107-28

Mitter C, Farrell B, Wiegmann B. 1988b. The Phylogenetic Study of Adaptive Zones: Has Phytophagy Promoted Insect Diversification? Am. Nat. 132(1):107-28

Monasterio M, Sarmiento L. 1991. Adaptive radiation of Espeletia in the cold Andean tropics. Trends Eco. Evol. 6(12): 387-391

Mouton P, Van Wyk JH. 1997. Adaptive radiation in cordyliform lizards: An overview. Af. J. Herpetol. 46(2): 78-88

Mullen SP, Shaw KL. 2014. Insect speciation rules: unifying concepts in speciation research. Annu. Rev. Entomol. 59:339-61

Muschick M, Indermaur A, Salzburger W. 2012. Convergent evolution within an adaptive radiation of cichlid fishes. Curr. Biol. 22(24):2362-68

Near TJ, Dornburg A, Kuhn KL, Eastman JT, Pennington JN, et al. 2012. Ancient climate change, antifreeze, and the evolutionary diversification of Antarctic fishes. Proc. Natl. Acad. Sci. U. S. A. 109(9):3434-39

Nosil P. 2012. Ecological Speciation. OUP Oxford

Odling-Smee FJ, Laland KN, Feldman MW. 2003. Niche Construction: The Neglected Process in Evolution. Princeton University Press

Odling-Smee J, Erwin DH, Palkovacs EP, Feldman MW, Laland KN. 2013. Niche Construction Theory: A Practical Guide for Ecologists. Source Q. Rev. Biol. 88(1):3-28

Parent CE, Crespi BJ. 2009. Ecological Opportunity in Adaptive Radiation of Galápagos Endemic Land Snails. Am. Nat. 174(6):898-905 
Parsons KJ, Son YH, Albertson RC. 2011. Hybridization Promotes Evolvability in African Cichlids: Connections Between Transgressive Segregation and Phenotypic Integration. Evol. Biol. 38(3):306-15

Paulay G. 1994. Biodiversity on Oceanic Islands: Its Origin and Extinction. Am. Zool. 34:134-44

Pfaender J, Hadiaty RK, Schliewen UK, Herder F. 2016. Rugged adaptive landscapes shape a complex, sympatric radiation. Proc. R. Soc. B Biol. Sci. 283(1822):20152342

Pfaender J, Schliewen UK, Herder F. 2010. Phenotypic traits meet patterns of resource use in the radiation of "sharpfin" sailfin silverside fish in Lake Matano. Evol. Ecol. 24(5):957-74

Pfennig DW, Pfennig KS. 2012a. Evolution’s Wedge: Competition and the Origins of Diversity. University of California Press

Pfennig DW, Pfennig KS. 2012b. Development and evolution of character displacement. Ann. N. Y. Acad. Sci. 1256(1):89-107

Pfennig DW, Rice AM, Martin RA. 2006. Ecological opportunity and phenotypic plasticity interact to promote character displacement and species coexistence. Ecology. 87(3):769-79

Price TD. 2008. Speciation in Birds. Roberts and Co.

Pyron RA, Burbrink FT. 2014. Ecological and evolutionary determinants of species richness and phylogenetic diversity for island snakes. Glob. Ecol. Biogeogr. 23(8):848-56

Rabosky DL. 2009. Ecological limits on clade diversification in higher taxa. Am. Nat. 173(5):662-74

Rabosky DL. 2014. Automatic detection of key innovations, rate shifts, and diversity-dependence on phylogenetic trees. PLoS One. 9(2):

Rabosky DL, Lovette IJ. 2008. Density-dependent diversification in North American wood warblers. Proc. Royal Soc. B. 275: 2363-2371

Rainey PB, Travisano M. 1998. Adaptive radiation in a heterogeneous environment. Nature. 394(6688):69-72

Rauscher JT. 2002. Molecular phylogenetics of the Espeletia complex (Asteraceae): evidence from nrDNA ITS sequences on the closest relatives of an Andean adaptive radiation. American Journal of Botany. 89(7): 1074-1084

Rawlins DR, Handasyde K a. 2002. The feeding ecology of the striped possum Dactylopsila trivirgata (Marsupialia : Petauridae) in far north Queensland, Australia. J. Zool. 257(June 2002):195-206

Reddy S, Driskell A, Rabosky DL, Hackett SJ, Schulenberg TS. 2012. Diversification and the adaptive radiation of the vangas of Madagascar. Proc. R. Soc. B Biol. Sci. 279(1735):2062-71 
Ree RH. 2005. Detecting the Historical Signature of Key Innovations Using Stochastic Models of Character Evolution and Cladogenesis. Evolution (N. Y). 59(2):257-65

Roderick GK, Gillespie RG. 1998. Speciation and phylogeography of Hawaiian terrestrial arthropods. Mol. Ecol. 7(4):519-31

Rosenzweig ML, McCord RD. 1991. Incumbent replacement: evidence for long-term evolutionary progress. Paleobiology. 17(3):202-13

Roy HE, Adriaens T, Isaac NJB, Kenis M, Martin GS, et al. 2012. Invasive alien predator causes rapid declines of native European ladybirds. Divers. Distrib. 18:717-25

Runemark A, Brydegaard M, Svensson EI. 2014. Does relaxed predation drive phenotypic divergence among insular populations? J. Evol. Biol. 27(8):1676-90

Rutherford SL, Lindquist S. 1998. Hsp90 as a capacitor for morphological evolution. Nature. 396(6709):336-42

Santos JC, Coloma LA, Cannatella DC. 2003. Multiple, recurring origins of aposematism and diet specialization in poison frogs. Proc. Natl. Acad. Sci. 100(22):12792-97

Sax DF, Stachowicz JJ, Brown JH, Bruno JF, Dawson MN, et al. 2007. Ecological and evolutionary insights from species invasions. Trends Ecol. Evol. 22(9):465-71

Schenk JJ, Rowe KC, Steppan SJ. 2013. Ecological opportunity and incumbency in the diversification of repeated continental colonizations by muroid rodents. Syst. Biol. 62(6):837-64

Schliewen UK, Tautz D, Pääbo S. 1994. Sympatric speciation suggested by monophyly of crater lake cichlids. Nature. 368(6472):629-32

Schluter D. 1988. Character displacement and the adaptive divergence of finches on islands and continents. Am. Nat. (6):799-824

Schluter D. 2000. The Ecology of Adaptive Radiation. Oxford University Press

Schluter D. 2009. Evidence for ecological speciation and its alternative. Science. 323(5915):73741

Schluter D. 2016. Speciation, ecological opportunity, and latitude. Am. Nat. 187(1): 1-18

Schluter D, Grant PR. 1984. Determinants of Morphological Patterns in Communities of Darwin's Finches. Am. Nat. 123(2):175-96

Schuster S, Wöhl S, Griebsch M, Klostermeier I. 2006. Animal cognition: How archer fish learn to down rapidly moving targets. Curr. Biol. 16(4):378-83

Seehausen O. 2014. Speciation in Freshwater Fishes. Annu. Rev. Ecol. Evol. Syst. 45:621-51

Sepkoski JJ, McKinney FK, Lidgard S. 2000. Competitive displacement among post-Paleozoic cyclostome and cheilostome bryozoans. Paleobiology. 26(1):7-18 
Silvestro D, Antonelli A, Salamin N, Quental TB. 2015. The role of clade competition in the diversification of North American canids. Proc. Natl. Acad. Sci. U. S. A. 112(28):8684-89

Silvestro D, Zizka G, Schulte K. 2014. Disentangling the effects of key innovations on the diversification of bromelioideae (Bromeliaceae). Evolution (N. Y). 68(1):163-75

Simpson GG. 1953. The Major Features of Evolution. Columbia University Press: New York Slater GJ. 2015. Not-so-early bursts and the dynamic nature of morphological diversification. Proc. Natl. Acad. Sci. 112(12): 3595-3596

Slatkin M. 1980. Ecological character displacement. Ecology. 61(1):163-77

Smith FA, Boyer AG, Brown JH, Costa DP, Dayan T, et al. 2010. The Evolution of Maximum Body Size of Terrestrial Mammals. Science (80-. ). 330(6008):1216-19

Snell-Rood EC. 2013. An overview of the evolutionary causes and consequences of behavioural plasticity. Anim. Behav. 85(5):1004-11

Strauss SY, Weber MG. 2016. Coexistence in close relatives: beyond competition and reproductive isolation in sister taxa. Annual Review of Ecology, Evolution and Systematics

Strobbe F, McPeek MA, De Block M, Stoks R. 2011. Fish predation selects for reduced foraging activity. Behav. Ecol. Sociobiol. 65(2):241-47

Stuart YE, Campbell TS, Hohenlohe P a., Reynolds RG, Revell LJ, Losos JB. 2014. Rapid evolution of a native species following invasion by a congener. Science (80-. ). 346(6208):46366

Stuart YE, Losos JB. 2013. Ecological character displacement: glass half full or half empty? Trends Ecol. Evol. 28(7):402-8

Sturmbauer C, Husemann M, Danley PD. 2011. Explosive Speciation and Adaptive Radiation of East African Cichlid Fishes. In Biodiversity Hotspots, eds. FE Zachos, JC Habel, pp. 3-8. Springer-Verlag Berlin Heidelberg

Summers K. 2003. Convergent evolution of bright coloration and toxicity in frogs. Proc. Natl. Acad. Sci. U. S. A. 100(22):12533-34

Supple M, Papa R, Counterman B, McMillan WO. 2013. The genomics of an adaptive radiation: insights across the Heliconius speciation continuum. In Ecological Genomics, pp. 249-71. Springer Netherlands

Svensson E, Calsbeek R. 2012. The Adaptive Landscape in Evolutionary Biology. OUP Oxford

Takahashi R, Watanabe K, Nishida M, Hori M. 2007. Evolution of feeding specialization in Tanganyikan scale-eating cichlids: a molecular phylogenetic approach. BMC Evol. Biol. 7:195 
Tanentzap AJ, Brandt AJ, Smissen RD, Heenan PB, Fukami T, Lee WG. 2015. When do plant radiations influence community assembly? The importance of historical contingency in the race for niche space. New Phytol. 207: 468-479

Thayer, CW. 1983. Sediment-mediated biological disturbances and the evolution of the marine benthos. In Biotic Interactions in Recent and Fossil Benthic Communities ～(Tevesz, M.J.S. and McCall, P.L., eds), pp. 480-625, Plenum Press

The Heliconius Genome Consortium, Dasmahapatra KK, Walters JR, Briscoe AD, Davey JW, et al. 2012. Butterfly genome reveals promiscuous exchange of mimicry adaptations among species. Nature. 487(7405):94-98

Thorpe RS, Surget-Groba Y, Johansson H. 2008. The relative importance of ecology and geographic isolation for speciation in anoles. Philos. Trans. R. Soc. Lond. B. Biol. Sci. 363(1506):3071-81

Tokeshi M. 2009. Species Coexistence: Ecological and Evolutionary Perspectives. John Wiley \& Sons

Tyerman JG, Bertrand M, Spencer CC, Doebeli M. 2008. Experimental demonstration of ecological character displacement. BMC Evol. Biol. 8:34

Valente LM, Phillimore AB, Etienne RS. 2015. Equilibrium and non-equilibrium dynamics simultaneously operate in the Galápagos islands. Ecol. Lett. 18(8):844-52

Valkenburgh B Van. 1999. Major Patterns in the History of Carnivorous Mammals

Vamosi SM. 2005. On the role of enemies in divergence and diversification of prey: a review and synthesis. Can. J. Zool. 83(7):894-910

Vermeij GJ. 1973. Adaptation, Versatility, and Evolution. Syst. Biol. 22(4):466-77

Vermeij GJ. 1987. Evolution and Escalation: An Ecological History of Life. Princeton University Press

von Hagen KB, Kadereit JW. 2003. The diversification of Halenia (Gentianaceae): ecological opportunity versus key innovation. Evolution (N. Y). 57(11):2507-18

Wagner CE, Harmon LJ, Seehausen O. 2012. Ecological opportunity and sexual selection together predict adaptive radiation. Nature. 487(7407):366-69

Wagner CE, Keller I, Wittwer S, Selz OM, Mwaiko S, et al. 2013. Genome-wide RAD sequence data provide unprecedented resolution of species boundaries and relationships in the Lake Victoria cichlid adaptive radiation. Mol. Ecol. 22(3):787-98

Walsh MR, Post DM. 2011. Interpopulation variation in a fish predator drives evolutionary divergence in prey in lakes. Proc. Biol. Sci. 278(1718):2628-37

Webb CO, Ackerly DD, McPeek MA, Donoghue MJ. 2002. Phylogenis and community ecology. Annu. Rev. Ecol. Syst. 33: 475-505 
Wellborn GA, Langerhans RB. 2015. Ecological opportunity and the adaptive diversification of lineages. Ecol. Evol. 5(1):176-95

West-Eberhard MJ. 2003. Developmental Plasticity and Evolution. Oxford University Press

Whittaker RH. 1977. Evolution of species diversity in land communities [Birds and vascular plants]. Evol. Biol. 10:1-67

Williams EE, Peterson JA, Petersen JA. 1982. Convergent and alternative designs in the digital adhesive pads of scincid lizards. Science (80-. ). 215(4539):1509-11

Wilson EO. 1992. The Diversity of Life. Cambridge, MA: Belknap

Wilson GP, Evans AR, Corfe IJ, Smits PD, Fortelius M, Jernvall J. 2012. Adaptive radiation of multituberculate mammals before the extinction of dinosaurs. Nature. 483:457-60

Wright JP, Jones CG. 2006. The concept of organisms as ecosystem engineers ten years on: Progress, limitations, and challenges. Bioscience. 56(3):203-9

Yamagishi S, Honda M, Eguchi K, Thorstrom R. 2001. Extreme endemic radiation of the Malagasy vangas (Aves: Passeriformes). J. Mol. Evol. 53:39-46

Yoder JB, Clancey E, Des Roches S, Eastman JM, Gentry L, et al. 2010. Ecological opportunity and the origin of adaptive radiations. J. Evol. Biol. 23(8):1581-96

Zaman L, Meyer JR, Devangam S, Bryson DM, Lenski RE, Ofria C. 2014. Coevolution Drives the Emergence of Complex Traits and Promotes Evolvability. PLoS Biol. 12(12): 
CHAPTER III

PRIORITY EFFECTS INFLUENCE ASYMMETRIC ASSEMBLY PATTERNS OF NOVEL ECOLOGICAL COMMUNITIES

\author{
J.T. Stroud ${ }^{1,2}$, S.T. Giery ${ }^{3}$, M. Outerbridge ${ }^{4}$, K.J. Feeley ${ }^{5}$ \\ ${ }^{1}$ Department of Biological Sciences, Florida International University, Miami FL, USA \\ ${ }^{2}$ Fairchild Tropical Botanic Gardens, Coral Gables FL, USA \\ ${ }^{3}$ Department of Ecology and Evolutionary Biology, University of Connecticut, Storrs CT, USA \\ ${ }^{4}$ Department of Environment and Natural Resources, Bermuda Government, Bermuda \\ ${ }^{5}$ Department of Biology, University of Miami, Miami FL, USA
}




\section{ABSTRACT}

Opportunities to observe assembly dynamics of novel ecological communities across entire regions are rare. Fundamental studies of early stage assembly dynamics of novel communities have often relied on experimentally replicable microbial systems, but there remains debate about how laboratory results scale to natural ecological processes. Here, we capitalize on a 100 year long natural experiment of community assembly on the oceanic island of Bermuda. Over the past century, three species of ecologically-similar but distantly-related Anolis lizards have been introduced to Bermuda, where no Anolis has ever naturally existed. The two most recently introduced species - the Antiguan anole (A. leachii) and the Barbadian anole (A. extremus) were introduced to geographically-independent locations and, following successful establishment, began dispersing towards the range of each other. We record that range expansion at the contact zone where their distributions meet has been asymmetrical, which has resulted in the formation of different ecological communities despite the same available species pool. In allopatry in Bermuda, both species occupy identical ecological space. Expansion of A. extremus into the range of $A$. leachii is blocked by priority effects, while $A$. leachii is able to invade communities of $A$. extremus through ecological flexibility via a rapid shift to unoccupied arboreal habitat. We suggest that this degree of ecological flexibility may be related to the evolutionary experience of biotic interactions, such that those species originating from more diverse communities are better able to mediate biotic interactions to achieve coexistence. 


\section{SIGNIFICANCE STATEMENT}

The global re-distribution of species in the Anthropocene provides an unprecedented opportunity to study fundamental ecological processes such as community assembly, which are often difficult to observe in nature or test experimentally. Taking advantage of non-native species introductions, we observed the assembly of novel ecological communities of introduced Anolis lizards on Bermuda over the past 100 years. We found that patterns of community assembly can be highly influenced by priority effects and the ecological "flexibility" of the species involved. Species with no recent evolutionary experience of interspecific competitive interactions with similar species can exist in a community if they are incumbent, but are not able to invade communities if their niche space is already occupied. This study provides a unique insight into how priority effects, biotic interactions, and evolutionary history may interact in community assembly.

\section{INTRODUCTION}

An ecological community is assembled when multiple interacting species come to coexist in the same place at the same time (Stroud et al. 2015). The processes that dictate community assembly dynamics, however, have been the root of major debates throughout modern studies of ecology and evolution (Weihner \& Keddy 1999, Fukami 2015). Historically, the assembly dynamics of ecological communities have been inferred from observed patterns of species distributions. From such observations, Diamond derived his now-classic assembly rule theory of forbidden vs. permissible species combinations, which he used to explain the observation that ecologically-similar bird species rarely coexist in the same island communities in the Papuan archipelago (Diamond 1975). Fueled by a concurrent surge in studies of interspecific competition (Grant 1972, Case \& Gilpin 1974, Diamond 1978, Grant \& Abbott 1980, Schoener 1982) - at the time proposed to be the principle interaction structuring ecological communities - Diamond's 
hypothesis spurred a series of studies exploring alternative models of community assembly that continues to present day (Connor and Simberloff 1979, Fox 1987, Patterson 1987, Wilson 1989, Simberloff and Boecklen 1991, Mikkelson 1993, Tilman 2004, Mittelbach and Schemske 2015).

The extent to which interspecific interactions, now recognized to span far beyond just competition, dictate the structure and composition of ecological communities is complicated and remains unresolved. Despite substantial work invested in this subject, few general principles have emerged. However, in recent years there has been a growing appreciation that the specific order in which species join a community can influence how the species in a community interact, and therefore can be instrumental in how communities assemble and the resulting final species composition (Fukami 2015). This phenomenon is known as the 'priority effect' in ecology (MacArthur 1972, Morin 1999, Chase 2007) and parallels to its basic concept - that the order of species arrival can influence proceeding patterns - have also been attributed with great importance in determining patterns of adaptive and evolutionary diversification (Rosenzweig \& McCord 1991, Brockhurst et al. 2007, Fukami et al. 2007, Knope et al. 2012, Kraft et al. 2015, Brandt et al. 2016).

The basic premise of the priority effect in community assembly is that niche space occupied by an incumbent species is inaccessible to any species that subsequently attempts to join or invade the community (Fig. 3.1b). However, the inhibiting features of priority effects may be avoided if rapid ecological divergence and niche shifts among species occur. In other words, niche shifts can reduce the interspecific interactions that would otherwise lead to competitive exclusion (as in Fig. 3.1b), allowing the pair of formerly similar species to co-occur (Fig. 3.1c). As a result of ecological divergence, species can adapt to new niche space and therefore this process may be an important aspect in explaining origins of adaptive divergence (Losos \& Mahler 
2010). How, and why, priority effects influence these two different mechanisms of community assembly remain questions of active research.

Interest in community assembly dynamics and the processes allowing for species coexistence has recently reignited (HilleRisLambers et al. 2012, Fukami 2015, Mittelbach and Schemske 2015, DeMeester et al. 2016, Weber and Strauss 2016), in part as a result of global change and the realization that many communities are changing due to anthropogenic processes (e.g. through non-native species introductions and/or climate-drive range shifts; Walther et al. 2002, Helmus et al. 2014). Although non-native species can have many negative, and occasionally devastating consequences for conservation (Simberloff et al. 2013), the resultant novel communities also present valuable "natural experiments” for testing hypotheses of species coexistence and community assembly (Lockwood et al. 1999, Sax et al. 2007), as well as associated eco-evolutionary processes (Mooney \& Cleland 2001, Sax et al. 2007) such as character displacement (Stuart \& Losos 2013, Stuart et al. 2014).

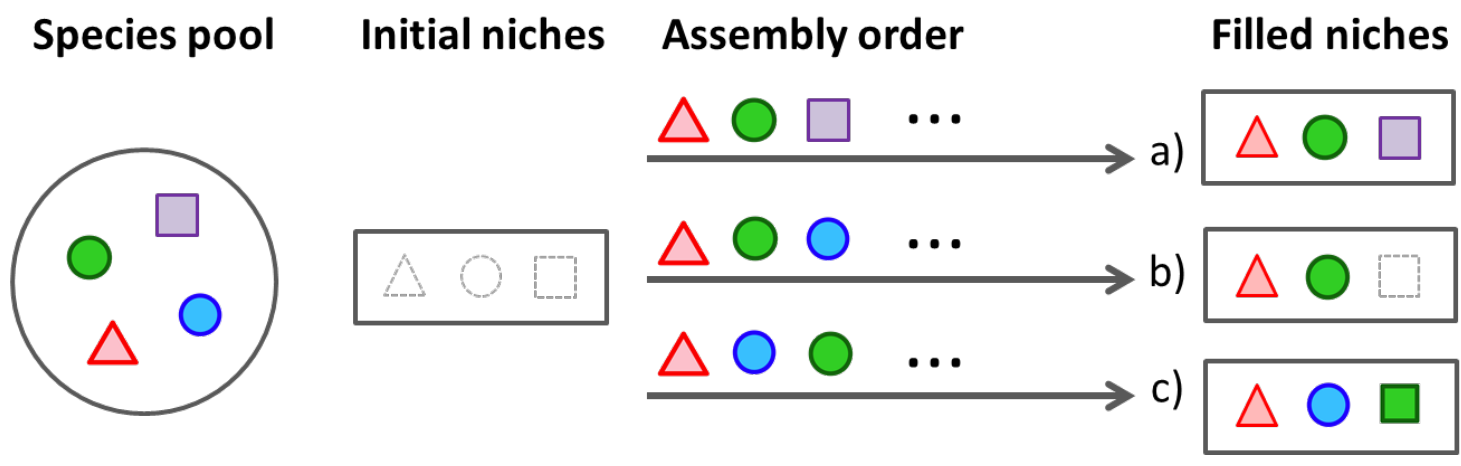

Figure 3.1. Conceptual representation of mechanisms through which different ecological communities can be formed from the same species pool: a) All species occupy independent niches; b) An incumbent species blocks an ecologically-similar species from joining the community through priority effects by niche pre-emption (i.e. competitive exclusion); c) An incumbent species blocks niche access to an ecologically-similar species through priority effects, but niche lability facilitates species coexistence and community assembly as each species utilizes independent ecological space. Symbol colors indicate different species. Symbol shapes denote the general ecological niche which that species occupies and dashed symbols represent vacant niches. Figure modified from Fukami (2015). 
In this study, we investigated the range dynamics, assembly patterns, and ecological organization of novel communities of non-native Caribbean Anolis (anole) lizards in Bermuda. Bermuda is a small $\left(53 \mathrm{~km}^{2}\right)$ and isolated oceanic island in the western North Atlantic (approximately 960km east of North Carolina, USA) with only one endemic reptile, the critically endangered Bermuda skink (Plestiodon [Eumeces] longirostris) (Wingate 1965). Over the past 100 years, three distantly-related species of anoles have been introduced, become established, and dispersed within Bermuda (Wingate 1965, Losos 1996; Fig. 3.2a-c). The Jamaican anole (A. graham; Fig. 3.2a) was first introduced to Bermuda in 1905 and, in the absence of any congeners, quickly spread across the island. In the mid-20 ${ }^{\text {th }}$ century two additional species, the Antiguan anole (A. leachii; Fig. 3.2b) and the Barbadian anole (A. extremus; Fig. 3.2c), were introduced to geographically distinct locations on Bermuda (Wingate 1965). Following successful establishment, these two species expanded their ranges toward one another’s (Wingate 1965). Twenty-five years ago, in 1991, the ranges of A. leachii and A. extremus were recorded to have met at a contact zone but were not observed to yet co-occur in sympatry at that time (Losos 1996; Fig 3.2d).

Here we report that a re-census of species distributions in 2014 revealed asymmetric range dynamics at the contact zone of A. leachii and A. extremus. To determine how priority effects may have influenced asymmetric community assembly patterns at this contact zone, we returned in 2015 and conducted detailed assessments of community structure and organization. To do this we quantified multiple dimensions of the species' ecologies including the use of structural habitat (i.e., perch use characteristics, a widely used metric of ecological niche in Anolis lizards; Losos 2009) and diet. Based on our findings we propose a new hypothesis describing how priority effects and a species' niche plasticity, as determined by a species’ recent ecological and evolutionary experience with interspecific interactions, can help to explain patterns of community assembly and species co-occurrences. 


\section{RESULTS}

\section{Priority Effects and Range Dynamics}

We recorded 2,615 Anolis lizards at 114 sites across the entirety of Bermuda to document detailed descriptions of species distributions in 2014 and 2015, roughly 25 years after the last distribution census in 1991 (Losos 1996). Surveys were focused on accurately delineating species distributions and identifying range dynamics at the contact zone of A. leachii and A. extremus as recorded in 1991 (Losos 1996; Fig 2d). At this contact zone we detected asymmetric range dynamics of A. leachii and A. extremus (Fig 2e), that has led to the persistence of 2-species (grahami-leachii) communities and the creation of novel 3-species communities (grahamiextremus-leachii). These community assembly patterns have resulted from the invasion of $A$. leachii into multiple grahami-extremus communities. In contrast, A. extremus has failed to invade any grahami-leachii communities (Fig 2d-e). The range expansion of A. leachii and its invasion into the remaining grahami-extremus communities is ongoing.

\section{Ecological Niches and Community Organization}

We recorded structural habitat use (perch height and diameter; $n=748$ lizards, Table S3.1) and diet (n=100 lizards; $n=1401$ prey items), which represent ecological axes along with divergence most commonly facilitates coexistence in Anolis lizards (Schoener 1968, Losos 2009). Data were collected for each species at multiple sites of each community type. When in sympatry, coexisting species always partitioned ecological space in structural habitat use, through differences in perch height (as in grahami-extremus communities; $\mathrm{F}=6.67, \mathrm{p}=0.01$ ) or perch diameter (as in both grahami-extremus $[\mathrm{F}=4.35, \mathrm{p}=0.03]$ and grahami-leachii $[\mathrm{F}=14.81, \mathrm{p}<$ 0.001] communities; Fig. 3.3 and Table S3.2). 
When in complete allopatry to each other on Bermuda, A. leachii and A. extremus occupy nearly identical ecological space. Specifically, there was no significant difference in perch height $(\mathrm{F}=0.006, \mathrm{p}=0.939)$, perch diameter use $(\mathrm{F}=1.67, \mathrm{p}=0.198)$, or prey size $(\mathrm{W}=0.52, \mathrm{p}=$ 0.451) between A. leachii in communities of grahami-leachii and A. extremus in communities of grahami-extremus. Despite this high overlap, A. leachii was able to invade communities of grahami-extremus (Fig. 3.3b). When A. leachii joined grahami-extremus communities (forming novel grahami-extremus-leachii communities) it increased in perch height $(\mathrm{F}=4.89, \mathrm{p}=0.028)$ into previously unoccupied niche space. Following the invasion of A. leachii, A. extremus did not significantly differ in any aspects of its “original” niche as recorded in grahami-extremus communities (perch height, $\mathrm{F}=0.18, \mathrm{p}=0.676$; perch diameter, $\mathrm{F}=3.65, \mathrm{p}=0.06$; prey size, $\mathrm{W}$ $=55, \mathrm{p}=0.841$ ). Similarly, as observed in pre-invaded A. extremus (i.e. in grahami-extremus communities), post-invasion A. extremus (sympatric with A. leachii) did not significantly differ in ecology with A. leachii from the grahami-leachii communities (perch height, $\mathrm{F}=1.01, \mathrm{p}=$ 0.297; perch diameter, $\mathrm{F}=0.66, \mathrm{p}=0.416$; prey size, $\mathrm{W}=58.5, \mathrm{p}=0.518$; Table S3.4). In sum, depending on the biotic landscape experienced, intraspecific niche variation was high for $A$. grahami, intermediate for A. leachii, and non-existent for A. extremus (see Table S3.5 for all pairwise analyses). 


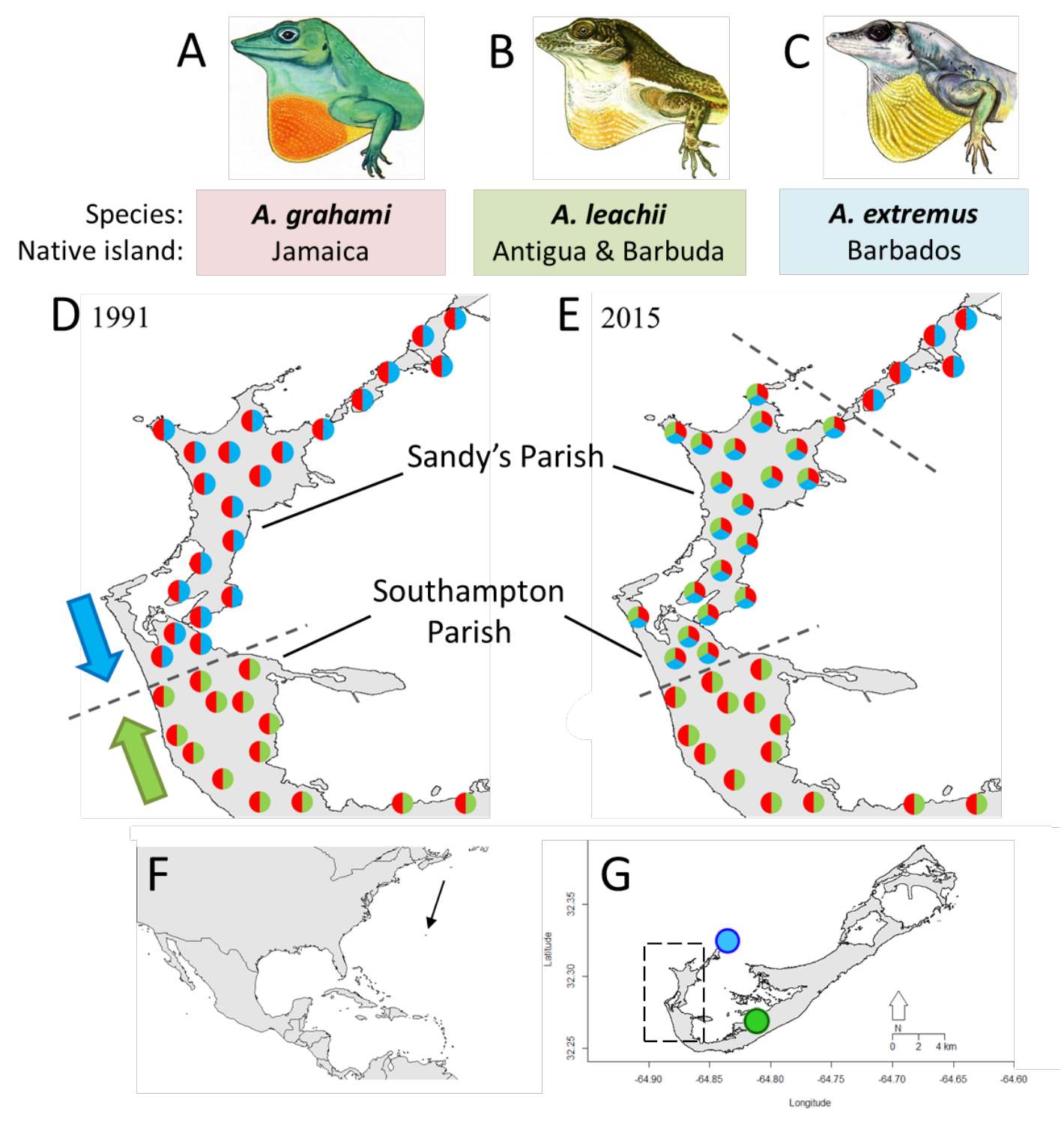

Figure 3.2. Community assembly patterns at the contact zone between two species ([B] A. leachii; green, and [C] A. extremus; blue) which both underwent rapid directional dispersal from original geographically-distinct locations on Bermuda (G). In 1964, only A. grahami [A; red] existed on Sandy's Parish, which was ubiquitous across the island except for the extreme northwestern tip where A. extremus established. By 1991, A. extremus had dispersed from its original site of introduction to form multiple 2 species communities with $A$. grahami, while $A$. leachii had dispersed through Southampton to the edge of the $A$. extremus range creating a contact zone (D; dotted line, arrows represent direction of dispersal). In 2015 (E), A. leachii had invaded Sandy's Parish to form 3 species communities, while $A$. extremus had failed to invade through the original contact zone with A. leachii in Southampton. Native islands from which each species originated are indicated under A-C. The geographic location of Bermuda is shown in F. Dashed lines represent range edges. Anole illustrations are used with permission from Schwartz \& Henderson (1987). 


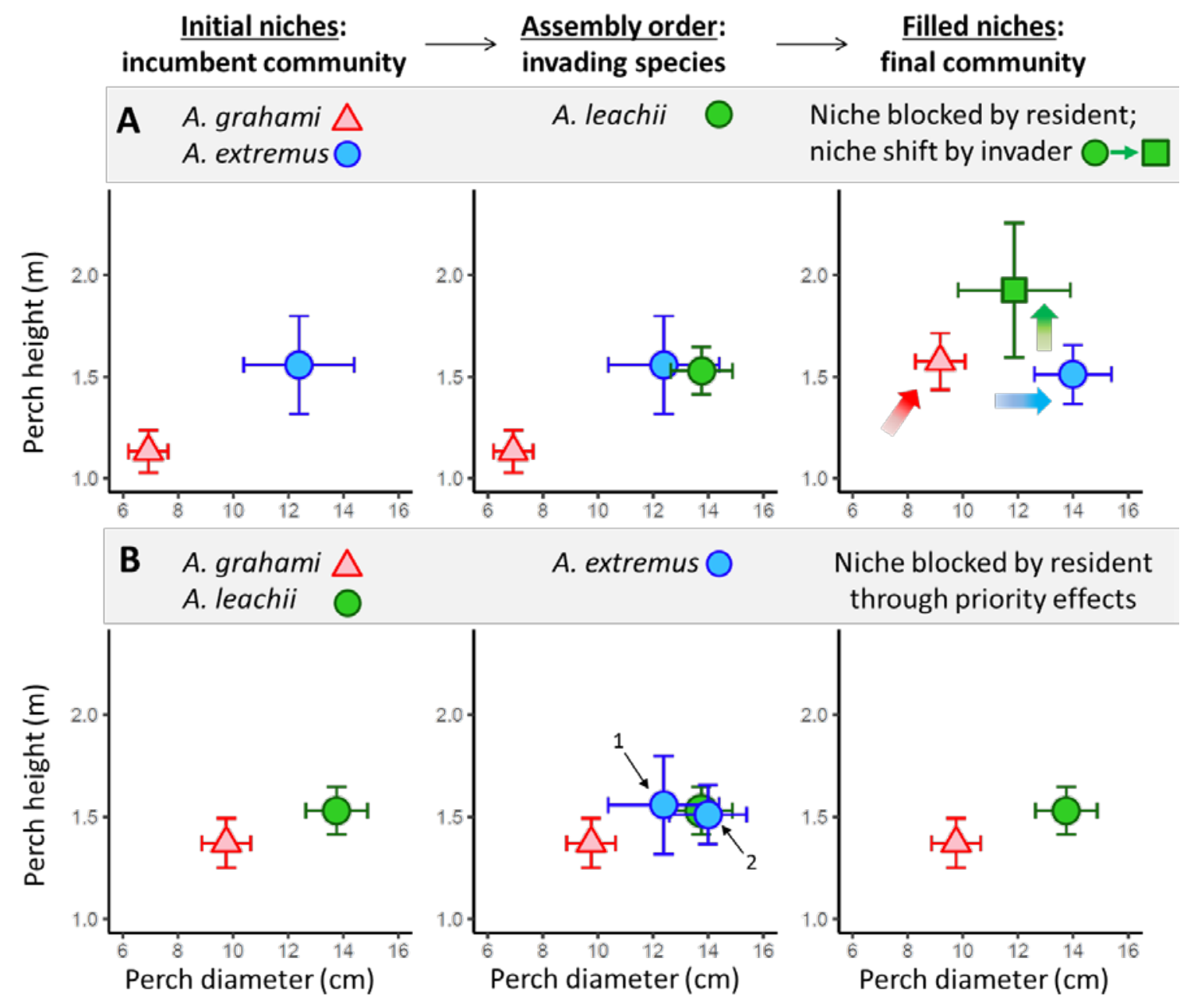

Figure 3.3. Community assembly and ecological niche organization of non-native Anolis lizards in Bermuda. Plots represent ecological niches of each species, here described through the axes along which divergence most commonly occurred to facilitate coexistence; structural habitat use (points represent species mean +/- 1 S.E.). (A) Anolis extremus blocks ecological access to leachii attempting to join grahami-extremus communities through priority effects and niche-preemption. However, leachii responds by shifting its niche into unoccupied ecological space (i.e. assembly mechanism shown in Fig 1c). In response, grahami returns to colonize ecological space made vacant by the shift of extremus, which corresponds with niche space it occupies when coexisting with only leachii. (B) However, extremus is unsuccessful in invading grahami-leachii communities (either before ${ }^{1}$ or after $^{2}$ the invasion of leachii) as priority effects from leachii blocks access to the preferred ecological space of extremus (i.e. assembly mechanism shown in Fig 1b). The invading species (in both A \& B) always significantly overlaps with the incumbent species in both axes of ecological space. 
Body Size and Interspecific Behavior

All three species are medium-sized arboreal anoles, however A. leachii are larger (mean $[\bar{x}]$ mature snout-vent length $[\mathrm{svl}]=8.86 \mathrm{~cm}$; Fig. 3.4$)$ and heavier-bodied $(\bar{x}$ [body mass $]=$ $18.75 \mathrm{~g})$ than both A. extremus $(\bar{x}=7.11 \mathrm{~cm}, \bar{x}=8.30 \mathrm{~g})$ and A. grahami $(\bar{x}=6.42 \mathrm{~cm}, \bar{x}=6.88 \mathrm{~g}$; Table S3.3). All species are sexually dimorphic in size, with size differences between species conserved within sexes. Interspecific differences in body size (Fig. 3.4) were determined from PC1 of a principal components analysis of 10 size-related morphological traits which explained $96.7 \%$ of variation between species, with factor loadings ranging from $22 \%$ for snout-vent length to $71.1 \%$ for mass. To investigate agonistic relationships between $A$. leachii and A. extremus, we conducted staged behavioural trials between sympatric (non-naïve) and allopatric (naïve) pairs of lizards. Naïveté refers to no prior experience of that individual to any individual of the heterospecific. In all trials, $A$. extremus either fled from, or was attacked by, A. leachii within 1 minute of trial commencement. These results were consistent regardless of the whether A. leachii was the resident or tethered intruder, and whether the individuals were or were not naïve to the other species. In all trails, A. leachii were larger than A. extremus. These data support an overarching pattern of dominance scaling with size in Anolis lizards (Losos 2009). 


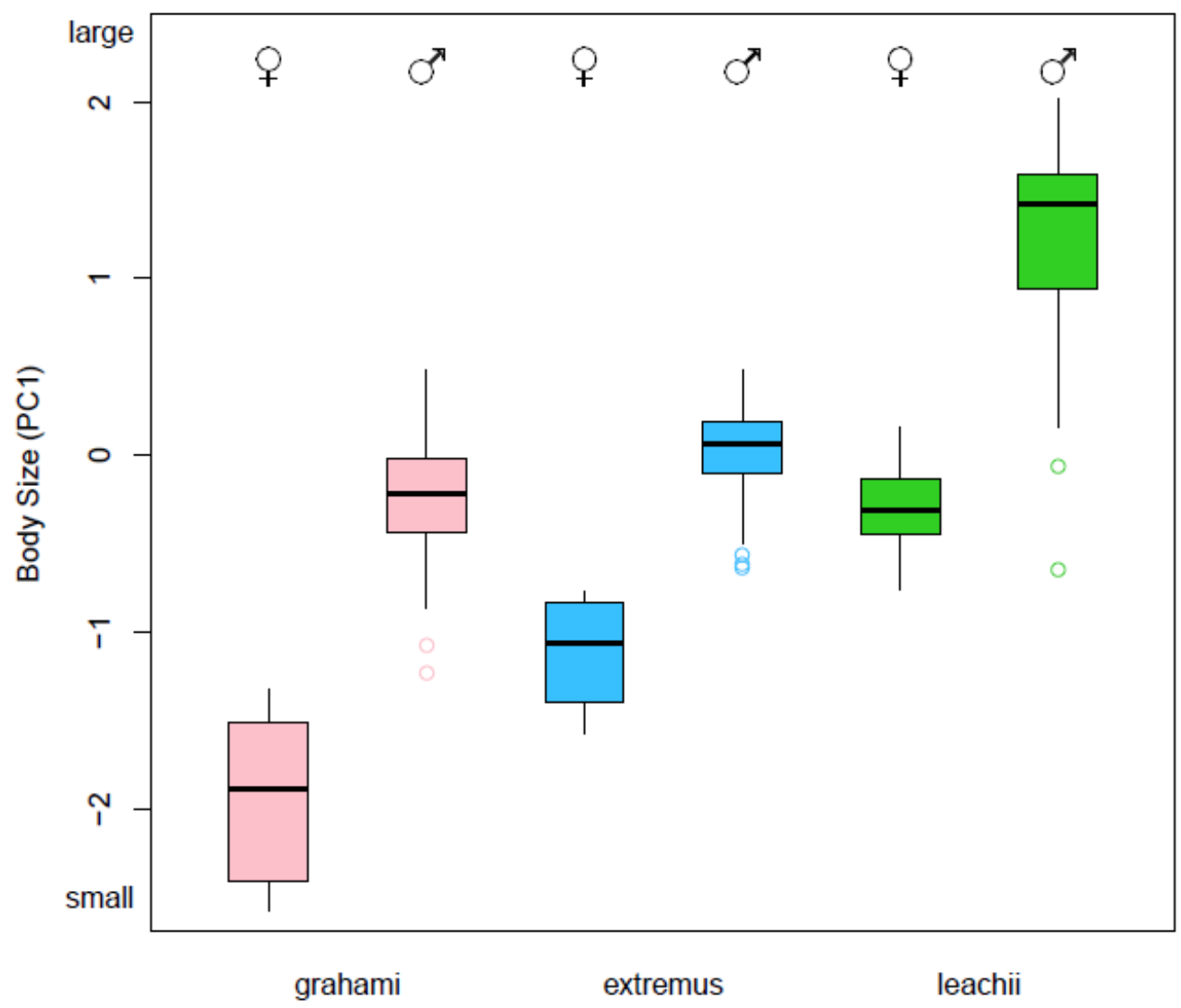

Figure 3.4. Body size differences of the introduced anoles of Bermuda; A. grahami (left), A. extremus (center), A. leachii (right). Body size is represented by PC1 of a principal components analysis of 10 size-related morphological traits which explained $96.7 \%$ of variation between species, with factor loadings ranging from $22 \%$ for snout-vent length to $71.1 \%$ for mass. Bold lines represent median values, error bars are 95\% C.I. 
Temporal Niche Stability

We contrasted our 2014/15 perch data collected with perch data collected in 1991 (Losos 1996). We used z-tests to determine if species’ niches were consistent within each community type through time. Perch data were collected using the same methods at the same sites. There was no significant difference in perch use from 1991-2014/2015 in either A. grahami $(z=-1, p=$ 0.388 ) or A. leachii ( $z=0.2, p=0.873)$ in grahami-leachii communities. In accord with the results above, there was no significant difference in perch height of $A$. extremus $(z=0.6, p=$ 0.532), but there was in A. grahami $(z=-2.1, p=0.04)$, in sites that have transitioned from communities of grahami-extremus in 1991 to communities of grahami-extremus-leachii in 2014/15.

\section{Native Range Characteristics}

Anolis leachii is endemic to the Barbuda Bank (Antigua \& Barbuda) where it coexists with a smaller congener, A. wattsi (Schoener 1970). Anolis extremus is the sole anole endemic on Barbados and has had no natural contact with a congener since splitting from its Martinique sister species A. roquet ca. 5.6-6.1mya (Thorpe et al. 2005). Anolis grahami originates from Jamaica, where it closely interacts with four other congener species (A. lineatopus, A. valencienni, $A$. opalinus, A. garmani) in communities of high ecomorphological diversity (Underwood \& Williams 1959, Losos 2009). Anolis leachii $\left(440 \mathrm{~km}^{2}\right)$ and A. extremus $\left(431 \mathrm{~km}^{2}\right)$ have extremely similar-sized native distributions, while $A$. grahami has a much larger native range and is widely distributed across Jamaica (ca. 11,044km²). None of these species are closely-position on a phylogeny (Fig 5). 


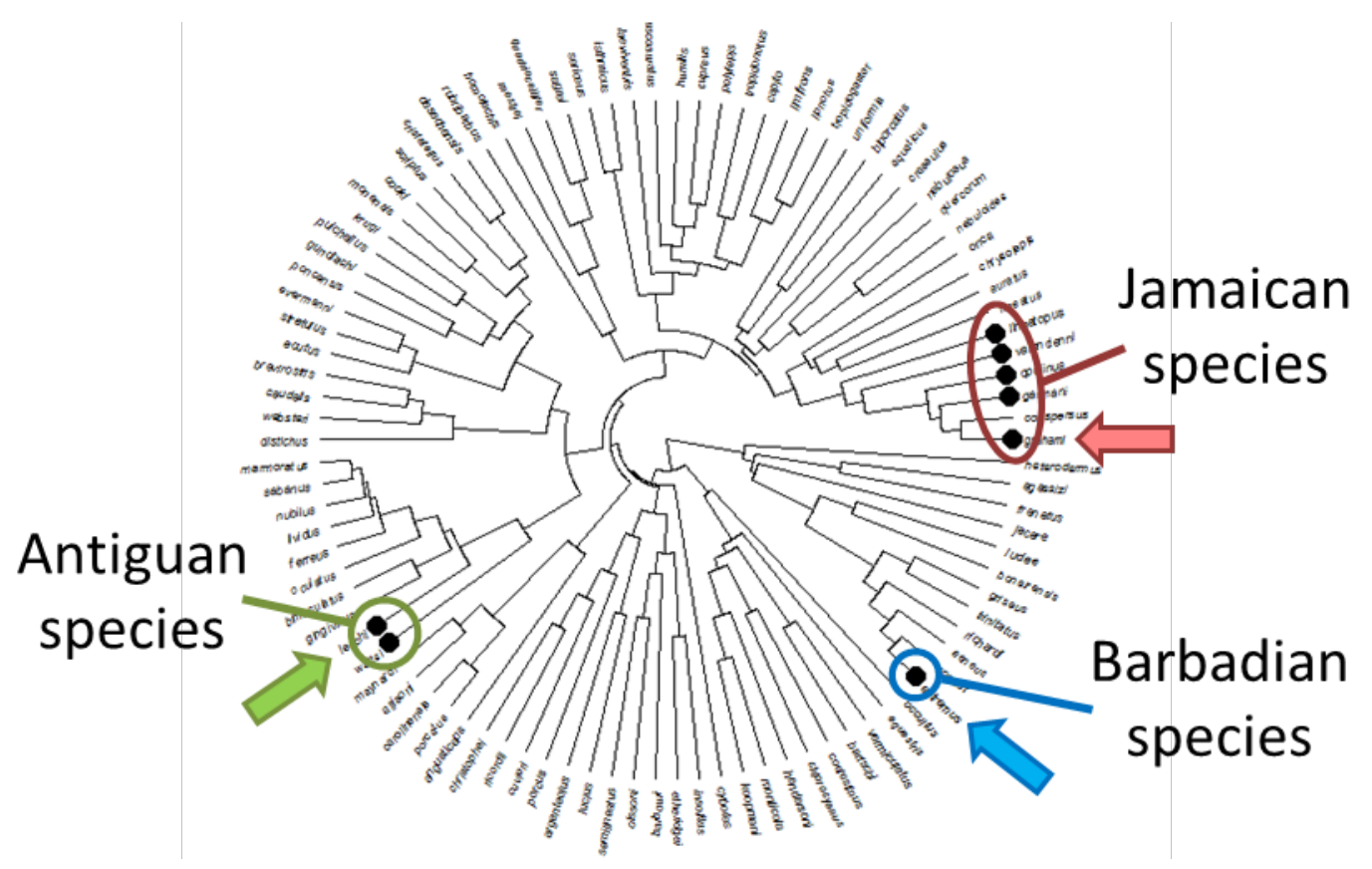

Figure 3.5. The phylogenetic distribution of non-native Bermudian Anolis lizards investigated in this study (colored arrows), alongside the communities from which they originate (circled). Each species established on Bermuda have different levels of evolutionary experience of interspecific interactions. Anolis extremus, endemic to Barbados, has had no contact with a congener for $\sim 6.1$ my (estimate of divergence from A. roquet [Thorpe et al. 2005], which coexists with $A$. lividus on Martinique). Anolis leachii coexists with 1 congener, A. wattsi, on the Barbuda Bank (Antigua \& Barbuda); Anolis grahami coexists with 4 congeners of high ecomorphological diversity on Jamaica. Phylogeny drawn from Gamble et al. (2012).

\section{DISCUSSION}

We recorded the formation of two different community types from the same species pool of non-native lizards on the oceanic island of Bermuda. Our results suggest that the assembly order of species was important in determining final community composition, such that the niche space occupied by an incumbent species was rendered unavailable through priority effects to similar species attempting to invade. However, we found that a species can join a community where an ecologically-similar species is already present if it has the ecological flexibility, or plasticity, to shift into novel unoccupied niche space. Specifically, we observed that Antiguan 
anoles (A. leachii) were able to invade 2-species communities of Jamaican (A. grahami) and Barbadian anoles (A. extremus) through shifting into unoccupied arboreal niche space. Invasion by $A$. leachii into these communities, as well as resistence against a reciprocal invasion of $A$. extremus, was likely facilitated by being larger and agonistically dominant, which reflects a general size-dominance pattern in Anolis lizards [Losos 2009]).

The extent of ecological flexibility, such as that observed by A. leachii in the formation of novel 3 species communities, appears to be unequal among species. One possible explanation for this variation may be each species’ recent evolutionary experience of biotic interactions with competitors. Species without competitors in their native range, such as A. extremus in this study an endemic Anolis isolated on Barbados for ca.5.6-6.1my - may lack the ecological flexibility to shift habitat or resource use in response to a new biotic landscape. Across the two community types where it occurs, A. extremus did not significantly shift in any aspect of its ecology, unlike the other two anole species, A. grahami and A. leachii, both of which exhibited significant shifts in niche space depending on the co-occurring species present in each community in Bermuda, and both of which originated from more speciose native communities.

Although it is clear that niches may be labile in some species when experiencing novel abiotic and biotic conditions (Valladares et al. 2014), many models of community assembly still assume that species’ niches are fixed (Broennimann et al. 2007, Vannette \& Fukami 2013, Tingley 2014). Our results provide an insight into the role niche lability may play in community assembly dynamics, as well as towards understanding why niche lability, as a trait, may vary among species. Further research will benefit from aiming to understand the extent to which niches are labile, how niche lability varies among species, and how niche lability influences patterns of species coexistence and community assembly in other model systems. As evidence continues to build for the significance of priority effects in other fields of ecology and evolution, 
particularly in understanding patterns of evolutionary and adaptive diversification (Fukami et al. 2007, De Meester et al. 2016), these research questions will likely provide important insights beyond the realm of simple ecological community assembly.

An alternative hypothesis that may explain the patterns of community assembly observed in this study, the native range size hypothesis (Moulton \& Pimm 1986, Daehler \& Strong 1993), argues that ecological flexibility will correlate positively with the geographic extent of species' native ranges (Brown 1995, Williamson 1996). This hypothesis cannot explain the patterns observed in Bermuda. The native ranges of A. leachii $\left(440 \mathrm{~km}^{2}\right)$ and $A$. extremus $\left(431 \mathrm{~km}^{2}\right)$ are extremely similar in size. Our alternative hypothesis, that the niche lability of species is based a species' evolutionary history of competitive interactions, does not contradict the native range size hypothesis but rather can help to explain a potential underlying mechanism within it. In other words, our findings suggest that the positive relationship sometimes seen between species niche lability and native range size is due to the fact that species richness, and hence the diversity of competitive interactions, commonly scales with area (Rosenzweig 1995).

It is possible that the anole communities observed on Bermuda are still dynamic. Indeed, the expanding range edge of $A$. leachii is continuing and it is expected to successfully invade all remaining grahami-extremus communities. Other studies have highlighted that during the early stages of community assembly, sometimes termed the 'noninteractive phase' (Wilson 1969, Simberloff \& Wilson 1970), more species may be supported than will eventually persist. As populations increase and competition likely strengthens, competitive exclusion may occur. In this study, all of the 3-species communities can be considered in the early stages of assembly having been formed relatively recently (sometime in the past 25 years), and so it is possible that these communities have not yet reached equilibrium and that competitive exclusion may still occur. Whether this happens, and the direction it occurs in, remains to be seen and will be the focus of 
future research. Similarly, the establishment of a fourth non-native Anolis on Bermuda, the Cuban brown anole (A. sagrei), has added yet another species to the species pool (Stroud et al. 2017). Despite being a new invader (ca. $<8$ years) with populations distant from the nearest 3-species community (ca. > $13 \mathrm{~km}$ ), A. sagrei already coexists with two species on Bermuda (A. grahami and A. leachii), and is known to undergo rapid range expansion through indirect anthropogenic dispersal elsewhere in its global non-native range (Lee 1985, Goldberg et al. 2002). The future range dynamics of $A$. sagrei on Bermuda provide an exciting accession in this simple model system of novel community dynamics.

The global re-distribution of biodiversity in the Anthropocene has brought a wealth of species into novel contact. Opportunities to study novel species coexistence and community assembly from inception, a typically elusive stage in community ecology, are unparalleled. Most commonly, recent advances in understanding the role of priority effects in community assembly have been propelled by experimentally replicable microbial systems (Fukami 2015). While microcosm experiments are undeniably valuable as model systems, there remains debate about how results obtained in laboratories scale to natural ecological processes. Without wishing to downplay the many devastating ecological consequences of non-native species, continued redistribution of species appears unavoidable in an increasingly connected world. Large-scale natural experiments instigated by the arrival of non-native species (Sax et al. 2007), as presented in this study, continue to provide opportunities to explore this comparison.

\section{CONCLUSION}

This study presents a simple novel hypothesis of how priority effects and niche plasticity may interact to influence ecological community assembly. Specifically, the diversity of interspecific interactions experienced in a species’ recent evolutionary history can significantly 
influence the extent of niche lability that species can display in the face of novel biotic conditions, which has consequential effects on community assembly. Our results add further support to the notion that the sequence of assembly influences the susceptibility of a community to invasion, and that different sequences can lead to different community configurations even when the species pool is held constant. The results from this simple model system are potentially illustrative of a general phenomenon in ecology and evolution, but one that has been previously difficult to identify due to more complex interaction dynamics in more diverse communities.

\section{MATERIALS AND METHODS}

\section{Study Area and History of Anolis Introductions to Bermuda}

A detailed history of anole introductions on Bermuda over the past century has been well documented (Wingate 1965, Losos 1996, Macedonia 2016). The Jamaican anole (A. grahami) was first introduced to the island in 1905 as a biological control of insect pests (Coccinelid beetles and parasitic Hymenoptera), which themselves were initially introduced as an attempted biological control of crop-destroying scale insects (Wingate 1965). In the absence of any other congeners, A. grahami rapidly spread and by 1963 it could be found across the entirety of the island, except the extreme northwestern tip of the archipelago (Ireland Island, Sandy’s Parish). This intentional introduction of A. grahami was followed by the unintentional introduction of two congeners; the Antiguan anole (A. leachii) and the Barbadian anole (A. extremus). Anolis leachii was first recorded in central Bermuda in 1940 within the range of A. grahami. Anolis extremus was first documented in 1953 at a geographically independent location (Ireland Island, NW Bermuda; Fig 2g). An island-wide census in 1963 documented that both recently-introduced species had spread from their original locations (Wingate 1965). Wingate (1965) predicted that $A$. leachii would continue to expand its range as it appeared behaviorally dominant over A. grahami; 
$\backslash$ the relationship between A. extremus and A. grahami was less clear - the two species had yet to come into contact as A. grahami dispersed north and A. extremus south. In 1991 an updated island-wide survey was conducted to determine if each species had continued to expand their distributions (Losos 1996). Substantial range expansions were recorded for both A. leachii and A. extremus, although neither species' respective range edges had yet met and therefore contact had still not been made (Losos 1996). There are no substantial differences in environment or vegetation either side of the recorded contact zone (Macedonia 2016). A fourth species, the Cuban brown anole (A. sagrei) was first recorded on Bermuda in 2014 (Stroud et al. 2017), but are confined to two small and localized, but geographically independent, sites in Central Bermuda where it coexists with only A. grahami and A. leachii (Stroud et al. 2017). No data were used in this study from any site containing A. sagrei. Similarly, no data were collected at sites which support Bermuda skink ( $P$. longirostris). This is a conservative approach as interactions between P. longirostris and the arboreal anoles in this study are most likely minimal, as it is strictly a terrestrial leaf-litter species (Stroud et al. 2017).

\section{Species Distributions and Community Structure}

Presence-absence surveys were conducted to investigate the current range of Anolis lizards across the entirety of Bermuda in August 2014. We recorded 2,615 lizards at 114 sites that were visited 1-3 times and searched for 10-30 min, or until 10+ lizards had been observed during any one sampling session (following the protocol established in Losos 1996). Anolis lizards are highly conspicuous, which makes visual encounter surveys a suitable sampling technique for recording presence-absence. No additional species were discovered at any sites during repeat samples. Surveys were concentrated in areas of apparent range edges to accurately delimit distributional boundaries and in areas of previously unrecorded range expansion. Sites located at range edge boundaries were revisited in August 2015 but resulted in no additional species being 
recorded at any site. Surveys were conducted at or near sites visited by Losos (1996) to provide accurate comparisons to previously published range distributions, including some additional areas never before surveyed for Anolis lizards in Bermuda; notably outlying islands (e.g. Port's, Hinson’s, Hall's, Smith’s, Hen, Palm, Morgan’s, and Humpback Islands). To assess relative differences in interspecific behavior, individuals of each species were collected from sympatric and allopatric locations ( $\mathrm{n}=10$ per species per treatment). Upon locating a resident lizard, a tethered intruder was introduced within 0.5-1.0m (following methods in Losos 1996). Introduced lizards were attached around the waist by a dental floss noose with a $0.75 \mathrm{~m}$ tether connected to the end of a 3m pole. The tether did not impede movement or visual displays. The trial was observed from a distance of $2-5 \mathrm{~m}$. Trials were conducted for 10 mins or until the resident either attacked the intruder or fled. Lizards from sympatric sites were taken to locations $>1 \mathrm{~km}$ into the allopatric distribution of the heterospecific to guarantee naïveté. To assess body size we measured mass (to nearest $0.01 \mathrm{~g}$ ), as well as length of snout-vent, forelimbs, hindlimbs, forefoot, hindfoot, head, and jaw, as well as head width and depth (all to nearest $0.01 \mathrm{~mm}$ ).

To demonstrate that the introduced Bermudian anoles are not closely phylogeneticallyrealted, we generated an Anolis phylogeny from Gamble et al. (2014) using R package ape (Paradis et al. 2004) and phytools (Revell 2012). The phylogeny from Gamble et al. (2014) contains 216 of 387 described Anolis species including all species of interest to this study.

\section{Ecological Niche Characterization}

For each community type, microhabitat (perch) use data were collected at 3 or more sites. For each observed lizard we recorded its perch height $(\mathrm{m})$ and diameter $(\mathrm{cm})$. Perch height is the distance of a lizard relative to the ground; perch diameter is the width of the substrate on which that the lizard is perching. We collected microhabitat data from all species in all community types in the study area detailed in Fig 2.; grahami-leachii (GL), grahami-extremus (GE), and grahami- 
extremus-leachii (GEL). To test for differences in perch height and diameter between coexisting Anolis species we used two-way ANOVAs. Both perch height and diameter data were log transformed to meet assumptions of normality. To test for habitat shifts of species between community types we ran linear models for each community type with more than one species. Linear models tested for differences in perch heights and diameters including site as an independent factor. The interaction between site and species was included to evaluate niche conservatism of all species among different sites. To test for shifts in perch characteristics of $A$. grahami - the most widespread species found in all community types - we used linear models with community type as the main factor and site nested within community type.

To assess diet, lizards were collected, euthanized, and stomach contents removed by dissection. Stomach contents were analyzed under a dissection microscope (10-60x magnification; as in Stroud et al. 2017). To test for differences in prey size between species in different communities we conducted Mann Whitney U-tests. To calculate prey size, we measured the length $(L)$ and width $(W)$ of each prey item, and then estimated prey item volume $(V)$ following Magnusson et al. (2003):

$$
V=\frac{4}{3} \pi\left(\frac{L}{2}\right)\left(\frac{W}{2}\right)^{2}
$$

To test for temporal niche consistency of species within each community type we contrasted our perch data with those collected in 1991 (Losos 1996) using z-tests. Perch use data were collected using the same methods and during the same diel and seasonal periods. 


\section{Acknowledgements}

We thank the Bermuda Zoological Society (Eric Clee Fund) for financial research support, as well as to Thad and Evan Outerbridge for providing accommodation. JS was supported by the FIU Judith Evans Parker Travel Fund, FIU DEA and DYF Fellowships, and an NSF DDIG. STG was supported by NSF DEB \#1406399.

\section{References}

Stroud, J. T., Bush, M. R., Ladd, M. C., Nowicki, R. J., Shantz, A. A., \& Sweatman, J. (2015). Is a community still a community? Reviewing definitions of key terms in community ecology. Ecology and evolution, 5(21), 4757-4765.

Weiher, E., \& Keddy, P. (Eds.). (2001). Ecological assembly rules: perspectives, advances, retreats. Cambridge University Press.

Fukami, T. (2015). Historical contingency in community assembly: integrating niches, species pools, and priority effects. Annual Review of Ecology, Evolution, and Systematics, 46.

Diamond, J. (1975). Assembly of species communities. Ecology and evolution of communities, 342-344.

Grant, P. R. (1972). Interspecific competition among rodents. Annual Review of Ecology and Systematics, 3(1), 79-106.

Case, T. J., \& Gilpin, M. E. (1974). Interference competition and niche theory. Proceedings of the National Academy of Sciences, 71(8), 3073-3077.

Diamond, J. M. (1978). Niche Shifts and the Rediscovery of Interspecific Competition: Why did field biologists so long overlook the widespread evidence for interspecific competition that had already impressed Darwin?. American Scientist, 66(3), 322-331.

Grant, P. R., \& Abbott, I. (1980). Interspecific competition, island biogeography and null hypotheses. Evolution, 34(2), 332-341.

Schoener, T. W. (1982). The controversy over interspecific competition: despite spirited criticism, competition continues to occupy a major domain in ecological thought. American Scientist, 70(6), 586-595.

Connor, E. F., \& Simberloff, D. (1979). The assembly of species communities: chance or competition?. Ecology, 60(6), 1132-1140.

Fox, B. J. (1987). Species assembly and the evolution of community structure. Evolutionary Ecology, 1(3), 201-213. 
Patterson, B. D. (1987). The principle of nested subsets and its implications for biological conservation. Conservation Biology, 1(4), 323-334.

Wilson, J. B. (1989). A null model of guild proportionality, applied to stratification of a New Zealand temperate rain forest. Oecologia, 80(2), 263-267.

Simberloff, D., \& Boecklen, W. (1991). Patterns of extinction in the introduced Hawaiian avifauna: a reexamination of the role of competition. The American Naturalist, 138(2), 300-327.

Mikkelson, G. M. (1993). How do food webs fall apart? A study of changes in trophic structure during relaxation on habitat fragments. Oikos, 539-547.

Tilman, D. (2004). Niche tradeoffs, neutrality, and community structure: a stochastic theory of resource competition, invasion, and community assembly. Proceedings of the National academy of Sciences of the United States of America, 101(30), 10854-10861.

MacArthur, R. H. (1972). Geographical ecology: patterns in the distribution of species. Princeton University Press.

Morin, P. J. (1999). Temporal patterns: seasonal dynamics, priority effects, and assembly rules. Community Ecology, 2nd Edition, 213-237.

Chase, J. M. (2007). Drought mediates the importance of stochastic community assembly. Proceedings of the National Academy of Sciences, 104(44), 17430-17434.

Rosenzweig, M. L., \& McCord, R. D. (1991). Incumbent replacement: evidence for long-term evolutionary progress. Paleobiology, 17(3), 202-213.

Brockhurst, M. A., Colegrave, N., Hodgson, D. J., \& Buckling, A. (2007). Niche occupation limits adaptive radiation in experimental microcosms. PLoS One, 2(2), e193.

Fukami, T., Beaumont, H. J., Zhang, X. X., \& Rainey, P. B. (2007). Immigration history controls diversification in experimental adaptive radiation. Nature, 446(7134), 436-439.

Knope, M. L., Forde, S. E., \& Fukami, T. (2012). Evolutionary history, immigration history, and the extent of diversification in community assembly. Frontiers in Microbiology, 2, 273.

Kraft, N. J., Adler, P. B., Godoy, O., James, E. C., Fuller, S., \& Levine, J. M. (2015). Community assembly, coexistence and the environmental filtering metaphor. Functional Ecology, 29(5), 592599.

Brandt, A. J., Tanentzap, A. J., Leopold, D. R., Heenan, P. B., Fukami, T., \& Lee, W. G. (2016). Precipitation alters the strength of evolutionary priority effects in forest community assembly of pteridophytes and angiosperms. Journal of Ecology, 104(6), 1673-1681.

Losos, J. B., \& Mahler, D. L. (2010). Adaptive radiation: the interaction of ecological opportunity, adaptation, and speciation. Evolution since Darwin: the first, 150, 381-420.

HilleRisLambers, J., Adler, P. B., Harpole, W. S., Levine, J. M., \& Mayfield, M. M. (2012). Rethinking community assembly through the lens of coexistence theory. Annual Review of Ecology, Evolution, and Systematics, 43. 
Mittelbach, G. G., \& Schemske, D. W. (2015). Ecological and evolutionary perspectives on community assembly. Trends in ecology \& evolution, 30(5), 241-247.

De Meester, L., Vanoverbeke, J., Kilsdonk, L. J., \& Urban, M. C. (2016). Evolving perspectives on monopolization and priority effects. Trends in ecology \& evolution, 31(2), 136-146.

Weber, M. G., \& Strauss, S. Y. (2016). Coexistence in close relatives: beyond competition and reproductive isolation in sister taxa. Annual Review of Ecology, Evolution, and Systematics, 47, 359-381.

Walther, G. R., Post, E., Convey, P., Menzel, A., Parmesan, C., Beebee, T. J., ... \& Bairlein, F. (2002). Ecological responses to recent climate change. Nature, 416(6879), 389-395.

Helmus, M. R., Mahler, D. L., \& Losos, J. B. (2014). Island biogeography of the Anthropocene. Nature, 513(7519), 543-546.

Simberloff, D., Martin, J. L., Genovesi, P., Maris, V., Wardle, D. A., Aronson, J., ... \& Pyšek, P. (2013). Impacts of biological invasions: what's what and the way forward. Trends in ecology \& evolution, 28(1), 58-66.

Lockwood, J. L., Moulton, M. P., \& Balent, K. L. (1999). Introduced avifaunas as natural experiments in community assembly. Ecological assembly rules: perspectives, advances, retreats, 108-129.

Sax, D. F., Stachowicz, J. J., Brown, J. H., Bruno, J. F., Dawson, M. N., Gaines, S. D., ... \& O’Connor, M. I. (2007). Ecological and evolutionary insights from species invasions. Trends in ecology \& evolution, 22(9), 465-471.

Mooney, H. A., \& Cleland, E. E. (2001). The evolutionary impact of invasive species. Proceedings of the National Academy of Sciences, 98(10), 5446-5451.

Stuart, Y. E., Campbell, T. S., Hohenlohe, P. A., Reynolds, R. G., Revell, L. J., \& Losos, J. B. (2014). Rapid evolution of a native species following invasion by a congener. Science, 346(6208), 463-466.

Wingate, D. B. (1965). Terrestrial herpetofauna of Bermuda. Herpetologica, 21(3), 202-218.

Losos, J. B. (1996). Dynamics of range expansion by three introduced species of Anolis lizards on Bermuda. Journal of Herpetology, 204-210.

Losos, J. B. (2009). Lizards in an evolutionary tree: ecology and adaptive radiation of anoles (Vol. 10). Univ of California Press.

Schoener, T. W. (1970). Size patterns in West Indian Anolis lizards. II. Correlations with the sizes of particular sympatric species-displacement and convergence. The American Naturalist, 104(936), 155-174.

Thorpe, R. S., Leadbeater, D. L., \& Pook, C. E. (2005). Molecular clocks and geological dates: cytochrome $\mathrm{b}$ of Anolis extremus substantially contradicts dating of Barbados emergence. Molecular Ecology, 14(7), 2087-2096.

Underwood, G., \& Williams, E. E. (1959). The anoline lizards of Jamaica. Institute of Jamaica. 
Valladares, F., Matesanz, S., Guilhaumon, F., Araújo, M. B., Balaguer, L., Benito-Garzón, M., ... \& Nicotra, A. B. (2014). The effects of phenotypic plasticity and local adaptation on forecasts of species range shifts under climate change. Ecology letters, 17(11), 1351-1364.

Broennimann, O., Mráz, P., Petitpierre, B., Guisan, A., \& Müller-Schärer, H. (2014). Contrasting spatio-temporal climatic niche dynamics during the eastern and western invasions of spotted knapweed in North America. Journal of Biogeography, 41(6), 1126-1136.

Vannette, R. L., \& Fukami, T. (2014). Historical contingency in species interactions: towards niche-based predictions. Ecology Letters, 17(1), 115-124.

Tingley, R., Vallinoto, M., Sequeira, F., \& Kearney, M. R. (2014). Realized niche shift during a global biological invasion. Proceedings of the National Academy of Sciences, 111(28), 1023310238.

Moulton, M. P., \& Pimm, S. L. (1986). Species introductions to Hawaii. In Ecology of biological invasions of North America and Hawaii (pp. 231-249). Springer New York.

Daehler, C. C., \& Strong Jr, D. R. (1993). Prediction and biological invasions. Trends in Ecology \& Evolution, 8(10), 380.

Brown, J. H. (1995). Macroecology. University of Chicago Press.

Williamson, M. (1996). Biological invasions (Vol. 15). Springer Science \& Business Media.

Rosenzweig, M. L. (1995). Species diversity in space and time. Cambridge University Press.

Wilson, E. O. (1969). The species equilibrium. In Brookhaven symposia in biology (Vol. 22, pp. 38-47).

Simberloff, D. S., \& Wilson, E. O. (1970). Experimental zoogeography of islands. A two-year record of colonization. Ecology, 51(5), 934-937.

Stroud, J. T., Giery, S. T., \& Outerbridge, M. E. (2017). Establishment of Anolis sagrei on Bermuda represents a novel ecological threat to Critically Endangered Bermuda skinks (Plestiodon longirostris). Biological Invasions, 19(6), 1723-1731.

Lee, J. C. (1985). Anolis sagrei in Florida: phenetics of a colonizing species I. Meristic characters. Copeia, 182-194.

Goldberg, S. R., Kraus, F., \& Bursey, C. R. (2002). Reproduction in an Introduced Population of the Brown Anole, Anoles sagrei, from O'ahu, Hawai'i. Pacific Science, 56(2), 163-168.

Macedonia, J. M., Clark, D. L., \& McIntosh, A. P. (2016). Differential Range Expansion and Habitat Use Among the Naturalized Anolis Lizards of Bermuda. Herpetological Review, 47(4), 529-535.

Gamble, T., Geneva, A. J., Glor, R. E., \& Zarkower, D. (2014). Anolis sex chromosomes are derived from a single ancestral pair. Evolution, 68(4), 1027-1041.

Paradis, E., Claude, J., \& Strimmer, K. (2004). APE: analyses of phylogenetics and evolution in R language. Bioinformatics, 20(2), 289-290. 
Revell, L. J. (2012). phytools: an R package for phylogenetic comparative biology (and other things). Methods in Ecology and Evolution, 3(2), 217-223. 
Table S3.1. Structural habitat selection (perch use height and diameter) of all non-native Bermuda Anolis lizards. Microhabitat use (mean $+/-$ 1 S.E.) by four introduced Anolis species on Bermuda. Communities are: GL = A. grahami/A. leachii, GE $=$ A. grahami/A. extremus, GEL $=$ A . grahami/A. leachii/A. extremus. Community level means are combined for sexes and replicate sites. Sample sizes are sometimes lower for perch diameter.

\begin{tabular}{|c|c|c|c|c|c|c|c|c|}
\hline Community & $\begin{array}{l}\text { No. } \\
\text { sites }\end{array}$ & Species & $\begin{array}{l}\text { Perch } \\
\text { height } \\
(\mathrm{m}) \\
\end{array}$ & Std Err & $\mathrm{N}$ & $\begin{array}{c}\text { Perch } \\
\text { diameter } \\
(\mathrm{cm}) \\
\end{array}$ & Std Err & $\mathrm{N}$ \\
\hline GL & 4 & A. grahami & 1.37 & 0.12 & 128 & 9.76 & 0.89 & 121 \\
\hline GL & 4 & A. leachii & 1.53 & 0.12 & 170 & 13.76 & 1.12 & 151 \\
\hline GE & 3 & A. grahami & 1.11 & 0.10 & 114 & 6.74 & 0.71 & 89 \\
\hline GE & 3 & A. extremus & 1.56 & 0.24 & 42 & 12.38 & 2.01 & 38 \\
\hline GEL & 3 & A. grahami & 1.58 & 0.14 & 132 & 9.78 & 0.90 & 108 \\
\hline GEL & 3 & A. leachii & 1.93 & 0.33 & 34 & 11.86 & 2.03 & 34 \\
\hline GEL & 3 & A. extremus & 1.51 & 0.14 & 110 & 13.99 & 1.40 & 100 \\
\hline All combined & & A. grahami & 1.37 & 0.02 & 374 & 8.74 & 0.49 & 318 \\
\hline All combined & & A. leachii & 1.60 & 0.11 & 204 & 13.41 & 0.99 & 185 \\
\hline All combined & & A. extremus & 1.52 & 0.12 & 152 & 13.55 & 1.15 & 138 \\
\hline
\end{tabular}


Table S3.2. Interspecific pairwise comparisons of three ecological axes; (i) prey item size, (ii) perch height, and (iii) perch diameter. In each community, each pair of species is using a significantly different part of the resource spectrum for at least one ecological variable.

\begin{tabular}{lclccccrrrr}
\hline \multicolumn{2}{l}{ Community organization } & & \multicolumn{3}{c}{ Prey item size } & \multicolumn{2}{c}{ Perch height } & \multicolumn{3}{c}{ Perch diameter } \\
Species 1 & Community & Species 2 & Community & W & p value & F & p value & F & p value \\
\hline A. grahami & GL & A. leachii & GL & 28 & 0.062 & 0.494 & 0.483 & 15.97 & $<\mathbf{0 . 0 0 1}$ \\
A. grahami & GE & A. extremus & GE & 42 & 0.162 & 3.606 & $\mathbf{0 . 0 2 9}$ & 8.832 & $<\mathbf{0 . 0 0 1}$ \\
A. grahami & GEL & A. leachii & GEL & 80 & 0.350 & 5.989 & $\mathbf{0 . 0 1 6}$ & 7.094 & $\mathbf{0 . 0 0 9}$ \\
A. leachii & GEL & A. extremus & GEL & 92 & 0.276 & 5.589 & $\mathbf{0 . 0 1 9}$ & 0.272 & 0.603 \\
A. grahami & GEL & A. extremus & GEL & 39 & 0.815 & 1.635 & 0.202 & 16.912 & $<\mathbf{0 . 0 0 1}$ \\
\hline
\end{tabular}


Table S3.3. Body size (snout-vent length [mm] and mass [g]) comparisons of anoles on Bermuda.

\begin{tabular}{ccrllrll}
\hline Species & $N$ & $\begin{array}{r}\text { Snout-vent } \\
\text { length (mm) }\end{array}$ & & Std Dev & Mass (g) & Std Dev \\
\hline A. extremus & $\mathbf{4 8}$ & 71.28 & \pm & 6.26 & 8.30 & \pm & 2.22 \\
\hline male & & 72.65 & \pm & 4.30 & 8.70 & \pm & 1.82 \\
female & & 56.28 & \pm & 4.54 & 3.85 & \pm & 1.00 \\
\hline A. grahami & $\mathbf{1 9 6}$ & 64.04 & \pm & 8.16 & 6.88 & \pm & 2.62 \\
\hline male & & 66.51 & \pm & 5.50 & 7.55 & \pm & 2.15 \\
female & & 48.56 & \pm & 3.88 & 2.71 & \pm & 0.68 \\
\hline A. leachii & $\mathbf{6 7}$ & 87.01 & \pm & 14.55 & 18.75 & \pm & 8.88 \\
\hline male & & 93.14 & \pm & 10.70 & 22.06 & \pm & 7.47 \\
female & 67.49 & \pm & 4.00 & 8.18 & \pm & 2.07 \\
\hline
\end{tabular}


Table S3.4. Identifying accessible ecological space by assessing interspecific differences of invader vs. resident species of anoles on Bermuda.

\begin{tabular}{lclccccccc}
\hline & & & \multicolumn{3}{c}{ Prey item size } & \multicolumn{2}{c}{ Perch height } & \multicolumn{3}{c}{ Perch diameter } \\
Invader & $\begin{array}{c}\text { Source } \\
\text { community }\end{array}$ & Resident & $\begin{array}{c}\text { Incumbent } \\
\text { community }\end{array}$ & W & $p$ value & F & $p$ value & F & $p$ value \\
\hline A. leachii & GL & A. grahami & GE & 72 & 0.2512 & 23.543 & $<\mathbf{0 . 0 0 0 1}$ & 26.979 & $<\mathbf{0 . 0 0 0 1}$ \\
A. leachii & GL & A. extremus & GE & 58 & 0.4512 & 0.006 & 0.9389 & 1.789 & 0.1828 \\
A. extremus & GE & A. grahami & GL & 115 & $\mathbf{0 . 0 0 2 1}$ & 0.352 & 0.5537 & 1.502 & 0.2223 \\
A. extremus & GE & A. leachii & GL & 58 & 0.4512 & 0.006 & 0.9389 & 1.789 & 0.1828 \\
A. extremus & GEL & A. leachii & GL & 40.5 & 0.5183 & 1.126 & 0.2896 & 0.700 & 0.4036 \\
A. extremus & GEL & A. grahami & GL & 6 & $\mathbf{0 . 0 0 1 6}$ & 0.229 & 0.6331 & 19.656 & $<\mathbf{0 . 0 0 0 1}$ \\
A. leachii & GEL & A, extremus & GE & 81 & 0.3237 & 0.511 & 0.4754 & 1.472 & 0.2297 \\
A. leachii & GEL & A. grahami & GE & 92 & 0.5512 & 1.472 & 0.2297 & 16.398 & $<\mathbf{0 . 0 0 0 5}$ \\
\hline
\end{tabular}


Table S3.5. Intraspecific niche variation on three ecological axes; (i) prey item size, (ii) perch height, and (iii) perch diameter. Intraspecific variation was high for A. graham (significant differences among all three axes), intermediate for A. leachii (significant difference in one axis; perch height), and non-existent for A. extremus (no difference in ecology between $A$. extremus regardless of the community).

\begin{tabular}{lllrrrrrr}
\hline \multicolumn{2}{l}{ Intraspecific niche variation } & & \multicolumn{2}{c}{ Prey item size } & \multicolumn{2}{c}{ Perch height } & \multicolumn{3}{c}{ Perch diameter } \\
Species 1 & Community 1 & Community 2 & W & p value & \multicolumn{1}{c}{ F } & p value & \multicolumn{1}{c}{ F } & p value \\
\hline A. grahami & GL & GEL & 9 & $\mathbf{0 . 0 0 7}$ & 3.080 & 0.081 & 1.154 & 0.284 \\
A. grahami & GE & GEL & 20 & 0.083 & 3.541 & 0.061 & 6.467 & $\mathbf{0 . 0 1 2}$ \\
A. grahami & GL & GE & 89 & $\mathbf{0 . 0 0 4}$ & 16.767 & $<\mathbf{0 . 0 0 1}$ & 1.483 & 0.225 \\
A. leachii & GL & GEL & 103 & 0.481 & 4.906 & $\mathbf{0 . 0 2 8}$ & 0.009 & 0.926 \\
A. extremus & GE & GEL & 55 & 0.841 & 0.533 & 0.467 & 3.712 & 0.056 \\
\hline
\end{tabular}




\section{CHAPTER IV}

\section{COMPLEX CHARACTER DISPLACEMENT DRIVEN SIMULTANEOUSLY BY NATURAL AND SEXUAL SELECTION}

\footnotetext{
James T. Stroud ${ }^{1,2}$, Sean T. Giery ${ }^{3}$, Robert Heathcote ${ }^{4}$, Oliver Ljustina ${ }^{5}$, Sarin Tiatragula ${ }^{6}$, Veronica Vargas ${ }^{1}$, Enrico Vezzani ${ }^{7}$, Kenneth J. Feeley ${ }^{2,8}$
}

\footnotetext{
${ }^{1}$ Florida International University, Miami, FL 33199, USA

${ }^{2}$ Fairchild Tropical Botanic Gardens, Coral Gables, FL 33156, USA

${ }^{3}$ University of Connecticut, Storrs, CT 06269, USA

${ }^{4}$ University of Exeter, Exeter EX4 4QG, UK

${ }^{5}$ Southeastern Louisiana University, Hammond, LA 70402, USA

${ }^{6}$ Auburn University, Auburn, AL 36849, USA

${ }^{7}$ University of Miami, Coral Gables, FL 33146, USA
} 


\section{ABSTRACT}

Character displacement, phenotypic divergence driven by interspecific interactions, is widely thought to be important to evolutionary diversification. However, few conclusive case studies of character displacement exist which assess the multi-faceted effects of interaction-driven ecological divergence on both ecologically and sexually-important traits. Here we present a case of complex character displacement between two Anolis lizards in evolutionary-novel contact. Following independent introductions to south Florida, ecologically-similar Cuban brown anoles (A. sagrei) and Puerto Rican crested anoles (A. cristatellus) interact strongly in sympatry which leads to vertical partitioning of structural habitat. Consequently, A. sagrei exhibit longer limbs and less-developed subdigital toepads, which is expected with increased terrestriality. However, natural selection has not acted on A. cristatellus as expected given increased arboreality. Instead, as an indirect effect of increased arboreality, concomitant with decreases in relative abundance, $A$. cristatellus become intraspecifically socially-isolated. This has relaxed selection on sexuallyimportant traits associated with intraspecific interactions, specifically bite force, and led to a decrease in head size in sympatry. We suggest that simple ecological character displacement can lead to phenotypic divergence much more complex than anticipated, and therefore may be responsible for a greater volume of observed phenotypic variation than previously recognized. 


\section{INTRODUCTION}

Understanding the origins of diversity is a fundamental challenge of evolutionary biology. In a quest to identify the underlying mechanisms driving phenotypic differentiation, early naturalists afforded great importance to resource competition (Lack 1947, Simpson 1953). Competition driven phenotypic divergence, whereby interspecific interactions - now widely recognized to span far beyond resource competition alone - leads natural selection to favor divergence in phenotype between species, is known as character displacement (Grant 1972, Pfennig \& Pfennig 2012, Stuart \& Losos 2013). The theory of character displacement has its roots in Darwin’s “principle of divergence of character” (Darwin 1859), but it was not explicitly formalized until the mid-1950s (Brown \& Wilson 1954). Although initially well received given the then-popular view that interspecific competition was the prevailing biotic interaction underlying broad patterns of coexistence and community assembly (MacArthur 1958, Hustchinson 1959, Connell 1961, Diamond 1975), character displacement went on to receive a turbulent theoretical re-assessment. The emergence of null model testing in ecology and evolution in the 1970-80s led many to argue that phenotypic divergence could simply not occur fast enough to prevent competitive exclusion (Wiens 1977, Strong et al. 1979, Simberloff \& Boecklen 1981, Lewin 1983). Now, commensurate with our understanding that adaptation can occur extremely rapidly if natural selection is strong, interest in character displacement has resurged (Schluter 2000, Dayan \& Simberloff 2005, Germain et al. 2018), developing from identifying geographic patterns of species co-occurrences to investigating the mechanisms that drive character displacement as a process (Stuart et al. 2017).

One group in which character displacement has been thought integral to the evolution of adaptive diversity is the Caribbean Anolis lizards. Anolis lizards, or anoles, are a species-rich and ecomorphologically diverse clade distributed throughout the Neotropics (Losos 2009). 
Divergence in body sizes between ecologically similar species of anoles, as well as the evolution of ecomorphological specialization, has widely been attributed to character displacement (Schoener 1977, Losos 1990c, Miles \& Dunham 1996, Butler \& Losos 1997, Losos 2009). More recently, a convincing contemporary case of character displacement in anoles has arisen. Following the introduction of Cuban brown anoles (A. sagrei) to Florida, USA, the single native Anolis, the American green anole (A. carolinensis), retreated to arboreality to minimize interspecific interactions with A. sagrei, which are typically more terrestrial (Campbell 2000, Stuart et al. 2014). As a result of increased arboreality, A. carolinensis evolved larger subdigital toepads with more adhesive toepad scales (lamellae) - traits that increase clinging performance and therefore facilitate a more arboreal lifestyle (Stuart et al. 2014). It is clear from these examples that character displacement is an important process driving the adaptive evolution of Anolis lizards over both long and short time scales.

Anole communities are typically organized through species partitioning of the structural habitat, supported by the repeated evolution of habitat specialists, termed 'ecomorphs', throughout independent Greater Antillean radiations (Williams 1972, 1983, Losos 2009). From this, the form-function relationship between structural habitat and morphology in anoles is wellunderstood (Losos 1990ab, Garland and Losos 1994, Irschick and Losos 1999), which provides a clear framework to test hypotheses for how behavioral changes in microhabitat, such as those driven by interspecific interactions consistent with character displacement, will be expected to influence morphological evolution. For example, relative limb length is strongly linked with locomotor performance and the width of the substrate most typically used; smaller limbed lizards perform better on thinner branches, while longer limbed lizards perform better on broader substrates (Williams 1983, Losos \& Sinervo 1989, Losos 1990a, Larson and Losos 1996, Irschick and Losos 1998). Similar, although much less studied in anoles, is the form-function relationship between sociality and morphology driven by sexual selection. For example, head size positively 
scales with bite force and is an important predictor of male-male agonistic interactions (Lailvaux et al. 2004), arguably one of the strongest drivers of male reproductive success in lizards (Olsson \& Madsen 1995, Lappin \& Husak 2005, While et al. 2015), since there is little evidence for female choice in anoles (Losos 2009; although see Kamath \& Losos 2017). Previous studies have only considered how ecological character displacement might lead to changes in phenotypic traits associated with the resource upon which divergence has occurred. Much less clear is how ecological divergence may simultaneously change the selection surface of traits associated with both ecology and reproduction.

The introduction of multiple evolutionarily-independent Caribbean Anolis species to south Florida over the past century has provided exceptional opportunities to study ecological interactions and their evolutionary effects (Losos 2009). Two of these species, the Cuban brown anole (A. sagrei) and the Puerto Rican crested anole (A. cristatellus; Fig. 4.1), are highly ecomorphologically similar (both "trunk-ground” ecomorphs; Fig. 4.2c) yet evolutionarily distinct, having originated independently from different island radiations, and therefore unable to hybridize. This has created an analogous situation to the early stages of adaptive radiation, whereby species who have evolved reproductive isolation in allopatry may be reunited as ecomorphologically-similar species in sympatry setting the scene for character displacement to occur (Schluter 2000, Losos \& Mahler 2010). In the early 1980’s, Salzburg (1984) reported that a population of A. cristatellus and A. sagrei sympatric for six years in Miami FL (1975-1981), coexisted by occupying different structural habitats: $A$. cristatellus was more arboreal, while $A$. sagrei was more terrestrial. Here we report how simple ecological divergence in perch height between these two species in sympatry has since been maintained and has led to a complex case of character displacement and adaptive divergence. 

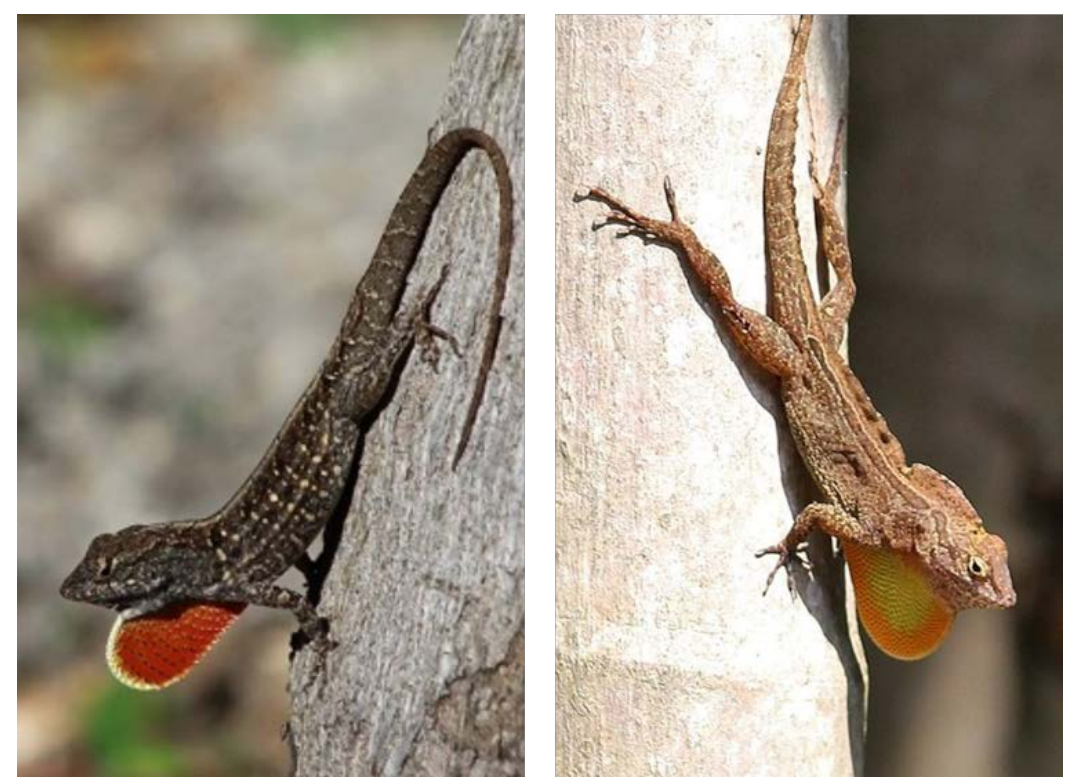

Figure 4.1. (Left) Cuban brown anole (Anolis sagrei) and (right) Puerto Rican crested anole (A. cristatellus). Photo: JStroud.

We used both experimental and observational approaches to investigate character displacement in sympatric populations of A. sagrei and A. cristatellus in south Florida, USA. Specifically, we first predicted that since A. sagrei and A. cristatellus are highly ecomorphologically-similar - more so other than to any other Anolis species in Florida - A. sagrei and A. cristatellus will show the highest levels of interspecific aggression towards each other as compared with other species (Ortiz \& Jenssen 1982, Losos 1985). Interspecific agonistic interactions may drive character displacement themselves (Grether et al. 2009), but are morelikely a behavioural facilitator to resource competition. Second, as observed in 1981 (Salzburg 1984), we predicted that $A$. sagrei and A. cristatellus continue to partition vertical habitat space. Additionally, as a result of strong interspecific interactions and resource competition, both species will occur at lower abundances in sympatry relative to allopatry. Third, as a result of increased arboreality, we predicted that $A$. cristatellus will have experienced directional selection on increased clinging performance, therefore resulting in more subdigital toepad lamellae (as 
lamellae assist with clinging to vertical surfaces; Collette 1961, Glossip \& Losos 1997, Stuart et al. 2014). Alternatively, a decrease in arboreality will work oppositely, therefore relaxing selection on toepad traits in A. sagrei (Muñoz \& Losos 2018). If a decrease in perch height is driven by increased terrestriality (i.e. use of the ground vs. elevated perches), then we expect relative limb length to have increased as a result of selection on increased locomotive performance on broader, flatter surfaces (i.e., the ground; Losos 1990ab, Larson \& Losos 1996, Macrini \& Irschick 1998, Calsbeek \& Irschick 2007). Finally, we predicted that any directional trait shifts will be accompanied by positive condition dependence, as body condition will correlate to fitness during natural selection (Lorch et al. 2003).

Assuming that a divergence in perch height between sympatric $A$. sagrei and $A$. cristatellus has been maintained, we also predicted that sociality will differ between allopatric and sympatric populations of $A$. sagrei and $A$. cristatellus. These changes in sociality will in turn lead to sexual selection acting on a different set of morphological traits to those expected from the first set of morphology-habitat predictions. Both A. sagrei and A. cristatellus are "trunk-ground" anoles, and in natural communities it is rare for more than one species per ecomorph to exist sympatrically without divergence in some aspect of microhabitat or body size (Losos 2009). Typically, trunk-ground species primarily disperse and forage on and across the ground and evolved specifically to do so compared to other ecomorphs (Losos 1990ab, Losos 2009). As such, we predicted that interspecific interactions between $A$. sagrei and A. cristatellus would also change the movement behavior of both species. Specifically, we predicted that A. cristatellus would become socially interact with other conspecifics less when sympatric with A. sagrei, as movement between trees across the ground would decrease with increased arboreality. In other words, arboreal lizards would be expected to interact with conspecifics less frequently compared to heterospecifics, as an interspecific barrier to across-ground dispersal with less-arboreal $A$. sagrei will exist. Increased intraspecific isolation in A. cristatellus will relax selection on 
sexually-selected traits associated with male-male social interactions, such as bite force (Lappin \& Husak 2005).

\section{METHODS}

Cuban brown anoles (Anolis sagrei) and Puerto Rican crested anoles (A. cristatellus) are small, 40-70mm snout-to-vent length, diurnal lizards that inhabit a range of natural and anthropogenic habitats. Anolis sagrei was first recorded in Miami FL in the early 1950s (Bell 1953), although multiple independent introductions and aggressive range expansion has seen it rapidly spread northwards such that it is now found abundantly across much of Florida (Kolbe et al. 2004). Anolis cristatellus was first introduced to Miami FL (Red Road canal) in the mid-1970s (Salzburg 1984), having originated from the Agua Claras/Ceiba region of northeast Puerto Rico (Kolbe et al. 2012). Since becoming established, A. cristatellus has passively dispersed and is now regionally abundant throughout south-east Miami (Kolbe et al. 2016). As A. sagrei and A. cristatellus originate from different island radiations (Cuba/Bahamas bank and Puerto Rico, respectively) and are only remotely phylogenetically related (Fig. SM4.1; estimated divergence is ca. 45-50 mya), hybridization is not possible. These species are completely reproductively isolated from each other.

We studied A. sagrei and A. cristatellus at 9 sites across Miami FL (3 allopatric sites per species and 3 sympatric sites; Table 4.1). Only established sympatric communities (i.e. those existing for $>30$ years) were used in this study (Salzburg 1984, Kolbe et al. 2016). 
Table 4.1. Site location details of all allopatric and sympatric populations in this study.

\begin{tabular}{llll}
\hline & & Site \\
Treatment & Site & code & Latitude, Longitude \\
\hline Allopatric: A. sagrei & F.I.U. Nature Preserve & FIU & $25.7542,-80.3789$ \\
Allopatric: A. sagrei & A.D. Barnes Park & BP & $25.7382,-80.3104$ \\
Allopatric: A. sagrei & Kendalwood Park & KP & $25.6934,-80.3450$ \\
Sympatric & Red Road canal & RR & $25.6737,-80.2839$ \\
Sympatric & Banyan Drive Park & BD & $25.6881,-80.2842$ \\
Sympatric & Matheson Hammock park & MHS & $25.6797,-80.2726$ \\
Allopatric: A. cristatellus & Barnacle State Park & BAR & $25.7259,-80.2432$ \\
Allopatric: A. cristatellus & Kendall Indian Hammocks & KIH & $25.6964,-80.3738$ \\
Allopatric: A. cristatellus & Matheson Hammock forest & MHA & $25.6832,-80.2766$ \\
\hline
\end{tabular}

Interspecific Aggression

We used an experimental approach to assess differences in interspecific aggression between the Anolis species present in study communities. Fully factorial of interspecific aggression trials were conducted with A. sagrei (“trunk-ground” ecomorph), A. cristatellus (“trunk-ground”), A. distichus (Hispaniolan bark anole; “trunk”), and A. carolinensis (American green anole; “trunk-crown”). Cuban knight anoles (A. equestris; “crown-giant”) are present in this community but were not included in this experiment as they are known to predate on all other species (Stroud 2015, Ljustina \& Stroud 2016, Giery et al. 2017). No sites were studied that included rare and locally-established anoles in Florida (e.g. A. garmani, A. cybotes, A. chlorocyanus) and therefore the were not included in this experiment. All lizards were adult males and captured from one site (Fairchild Tropical Botanic Gardens, Coral Gables FL; $25.676^{\circ} \mathrm{N}, 80.274^{\circ} \mathrm{W}$ ) where every species has been present in sympatry for $>30$ years. We staged interspecific trials ( $\mathrm{n}=20$ trials per species-pair, total trials $N=100$ ) by placing randomly selected pairs of individuals in a standardized contest arena $(50 \times 50 \times 100 \mathrm{~cm})$ with a single focal perch in the center. All trials were conducted outside in a secluded area with no external environmental stimuli. Each trial was conducted for 15 minutes as preliminary investigations 
suggested most agonistic behavior occurred within this time (usually within the first 1-5 mins). Agonistic behaviors included head bobbing, lateral body presses (pushups), throat fan (dewlap) extensions, physical aggression (biting, lunging). All behaviors were tallied, and the cumulative time that lizards were interacting aggressively in close contact $(<5 \mathrm{~cm})$ was recorded. All aggressive behaviors were log-transformed and then combined in a scaled Principal Components analysis to produce a single multivariate index of aggression. Separate one-way ANOVA's were used to assess differences in aggression of $A$. sagrei and $A$. cristatellus towards heterospecifics, with Tukey’s HSD post hoc tests to explore paired interspecific relationships.

\section{Structural Microhabitat Use}

To establish whether ecological character displacement, in the form of divergence in structural microhabitat use, has occurred when A. sagrei and A. cristatellus are in sympatry, we collected perch height data on 1185 lizards from 9 populations ( $n=47-221$ lizards per site). Specifically, we used the "Rand survey” method (Rand 1964), in which we slowly walked through each site and recorded the perch height (from the ground; to the nearest $\mathrm{cm}$ ) and diameter (width of perch to nearest $\mathrm{cm}$ ) of each observed undisturbed lizard using a tape measure. Anolis sagrei and $A$. cristatellus are both classified as "trunk-ground" anoles and are therefore expected to be ecologically similar in their structural microhabitat use. Differences in relative abundance of each species between allopatric and sympatric populations was assessed using 15 minute visual encounter surveys, replicated 3 times per site on independent days, which recorded the number of individuals per species (following Kolbe et al. 2016). Male density (males per $\mathrm{m}^{2}$ ) at each site was recorded using 50m distance transect surveys ( 3 per site) and estimates produced using the program Distance (Thomas et al. 2010). 


\section{Morphological Analysis}

We measured 11 morphological traits on captured adult male lizards from each study site (n = 23-53 per site, total $N=453$ ) where ecological data were collected. All morphological traits were measured using calipers accurate to $0.01 \mathrm{~mm}$, with the exception of body mass (measured in grams to nearest $0.01 \mathrm{~g}$ ) and toepad traits. Specifically, we measured body size (snout-vent length [SVL]; length from tip of snout to cloaca), lengths of forelimb, forefeet, hindlimb, hindfeet, jaw, and head, as well as head depth and width (see SM for detailed descriptions). Toepad traits (i.e., the number of subdigital adhesive scales [lamellae]) were obtained from high resolution digital images (1200dpi) using a flatbed digital scanner, and were recorded on the $3^{\text {rd }}$ digit of the forefoot and $4^{\text {th }}$ digit of the hindfoot, following Glossip and Losos's (1997) review of their functional importance relative to other digits.

\section{Functional Analysis of Trait Performance}

To understand the functional significance of head length, we assessed the bite force of adult male A. cristatellus $(\mathrm{n}=21)$ captured at Fairchild Tropical Botanic Gardens, Miami FL. Bite force measures were collected from lizards using a modified Sauter FK 25N force meter (as in While et al. 2015). Lizards were encouraged to bite on two metal plates covered with lightly padded insulation tape, one of which was directly attached to the force meter and the other attached to the recording sensor (separated by ca. $1 \mathrm{~mm}$ ). On biting the plates, the lizard would push the (moveable) recording plate into the (static) frame plate. All bite force measurements were recorded by one person under identical conditions and procedures. Each lizard's bite force was assessed 3 times (with 30 seconds between each test), and the highest bite force recorded was taken as that individual's performance score. 
To measure the relationship between clinging force and hindfoot size we used a similar approach to Kolbe (2015). Lizards were fitted with a harness around their midsection tethered to a digital force meter (Extech 475040) accurate to 0.01N. Lizards were placed vertically on a tree (Veitchia sp. [Arecaceae], all trials conducted on the same tree at Fairchild Tropical Botanic Gardens, Miami FL) and the tether was slowly pulled at a consistent speed perpendicular from the tree until the lizard became unattached. Both A. sagrei and A. cristatellus had been observed naturally perching on this tree. As in bite force measurements, 3 trials were conducted and the maximum clinging performance was used in analyses. Bite and clinging force $(\mathrm{N})$ and morphological traits (head length, jaw length, head width) were analyzed using an ordinary least squares regressions of functional vs. morphological trait.

\section{Dietary Analysis}

We analyzed the diet of each species at every site (total lizards = 131; see Table SM4.2). Lizards were caught using dental floss nooses attached to Cabela’s panfish poles. Stomach contents were analyzed under a dissection microscope (10-60x magnification) and identified to the lowest taxonomic level possible (as in Stroud et al. 2017). To test for differences in prey size between species in different communities we conducted Linear Mixed Effects Models of prey size (log volume +1 ) for each species with treatment as a fixed effect and site as a random effect. To assess whether source of prey (e.g. terrestrial vs. semi-terrestrial vs. arboreal) is different between populations we conducted chi-square tests on proportional prey per category. To calculate prey size (in $\mathrm{mm}^{3}$ ), we measured the length $(L)$ and width ( $W$; both $\mathrm{mm}$ ) of each prey item, and estimated [spheroid] prey item volume (V) following Magnusson et al. (2003): 


$$
V=\frac{4}{3} \pi\left(\frac{L}{2}\right)\left(\frac{W}{2}\right)^{2}
$$

To avoid overestimating volume of cylindrical [non-spheroid] prey items (e.g. Lepidopteran larvae, centipedes/millipedes, and Oligochaete worms) we calculated the volume of those prey items as:

$$
V=3.14\left(\left(\frac{W}{2}\right)^{2}\right) L
$$

\section{Ethological Assessments of Movement Behavior}

We conducted behavioral observations on adult male lizards of both species at each study site ( $\mathrm{n}=28-31$ indivudals [per species] per site; total $N=358$ lizards). After an undisturbed lizard was identified, a continuous observation of that individual was conducted for 8-20mins (mean = 14.6mins, cumulative observation time $=5,233$ mins [87.22hours]). All behavioral assessments were conducted during daylight hours (8:27am-4:52pm) when anoles are most active. We recorded several characteristics of movement behavior of each individual; movement (i) within the same perch, (ii) between different perches on the same plant, (iii) between different plants (cumulative), (iv) between different plants via routes above the ground (e.g. from plant to plant without touching the ground), and (v) between different plants across the ground. Movement data were log transformed (+1) and analyzed using linear mixed effects models, including length of observations (mins) and treatment as fixed effects, and site as a random effect. 


\section{Social Network Analysis}

To investigate whether shifts in intraspecific sociality between allopatric vs. sympatric sites were driven by interactions with heterospecifics, we created a social network of all interacting individuals of both species. Specifically, we caught and marked 72 lizards (A. sagrei $n$ $=35$ [17M:18F], A. cristatellus $\mathrm{n}=37$ [14M:23F]) in a focal sympatric site (MHS). Locations of all individuals were recorded every 30 mins for 5 days (ca. 50 hours, 0830-1730 each day). Lizards were marked latero-dorsally with a unique alphanumeric code using a permanent marker that allowed visual identification. Lizards were recorded as associating when they were in visual contact within 3m of one another (see Heathcote et al. 2016), following visual acuities calculated by Steinberg et al (2014). Association-by-distance interaction data were then used to calculate a weighted social network of all the tagged lizards. The social network was then used to calculate the 'weighted degree' for each lizard, for both conspecific and heterospecific associations, using the R package ‘igraph’ (Csardi \& Nepusz 2006). Weighted degree is a network metric used to approximate the strength of all social connections (i.e. it takes into account unique single associations as well as repeated associations with the same individual) by weighting taking into account repeated interactions with the same individuals All observations were made from a distance of $>4 \mathrm{~m}$ using binoculars (EagleOptics $8 \mathrm{x} 42$ ) to avoid observer bias in lizard behavior.

We determined what predicts the degree of intraspecific interactions per individual (i.e., conspecific weighted degree) using a general linear model (GLM). We first created a maximal model for both species combined with weighted degree of conspecific interactions as the response variable and weighted degree of heterospecific interactions as the predictor variable, with sex, SVL and species (all with their full interactions) as covariates. The weighted degree of conspecific interactions was right-skewed for both species and so square-root transformed to achieve normality. We then also ran models for A. sagrei and A. cristatellus independently, with 
identical structure to the both species model although with 'species' removed as a predictor. Additionally, we then selected the optimal model using likelihood-ratio-tests for each test, removing terms (starting with higher-order interactions) that did not cause a significant change in deviance in the model. Because network metrics are not independent of one another (Croft et al, 2004), the significance of terms in our optimal model were then calculated using permutations. Specifically, we compared the coefficient obtained from the real observed data against 10,000 randomized coefficients obtained by randomly swapping 10 individual lizards between their social groups, recalculating the network metrics and re-running the GLM after each set of swaps. The proportion of coefficients from the permuted GLMs that were higher than the GLM coefficient obtained from our real data (using a one-tailed test because our expected relationship between the network metrics was based on the direction obtained from our observed data) was then used as the $p$-value. We tested for differences in frequency of conspecific male interactions between allopatric and sympatric A. cristatellus males using an ANCOVA, with weighted degree of conspecific male associations as the response variable, and total interactions, treatment (allopatric vs. sympatric), and SVL as covariates. All association data were square-root transformed to conform to normality.

\section{Estimating Evolutionary Rates of Divergence}

We estimated mean rates of divergence for all morphological traits in haldanes ( $h$ ) (as in Stuart et al. 2014). Haldanes are a measure of the proportional change per generation in standard deviation units (Hendry and Kinnison 1999). This method assumes that each allopatric population represents the ancestral state from which sympatric populations have diverged. To calculate divergence in haldanes we used the following equation: 


$$
h=\left(\left(\frac{x_{s}}{s_{p}}\right)-\left(\frac{x_{a}}{s_{p}}\right)\right) / g
$$

Here, $x$ represents the average of site averages of a given morphological trait for sympatric $\left(x_{s}\right)$ and allopatric $\left(x_{a}\right)$ treatments with $s_{p}$ representing the pooled standard deviation; $g$ is an estimate of generations since divergence began which we conservatively estimate to be 40 generations following a detailed record of introduction history of both species in our study sites (Salzburg 1984, Kolbe et al. 2016).

\section{Statistical analyses}

All data were analyzed using R version 3.4.2 (R Core Team 2017) using the RStudio 1.1.383 (RStudio Team 2016). We used linear mixed effects models to test for differences in ecological (perch height and prey size), behavioral, and morphological traits between allopatric and sympatric populations of each species. Mixed effects models were conducted using the Ime() function implemented in the R package nlme (Pinheiro et al. 2017). All models included treatment (i.e. allopatric vs. sympatric) as a fixed effect; morphological analyses also included body size (snout-vent length) as a covariate so traits were size-relative. All models included site as a random effect; morphological analyses also included body size as a random effect. Linear mixed models with this configuration were used because they incorporate between-site variation as sites are nested as a random effect within the fixed effect treatment (Gelman \& Hill 2007, Stuart 2013). To meet assumptions of normality, all behavioral, morphological, and perch diameter data were log transformed, while perch height data were square-root transformed as it was right-skewed (as in Stuart et al. 2014). In all morphological trait models, interaction terms of treatment to body size were not significant. To assess for differences in consumption of terrestrial 
vs. arboreal prey in each species between allopatry and sympatry, we conducted generalized linear models with prey source as binomial data. Differences in relative abundance in both species between allopatry and sympatry were assessed using Wilcoxon tests as data were not normally distributed. To assess differences in the frequency of lizards perching on the ground vs. off the ground (i.e. on an elevated perch) we used chi-square contingency tests.

\section{RESULTS}

Interspecific Aggression

We observed that levels of interspecific aggression exhibited by A. sagrei and A. cristatellus were higher towards each other, than toward any other Anolis from our study communities. Specifically, $A$. sagrei differed in levels of aggression towards other species $\left(F_{2,57}\right.$ $=4.59, p=0.014$; Fig. 4.2a), such that aggression towards $A$. cristatellus was higher than towards either A. distichus (Tukey: $p=0.021$ ) or A. carolinensis (Tukey: $p=0.043$ ). There was no difference in levels of behavioral aggression exhibited by A. sagrei towards A. distichus or A. carolinensis (Tukey: $p=0.954$ ). Similarly, there was a significant difference in levels of behavioral aggression displayed by $A$. cristatellus towards heterospecifics $\left(F_{2,57}=13.31\right.$, $\mathrm{p}<$ 0.0001; Fig. 4.2b). Specifically, A. cristatellus was more aggressive towards A. sagrei than towards either A. distichus (Tukey: $p<0.0001$ ) or A. carolinensis (Tukey: $p=0.001$ ), although there was no difference between aggression displayed towards A. distichus and A. carolinensis (Tukey: $p=0.413$ ). Interspecifi aggression is represented by PC1 of a principal components analysis of 5 agonistic behaviors which explained 37.8\% of variation, with factor loadings ranging from $36 \%$ for physical aggression to $51.1 \%$ for head bobbing behaviors (Table 4.2). 

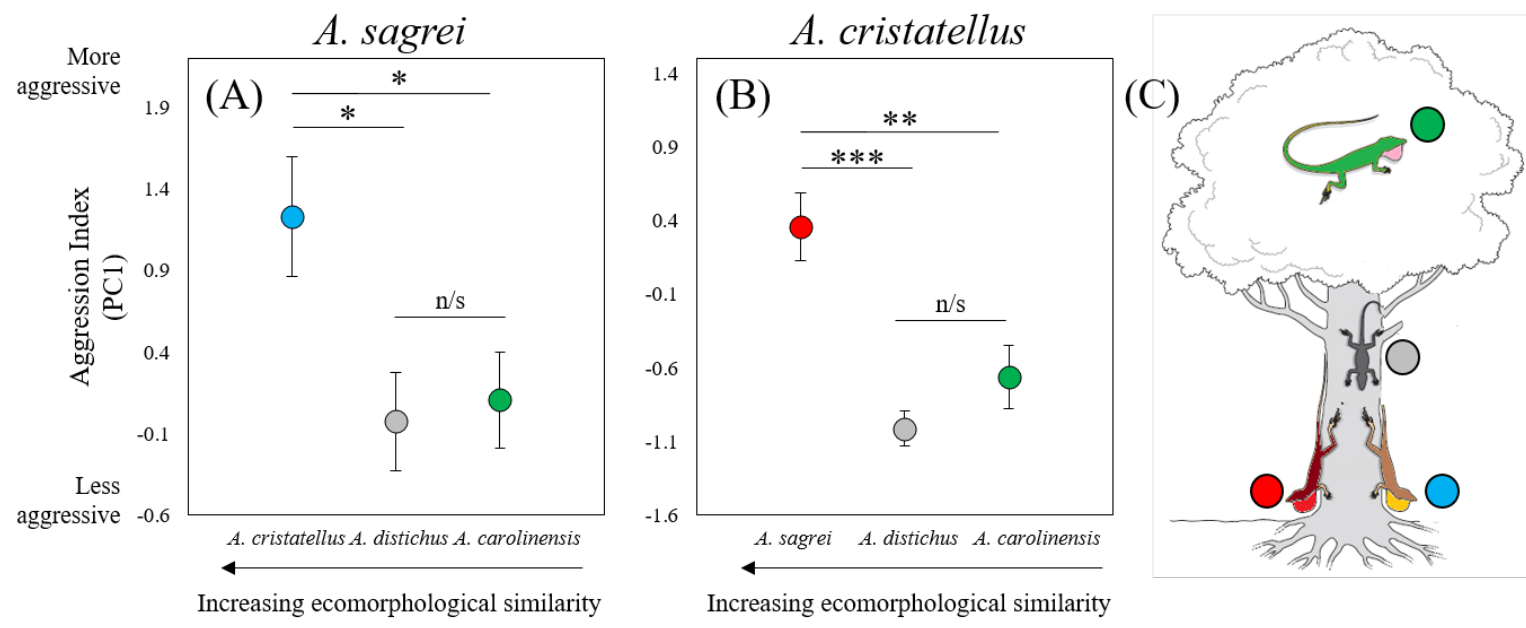

Figure 4.2 Behavioral aggression (mean +- $1 \mathrm{SE}$ ) of (A) A. sagrei and (B) A. cristatellus towards sympatric heterospecifics in experimental trials. (C) Conceptual representation of ecomorphological similarity among established Anolis lizards in Florida following "ecomorph" categorizations (from Losos 2009). Symbol colors identify each species; A. cristatellus (blue; “trunk-ground”, Puerto Rico), A. sagrei (red; “trunk-ground”, Cuba/Bahamas), A. distichus (grey; "trunk”, Hispaniola), and A. carolinensis (green; "trunk-crown”, USA). ${ }^{*} \mathrm{p}<0.05,{ }^{* *} \mathrm{p}<0.001$, $* * * \mathrm{p}<0.0001$. Figure (C) reproduced with permission from Losos (2009).

Table 4.2. Component matrix for the first 3 principal components (PC1:PC3) of aggressive behaviors observed during interspecific behavioral trials.

\begin{tabular}{lccc}
\hline Behavior & PC1 & PC2 & PC3 \\
\hline Proportion of Variance & $37.8 \%$ & $26.9 \%$ & $8.2 \%$ \\
Head bobbing & 0.511 & -0.280 & 0.168 \\
Dewlap extensions & 0.456 & -0.311 & -0.792 \\
Lateral body presses & 0.444 & -0.390 & 0.585 \\
Physical aggression & 0.360 & 0.620 & 0.006 \\
Time spent aggressively interacting & 0.442 & 0.537 & 0.047 \\
\hline
\end{tabular}

\section{Ecological Character Displacement in Microhabitat Use}

Brown (A. sagrei) and crested (A. cristatellus) anoles diverge in habitat use in sympatry. We recorded the perch heights of 1,185 adult male lizards $(n=205-381$ per treatment, $n=47-221$ per site; Table SM4.1). We found that these two species partition vertical habitat space such that 
A. sagrei perches lower (Linear Mixed Model: $\beta_{\text {cristatellus.present }}=-2.06, t_{6,623}=-3.97, p=0.017$; Fig. 4.3b) and more frequently on the ground $\left(\chi^{2}=89.49, p<0.0001\right.$; Fig. 4.4) when sympatric with A. cristatellus than when allopatric. Conversely, A. cristatellus perches higher when in sympatry than when in allopatry (Linear Mixed Model: $\beta_{\text {sagrei.present }}=3.39, t_{6,562}=3.43, p=0.026$; Fig. 4.3b), and also is less frequently found on the ground than when in allopatry $\left(\chi^{2}=9.89, p=0.002\right.$; Fig. 4.4). When allopatric, there is no significant difference in the distributions of perch height use of A. sagrei and A. cristatellus ( $\left.t_{6,738}=0.36, p=0.739\right)$; however when sympatric there is a highly significant difference in distribution driven by increased terrestriality in A. sagrei and increased arboreality in A. cristatellus ( $t_{3,447}=-13.32, p<0.0001$; Fig. 4.4b). Excluding those lizards found on the ground, there was no significant difference in perch diameter use for either A. sagrei (Linear Mixed Model: $\beta=0.96, t_{6,536}=1.77, p=0.151$ ) or $A$. cristatellus (Linear Mixed Model: $\beta$ $\left.=1.16, t_{6,525}=1.92, p=0.127\right)$.

Both $A$. sagrei $(W=72, p=0.0056)$ and $A$. cristatellus $(W=81, p=0.0003)$ decreased significantly in relative abundance in sympatry (Fig. 4.3a). Specifically, A. cristatellus male density decreased almost eight-fold between allopatric (mean $=0.047$ individuals per $\mathrm{m} 2$ ) and sympatric $($ mean $=0.007$ individual per $\mathrm{m} 2)$ populations $(t=7.91, p=0.001)$. 

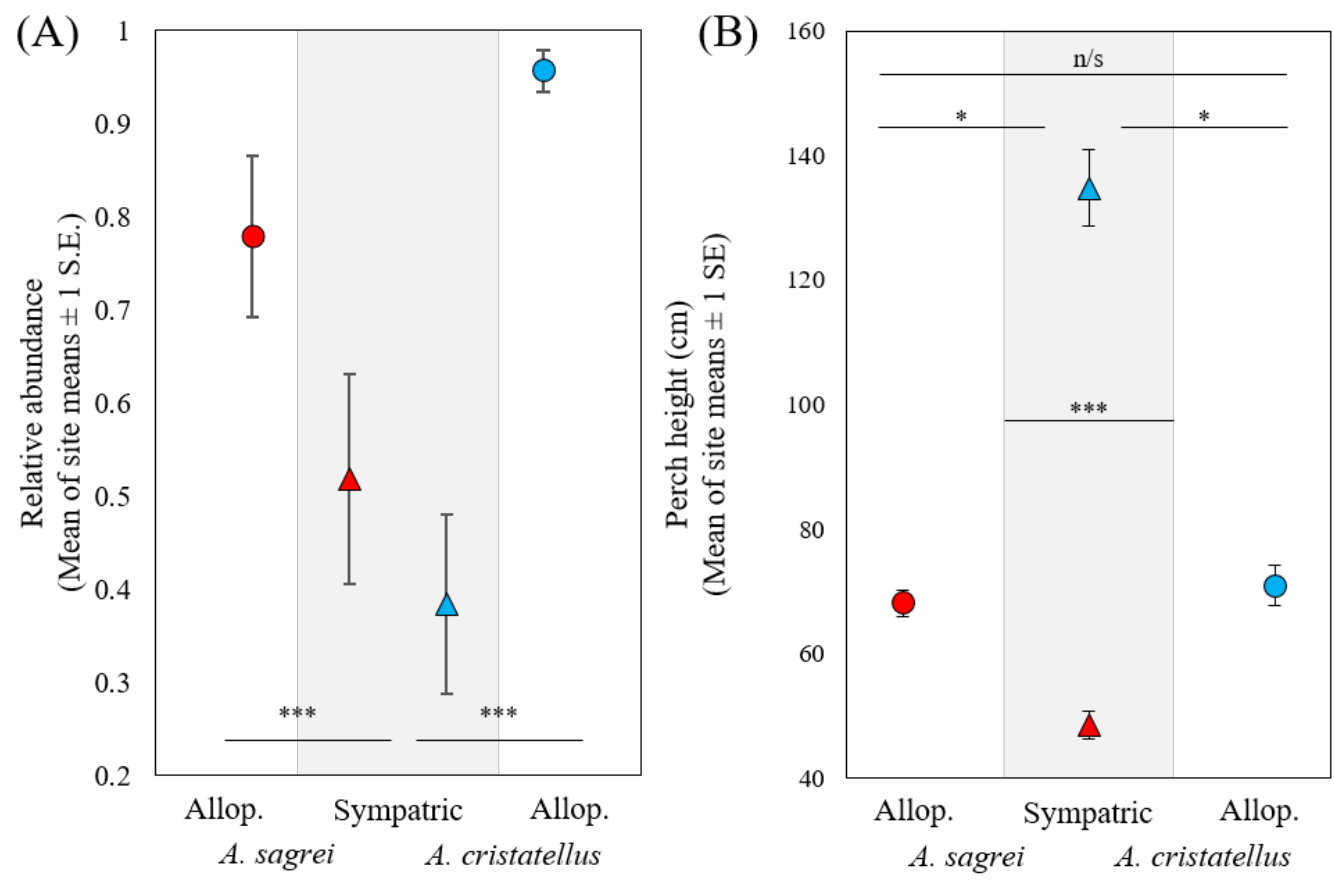

Fig. 4.3. Brown anoles (A. sagrei) and crested anoles (A. cristatellus) interact strongly in sympatry, resulting in (A) symmetric decreases in relative abundances, and (B) ecological character displacement through divergence in perch height. 

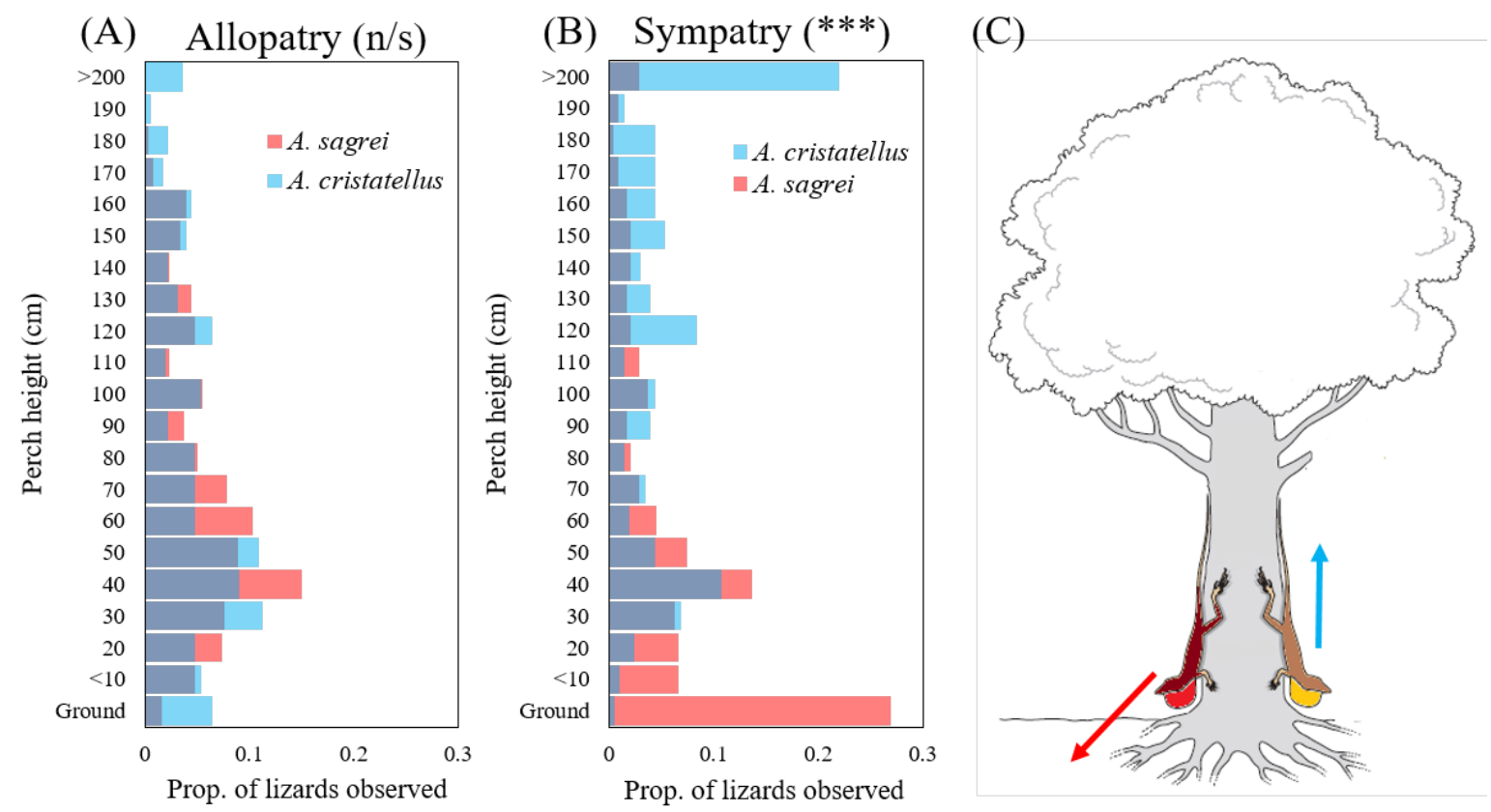

Fig. 4.4. Ecological character displacement in sympatry. (A) In allopatry, $A$. sagrei and $A$. cristatellus do not differ in the distributions of observed perch height $(p=0.739)$, however diverge in sympatry (B; $p<0.0001$ ), such that $(C)$ A. sagrei are more commonly found on the ground, and $A$. cristatellus increase in arboreality.

\section{Morphological Divergence in Sympatry}

Morphological analyses of 453 wild-caught lizards revealed that there were significant differences in certain traits of both species between allopatry and sympatry (Fig. 4.5, Table 4.3; Table SM4.1 for full details of sample sizes). When sympatric with A. cristatellus, A. sagrei have longer limbs (both forelimb [ $p=0.028]$ and hindlimb [ $p=0.026]$; Fig. 4.5a-b), longer hindfeet ( $p$ $=0.038$; Fig. 4.5c), and fewer toepad lamellae (forefoot toepad [ $p=0.001]$ and hindfoot toepad [ $p$ $=0.002]$; Fig. 4.5d-e) than allopatric populations. Conversely, symaptric A. cristatellus have smaller heads (shorter head $[p=0.006]$ and jaw length $[p=0.026]$, and narrower head width $[p=$ 0.056]; Fig. 4.5f-h) and smaller hindfeet ( $p=0.026$, Fig. 4.5i) than allopatric populations. 

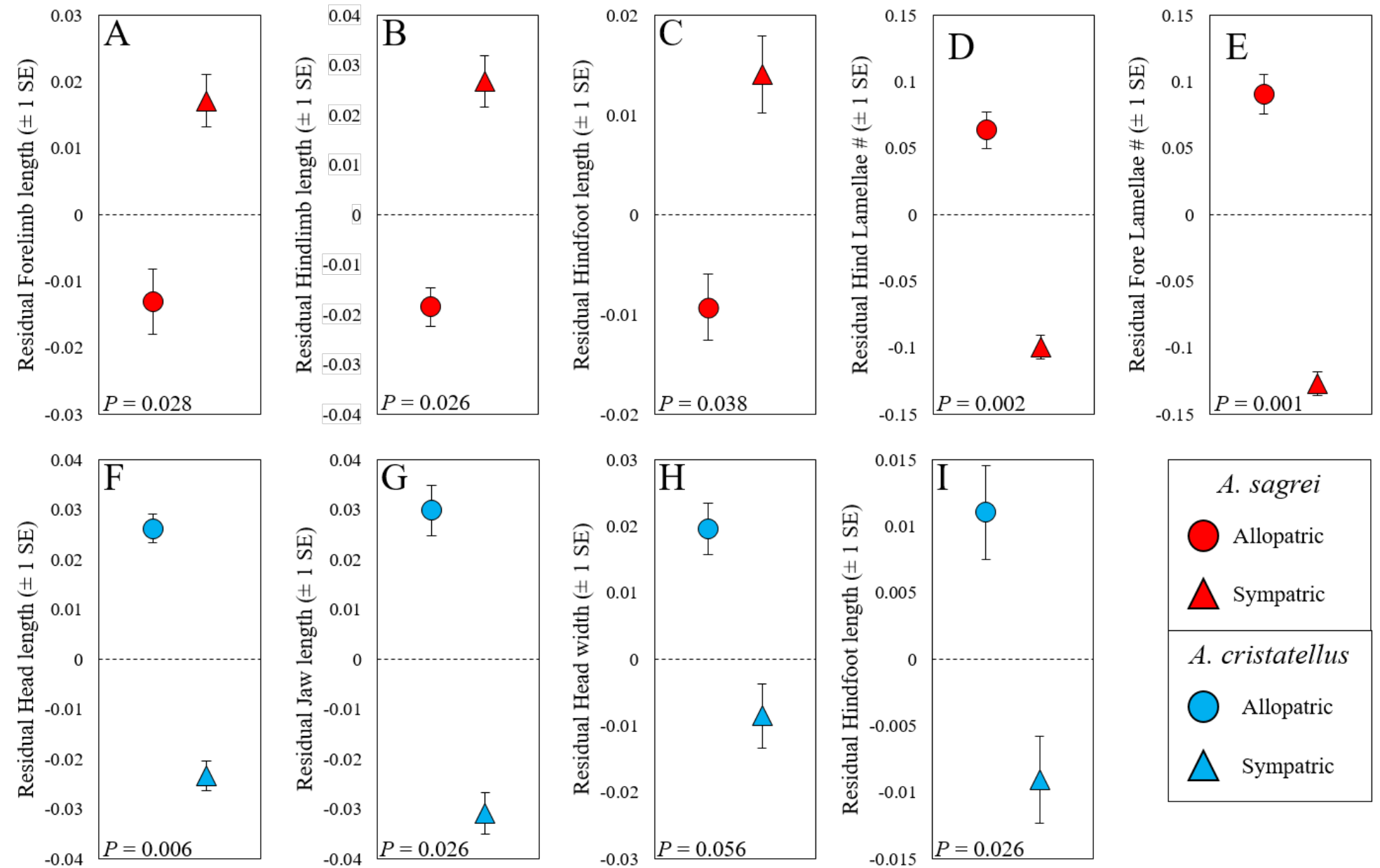

Figure 4.5. Morphological divergence in sympatry. Anolis sagrei (A-E) had longer limbs and hindfeet, as well as fewer toepad lamellae, when sympatric with A. cristatellus than when allopatric. Anolis cristatellus (F-I) had a smaller heads and shorter hindfeet when sympatric with A. sagrei than when allopatric. 
Table 4.3. Morphological trait shifts between allopatry and sympatry in A. sagrei and A. cristatellus. All results are from Linear Mixed Effects Models, with model coefficient ( \pm 1 SEM), $t$ value with degrees of freedom (note: ${ }^{a} t_{4,197}{ }^{b} t_{4,186}$ ), and significance value ( $p$ ) given. To assess differences in traits relative to body size, all models include snout-vent length as a fixed effect, except for the snout-vent length model. itself. Anolis sagrei have longer limbs and fewer toepad lamellae in sympatry with A. cristatellus, while A. cristatellus have smaller and narrower heads, and smaller hindfeet when sympatric with $A$. sagrei. All models in bold are significant at $\alpha=0.05 .{ }^{\dagger} p<0.06$.

\begin{tabular}{|c|c|c|c|c|c|c|c|c|c|c|c|c|}
\hline \multirow[b]{2}{*}{ Trait } & \multirow{2}{*}{$\begin{array}{l}\text { A. sagrei } \\
\text { Coefficient }\end{array}$} & & \multicolumn{10}{|c|}{ A. cristatellus } \\
\hline & & & & $t_{4,233}$ & $P$ & $\begin{array}{l}\text { Directional } \\
\text { change in } \\
\text { sympatry }\end{array}$ & Coefficient & & & $t_{4,204}$ & $P$ & $\begin{array}{l}\text { Directional } \\
\text { change in } \\
\text { sympatry }\end{array}$ \\
\hline Snout-vent length & 0.064 & \pm & 0.026 & 2.47 & 0.069 & - & 0.036 & \pm & 0.016 & 2.31 & 0.082 & - \\
\hline Head length & 0.010 & \pm & 0.005 & 1.94 & 0.125 & - & -0.053 & \pm & 0.010 & -5.40 & 0.006 & Smaller \\
\hline Jaw length & 0.024 & \pm & 0.014 & 1.76 & 0.153 & - & -0.070 & \pm & 0.020 & -3.46 & 0.026 & Smaller \\
\hline Head width & 0.008 & \pm & 0.009 & 0.91 & 0.414 & - & -0.038 & \pm & 0.014 & -2.68 & $0.056^{\dagger}$ & Smaller \\
\hline Head depth & 0.022 & \pm & 0.009 & 2.60 & 0.060 & - & -0.027 & \pm & 0.019 & -1.41 & 0.232 & - \\
\hline Forelimb & 0.035 & \pm & 0.011 & 3.36 & 0.028 & Longer & -0.037 & \pm & 0.121 & -0.31 & 0.760 & - \\
\hline Forefoot & 0.029 & \pm & 0.015 & 1.90 & 0.130 & - & -0.016 & \pm & 0.011 & -1.43 & 0.227 & - \\
\hline Hindlimb & 0.053 & \pm & 0.015 & 3.46 & 0.026 & Longer & -0.014 & \pm & 0.016 & -0.87 & 0.436 & - \\
\hline Hindfoot & 0.028 & \pm & 0.009 & 3.06 & 0.038 & Longer & -0.022 & \pm & 0.006 & -3.47 & 0.026 & Smaller \\
\hline Hindfoot lamellae & -0.188 & \pm & 0.025 & $-7.40^{\mathrm{a}}$ & 0.002 & Fewer & -0.047 & \pm & 0.026 & $-1.78^{\mathrm{b}}$ & 0.150 & - \\
\hline Forefoot lamellae & -0.239 & \pm & 0.025 & $-9.74^{\mathrm{a}}$ & 0.001 & Fewer & -0.057 & \pm & 0.022 & $-2.63^{b}$ & 0.060 & - \\
\hline
\end{tabular}




\section{Directional Trait Shifts Are Condition-Dependent}

We found that, in most cases, traits which shifted directionally larger in sympatry were condition-dependent, while traits which experienced relaxed selection had no relationship with body condition in sympatry. In A. sagrei we recorded positive condition-dependence in forelimb $\left(\beta=0.107, t_{(113)}=2.85, p=0.005\right.$; Fig. 4.6b) and hindlimb length $\left(\beta=0.118, t_{(113)}=2.43, p=\right.$ 0.016; Fig. 4.6a) when sympatric with A. cristatellus, although neither were significantly condition-dependent when in allopatry (forelimb: $\beta=0.064, t_{(125)}=1.61, p=0.109$; hindlimb: $\beta=$ $\left.0.002, t_{(125)}=0.06, p=0.955\right)$. Hindfoot length was condition-dependent in both sympatry $(\beta=$ 0.103, $t_{(125)}=2.82, p=0.006$; Fig. 4.6c $)$ and allopatry $\left(\beta=0.116, t_{(125)}=4.46, p<0.0001\right)$. In allopatric A. cristatellus we recorded positive condition-dependence in head (Fig. 4.6d) and jaw length (Fig. 4.6e) in both sympatry (head length: $\beta=0.121, t_{(105)}=4.29, p<0.0001$; jaw length: $\beta$ $\left.=0.128, t_{(105)}=3.19, p=0.002\right)$ and allopatry $\left(\beta=0.098, t_{(102)}=4.82, p<0.0001\right.$; jaw length: $\beta=$ $\left.0.103, t_{(102)}=2.73, p=0.008\right)$. However, hindfoot length was only condition-dependent in allopatry (allopatry: $\beta=0.099, t_{(102)}=3.79, p<0.001$; sympatry: $\beta=0.051, t_{(105)}=1.55, p=$ $0.124)$. 

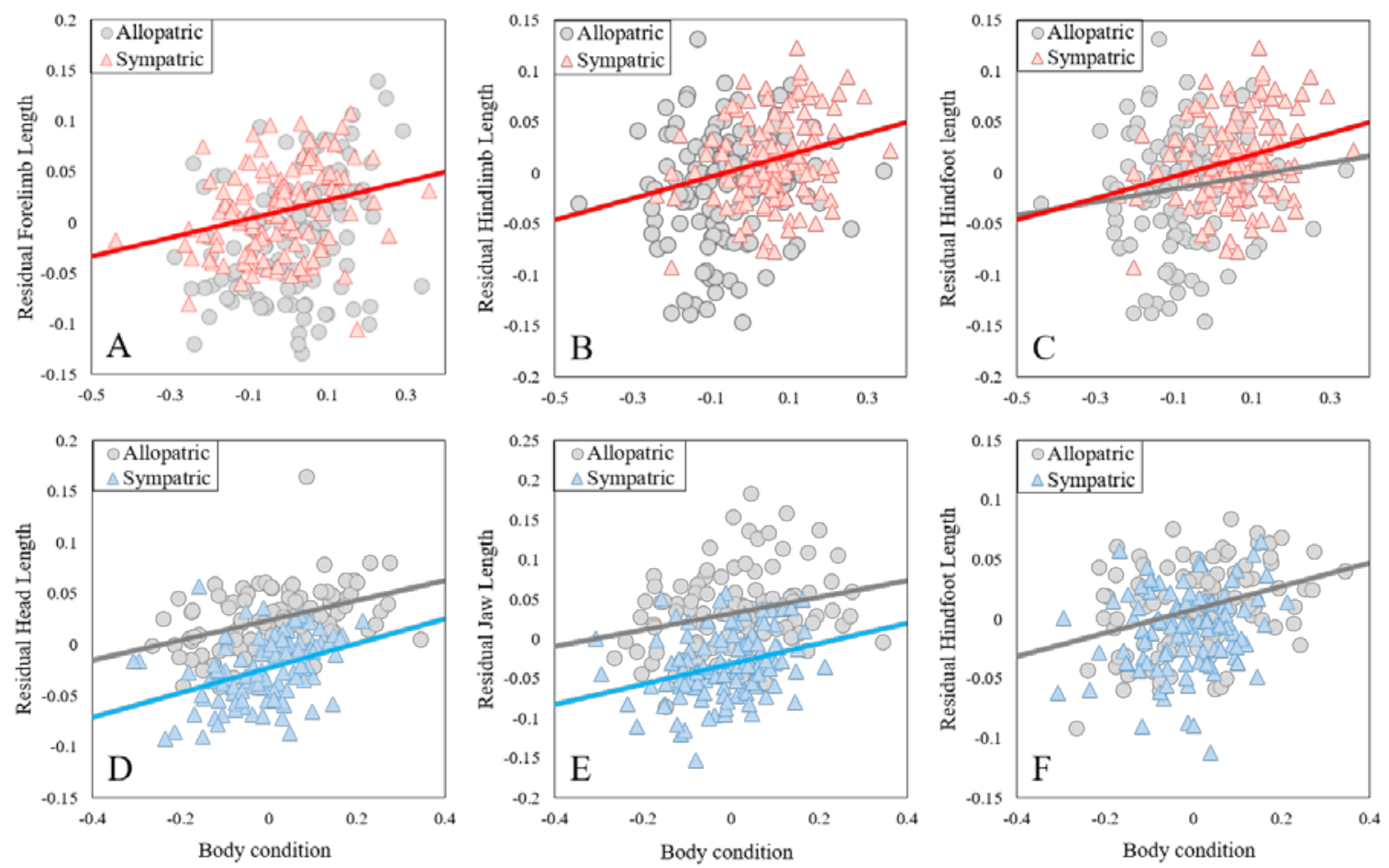

Fig. 4.6. Condition dependence of morphological traits that experienced population-level shifts from allopatry to sympatry in A. sagrei (A-C) and A. cristatellus (D-F). Regression lines are only shown for significant relationships (at $\alpha=0.05$ ). Anolis sagrei exhibit positive conditiondependence in hindlimb $(\mathrm{p}=0.005)$ and forelimb length $(\mathrm{p}=0.016)$ in sympatry with $A$. cristatellus, but not in allopatry (see text for details). Anolis cristatellus exhibit positive condition dependence of head size in both sympatry and allopatry, however only positive conditiondependence in hindfoot when in allopatry $(\mathrm{p}<0.001)$. All traits are relative to body size (residuals derived from ordinary least squares regressions of each trait independently against snout-vent length) and body condition represents residuals of mass against svl. Trendlines are only shown for significant relationships $(\alpha=0.05)$. 
Functional Significance of Trait Shifts in A. cristatellus

In accordance with other studies of Anolis (Lailvaux et al. 2004, Herrel \& O’Reilly 2005, Herrel et al. 2007), we found a strong positive relationship between head size and bite force (Fig. 4.7a-c). Specifically, bite force was positively correlated with head length $\left(F_{1,19}=36.23, p=8.62\right.$ x $\left.10^{-6}\right)$, jaw length $\left(F_{1,19}=30.73, p=2.40 \times 10^{-5}\right)$, and head width $\left(F_{1,19}=39.12, p=5.25 \times 10^{-6}\right)$. Additionally, we found that clinging force was positively correlated with hindfoot length in $A$. crisatellus $\left(F_{1,19}=5.25, p=0.034\right.$; Fig. $\left.4.7 d\right)$. Limb traits that diverged in A. sagrei were not related to clinging force in $A$. sagrei (forelimb: $F_{1,21}=0.02, p=0.894$; hindlimb: $F_{1,21}=0.58, p=$ 0.456; hindfoot: $\left.F_{1,21}=3.32, p=0.0825\right)$.
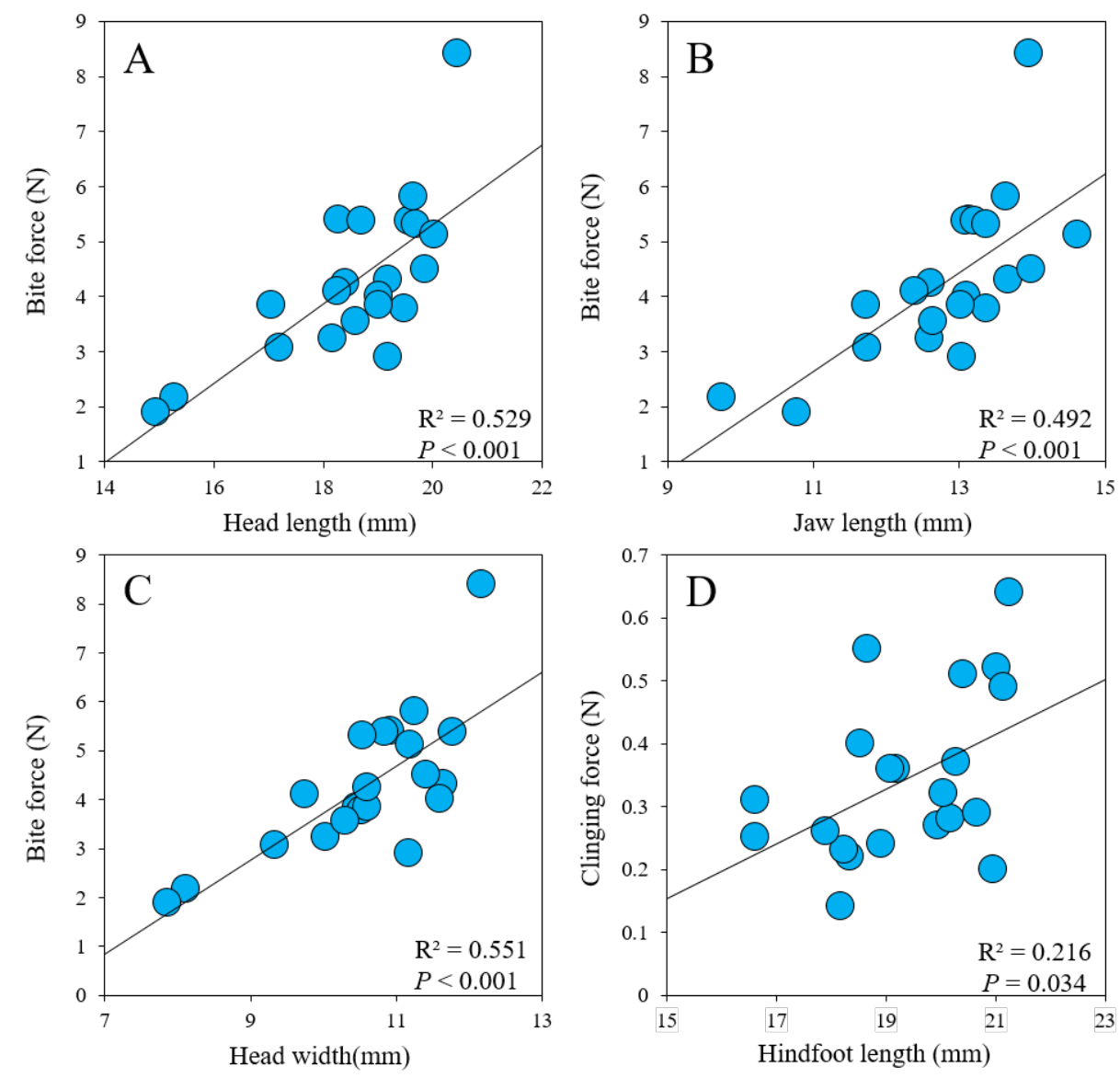

Fig. 4.7. There is a strong positive relationship between head size (A. Head length, B. Jaw length, C. Head width) and bite force, and hindfoot length and clinging force (D), in A. cristatellus. 


\section{No Shift in Diet in Sympatry}

We analyzed the diet of each species at every site (total adult male lizards $=131$, range $=$ 9-15 individuals per species per site; see Table SM4.2), which yielded prey items from 24 orders ( $\mathrm{n}=575$ total prey items). We found no differences in the size of prey items consumed by individuals of sympatric vs. allopatric populations of either $A$. sagrei (Linear Mixed Model: $\beta=$ $0.87, t_{4,274}=1.35, p=0.249$ ) or A. cristatellus (Linear Mixed Model: $\beta=0.49, t_{4,238}=1.06, p=$ 0.347; Fig. 4.8a). However, consistent with observed vertical shifts in perch height, A. sagrei consumed less arboreal and more terrestrial prey when sympatric with A. cristatellus $\chi^{2}=$ 5499.1, $p<0.0001$; Fig. 4.8b), while A. cristatellus consumed more arboreal and less terrestrial prey $\left(\chi^{2}=158.52, p<0.001\right)$ when sympatric with A. sagrei.
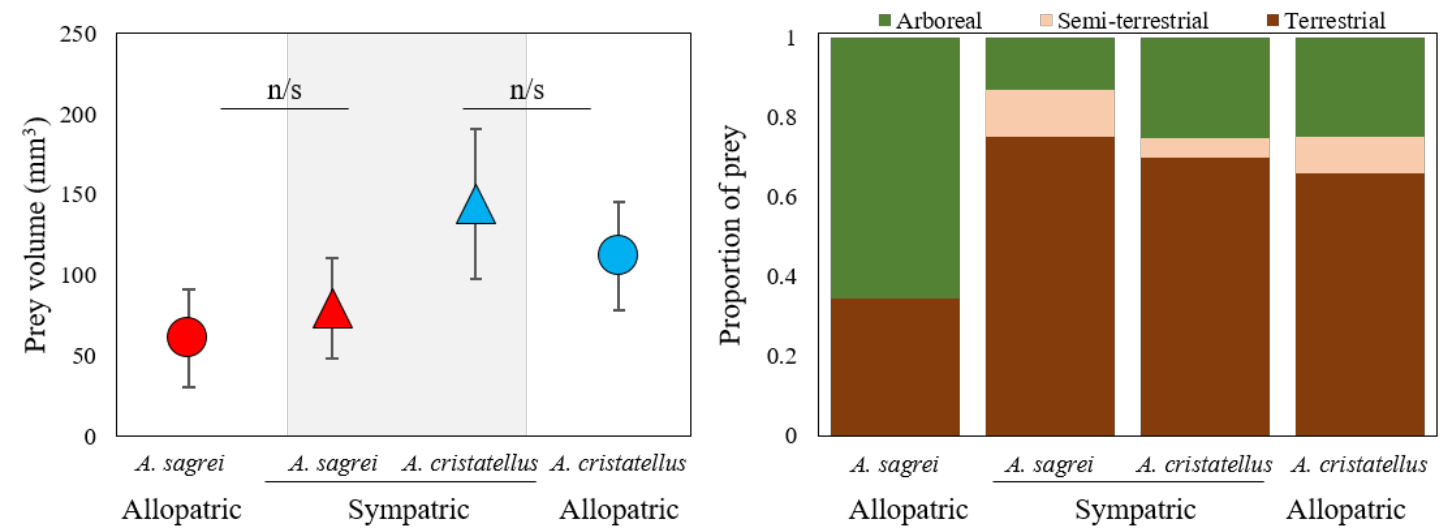

Figure 4.8. Dietary analysis of prey size and source in allopatric vs. sympatric populations of A. sagrei and A. cristatellus. (a) Neither A. sagrei ( $p=0.249$; points represent mean of site means \pm 1 S.E.) or $A$. cristatellus ( $p=0.347$ ) ate different sized prey items when in allopatry or sympatry. However, in concordance which shifts in perch height, (b) A. sagrei consumed significantly more terrestrial prey and significantly less arboreal prey when sympatric with A. cristatellus $(p<0.0001)$, and A. cristatellus consumed significantly more arboreal prey and less terrestrial prey in sympatry $(p<0.001)$. 
Shifts in Movement Behavior in Sympatry

We conducted ethological observations on 358 adult male lizards (28-30 per species per site) for a total of 87.22 hours (8-20mins per lizard, median = 15mins; Table SM4.3). When sympatric with $A$. cristatellus, $A$. sagrei moved between plants across the ground at a higher rate than when in allopatry (Table 4.4). When sympatric with A. sagrei, A. cristatellus moved between plants less frequently than when in allopatry $(p=0.038)$, either above $(p=0.026)$ or across the ground $(p=0.092)$.

Table 4.4. Comparisons of movement behavior between sympatric and allopatric populations of A. sagrei and A. cristatellus. Data represent mean of site means of behavior rate per hour ${ }^{-1}$. N represents number of lizards observed (and cumulative minutes of observation). Results in bold indicate model significance at $\alpha=0.05 .{ }^{\dagger} P<0.1$.

\begin{tabular}{|c|c|c|c|c|c|}
\hline Species & Allopatry & Sympatry & $d f$ & $t$ & $p$ \\
\hline Anolis sagrei & 89 (1279) & 89 (1329) & & & \\
\hline $\begin{array}{l}\text { Movement within the } \\
\text { same perch }\end{array}$ & 15.04 & 26.59 & 4,171 & 1.24 & 0.284 \\
\hline $\begin{array}{l}\text { Moving between perches } \\
\text { (on the same plant) }\end{array}$ & 2.51 & 2.53 & 4,171 & 0.07 & 0.945 \\
\hline $\begin{array}{l}\text { Moving between plants } \\
\text { (cumulative) }\end{array}$ & 4.46 & 5.79 & 4,171 & -1.63 & 0.178 \\
\hline $\begin{array}{l}\text { Moving between plants } \\
\text { (above the ground) }\end{array}$ & 3.72 & 2.42 & 4,171 & -1.63 & 0.178 \\
\hline $\begin{array}{l}\text { Moving between plants } \\
\text { (across the ground) }\end{array}$ & 0.74 & 3.36 & 4,171 & 3.05 & 0.038 \\
\hline Anolis cristatellus & 89 (1268) & 91 (1357) & & & \\
\hline $\begin{array}{l}\text { Movement within the } \\
\text { same perch }\end{array}$ & 47.05 & 41.58 & 4,173 & -0.93 & 0.403 \\
\hline $\begin{array}{l}\text { Moving between perches } \\
\text { (on the same plant) }\end{array}$ & 4.53 & 3.28 & 4,173 & -1.19 & 0.301 \\
\hline $\begin{array}{l}\text { Moving between plants } \\
\text { (cumulative) }\end{array}$ & 9.53 & 3.42 & 4,173 & -3.06 & 0.038 \\
\hline $\begin{array}{l}\text { Moving between plants } \\
\text { (above the ground) }\end{array}$ & 6.50 & 2.14 & 4,173 & -3.45 & 0.026 \\
\hline $\begin{array}{l}\text { Moving between plants } \\
\text { (across the ground) }\end{array}$ & 4.09 & 2.26 & 4,173 & -1.35 & $0.092^{\dagger}$ \\
\hline
\end{tabular}


Social Isolation of A. cristatellus Driven by Interactions with A. sagrei

When sympatric with A. sagrei, male A. cristatellus significantly interacted with conspecific males less than when allopatric $\left(F_{1,35}=21.21, p<0.001\right.$; Fig. 4.9a). There was no effect of body size on this relationship $(\mathrm{F} 1,35=0.61, p=0.439)$. Social network analyses revealed that when $A$. cristatellus and $A$. sagrei occur in sympatry, interspecific interactions significantly predicted the frequency of intraspecific interactions of $A$. cristatellus, but not $A$. sagrei (Table 4.5). This was supported by GLMs of permutations of observed coefficients against 10,000 randomized coefficients from optimal models (Table SM4.4; see Methods for details). Specifically, A. cristatellus males that had high levels of interactions with A. sagrei males (heterospecifics) had low levels of interactions with other $A$. cristatellus males (conspecifics; $F_{1,11}$ $=26.96, p<0.001$, Fig. 4.9b). This relationship did not exist for A. sagrei males, who had similar levels of conspecific interactions regardless of how many heterospecific interactions it also encountered $\left(F_{1,9}=2.19, p=0.174\right.$, Fig. 4.9b). These patterns were replicated in females of both species $\left(\right.$ A. cristatellus females; $F_{1,18}=10.46, p=0.005$ : A. sagrei females; $F_{1,12}=2.74, p=$ 0.124). There was a significant effect of sex on the extent of conspecific interactions for the combined species model ( $p=0.039$; Table SM4.4), as males of both species had more cumulative social interactions than females. 

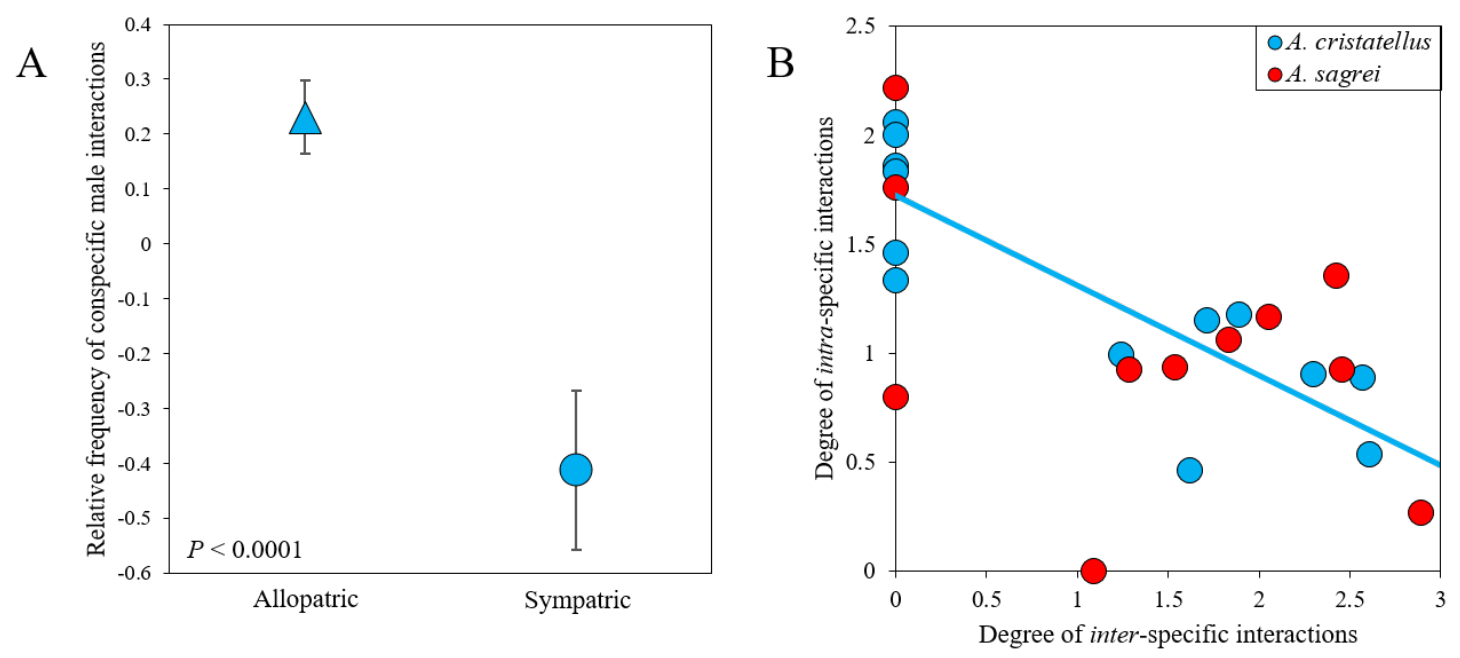

Fig. 4.9. (A) When in sympatry with A. sagrei, male A. cristatellus interact with conspecific males significantly less than when allopatric $(p<0.001)$. Frequency of interactions represent residuals from a regression of weighted conspecific male associations against cumulative associations. Points represent mean values \pm 1 S.E. (B) Social isolation of A. cristatellus from conspecific males is driven by interactions with heterospecific $A$. sagrei males (blue solid line, $p$ $<0.001$ ). This conspecific vs. heterospecific interaction relationship does not exist for sympatric A. sagrei $(p=0.161)$. Only significant trendlines shown. Each point represents an individual adult male lizard. Interaction data represent weighted association coefficients (see Methods for details).

Table 4.5. Repeated measures GLMs investigating the effect of interspecific interactions on intraspecific sociality. In sympatry, interspecific interactions significantly predict the frequency of conspecific interactions in A. cristatellus $(p<0.001)$ but not in A. sagrei $(p=0.181)$.

\begin{tabular}{lrcccc}
\hline Species & Coefficient & & $t$ & $p$-value \\
\hline A. cristatellus & & & & & \\
$\quad$ Interspecific interactions & $\mathbf{- 0 . 2 5 4}$ & \pm & $\mathbf{0 . 0 5 6}$ & $\mathbf{- 4 . 5 7}$ & $\mathbf{0 . 0 0 1}$ \\
Sex & 0.012 & \pm & 0.370 & 0.03 & 0.974 \\
SVL & 0.010 & \pm & 0.019 & 0.51 & 0.614 \\
A. sagrei & & & & & \\
Interspecific interactions & -0.123 & \pm & 0.089 & -1.38 & 0.181 \\
Sex & -0.068 & \pm & 0.041 & -1.64 & 0.117 \\
SVL & 1.040 & \pm & 0.557 & 1.87 & 0.076 \\
\hline
\end{tabular}




\section{Estimated Rates of Divergence}

Assuming that the morphological traits upon which divergence was observed are all heritable, we estimated rates of evolution from allopatric to sympatric populations. We found that in A. sagrei, limb and hindfoot dimensions diverged at rates of 0.025-0.048 haldanes, while toepad traits diverged much faster (0.225-0.298 haldanes; Table 4.6). In A. cristatellus, we found that head dimensions diverged at rates of 0.010-0.117 haldanes, and hindfoot length diverged at 0.025 haldanes. These estimated rates of evolutionary divergence are conservative among other published estimates of similar evolutionary field studies (reviewed in Hendry \& Kinnison 1999).

Table 4.6. Comparisons of morphological traits which have diverged in each species between sympatry and allopatry, alongside estimates of evolutionary divergence in Haldanes.

\begin{tabular}{cccc}
\hline \multicolumn{1}{c}{ Trait } & $\begin{array}{c}\text { Allopatry } \\
\text { Size-corrected } \\
\text { (trait/svl) }\end{array}$ & $\begin{array}{c}\text { Sympatry } \\
\text { Size-corrected } \\
\text { (trait/svl) }\end{array}$ & $\begin{array}{c}\text { Estimate of divergence } \\
\text { (Haldanes) }\end{array}$ \\
\hline A. sagrei & & & \\
Hindlimb length & 0.424 & 0.443 & 0.045 \\
Forelimb length & 0.256 & 0.262 & 0.048 \\
Hindfoot length & 0.309 & 0.312 & 0.025 \\
Hind lamellae & 0.283 & 0.227 & 0.298 \\
Fore lamellae & 0.225 & 0.173 & 0.225 \\
A. cristatellus & & & 0.117 \\
Head length & 0.291 & 0.275 & 0.059 \\
Jaw length & 0.204 & 0.190 & 0.010 \\
Head width & 0.165 & 0.158 & 0.025 \\
Hindfoot length & 0.315 & 0.306 & \\
\hline
\end{tabular}




\section{DISCUSSION}

\section{Complex Character Displacement: Natural Meets Sexual Selection}

The hypothesis of character displacement is central to our understanding of the origins of phenotypic diversity. Our results show that simple habitat divergence can simultaneously affect fitness surfaces of both ecologically and sexually-important traits, leading to morphological divergence in sympatry. Specifically, we documented that in sympatry A. sagrei and A. cristatellus interact strongly and exhibit ecological divergence in perch height to minimize interspecific interactions; A. cristatellus perches higher (increases in arboreality) and A. sagrei perches lower (increases in terrestriality). Our data support that both resource competition (Fig. 4.3), known to be strong between Anolis species elsewhere (Schoener 1974, 1975, Lister 1976, Roughgarden et al. 1983, Rummel \& Roughgarden 1985, Losos 2009), and agonistic interference (Fig. 4.2; Salzburg 1984, Losin 2012), possibly both play a role in perch height divergence.

As a result of decreased perch height and increased terrestriality, natural selection has acted on A. sagrei as expected given the form-function relationship in anoles between habitat and morphology; sympatric populations of A.sagrei have fewer toepad lamellae, which is associated with a decrease in arboreality, and longer limbs, associated with increased sprint performance on the ground. We observed positive condition-dependence of limb lengths in sympatric but not in allopatric A. sagrei (Fig. 4.6), providing further support for directional selection towards longer limbs in sympatry (Lorch et al. 2003). We also recorded morphological shifts in A.cristatellus when in sympatry, however not on those traits expected under the same morphology-habitat predictions. Sympatric populations of $A$. cristatellus did not have more subdigital toepad lamellae as would have been expected with an increase in arboreality. Instead, sympatric A. cristatellus had smaller heads. Head size is highly correlated with bite force performance (Herrel et al. 2007), and so behaviors contingent on bite force may have been under selection. To investigate which 
other changes in ecology or behavior might have facilitated relaxed selection on bite force and head size we assessed diet, movement behavior, and sociality.

We found no difference in prey size consumption (Fig. 4.8) - a shift to smaller prey may relax selection on head size (Measey et al. 2011) - and so we investigated differences in sociality between allopatric vs. sympatric $A$. cristatellus. The outcome of male-male aggressive combat can often be reliably predicted from head size, such that larger headed lizards with the strongest bite force are most often dominant (Hews 1990, Pratt et al. 1992, Lopez et al. 2002, Gvozdík and Van Damme 2003, Lappin \& Husak 2005, Husak et al. 2006), and - in the absence of female choice, for which there is little evidence in anoles (Losos 2009) - is therefore a key social component of fitness. We observed that when sympatric with A. sagrei, A. cristatellus moved around their environment significantly less and consequently interacted with conspecific males significantly less frequently than when in allopatry (Table 4.4). A decrease in conspecific interactions in sympatry was driven by high frequency of interactions with heterospecific $A$. sagrei (Fig. 4.9b). These data support a hypothesis that in sympatry with A. sagrei, following a decrease in abundance and an increase in arboreality, A. cristatellus experience intraspecific social isolation, as movement throughout the environment to encounter conspecifics decreases as interspecific interactions with $A$. sagrei increase. The mechanisms which maintain this pattern is likely a mixture of interspecific resource competition and agonistic interactions, although other uninvestigated interactions cannot be ruled out (i.e. intraguild predation, apparent competition). A decrease in the frequency of conspecific male interactions in A. cristatellus may have relaxed selection on bite force, which is a possible explanation for a smaller relative head size in sympatry.

So, why has natural selection apparently failed to act on those traits usually associated with increased aboreality? Arguably for the same reasons. Given our understanding of the 
morphology-habitat relationship in anoles, performance-driven natural selection would be expected to favor individuals with more toepad lamellae in response to an increase in arboreality. However, toepad traits may also operate under male-driven sexual-selection, as clinging force is an important functional trait during male-male interactions, particularly agonistic combat. Males that are usurped by competitors with better clinging force may experience direct negative fitness consequences, for example through reduced fecundity via lost access to females. Comparatively, natural selection on performance may be a pertinent but fairly weak influence on fitness compared to traits under sexual selection, which could directly influence reproductive success. Although selection on increased arboreal performance might drive an increase in lamellae number in sympatry, a decrease in the frequency of conspecific male interactions may simultaneously relax selection. In this way natural and sexual selection may conflate, resulting in the stasis observed in toepad lamellae.

Overall, our data support the hypothesis that interspecific interactions between A. sagrei and A. cristatellus in sympatry has driven ecological divergence in perch height. This has led to morphological shifts in A. sagrei driven by natural selection through adaptation to increased terrestriality, and a relaxation on sexually-important traits of A. cristatellus as the intraspecific social landscape is fragmented due to interspecific interactions.

\section{Alternative Explanations: Ecological Sorting and Phenotypic Plasticity}

It is possible that the patterns of ecomorphological divergence observed in this study are not the product character displacement driven by interspecific interactions. One alternative explanation for these patterns is ecological sorting, which can falsely lead one to identify character displacement when it has not occurred. Ecological sorting describes a phenomenon whereby two similar species can coexist if only those individuals of each species which are 
already phenotypically different are present. In this example, ecological sorting would describe a scenario whereby only those individuals that were already ecologically different in perch height (i.e., innately terrestrial $A$. sagrei and arboreal $A$. cristatellus) were able to coexist, rather than divergence arising in situ from interspecific interactions (i.e., ecological character displacement). This phenomenon would also lead to stable coexistence, and could also explain observed patterns ecomorphological differences between A. sagrei and A. cristatellus in sympatry.

I will now explain why I think ecological sorting is an unlikely explanation for the patterns observed in this study. In 1981, ca. 6 years after A. cristatellus and A. sagrei first came into contact in Miami FL, Salzburg (1984) conducted a removal experiment of A. cristatellus to test the behavioral response of $A$. sagrei immediately after its removal (site RR in this study). Prior to the removal of A. cristatellus, and consistent with our results, A. sagrei was frequently found on the ground. Following the removal of $A$. cristatellus, the proportion of adult male $A$. sagrei found on the ground significantly decreased as Salzburg recorded A. sagrei rapidly returning to elevated perches. This provides evidence that the phenotypes originally sympatric with A. cristatellus were not already pre-disposed to terrestriality and, given the removal of the biotic barrier imposed by A. cristatellus, rapidly returned to its preferred arboreal niche as observed in allopatry.

A second alternative for these patterns is phenotypic plasticity in habitat use. In 2011, 30 years after Salzburg's (1984) initial experiment, Losin (2012) again removed A. cristatellus from the same sympatric site (RR). In contrast to the previous results, there was no shift in habitat use of A. sagrei following the removal of A. cristatellus. This provides support for character displacement driving in situ co-evolution rather than phenotypic plasticity, as the population of $A$. sagrei appear to have now adapted in both habitat use (Losin 2012) and morphology (Fig. 4.5) to terrestriality. 
Lastly, it is possible that the morphological trait shifts recorded in this study are the results of phenotypic plasticity. We did not directly test whether morphological trait shifts in this study represent either adaptive evolution, involving a genetic component through heritability, or phenotypic plasticity. Similar studies which have addressed this question observed that toepad traits, including the number of lamellae (Stuart et al. 2014, Winchell et al. 2015), as well as head size (Muñoz \& Losos 2018) and limb dimensions (Thorpe et al. 2005, Calsbeek et al. 2006, 2007, 2008, Winchell et al. 2016), all have a genetically heritable basis. Although phenotypic plasticity in at least one trait (limb length; Losos 2000) cannot be conclusively ruled out, it is possible that the morphological trait shifts observed in A. sagrei (limb length and lamellae number) and $A$. cristatellus (head size) may also represent heritable patterns.

\section{Conclusion}

In summary, this study provides strong empirical support for the hypothesis that interspecific interactions between $A$. sagrei and A. cristatellus in sympatry leads to ecological character displacement in perch height. As a result of this, A. sagrei has evolved longer limbs and fewer toepad lamellae through adaptation to increased terrestriality, and A. cristatellus has evolved smaller head size as sexual selection is relaxed following intraspecific social network fragmentation, which is driven by interactions with A. sagrei. These results suggest that complex character displacement involving selection on both ecologically and sexually-important traits can be the result of multiple ecological and behavioural mechanisms. This study presents evidence to explain how ecological character displacement may be responsible for the evolution of a far greater extent of adaptive diversity than previously realized. 


\section{Acknowledgements}

JS was supported by FIU DEA and DYF Fellowships, and an NSF DDIG. Fairchild Tropical Botanic Garden were very helpful in facilitating this research.

\section{References}

Baldwin, J.M., 1896. A new factor in evolution. The American Naturalist, 30(354), pp.441-451.

Barrett, R.D. and Bell, G., 2006. The dynamics of diversification in evolving Pseudomonas populations. Evolution, 60(3), pp.484-490.

Bell, L.N., 1953. Notes on three subspecies of the lizard Anolis sagrei in southern Florida. Copeia, 1953(1), pp.63-63.

Brown, W.L. and Wilson, E.O., 1956. Character displacement. Systematic zoology, 5(2), pp.4964.

Butler, M.A. and Losos, J.B., 1997. Testing for unequal amounts of evolution in a continuous character on different branches of a phylogenetic tree using linear and squared-change parsimony: an example using Lesser Antillean Anolis lizards. Evolution, 51(5), pp.1623-1635.

Calsbeek, R., Bonneaud, C. and Smith, T.B., 2008. Differential fitness effects of immunocompetence and neighbourhood density in alternative female lizard morphs. Journal of Animal Ecology, 77(1), pp.103-109.

Calsbeek, R. and Irschick, D.J., 2007. The quick and the dead: correlational selection on morphology, performance, and habitat use in island lizards. Evolution, 61(11), pp.2493-2503.

Calsbeek, R., Knouft, J.H. and Smith, T.B., 2006. Variation in scale numbers is consistent with ecologically based natural selection acting within and between lizard species. Evolutionary Ecology, 20(4), pp.377-394.

Calsbeek, R. and Smith, T.B. (2007) Probing the adaptive landscape using experimental islands: density-dependent natural selection on lizard body size. Evolution 61, 1052-1061.

Campbell, T. S. (2000) Analyses of the effects of an exotic lizard (Anolis sagrei) on a native lizard (Anolis carolinensis) in Florida, using islands as experimental units. Ph.D.

Dissertation, University of Tennessee Knoxville.

Collette, B. B. 1961. Correlations between ecology and morphology in anoline lizards from Havana, Cuba and southern Florida. Bulletin of the Museum of Comparative Zoology 5:137-162.

Connell, J.H. (1961) The influence of interspecific competition and other factors on the distribution of the barnacle Chthamalus stellatus. Ecology 42, 710-723.

Croft, DP, James, R., \& Krause, J. 2008. Exploring animal social networks. Princeton University Press. 
Csardi G, Nepusz T: The igraph software package for complex network research, InterJournal, Complex Systems 1695. 2006. http://igraph.org

Darwin, C. (1859/2009). The annotated origin: A facsimile of the first edition of on the origin of species. J. T. Costa, annotator (1st ed.). Cambridge, MA: The Belknap Press of Harvard University Press.

Darwin, C. 1859. On the origin of species by natural selection. Murray, London. Diamond, J., 1975. Assembly of species communities. Ecology and evolution of communities, pp.342-344.

Futuyma DJ. 1998. Evolutionary Biology. Sunderland, MA: Sinauer. 3rd ed.

Gamble, T., Geneva, A.J., Glor, R.E. and Zarkower, D., 2014. Anolis sex chromosomes are derived from a single ancestral pair. Evolution, 68(4), pp.1027-1041.

Garland Jr, T. and Losos, J.B., 1994. Ecological morphology of locomotor performance in squamate reptiles. Ecological morphology: integrative organismal biology, pp.240-302.

Gelman, A. and Hill, J. (2007) Data analysis using regression and multilevel/hierarchical models, Cambridge University Press.

Germain, RM., 2018. Moving character displacement beyond characters using contemporary coexistence theory. Trends in Ecology \& Evolution,

DOI: http://dx.doi.org/10.1016/j.tree.2017.11.002.

Ghalambor, C.K., McKay, J.K., Carroll, S.P. and Reznick, D.N., 2007. Adaptive versus nonadaptive phenotypic plasticity and the potential for contemporary adaptation in new environments. Functional ecology, 21(3), pp.394-407.

Glossip, D., and Losos, J.B. 1997. Ecological correlates of number of subdigital lamellae in anoles. Herpetologica, 53:192-199.

Gotthard, K. and Nylin, S., 1995. Adaptive plasticity and plasticity as an adaptation: a selective review of plasticity in animal morphology and life history. Oikos, pp.3-17.

Grant, B.R. and Grant, P.R., 2008. Fission and fusion of Darwin's finches populations. Philosophical Transactions of the Royal Society B: Biological Sciences, 363(1505), pp.2821-2829.

Grant, P.R., 1972. Convergent and divergent character displacement. Biological journal of the Linnean Society, 4(1), pp.39-68.

Grant, P.R. and Grant, B.R., 2011. How and why species multiply: the radiation of Darwin's finches. Princeton University Press.

Grant, P.R. and Grant, B.R., 2014. 40 Years of Evolution: Darwin's Finches on Daphne Major Island. Princeton University Press.

Grether, G.F., Losin, N., Anderson, C.N. and Okamoto, K., 2009. The role of interspecific interference competition in character displacement and the evolution of competitor recognition. Biological Reviews, 84(4), pp.617-635. 
Grether, G.F., Peiman, K.S., Tobias, J.A. and Robinson, B.W., 2017. Causes and consequences of behavioral interference between species. Trends in ecology \& evolution.

Gvozdík, L. and Van Damme, R., 2003. Evolutionary maintenance of sexual dimorphism in head size in the lizard Zootoca vivipara: a test of two hypotheses. Journal of Zoology, 259(1), pp.7-13.

Hendry, A.P. and Kinnison, M.T., 1999. Perspective: the pace of modern life: measuring rates of contemporary microevolution. Evolution, 53(6), pp.1637-1653.

Herrel, A., McBrayer, L.D. and Larson, P.M., 2007. Functional basis for sexual differences in bite force in the lizard Anolis carolinensis. Biological Journal of the Linnean Society, 91(1), pp.111-119.

Herrel, A. and O’Reilly, J.C., 2005. Ontogenetic scaling of bite force in lizards and turtles. Physiological and Biochemical Zoology, 79(1), pp.31-42.

Hews, D.K., 1990. Examining hypotheses generated by field measures of sexual selection on male lizards, Uta palmeri. Evolution, 44(8), pp.1956-1966.

Husak, J.F., Kristopher Lappin, A., Fox, S.F. and Lemos-Espinal, J.A., 2006. Bite-force performance predicts dominance in male venerable collared lizards (Crotaphytus antiquus). Copeia, 2006(2), pp.301-306.

Hutchinson, G.E. 1959. Homage to Santa Rosalia, or why are there so many kinds of animals? American Naturalist, 93: 145-159.

Irschick, D.J. and Losos, J.B., 1998. A comparative analysis of the ecological significance of maximal locomotor performance in Caribbean Anolis lizards. Evolution, 52(1), pp.219-226.

Kamath, A. and Losos, J., 2017. The erratic and contingent progression of research on territoriality: a case study. Behavioral Ecology and Sociobiology, 71(6): 71-89.

Kassen, R., 2009. Toward a general theory of adaptive radiation. Annals of the New York Academy of Sciences, 1168(1), pp.3-22.

Kolbe, J.J., 2015. Effects of hind-limb length and perch diameter on clinging performance in Anolis lizards from the British Virgin Islands. Journal of Herpetology, 49(2), pp.284-290.

Kolbe, J.J., Glor, R.E., Schettino, L.R., Lara, A.C., Larson, A. and Losos, J.B., 2004. Genetic variation increases during biological invasion by a Cuban lizard. Nature, 431(7005), pp.177-181.

Kolbe, J.J. and Losos, J.B., 2005. Hind-limb length plasticity in Anolis carolinensis. Journal of Herpetology, 39(4), pp.674-678.

Kolbe, J.J., VanMiddlesworth, P., Battles, A.C., Stroud, J.T., Buffum, B., Forman, R.T. and Losos, J.B., 2016. Determinants of spread in an urban landscape by an introduced lizard. Landscape Ecology, 31(8), pp.1795-1813.

Kolbe, J.J., VanMiddlesworth, P.S., Losin, N., Dappen, N. and Losos, J.B., 2012. Climatic niche shift predicts thermal trait response in one but not both introductions of the Puerto Rican lizard Anolis cristatellus to Miami, Florida, USA. Ecology and Evolution, 2(7), pp.1503-1516. 
Lailvaux, S.P., Herrel, A., VanHooydonck, B., Meyers, J.J. and Irschick, D.J., 2004. Performance capacity, fighting tactics and the evolution of life-stage male morphs in the green anole lizard (Anolis carolinensis). Proceedings of the Royal Society of London B: Biological Sciences, 271(1556), pp.2501-2508.

Lappin, A.K. and Husak, J.F., 2005. Weapon performance, not size, determines mating success and potential reproductive output in the collared lizard (Crotaphytus collaris). The American Naturalist, 166(3), pp.426-436.

Lewin, R., 1983. Santa Rosalia was a goat. Science, 221(4611), pp.636-639.

Lister, B.C., 1976. The nature of niche expansion in West Indian Anolis lizards I: ecological consequences of reduced competition. Evolution, 30(4), pp.659-676.

López, P., Muñoz, A. and Martín, J., 2002. Symmetry, male dominance and female mate preferences in the Iberian rock lizard, Lacerta monticola. Behavioral Ecology and Sociobiology, 52(4), pp.342-347.

Losos, J., 1985. Male aggressive behavior in a pair of sympatric sibling species. Breviora, 484: 130.

Losos, J.B., 1990a. Ecomorphology, performance capability, and scaling of West Indian Anolis lizards: an evolutionary analysis. Ecological Monographs, 60(3), pp.369-388.

Losos, J.B., 1990b. The evolution of form and function: morphology and locomotor performance in West Indian Anolis lizards. Evolution, 44(5), pp.1189-1203.

Losos, J.B., 1990c. A phylogenetic analysis of character displacement in Caribbean Anolis lizards. Evolution, 44(3), pp.558-569.

Losos, J.B., 2000. Ecological character displacement and the study of adaptation. Proceedings of the National Academy of Sciences, 97(11), pp.5693-5695.

Losos, J.B., 2009. Lizards in an evolutionary tree: ecology and adaptive radiation of anoles (Vol. 10). Univ. of California Press.

Losos, J.B., Creer, D.A., Glossip, D., Goellner, R., Hampton, A., Roberts, G., Haskell, N., Taylor, P. and Ettling, J., 2000. Evolutionary implications of phenotypic plasticity in the hindlimb of the lizard Anolis sagrei. Evolution, 54(1), pp.301-305.

Losos, J.B. and Mahler, D.L., 2010. Adaptive radiation: the interaction of ecological opportunity, adaptation, and speciation. Evolution since Darwin: the first, 150, pp.381-420.

Losos, J.B. and Sinervo, B., 1989. The effects of morphology and perch diameter on sprint performance of Anolis lizards. Journal of Experimental Biology, 145(1), pp.23-30.

MacArthur, R.H. (1958) Population ecology of some warblers of Northeastern coniferous forests. Ecology 39, 599-619.

Macrini, T.E. and Irschick, D.J., 1998. An intraspecific analysis of trade-offs in sprinting performance in a West Indian lizard species (Anolis lineatopus). Biological Journal of the Linnean Society, 63(4), pp.579-591. 
Measey, G.J., Rebelo, A.D., Herrel, A., Vanhooydonck, B. and Tolley, K.A., 2011. Diet, morphology and performance in two chameleon morphs: do harder bites equate with harder prey? Journal of Zoology, 285(4), pp.247-255.

Miles, D.B. and Dunham, A.E., 1996. The paradox of the phylogeny: character displacement of analyses of body size in island Anolis. Evolution, 50(2), pp.594-603.

Muñoz, M.M. and Losos, J.B., 2018. Thermoregulatory Behavior Simultaneously Promotes and Forestalls Evolution in a Tropical Lizard. The American Naturalist, 191(1), pp.E000-E000.

Olsson, M. and Madsen, T., 1995. Female choice on male quantitative traits in lizards-why is it so rare? Behavioral Ecology and Sociobiology, 36(3), pp.179-184.

Ortiz, P.R. and Jenssen, T.A., 1982. Interspecific aggression between lizard competitors, Anolis cooki and Anolis cristatellus. Ethology, 60(3), pp.227-238.

Pfennig, D.W. and Martin, R.A., 2009. A maternal effect mediates rapid population divergence and character displacement in spadefoot toads. Evolution, 63(4), pp.898-909.

Pfennig, D.W. and Pfennig, K.S., 2012. Evolution's wedge: competition and the origins of diversity (No. 12). Univ. of California Press.

Pfennig, D.W., Wund, M.A., Snell-Rood, E.C., Cruickshank, T., Schlichting, C.D. and Moczek, A.P., 2010. Phenotypic plasticity's impacts on diversification and speciation. Trends in ecology \& evolution, 25(8), pp.459-467.

Pinheiro J, Bates D, DebRoy S, Sarkar D and R Core Team (2017). nlme: Linear and Nonlinear Mixed Effects Models. R package version 3.1-131, https://CRAN.R-project.org/package=nlme

Roughgarden, J., 1983. Competition and theory in community ecology. The American Naturalist, 122(5), pp.583-601.

Rummel, J.D. and Roughgarden, J., 1985. Effects of reduced perch-height separation on competition between two Anolis lizards. Ecology, 66(2), pp.430-444.

Salzburg, M.A., 1984. Anolis sagrei and Anolis cristatellus in southern Florida: a case study in interspecific competition. Ecology, 65(1), pp.14-19.

Schluter, D., 2000. The ecology of adaptive radiation. OUP Oxford.

Schmalhausen, I.I., 1949. Factors of evolution: the theory of stabilizing selection.

Schoener, T.W., 1974. Resource partitioning in ecological communities. Science, 185(4145), pp.27-39.

Schoener, T.W., 1975. Presence and absence of habitat shift in some widespread lizard species. Ecological Monographs, 45(3), pp.233-258.

Schoener, T.W., 1977. Competition and the niche. Biology of the Reptilia, 7, pp.35-136.

Simberloff, D. and Boecklen, W., 1981. Santa Rosalia reconsidered: size ratios and competition. Evolution, 35(6), pp.1206-1228.

Simpson, G.G., 1953. The baldwin effect. Evolution, 7(2), pp.110-117. 
Strong, D.R., Szyska, L.A. and Simberloff, D.S., 1979. Tests of community-wide character displacement against null hypotheses. Evolution, 33(3), pp.897-913.

Stroud, J.T., Giery, S.T. and Outerbridge, M.E., 2017. Establishment of Anolis sagrei on Bermuda represents a novel ecological threat to Critically Endangered Bermuda skinks (Plestiodon longirostris). Biological Invasions, 19(6), pp.1723-1731.

Stuart, Y. 2013. Character displacement and community assembly in Anolis lizards. PhD Dissertation, Harvard University.

Stuart, Y.E., Inkpen, S.A., Hopkins, R. and Bolnick, D.I., 2017. Character displacement is a pattern: so, what causes it? Biological Journal of the Linnean Society, p.blx013.

Stuart, Y.E. and Losos, J.B., 2013. Ecological character displacement: glass half full or half empty? Trends in ecology \& evolution, 28(7), pp.402-408.

Thomas L, Buckland ST, Rexstad EA, Laake JL, Strindberg S, Hedley SL, Bishop JRB, Marques TA, Burnham KP (2010) Distance software: design and analysis of distance sampling surveys for estimating population size. Journal of Applied Ecology 47: 5-14.

Thorpe, R.S., Reardon, J.T. and Malhotra, A., 2005. Common garden and natural selection experiments support ecotypic differentiation in the Dominican anole (Anolis oculatus). The American Naturalist, 165(4), pp.495-504.

Tyerman, J.G., Bertrand, M., Spencer, C.C. and Doebeli, M., 2008. Experimental demonstration of ecological character displacement. BMC Evolutionary Biology, 8(1), p.34.

Waddington, C.H., 1953. The "Baldwin effect”, "genetic assimilation” and "homeostasis”. Evolution, 7(4), pp.386-387.

Waddington, C.H., 1953. Genetic assimilation of an acquired character. Evolution, 7(2), pp.118126.

West-Eberhard, M.J., 1989. Phenotypic plasticity and the origins of diversity. Annual review of Ecology and Systematics, 20(1), pp.249-278.

While, G.M., Michaelides, S., Heathcote, R.J., MacGregor, H.E., Zajac, N., Beninde, J., Carazo, P., Pérez i de Lanuza, G., Sacchi, R., Zuffi, M.A. and Horváthová, T., 2015. Sexual selection drives asymmetric introgression in wall lizards. Ecology letters, 18(12), pp.1366-1375.

Wiens, J.A., 1977. On Competition and Variable Environments: Populations may experience" ecological crunches" in variable climates, nullifying the assumptions of competition theory and limiting the usefulness of short-term studies of population patterns. American Scientist, 65(5), pp.590-597.

Winchell, K.M., Reynolds, R.G., Prado-Irwin, S.R., Puente-Rolón, A.R. and Revell, L.J., 2016. Phenotypic shifts in urban areas in the tropical lizard Anolis cristatellus. Evolution, 70(5), pp.1009-1022.

Wund, M.A. 2012. Assessing the Impacts of Phenotypic Plasticity on Evolution. Integrative and Comparative Biology, 52(1): 5-15. 
Table SM4.1. Perch height and morphology. Sample sizes and basic summary statistics by site (and per treatment) for perch height and morphological analyses and allopatric vs. sympatric A. sagrei and A. cristatellus.

\begin{tabular}{|c|c|c|c|c|c|c|}
\hline Species & Treatment & Site & No. lizards & $\begin{array}{l}\text { Perch height } \\
\text { (mean; cm) }\end{array}$ & St. Err & $\begin{array}{l}\text { No. lizards } \\
\text { (morphology) }\end{array}$ \\
\hline \multirow[t]{4}{*}{ Anolis sagrei } & Allopatric & Total & 381 & 68.10 & & 127 \\
\hline & & FIU & 167 & 62.92 & 3.42 & 44 \\
\hline & & BP & 107 & 67.27 & 3.83 & 39 \\
\hline & & KP & 107 & 74.12 & 4.44 & 44 \\
\hline \multirow[t]{4}{*}{ Anolis sagrei } & Sympatric & Total & 242 & 49.67 & & 115 \\
\hline & & RR & 53 & 39.69 & 5.91 & 23 \\
\hline & & $\mathrm{BD}$ & 49 & 56.40 & 6.27 & 39 \\
\hline & & MHS & 140 & 52.91 & 5.64 & 53 \\
\hline \multirow[t]{4}{*}{ Anolis cristatellus } & Sympatric & Total & 205 & 134.73 & & 107 \\
\hline & & RR & 47 & 157.26 & 12.13 & 29 \\
\hline & & $\mathrm{BD}$ & 54 & 109.61 & 12.47 & 41 \\
\hline & & MHS & 104 & 137.32 & 8.41 & 37 \\
\hline \multirow[t]{4}{*}{ Anolis cristatellus } & Allopatric & Total & 357 & 70.94 & & 104 \\
\hline & & BAR & 63 & 50.54 & 6.42 & 46 \\
\hline & & KA & 73 & 79.32 & 7.86 & 24 \\
\hline & & MHA & 221 & 82.96 & 4.18 & 34 \\
\hline
\end{tabular}


Table SM4.2. Diet. Sample sizes of number of lizards (and number of resulting prey items) by site (and per treatment) in allopatric vs. sympatric $A$. sagrei and A. cristatellus.

\begin{tabular}{lllrr}
\hline Species & Treatment & Site & No. lizards & No. prey items \\
\hline Anolis sagrei & Allopatric & Total & $\mathbf{3 5}$ & $\mathbf{1 8 8}$ \\
& & FIU & 13 & 27 \\
& & BP & 12 & 119 \\
Anolis sagrei & Sympatric & Total & 10 & 42 \\
& & RR & 9 & $\mathbf{1 1 4}$ \\
& & BD & 12 & 35 \\
Anolis cristatellus & \multirow{2}{*}{ Sympatric } & MHS & 10 & 34 \\
& & Total & $\mathbf{3 5}$ & 45 \\
& & RR & 9 & $\mathbf{1 5 0}$ \\
Anolis cristatellus & Allopatric & BD & 15 & 41 \\
& & MHS & 11 & 77 \\
& & Botal & $\mathbf{3 0}$ & 32 \\
& & KIH & 10 & $\mathbf{1 1 0}$ \\
& & MHA & 10 & 41 \\
& & & 32 \\
\hline
\end{tabular}


Table SM4.3. Movement behavior. Sample sizes and basic summary statistics of number of lizards and length of observation by site (and per treatment) in allopatric vs. sympatric A. sagrei and A. cristatellus.

\begin{tabular}{lllccc}
\hline \multirow{2}{*}{ Species } & Treatment & Site & $\begin{array}{c}\text { No. } \\
\text { lizards }\end{array}$ & $\begin{array}{c}\text { Observation time } \\
\text { (cumulative; mins) }\end{array}$ & $\begin{array}{c}\text { Observation time } \\
\text { (mean; mins) }\end{array}$ \\
\hline Anolis sagrei & Allopatric & Total & $\mathbf{8 9}$ & $\mathbf{1 2 7 9}$ & $\mathbf{1 4 . 3 6}$ \\
& & FIU & 28 & 389 & 13.89 \\
& & BP & 30 & 440 & 14.67 \\
Anolis sagrei & KP & 31 & 450 & 14.52 \\
& Sympatric & Total & $\mathbf{8 9}$ & $\mathbf{1 3 2 9}$ & $\mathbf{1 4 . 9 4}$ \\
& & RR & 30 & 446 & 14.87 \\
Anolis cristatellus & Sympatric & Total & $\mathbf{9 0}$ & $\mathbf{1 3 4 2}$ & 15.38 \\
& & RR & 30 & 444 & 14.57 \\
& & BD & 30 & 454 & 14.91 \\
Anolis cristatellus & Allopatric & Total & $\mathbf{9 0}$ & $\mathbf{1 2 8 3}$ & 15.13 \\
& & BAR & 30 & 428 & 14.80 \\
& & KA & 30 & 417 & 14.26 \\
& & MHA & 30 & 438 & 13.90 \\
& & & & & 14.60 \\
\hline
\end{tabular}


Table SM4.4. Maximal model estimates of repeated measures GLM investigating the effect of interspecific interactions on intraspecific sociality. Only $p$-values obtained from permutations of observed coefficients against 10,000 randomized coefficients from optimal models are shown (see Methods for details of model optimization).

\begin{tabular}{|c|c|c|c|c|c|}
\hline Species & \multicolumn{3}{|c|}{ Coefficient } & \multirow[t]{2}{*}{$t$} & \multirow[t]{2}{*}{$p$-value } \\
\hline A. cristatellus & & & & & \\
\hline Interspecific interactions & 0.870 & \pm & 1.751 & 0.50 & $<0.001$ \\
\hline Sex & 3.643 & \pm & 2.979 & 1.22 & \\
\hline SVL & 0.067 & \pm & 0.054 & 1.25 & 0.068 \\
\hline Sex*SVL & -0.074 & \pm & 0.060 & -1.24 & \\
\hline Interspecific interactions*Sex & -0.107 & \pm & 3.844 & -0.03 & \\
\hline Interspecific interactions*SVL & -0.026 & \pm & 0.037 & -0.68 & \\
\hline Interspecific interactions*Sex*SVL & 0.011 & \pm & 0.063 & 0.18 & \\
\hline \multicolumn{6}{|l|}{ A. sagrei } \\
\hline Interspecific interactions & 0.569 & \pm & 6.876 & 0.40 & \\
\hline Sex & 10.113 & \pm & 9.720 & 1.04 & \\
\hline SVL & -0.037 & \pm & 0.150 & -0.24 & \\
\hline Sex*SVL & -0.165 & \pm & 0.191 & -0.87 & \\
\hline Interspecific interactions*Sex & -4.370 & \pm & 5.996 & -0.73 & \\
\hline Interspecific interactions*SVL & -0.017 & \pm & 0.109 & -0.16 & \\
\hline Interspecific interactions*Sex*SVL & 0.081 & \pm & 0.123 & 0.66 & \\
\hline \multicolumn{6}{|l|}{ Both species } \\
\hline Interspecific interactions & -1.900 & \pm & 2.913 & -0.65 & $<0.001$ \\
\hline Sex & 3.643 & \pm & 3.460 & 1.05 & 0.039 \\
\hline SVL & 0.067 & \pm & 0.063 & 1.07 & \\
\hline Species & 4.638 & \pm & 6.536 & 1.05 & \\
\hline Sex*SVL & -0.074 & \pm & 0.069 & -1.07 & \\
\hline Sex*Species & 6.471 & \pm & 8.963 & 0.72 & \\
\hline SVL*Species & -0.103 & \pm & 0.142 & -0.73 & \\
\hline Interspecific interactions*Sex & -0.107 & \pm & 4.465 & -0.02 & \\
\hline Interspecific interactions*SVL & -0.025 & \pm & 0.043 & -0.59 & \\
\hline Interspecific interactions*Species & -0.302 & \pm & 4.693 & -0.06 & \\
\hline Interspecific interactions*Sex*SVL & 0.011 & \pm & 0.073 & 0.15 & \\
\hline Interspecific interactions*Sex*Species & -4.264 & \pm & 6.781 & -0.63 & \\
\hline Interspecific interactions*SVL*Species & 0.008 & \pm & 0.102 & 0.08 & \\
\hline Sex*SVL*Species & -0.091 & \pm & 0.176 & -0.52 & \\
\hline Interspecific interactions*Sex*SVL*Species & 0.070 & \pm & 0.128 & 0.55 & \\
\hline
\end{tabular}




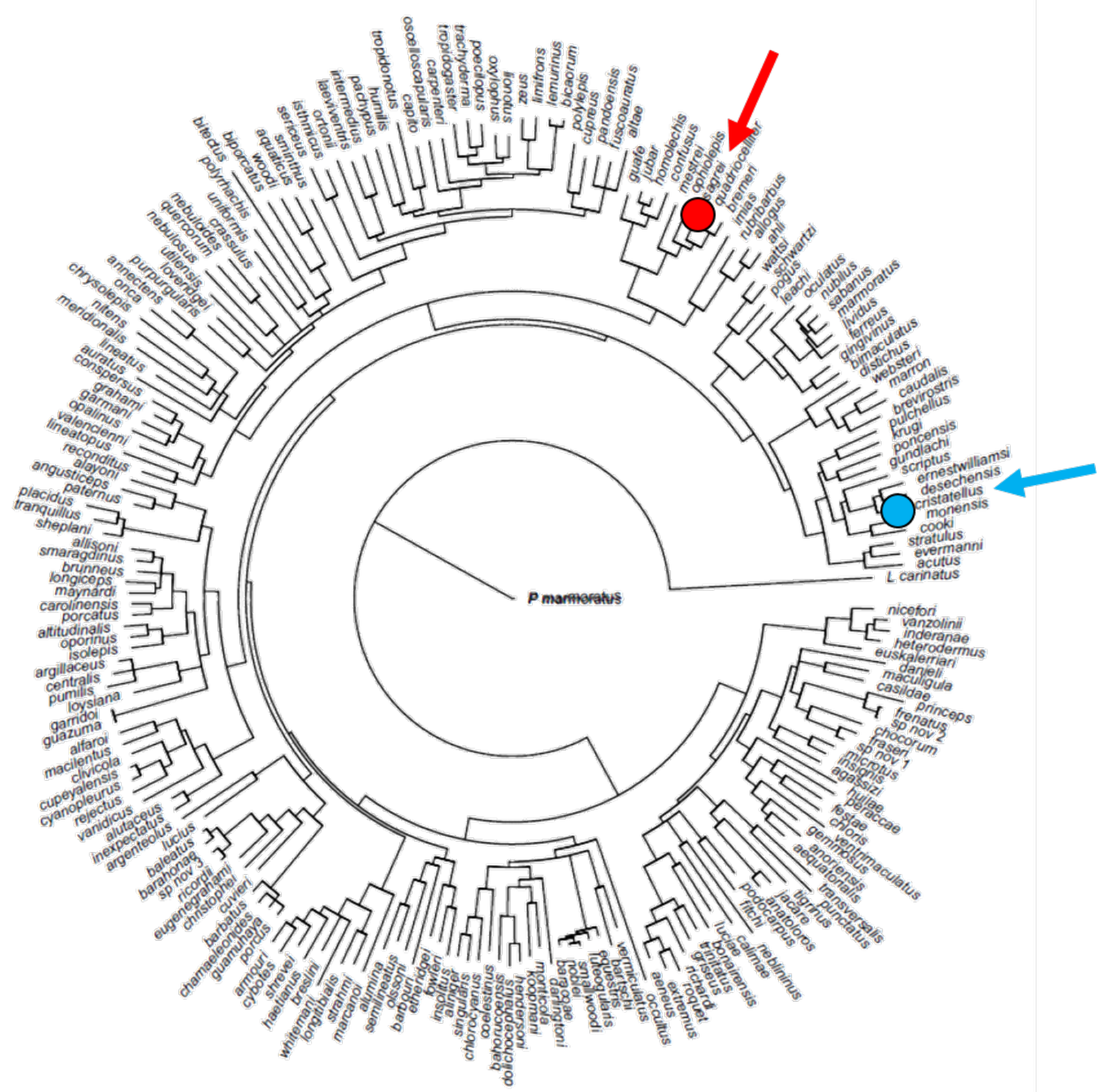

Figure SM4.1. Phylogenetic relationship of Anolis sagrei (red arrow) and A. cristatellus (blue arrow); A. sagrei and A. cristatellus are diverged by ca. 45-50my. Phylogeny produced from Gamble et al. 2014. 
CHAPTER V

\section{ESTABLISHMENT OF ANOLIS SAGREI ON BERMUDA REPRESENTS A NOVEL ECOLOGICAL THREAT TO CRITICALLY ENDANGERED BERMUDA SKINKS (PLESTIODON LONGIROSTRIS)}

Stroud, J.T., Giery, S.T., Outerbridge, M.E. (2017) Establishment of Anolis sagrei on Bermuda represents a novel ecological threat to Critically Endangered Bermuda skinks (Plestiodon longirostris). Biological Invasions, 19: 1723-1731 


\section{ABSTRACT}

Bermuda is an isolated, oceanic island with only one endemic terrestrial vertebrate, the Critically Endangered Bermuda skink (Plestiodon longirostris; Squamata, Scincidae). Major declines in P. longirostris populations have been caused primarily by habitat loss and mortality via invasive species (e.g., predation from birds and cats) and human waste products (e.g., trapped in discarded bottles). However, biotic interactions and interspecific competition with invasive lizards have also been identified as potentially detrimental to $P$. longisrostris populations. Here, we provide the first occurrence records of a highly invasive lizard, the Cuban brown anole (A. sagrei), on Bermuda. We assess the brown anole’s diet, habitat use, morphology, and island-wide distribution for comparison to the native skink, $P$. longirostris. Results of this study indicate that A. sagrei in Bermuda are highly terrestrial ( $>60 \%$ of all lizards observed on the ground vs. in trees) and forage primarily on terrestrial invertebrates. These data indicate substantial ecological overlap with the exclusively-terrestrial P. longirostris. This is in contrast to the other established non-native lizards on Bermuda, which are principally arboreal and have successfully coexisted with $P$. longirostris for $>60$ years. At present, the geographic distributions of $A$. sagrei and $P$. longirostris do not overlap. However, all extant skink populations are within several kilometers of brown anole populations (with the nearest being $<0.5 \mathrm{~km}$ ). The extensive overlap in ecological niche between the Bermuda skink and the invasive brown anole will likely present a serious conservation threat if contact is made. This study is exceptional in providing clear in situ ecological data which predict a conservation threat of an established invasive species to a Critically Endangered island endemic prior to coexistence. Continued monitoring of this situation as $P$. longirostris and $A$. sagrei inevitably come into contact will allow these $a$ priori hypotheses of conservation risk via ecological overlap to be tested. 


\section{INTRODUCTION}

Understanding how introduced species interact with native species is a primary conservation issue (Powell et al. 2011). The introduction of non-native species can increase the extinction vulnerability of native species if they represent novel sources of competition, predation, or disease. These biotic interactions are particularly concerning for native species already considered vulnerable to extinction due to other factors. Many island endemics, in particular, face heightened extinction risks due to a combination of threats such as low genetic diversity, overexploitation, and habitat loss and fragmentation (Sodhi et al. 2009). From an evolutionary perspective, island endemics are at a further disadvantage as they are often considered to be competitively inferior relative to invasive species derived from more diverse communities (Simberloff 1995).

Here we report the first official records of a highly invasive vertebrate, the Cuban brown anole (Anolis sagrei; Fig. 5.1) on Bermuda. In addition to documenting the establishment of this invasive species, the purpose of this study was to estimate the potential impact of the A. sagrei invasion on the Critically Endangered Bermuda skink ( $P$. longirostris), prior to contact between the two species. Risk assessments of newly established non-native species is an integral yet often overlooked aspect of invasion biology (Andersen et al. 2004). Commonly, invasive species management is reactionary with risk management being used in place of risk assessment. Management protocols are only implemented following perceived or observed negative effects of invasives on native species or ecosystems. However, reactive management can be expensive, ineffective, and extremely difficult to successfully complete (Davies and Johnson 2011). Because we have detected this invasion in its initial stages, whereby a non-native species is established but contact with a vulnerable endemic has not yet been made, we designed our study to capitalize on this opportunity. 


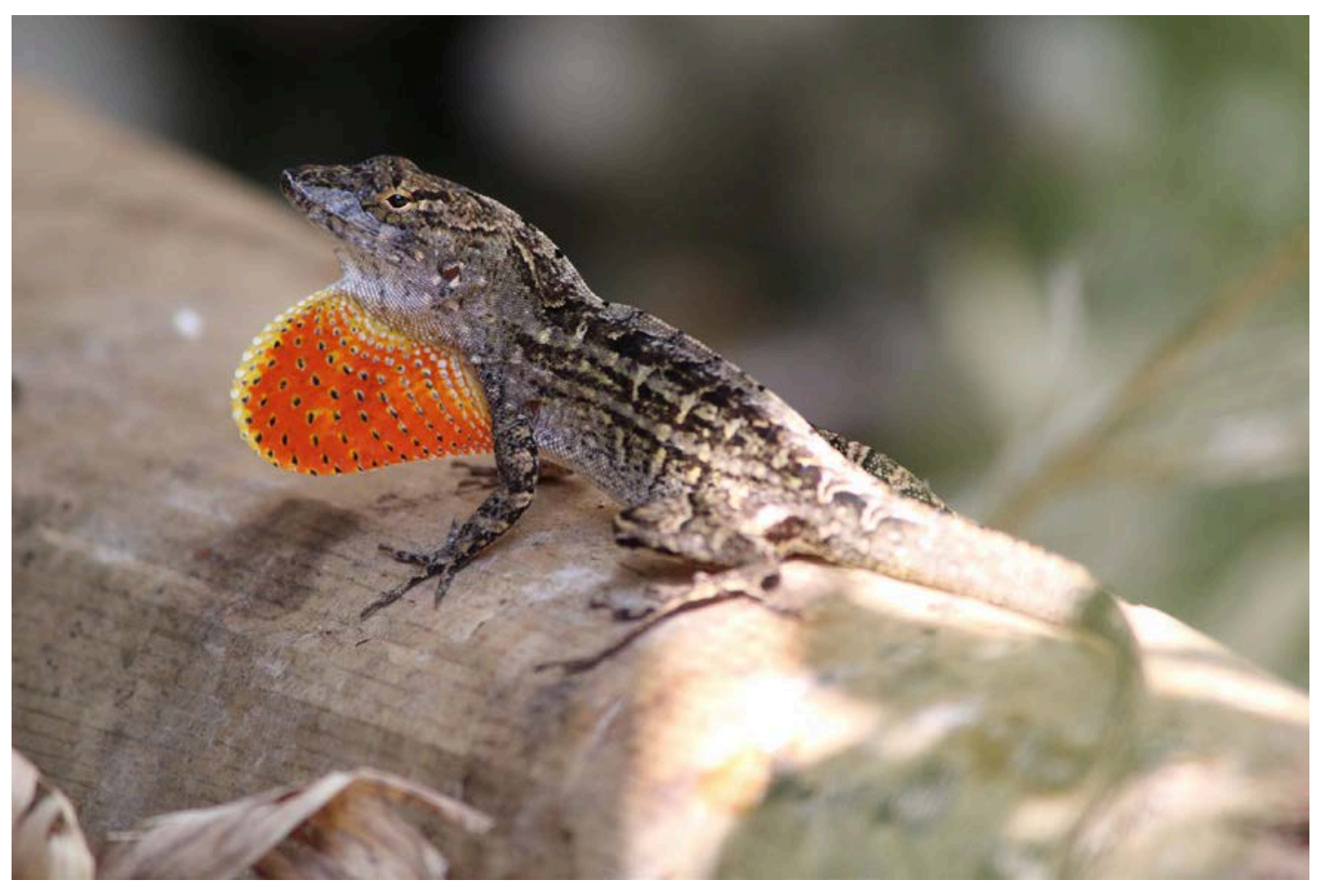

Figure 5.1. Adult male Cuban brown anole (A. sagrei) in Bermuda with an extended dewlap during a signal display: this species is easily distinguishable from other established Anolis lizards on Bermuda by a brown dorsal pattern and red coloration of the dewlap. Photo: JStroud.

First, we estimate the degree of potential competitive interference between A. sagrei and $P$. longirostris by assessing ecological overlap in structural habitat use and diet. To estimate the uniqueness of the threat posed by A. sagrei we compare these same ecological niche axes between A. sagrei and the three other established non-native Anolis on Bermuda. We then examine the degree of morphological overlap between $A$. sagrei and $P$. longirostris as a proxy of both competitive and predatory interaction potential. Finally, we use ecological theory and published data to develop predictions regarding the likely conservation threat $A$. sagrei poses to P. longirostris if spread continues and contact is made. 


\section{METHODS}

Bermuda is a small, isolated oceanic island $\left(32.30^{\circ} \mathrm{N},-64.78^{\circ} \mathrm{W} ; 5,500\right.$ ha total land area) located in the western North Atlantic, ca. 960km east of North Carolina, USA, with only one endemic terrestrial vertebrate, the Critically Endangered Bermuda skink (Plestiodon (syn Eumeces) longirostris) (Bacon et al. 2006, IUCN 2015). Bermuda does, however, have a rich and well-documented history of non-native lizard introductions. In 1905, Graham’s anoles (A. grahami) were purposefully introduced from Jamaica as a biological control of crop-destroying scale insects (Carulaspos minima) (Wingate 1965). Despite the quick establishment, high population density, and rapid expansion of A. grahami in Bermuda, biological control of the pest insect was unsuccessful as they were rarely eaten. Great kiskadee flycatchers (Pitangus sulphuratus) were subsequently introduced in 1957 to control A. grahami populations, and in a classic case of conservation mismanagement, both species (Great kiskadees and Graham’s anoles) have subsequently flourished and have been observed predating native fauna, including Bermuda skinks (Davenport et al. 2001, Bacon et al. 2006). In the 1940’s two additional Anolis species were introduced, albeit this time unintentionally: first, the Antiguan marbled anole (A. leachii; known locally as "the Warwick lizard”) was observed in Central Bermuda, and second, the Barbados painted anole (A. extremus) was recorded from Sandy’s Parish in north-west Bermuda (Losos 1996). All three anoles are successfully established on Bermuda and, as of 2015, at least two species (A. grahami and A. leachii) are found throughout the island. A single specimen of a fifth species, the American green anole (A. carolinensis) has been recorded, but as no subsequent individuals have been located it is assumed to be an isolated event and does not represent the species’ presence on Bermuda (Stroud et al. 2016).

Anolis sagrei is a small ( 40-60mm snout-vent length [SVL]), predominantly terrestrial lizard with a generalist invertebrate diet (Schoener 1968, Giery et al. 2014). Native to Cuba and 
the Bahamas, A. sagrei is also an extremely successful and aggressive invasive species with longestablished, rapidly expanding populations in the USA (Florida, Georgia, Alabama, Louisiana, Texas, and California), the Caribbean (Grand Cayman, Grenada, Barbados, Turks \& Caicos, and Jamaica), Pacific islands (Hawaii and Taiwan), Costa Rica, and Singapore (Kolbe et al. 2007). In its non-native range $A$. sagrei competes with native lizard species leading to substantial population declines, as well as shifts in resource use and spatial ecology, of the native species (Stuart et al. 2014).

Suspected populations of A. sagrei were known to the Bermuda Department of Environment and Natural Resources since 2013 (J. Macedonia pers comms). On 16 August 2014 we confirmed the presence of $A$. sagrei in Paget Parish (hereafter Site A: $32.290^{\circ} \mathrm{N},-64.771^{\circ} \mathrm{W}$ ). Subsequently, from 17-31 Aug 2014 and 17-30 Aug 2015 we conducted extensive visual surveys of 114 sites including several offshore islands in order to map the distribution of A. sagrei throughout Bermuda. We recorded microhabitat use, specifically perch height (cm) (i.e. the vertical distance from ground of the observed lizard), to provide ecological comparisons between A. sagrei and other introduced Anolis lizards. To do this we haphazardly collected data on all other species throughout both 2014 and 2015 research trips at multiple sites across Bermuda. In 2015 we discovered an additional geographically distinct population of A. sagrei in Hamilton Parish (hereafter Site B: $32.299^{\circ} \mathrm{N},-64.792^{\circ} \mathrm{W} ; 22$ August 2015). A distance transect survey was conducted at site A in 2015 whereby the distance of all observed lizards from the transect allows estimations of population density and size to be calculated. The transect totaled 466 meters in length and covered both core and peripheral areas of the A. sagrei population. Estimates of population density and size using this method were calculated using the program Distance (Thomas et al. 2010). 
To assess morphology and diet of A. sagrei, we collected 63 individuals from Site A (32 males, 31 females), and 25 individuals from Site B (20 males, 5 females) during August 2015 (total N=88). Lizards were caught using dental floss nooses attached to Cabela's panfish poles and euthanized. Stomach contents were analyzed under a dissection microscope (10-60x magnification) and identified to the lowest taxonomic level possible. Reproductive state (gravidity) of mature females (SVL >34mm; Norval et al. 2010) was assessed during dissection. Plestiodon longirostris specimens were not collected for diet analysis as populations are vulnerable and highly protected (Level 1, Bermuda Protected Species Act 2012); diet data for $P$. longirostris were supplied by the Bermuda Department of Environment and Natural Resources, and morphology data taken from Raine (1998). General body size comparisons of A. sagrei vs. P. longirostris were assessed by regressing SVL (mm) to mass (g).

\section{RESULTS}

During island-wide surveys, we identified two geographically distinct populations of $A$. sagrei in Bermuda (Fig. 5.2). At both sites, A. sagrei occurred at high densities and individuals of all age classes were recorded (i.e., hatchlings and reproductively-mature adults). Conversations with a resident of Site A revealed the population has been established and reproducing since at least 2011 and has grown substantially (Trent Garner pers. comms.). All adult female A. sagrei collected from both sites in this study $(\mathrm{n}=36)$ were gravid (smallest gravid female $=37.5 \mathrm{~mm}$ SVL). We recorded range expansion of A. sagrei at Site A of 50m between 2014 and 2015 sampling expeditions. Distance transect data generated an estimated population density of 1 individual per $10 \mathrm{~m}^{2}(\mathrm{SE}=-0.06)$ which, given the current distribution of $A$. sagrei at Site A ( 2.27ha), results in a population estimate of $2274+/-134$ individuals. If our density estimate of Site A is representative of the population at Site B (as suspected based on personal observations), 
then we estimate that population B ( 2.5ha) also supports >2000 individuals. Taken together, a coarse but conservative estimate of the total number of A. sagrei on Bermuda is therefore ca. 4000-5000 individuals.

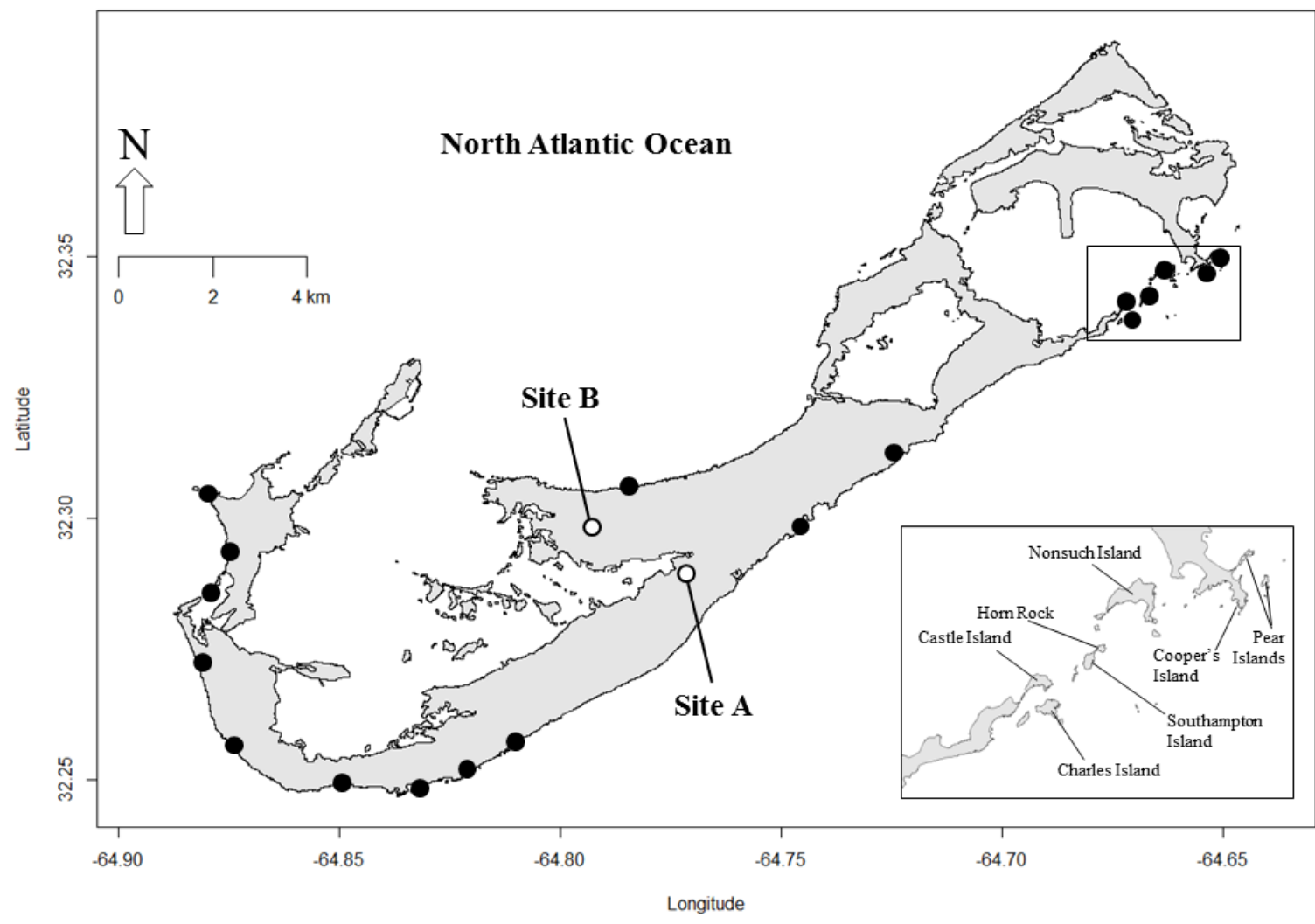

Figure 5.2. The current distribution of Bermuda skinks ( $P$. longirostris: black circles) and the recently discovered Cuban brown anole (A. sagrei: white circles) populations. All islands labelled in the inset have established $P$. longirostris populations. Skink population data are the most up-todate available from the Bermuda Department of Environment and Natural Resources.

Our assessment of structural habitat use of $A$. sagrei on Bermuda revealed that they are highly terrestrial ( $>60 \%$ of individuals observed on the ground), especially compared to other Anolis species established on Bermuda which are all predominantly arboreal (Fig. 5.3). Adult male $A$. sagrei perched higher (mean $=32.2 \mathrm{~cm}, \mathrm{SE}=4.7 \mathrm{~cm}, \mathrm{n}=92$ ) than both adult females (mean $14.2 \mathrm{~cm}, \mathrm{SE}=3.0 \mathrm{~cm}, \mathrm{n}=63$ ) and juveniles (mean $=3.9 \mathrm{~cm}, \mathrm{SE}=1.4 \mathrm{~cm}, \mathrm{n}=42$ ). Plestiodon 
longirostris are almost exclusively terrestrial but will occasionally perch on substrates low to the ground (i.e. $<10 \mathrm{~cm}$ ) (Wingate 1965, Bacon et al. 2006). These results suggest a high structural habitat overlap of $A$. sagrei with $P$. longirostris of all age and size classes, and detailed assessments of morphology reveal a considerable size overlap of adult $A$. sagrei with young $P$. longirostris (Fig 5.4).

Plestiodon longirostris primarily consume terrestrial and leaf-litter arthropods (L. Kitson unpub. data). Wingate (1965) and Verrill (1902) noted that ants (Formicidae) specifically Pheidole megacephala - and woodlice (Isopoda) comprised the greatest proportion of the skink's diet. The marine amphipod Platorchestia platensis (formerly Orchestia agilis) were observed in the stomachs of skinks collected near the coast (Verrill 1902). Additionally, $P$. longirostris opportunistically scavenge on a variety of non-arthropod food items (e.g., broken seabird eggs, carrion, cactus fruit (Opuntia sp.)) (Davenport et al. 2001).

We identified 558 individual food items of 17 different Orders in the stomachs of $63 \mathrm{~A}$. sagrei (Table 5.1). Our results show that $A$. sagrei on Bermuda are generalist consumers of terrestrial arthropods. Ants (Formicidae) contributed a substantial proportion (71.3\%) of total prey items, but lepidopterans (5.9\%), homopterans (5.0\%), coleopterans (4.3\%), and hemipterans (4.3\%) were also frequently recorded. Both Pheidole megacephalus and Platorchestia platensis the only prey items of Bermuda skinks identified to species in previous studies (Verril 1902, Wingate 1965) - were found in the stomachs of A. sagrei. There were no major differences in diet between adult males and females. Two cases of cannibalism by A. sagrei were recorded; once by an adult male (found perched $1.9 \mathrm{~m}$ from the ground) and once by an adult female (found on the ground).

Overall there was an extremely high dietary overlap between the A. sagrei investigated in this study and published stomach contents of P. longirostris. Specifically, 80.8\% of Arthropod 
Orders recorded in the stomach of $A$. sagrei in this study are known prey items of $P$. longirostris (Table 1).
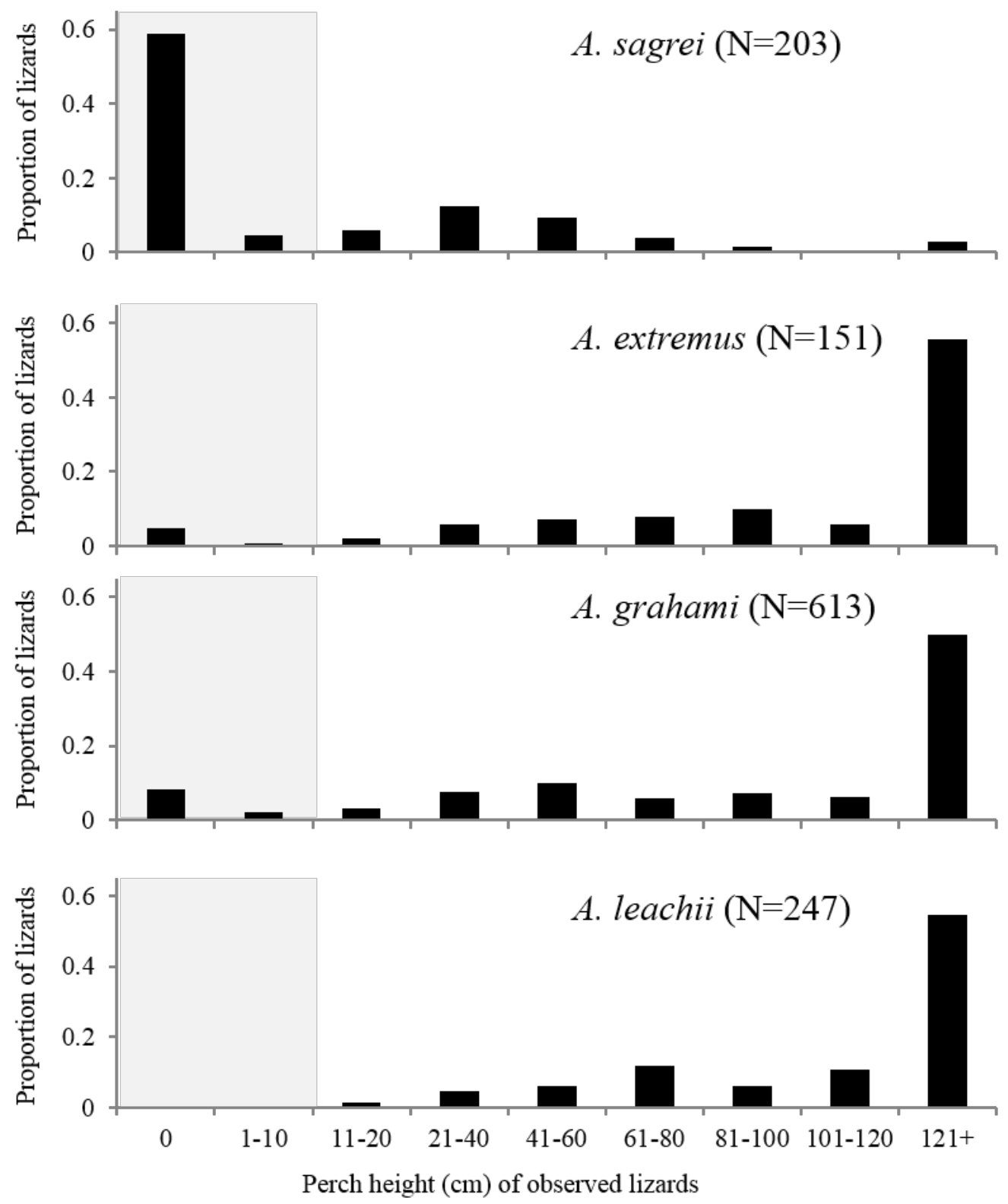

Figure 5.3. Proportional habitat use of Anolis lizards established on Bermuda. Grey areas indicated high terrestriality (lizards observed $0-10 \mathrm{~cm}$ from the ground) which Bermudian skinks (Plestiodon longirostris) solely utilize. Data are combined for all mature individuals of both sexes. 


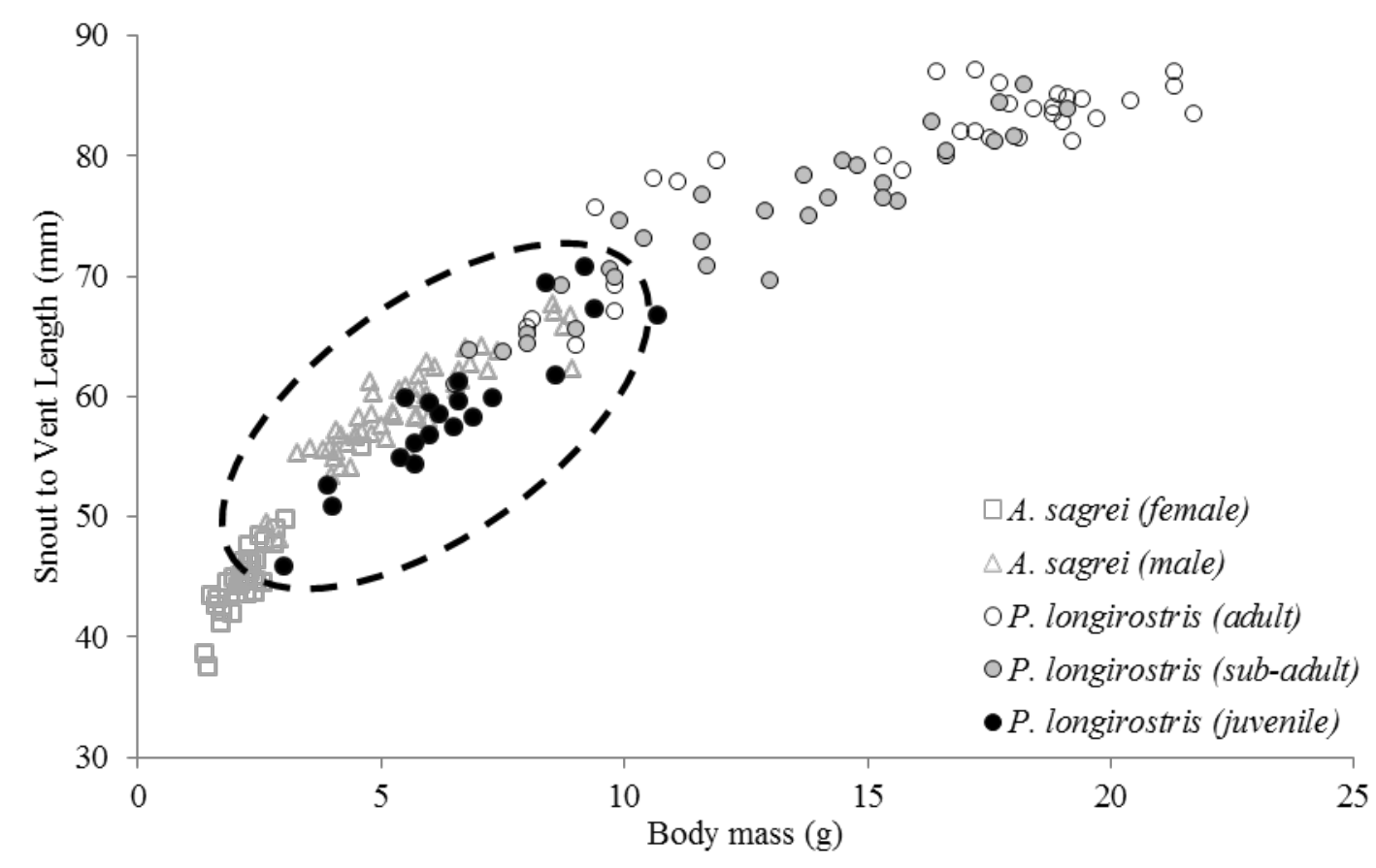

Figure 5.4. General body size overlap between $P$. longirostris (juveniles $n=20$, subadults $n=32$, adults $\mathrm{n}=33$ ) and $A$. sagrei (males $\mathrm{n}=52$, female $\mathrm{n}=36$ ). Circled area indicates body size overlap. $P$. longirostris snout-vent length and mass data taken from Raine (1998). 
Table 5.1. Stomach contents analysis of two independent populations of Cuban brown anoles ( $A$. sagrei) (Site A, Site B) and a combined species total. Data are presented as raw stomach contents and as proportion of total stomach contents. Taxonomic Orders are highlighted in gray, with a breakdown to family where possible highlighted underneath in italics. Orders known to be consumed by Bermudian skinks ( $P$. longirostris) are marked with an ' $\mathrm{X}$ ' in the final column.

\section{Anolis sagrei diet}

\begin{tabular}{|c|c|c|c|c|c|c|c|c|}
\hline \multirow[b]{3}{*}{ Order } & \multirow[b]{3}{*}{ Family } & \multirow{2}{*}{\multicolumn{3}{|c|}{ No. of prey items }} & \multirow{2}{*}{\multicolumn{3}{|c|}{ Proportional no. prey items (\%) }} & \multirow{3}{*}{$\begin{array}{c}\text { Skink } \\
\text { diet }\end{array}$} \\
\hline & & & & & & & & \\
\hline & & Site A & Site B & Combined & Site A & Site B & Combined & \\
\hline \multicolumn{2}{|c|}{ ARANAEA } & 1 & 1 & 2 & 0.4 & 0.3 & 0.4 & $\mathbf{X}$ \\
\hline & Araneidae & 1 & 1 & 2 & 0.4 & 0.3 & 0.4 & \\
\hline \multicolumn{2}{|c|}{ GASTROPODA } & 4 & $\mathbf{0}$ & 4 & 1.7 & $\mathbf{0}$ & 0.7 & $\mathbf{X}$ \\
\hline \multicolumn{2}{|c|}{ BLATTODEA } & $\mathbf{0}$ & 1 & 1 & $\mathbf{0}$ & 0.3 & 0.2 & $\mathbf{X}$ \\
\hline & Blattidae & 0 & 1 & 1 & 0 & 0.3 & 0.2 & \\
\hline \multicolumn{2}{|c|}{ COLEOPTERA } & 17 & 7 & 24 & 7.3 & 2.2 & 4.3 & $\mathbf{X}$ \\
\hline & Chrysomelidae & 2 & 1 & 3 & 0.9 & 0.3 & 0.5 & \\
\hline & Coccinellidae & 2 & 0 & 2 & 0.9 & 0 & 0.4 & \\
\hline & Curculionidae & 1 & 2 & 3 & 0.4 & 0.6 & 0.5 & \\
\hline & Elateridae & 1 & 2 & 3 & 0.4 & 0.6 & 0.5 & \\
\hline & Scarabaeidae & 7 & 2 & 9 & 3 & 0.6 & 1.6 & \\
\hline & Scolytidae & 4 & 0 & 4 & 1.7 & 0 & 0.7 & \\
\hline \multicolumn{2}{|c|}{ DERMAPTERA } & 14 & 1 & 15 & 6 & 0.3 & 2.7 & \\
\hline & Anisolabididae & 14 & 1 & 15 & 6 & 0.3 & 2.7 & \\
\hline \multicolumn{2}{|c|}{ DIPTERA } & 4 & 1 & 5 & 1.7 & 0.3 & 0.9 & $\mathbf{X}$ \\
\hline \multicolumn{2}{|c|}{ HEMIPTERA } & 11 & 13 & 24 & 4.7 & 4 & 4.3 & \\
\hline & Aphididae & 1 & 6 & 7 & 0.4 & 1.9 & 1.3 & \\
\hline & Blissidae & 8 & 7 & 15 & 3.4 & 2.2 & 2.7 & \\
\hline & Cydnidae & 2 & 0 & 2 & 0.9 & 0 & 0.3 & \\
\hline \multicolumn{2}{|c|}{ HOMOPTERA } & 20 & 8 & 28 & 8.6 & 2.5 & 5 & \\
\hline & Cicadellidae & 20 & 8 & 28 & 8.6 & 2.5 & 5 & \\
\hline \multicolumn{2}{|c|}{ HYMENOPTERA } & 122 & 277 & 399 & 52.1 & 85.5 & 71.5 & $\mathbf{X}$ \\
\hline & Apidae & 1 & 0 & 1 & 0.4 & 0 & 0.2 & \\
\hline & Formicidae & 121 & 277 & 398 & 51.7 & 85.5 & 71.3 & \\
\hline \multirow{2}{*}{\multicolumn{2}{|c|}{$\begin{array}{l}\text { ISOPTERA } \\
\text { LEPIDOPTERA }\end{array}$}} & $\mathbf{0}$ & 1 & 1 & $\mathbf{0}$ & 0.3 & 0.2 & \\
\hline & & 28 & 5 & 33 & 12 & 1.5 & 5.9 & $\mathbf{x}$ \\
\hline & Hesperiidae & 16 & 0 & 16 & 6.8 & 0 & 2.9 & \\
\hline & Nymphalidae & 1 & 3 & 4 & 0.4 & 0.9 & 0.7 & \\
\hline & Pieridae & 11 & 2 & 13 & 4.7 & 0.6 & 2.3 & \\
\hline ORTH & PTERA & 1 & 1 & 2 & 0.4 & 0.3 & 0.4 & $\mathbf{X}$ \\
\hline & Gryllidae & 1 & 0 & 1 & 0.4 & 0 & 0.2 & \\
\hline & Acridae & 0 & 1 & 1 & 0 & 0.3 & 0.2 & \\
\hline
\end{tabular}




\begin{tabular}{|c|c|c|c|c|c|c|c|}
\hline THYSANOPTERA & 1 & 0 & 1 & 0.4 & $\mathbf{0}$ & 0.2 & \\
\hline Thripidae & 1 & 0 & 1 & 0.4 & 0 & 0.2 & \\
\hline AMPHIPODA & 1 & 0 & 1 & 0.4 & $\mathbf{0}$ & 0.2 & $\mathbf{X}$ \\
\hline Talitridae & 1 & 0 & 1 & 0.4 & 0 & 0.2 & \\
\hline ISOPODA & 7 & 6 & 13 & 3 & 1.9 & 2.3 & $\mathbf{X}$ \\
\hline Porcellionidae & 7 & 6 & 13 & 3 & 1.9 & 2.3 & \\
\hline CHILOPODA & 1 & $\mathbf{0}$ & 1 & 0.4 & $\mathbf{0}$ & 0.2 & \\
\hline Geophilidae & 1 & 0 & 1 & 0.4 & 0 & 0.2 & \\
\hline SQUAMATA & 2 & 2 & 4 & 0.9 & 0.6 & 0.7 & \\
\hline Dactyloidae & 2 & 2 & 4 & 0.9 & 0.6 & 0.7 & \\
\hline
\end{tabular}

\section{DISCUSSION}

While the origin of A. sagrei populations on Bermuda is unknown, these populations are established (reproducing for at least five years), large (our estimate of ca. 4000-5000 individuals already exceeds the total global population of $P$. longirostris with ca. 3500 individuals; Edgar et al. 2010), and expanding. Firstly, we identify a substantial ecological overlap between A. sagrei and P. longirostris - both species are highly terrestrial (Fig 5.3) and feed primarily on grounddwelling arthropods (Table 5.1). Secondly, we demonstrate that $A$. sagrei broadly overlap in body size with P. longirostris (Fig 5.4), meaning competitive interactions may be likely, and that Bermudian A. sagrei consume smaller lizards. And thirdly, that the ecological threat posed by A. sagrei to P. longirostris is unique compared to those posed by all other non-native Anolis lizards on Bermuda.

Based on our observed range expansion at Site A from 2014 to 2015 (0.05km/year), we estimate that contact between $A$. sagrei and $P$. longirostris may occur in $\sim 10$ years $(0.5 \mathrm{~km}$ linear distance). It is highly likely, however, that contact between the two species will occur sooner. Indirect dispersal via human transport is commonly observed in A. sagrei; adults stowaway in nursery plants, on cars, and inside garbage waste, while eggs are easily transported in soil (Lee 
1985, Goldberg et al. 2002, Kolbe et al. 2016). Site A is a plant nursery which could greatly expedite the spread of $A$. sagrei.

If contact is made between $A$. sagrei and $P$. longirostris, the possibility of extended coexistence is unclear. In islands across the Caribbean, establishment success of introduced Anolis lizards has a strong negative relationship with the degree of ecological similarity they have with native lizards (Losos et al. 1993). This relationship suggests that priority effects - the prior establishment of a species in an area (Fukami 2015) - may be particularly important for assembly patterns of introduced Anolis lizards on Bermuda (Wingate, 1965; Losos, 1996). The prior establishment of $P$. longirostris in areas devoid of $A$. sagrei may provide a demographic advantage rendering A. sagrei expansion attempts unsuccessful. This is a hypothesis that can be tested by continued monitoring of species distributions.

If coexistence does occur, we predict that there will be strong interspecific competition for habitat, prey, or both. Given that $A$. sagrei achieves extremely high densities once established (4,900-12,000 individuals/ha; Campbell and Echternacht 2003), space and food may become limiting. Our estimates of A. sagrei population densities in Bermuda are high (ca. 1000 individuals/ha), however it is likely that these populations are in an initial stage of invasion, and prior to exponential growth - a lag time pattern commonly recorded in invasive species (Sakai et al. 2001). High density populations of invasive A. sagrei in Taiwan (1,275-2,900 individuals/ha; Huang et al. 2008) were such a robust predatory force that ground arthropod diversity and structure were dramatically altered. Furthermore, the communities most affected by Taiwanese $A$. sagrei were ant communities, the primary prey resource of $P$. longirostris (Wingate 1965). If sites of coexistence are identified, rapid monitoring of the arthropod community will help to understand the extent of A. sagrei effects on food resources, and provide further insight into potential conservation risks for $P$. longirostris via dietary overlap. 
Predation is the most common interaction through which invasive species negatively affect endemic species (Sodhi et al. 2009). Although $P$. longirostris experience predation from several non-native predators, all have coexisted with $P$. longirostris for at least 40 years (Davenport et al. 2001, Bacon et al. 2006). It has been suggested, following direct observations of P. longirostris predation by A. grahami, that exceptionally high population densities of $P$. longirostris on islands devoid of Anolis lizards provides evidence for a predator-prey interaction (Wingate 1998). While this may be true, this could also be explained by a competitive relationship. Whether $A$. sagrei poses a significant predatory risk is difficult to predict; adult $P$. longirostris are much larger than A. sagrei, but skink hatchlings and juveniles are small enough to be considered viable prey items for adult $A$. sagrei, particularly adult males (hatchling SVL 35mm, mass 1.1g; juvenile SVL 49.5 mm; mass 4.1g; L. Kitson unpubl. data). Although adult males are the most arboreal age/sex class of $A$. sagrei on Bermuda and therefore encounter rates with skinks may be lower, the majority of individuals were found on or near to the ground, which is typically where most foraging activity occurs (Giery et al. 2013). Therefore, during periods of active foraging, A. sagrei will experience a high habitat overlap with P. longirostris. Adult Anolis sagrei of both sexes on Bermuda are saurophagus (Table 1), and therefore the conservation threat to $P$. longirostris from $A$. sagrei may include predation on hatchlings.

Our assessment of niche overlap between Bermudian A. sagrei and P. longirostris suggests that the $A$. sagrei invasion could pose a unique and substantial conservation threat through competition for space and food. However, native species extinctions resulting from interspecific competition with invasive species are extremely rare (Sax et al. 2007), suggesting that estimates of ecological overlap may not predict extinction risk in cases like this. Predation by invasive species, however, does drive native species to extinction. Given the saurophagous nature of Bermudian A. sagrei, and the small size of $P$. longirostris hatchlings, we believe a predatory interaction is possible, although as coexistence does not yet occur this remains undocumented. 
The situation on Bermuda provides an exceptional opportunity to test further a priori predictions about how ecological interactions, specifically competition and predation, between an invasive and a vulnerable endemic may pose a conservation risk when the species come into contact. Future monitoring of the distribution, population demographics, and ecology of A. sagrei on Bermuda is critically important to maintain effective conservation and management of the few remaining natural $P$. longisrostris populations in the world.

\section{Acknowledgements}

This is contribution \# 246, Bermuda Biodiversity Project (BBP), Bermuda Aquarium, Natural History Museum and Zoo, Department of Environment and Natural Resources. We thank the Bermuda Zoological Society (Eric Clee Fund) for financial research support, as well as to Thad and Evan Outerbridge for providing accommodation. We thank Kenneth Feeley, Evan Rehm, Rachel Hillyer, Catherine Bravo-Avila, Jason Kolbe, Joe Macedonia, and one anonymous reviewer for providing important and insightful comments on previous versions of this manuscript. JS was supported by the FIU Judith Evans Parker Travel Fund and an FIU Dissertation Evidence Acquisition Fellowship. STG was supported by NSF DEB \#1406399. 


\section{References}

Andersen MC, Adams H, Hope B, Powell M (2004). Risk assessment for invasive species. Risk analysis 24(4): 787-793

Bacon JP, Gray JA, Kitson L (2006) Status and conservation of the reptiles and amphibians of the Bermuda islands. Applied Herpetology 3(4): 323-344

Campbell TS, Echternacht AC (2003) Introduced species as moving targets: changes in body sizes of introduced lizards following experimental introductions and historical invasions. Biological Invasions 5(3): 193-212

Davenport J, Hills J, Glasspool A, Ward J (2001) Threats to the Critically Endangered endemic Bermudian skink Eumeces longirostris. Oryx 35: 332-339

Davies KW, Johnson DD (2011) Are we "missing the boat" on preventing the spread of invasive plants in rangelands? Invasive Plant Science and Management 4: 166-171

Edgar P, Kitson L, Glasspool AF, Sarkis S (2010) Recovery plan for the Bermuda skink, Eumeces longirostris. Department of Conservation Services, Government of Bermuda.

Fukami T. (2015) Historical contingency in community assembly: integrating niches, species pools, and priority effects. Annual Review of Ecology, Evolution, and Systematics 46(1): 1-23

Giery ST, Lemoine NP, Hammerschlag-Peyer CM, Abbey-Lee RN, Layman CA (2013)

Bidirectional trophic linkages couple canopy and understorey food webs. Functional

Ecology. 27(6): 1436-1441.

Goldberg SR, Kraus F, Bursey CR (2002) Reproduction in an introduced population of the brown anole, Anolis sagrei, from O’ahu, Hawai’i. Pacific Science. 56(2): 163-168

Huang S-C, Norval G, Tso I-M (2008) Predation by an exotic lizard, Anolis sagrei, alters the ant community structure in betelnut palm plantations in southern Taiwan. Ecological Entomology. 33: 569-76

IUCN (2015) The IUCN Red List of Threatened Species. Version 2015-4.

<http://www.iucnredlist.org>. Downloaded on 17 March 2016.

Kolbe JJ, Glor RE, Rodriguez-Schettino L, Chamizo-Lara A, Larson A, Losos JB (2007) Multiple sources, admixture, and genetic variation in introduced Anolis lizard populations. Conservation Biology 21(6): 1612-1625.

Kolbe JJ, VanMiddlesworth P, Battles AC, Stroud JT, Buffum B, Forman RTT, Losos JB (2016) Determinants of spread in an urban landscape by an introduced lizard. Landscape Ecology. 31(8): 1795-1813

Lee JC (1985) Anolis sagrei in Florida: Phenetics of a colonizing species I. Meristic characters. Copeia. 1985(1): 182-194 
Losos JB, Marks JC, Schoener TW (1993) Habitat use and ecological interactions of an introduced and native species of Anolis lizard on Grand Cayman, with a review of the outcomes of anole introductions. Oecologia. 95(4): 525-532

Losos JB (1996) Dynamics of range expansion by three introduced species of Anolis lizards on Bermuda. Journal of Herpetology 1996: 204-210.

Norval G, Hsiao WF, Huang SC, Chen CK (2010) The diet of an introduced lizard species, the brown anole (Anolis sagrei), in Chiayi County, Taiwan. Russian. Journal of Herpetology. 17(2): 131-138.

Powell R, Henderson RW, Farmer MC, Breuil M, Echternacht AC, van Buurt G, Romagosa CM, Perry G (2011) Introduced amphibians and reptiles in the greater Caribbean: Patterns and conservation implications, pp. 63-143. In Hailey A, Wilson BS, Horrocks JA (eds.), Conservation of Caribbean Island Herpetofaunas. Volume 1: Conservation Biology and the Wider Caribbean. Brill, Leiden, The Netherlands.

Raine A (1998) A study of the morphological differentiation, fluctuating asymmetry and the threats facing isolated populations of the Critically Endangered Bermuda Rock Lizard (Eumeces longirostris). Dissertation, University College London, England UK.

Sakai AK, Allendorf FW, Holt JS, Lodge DM, Molofsky J, With KA, Baughman S, Cabin RJ, Cohen JE, Ellstrand NC, McCauley DE, O’Neil P, Parker IM, Thompson JN, Weller SG (2001) The population biology of invasive species. Annual Review of Ecology, Evolution, and Systematics. 32: 305-332

Sax DF, Stachowicz JJ, Brown JH, Bruno JF, Dawson MN, Gaines SD, Grosberg RK, Hastings A, Holt RD, Mayfield MM, O’Connor MI, Rice WR (2007) Ecological and evolutionary insights from species invasions. Trends in Ecology \& Evolution 22(9): 465-471.

Schoener TW (1968) The Anolis lizards of Bimini: resource partitioning in a complex fauna. Ecology 49(4): 704-726

Simberloff D (1995) Why do introduced species appear to devastate islands more than mainland areas? Pacific Science 49(1): 87-97

Sodhi NS, Brook BW, Bradshaw CJ (2009) Causes and consequences of species extinctions. The Princeton Guide to Ecology, 514-520.

Stuart YE, Campbell TS, Hohenlohe PA, Reynolds RG, Revell LJ, Losos JB (2014) Rapid evolution of a native species following invasion by a congener. Science 346(6208): 463-466.

Thomas L, Buckland ST, Rexstad EA, Laake JL, Strindberg S, Hedley SL, Bishop JRB, Marques TA, Burnham KP (2010) Distance software: design and analysis of distance sampling surveys for estimating population size. Journal of Applied Ecology 47: 5-14

Verill AE (1902) The Bermuda Islands: Their scenery, climate, productions, physiography, natural history and geology: with sketches of their early history and the changes due to man. Vol. 11. Connecticut Academy of Arts and Sciences

Wingate DB (1965) Terrestrial herpetofauna of Bermuda. Herpetologica 21: 202-218 
Wingate R (1998) A comparison of demography and morphological variation in two insular populations of the Bermuda rock lizard (Eumeces longirostris). Dissertation, University 
CHAPTER VI

CONCLUSIONS 
The historical nature of evolutionary biology has meant that the field has classically relied on piecing together evidence from the present to test hypotheses about processes which happened in the past (Mayr 2004). However, the realization that evolution can happen on observable time scales if natural selection is strong has propelled evolutionary biology into the age of experiments. A new wave of studies investigating the behavioral and ecological mechanisms underlying classic hypotheses of evolutionary diversification are now connecting the process-pattern bridge between mircoevolution and macroevolution.

In Chapter II, I reviewed macroevolutionary hypotheses for the origins of species and the evolution of phenotypic diversity in adaptive radiations. The process of adaptive radiation - the proliferation of species from a single ancestor and diversification into many ecologically-different forms - has long been considered important to the origins of diversity. However, the conditions and events which trigger adaptive radiations remains unresolved. The hypothesis of "ecological opportunity” has been classically invoked as a potential key to understanding when and how adaptive radiation occurs (Simpson 1953). I broadly reviewed the conceptualization and use of ecological opportunity in adaptive radiation research, how it might mechanistically lead to adaptive radiation, and discussed whether it has any predictive value, or is simply only of heuristic value as a post hoc explanation.

I concluded that Simpson's (1953) hypothesis of ecological opportunity as the impetus for adaptive radiation is well-supported. However, now is the time for studies of adaptive radiation to continue to push forward beyond identifying temporal patterns of phylogenetic and phenotypic diversificiation, and investigate in greater detail the underlying mechanistic basis of adaptive radiations. I suggested several avenues of future research which provide exciting opportunities to extend our knowledge about adaptive radiations; i) empirical assessment of adaptive landscapes, (ii) investigating the genomic structure of adaptive radiations, (iii) understanding the eco-evolutionary nature of niche construction, (iv) using non-native species as 
experimental analogues of adaptive radiations, (v) observing evolutionary responses to widespread global extinctions, and (vi) investigating the relationship between ecological opportunity and the latitudinal diversity gradient.

I concluded by emphasizing that it remains important, however, to maintain a detailed understanding of the natural history of study organisms and model systems (Greene 1986, Grant \& Grant 2008, 2014, Losos 2009). Only those researchers that do so will successfully connect miroevolutionary processes with macroevolutionary patterns. I strongly expect the study of ecological opportunity and adaptive radiations to continue to blossom in the near future.

Non-native species: Eco-evolutionary experiments in the Anthropocene

In Chapters III and IV, I pursued one of the future directions suggested in Chapter II and studied two different communities of non-native Anolis lizards. Specifically, in Chapter III, I investigated the mechanisms which allow ecologically-similar, but evolutionarily-novel, species of anoles introduced to Bermuda to coexist. I discovered that range expansion at the contact zone of the distributions of two species in Bermuda has been asymmetrical, which has resulted in the assembly of different ecological communities despite the same available species pool. Priority effects blocked the invasion of one species into the range of the other, but that pattern was not reciprocal; the reverse invasion was facilitated by the invader shifting into unoccupied ecological space. I suggested that differences between species in the extent of ecological flexibility could be related to each species evolutionary experience of biotic interactions, such that those species originating from more diverse communities are better able to mediate biotic interactions to achieve coexistence. This unequal degree of ecological flexibility between species may explain broad patterns in ecological community assembly dynamics and community diversity, and could be an interesting hypothesis to explain non-random macroevolutionary patterns, such as phylogenetic tree imbalance and a clustered community phylogenetic structure. 
In Chapter IV, I investigated the evolutionary consequences of novel coexistence. Specifically, I examined a case of ecological character displacement driven by interspecific interactions in two species of anoles introduced to south Florida; the Cuban brown anole (Anolis sagrei) and the Puerto Rican crested anole (A. cristatellus). I documented that when in sympatry, A. sagrei and A cristatellus interact strongly and stable cooexistence is achieved through vertical partitioning of structural habitat; A. sagrei are more terrestrial, and A. crisatellus are more arboreal. Consequently, A. sagrei exhibit longer limbs and less-developed subdigital toepads, which is expected with increased terrestriality. However, natural selection has not acted on $A$. cristatellus as expected given increased arboreality. Instead, as an indirect effect of increased arboreality, concomitant with decreases in relative abundance, A. cristatellus become intraspecifically socially-isolated. This has relaxed selection on sexually-important traits associated with intraspecific interactions, specifically bite force, and led to a decrease in head size in sympatry. I suggested that simple ecological character displacement, such as vertical partitioning of habitat as observed here, can lead to phenotypic divergence much more complex than anticipated, and therefore may be responsible for a greater volume of observed phenotypic variation than previously recognized.

Lastly, in my introduction to this dissertation (Chapter I), I explained that it would be unwise and irresponsible of me to capitalize on non-native species introductions as incidental experiments in ecology and evolution without also recognizing the conservation threat that introduced species can pose to native biodiversity (Clavero \& Garcia-Berthou 2005). While in Bermuda conducting my research on community assembly dynamics of three established anoles (Chapter III), I discovered a new species with whom I had become very familiar with in Miami FL; Cuban brown anoles (A. sagrei; Fig. 6.1). In Chapter V, I investigated the conservation threat that A. sagrei poses to Bermuda’s only native lizard, the Critically Endangered endemic Bermuda skink (Plestiodon longirostris). My multi-faceted assessemnet of ecological niche overlap 
between Bermuda populations of $A$. sagrei and Bermuda skinks ( $P$. longirostris) suggests that its invasion could pose a unique and substantial conservation threat through competition for space and food.

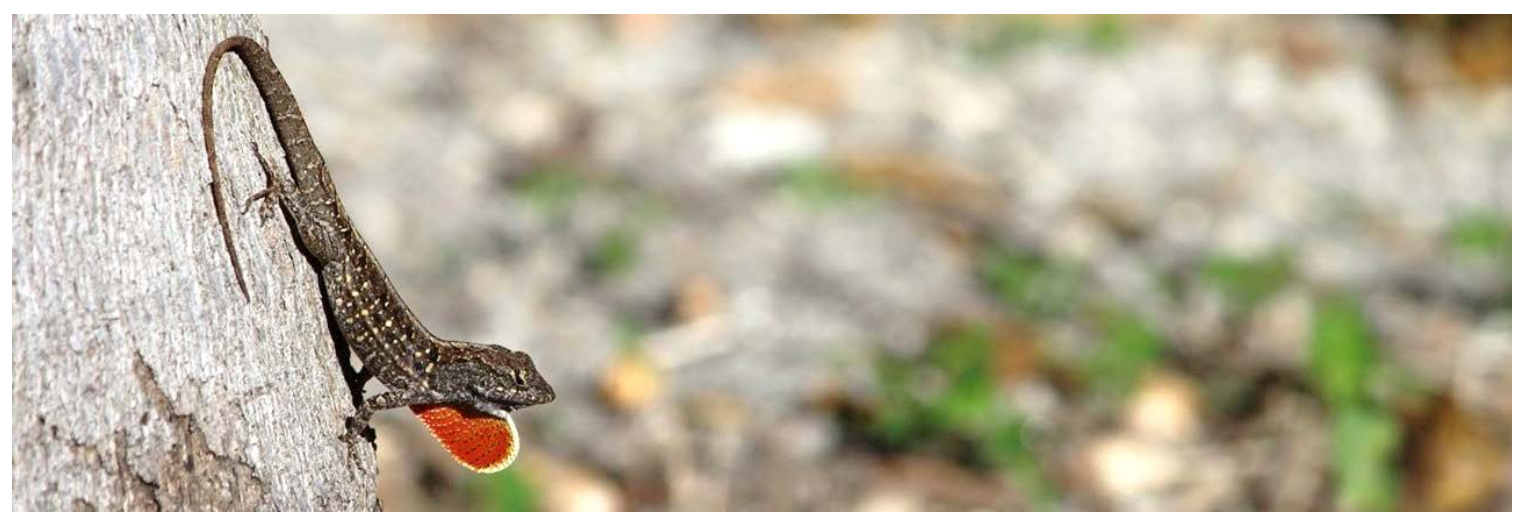

Figure 6.1. An adult male Cuban brown anole (Anolis sagrei) in Miami, FL. Photo: JStroud.

In summary, this dissertation provides compelling evidence that biotic interactions are an important process in structuring ecological communities and driving evolutionary diversification of anoles. By first reviewing macroevolutionary theory of adaptive radiation, it provided me with a clear framework to identify which underlying behavioral and ecological processes are important in the evolution of phenotypic diversity. This dissertation investigated the mechanisms underlying species coexistence, community assembly, and phenotypic divergence, as is predicted in the elusive early stages of adaptive radiation. 


\section{References}

Clavero, M. and García-Berthou, E., 2005. Invasive species are a leading cause of animal extinctions. Trends in Ecology \& Evolution, 20(3): 110.

Grant PR, Grant BR. 2008. How and Why Species Multiply. The Radiation of Darwin's Finches. Princeton Series in Evolutionary Biology

Grant PR, Grant BR. 2014. 40 Years of Evolution: Darwin’s Finches on Daphne Major Island. Princeton University Press

Greene HW. 1986. Natural history and evolutionary biology. Predator-prey relationships: Perspectives and approaches from the study of lower vertebrates. (Feder ME, Lauder GV, eds). pp. 99-108, University of Chicago Press

Losos, J.B., 2009. Lizards in an evolutionary tree: ecology and adaptive radiation of anoles (Vol. 10). Univ. of California Press.

Mayr E. 2004. What Makes Biology Unique? Cambridge (United Kingdom): Cambridge University Press.

Simpson GG. 1953. The Major Features of Evolution. Columbia University Press: New York. 


\section{VITA}

\section{JAMES T. STROUD}

Born, London, England UK

2005-2008

B.Sc. (Hons), Zoology with Conservation

University of Wales, Bangor

Gwynedd, Wales UK

2009-2011

M.Sc. by Research, Landscape Ecology

University of Hull

Scarborough, North Yorkshire, England UK

2012-2017

Doctoral Candidate

Florida International University

Miami, Florida USA

\section{PUBLICATIONS}

Thawley, C.J., Stroud, J.T. (2017) Phelsuma grandis (Madagascan Giant Day Gecko). Geographic distribution: New record for Miami-Dade County. Herpetological Review, 48(4): 812

Tiatragula, S., Murali, G., Stroud, J.T. (2017) Different evolutionary dynamics led to the convergence of clinging performance in lizard toepads. Evolution, 71(10): 2537-2538

Stroud, J.T., Feeley, K.J. (2017) Neglect of the tropics is widespread in ecology and evolution. Trends in Ecology and Evolution, 32(9): 626-629

Giery, S.T., Donte, R., Stroud, J.T. (2017) A review of the current distribution of eastern narrowmouthed frogs in the Greater Caribbean, with a first record from Abaco Island, The Bahamas. IRCF Reptiles \& Amphibians, 24(2): 139-141

Stroud, J.T., Alexander, P., Powell, I.V., Krysko, K.L. (2017) First Record of a Polychrotid Lizard, The Many-colored Bush Anole (Polychrus marmoratus), in Florida, USA. IRCF Reptiles \& Amphibians, 24(2): 148-149

Stroud, J.T. (2017) Ecological opportunity, competition, and diversity-dependence in macroevolution. Evolution, 71(7): 1915-1916

Martin, T.E., Guilleman, M., Nivet-Mazerolles, V., Landsmann, C., Dubos, J., Eudeline, R., Stroud, J.T. (2017) The herpetofauna of central Uzbekistan. Amphibian \& Reptile Conservation, 11(1): 93-107 (e140)

Giery, S.T., Vezzani, E., Zona, S., Stroud, J.T. (2017) Frugivory and seed dispersal by the invasive knight anole (Anolis equestris) in Florida, USA. Food Webs, 11: 13-16

Stroud, J.T., Giery, S.T., Outerbridge, M.E. (2017) Establishment of Anolis sagrei on Bermuda represents a novel ecological threat to Critically Endangered Bermuda skinks (Plestiodon longirostris). Biological Invasions, 19: 1723-1731_

Ljustina O, Stroud J.T. (2017) Anolis carolinensis (American Green Anole): Kleptothermy. Herpetological Review, 48(2)

Feeley, K.J., Stroud, J.T., Perez, T.M. (2016) Most global reviews of climate change impacts aren't truly global. Diversity and Distributions, 23(3): 231-234

Stroud, J.T., Outerbridge, M.E., Giery, S.T. (2016) First specimen of an American green anole (Anolis carolinensis) on the oceanic island of Bermuda, with a review of the species' current global distribution. IRCF Reptiles \& Amphibians, 23(3): 188-190 
Stroud, J.T., \& Losos, J.B. (2016) Ecological Opportunity and Adaptive Radiation. Annual Review of Ecology, Evolution \& Systematics, 47: 507-532

Stroud, J.T., \& Giery, S.T. (2016) Nesting behavior and egg incubation time of introduced brown basilisks (Basiliscus vittatus) in South Florida. IRCF Reptiles \& Amphibians, 23(2): 104107

Kolbe, J.J., VanMiddlesworth, P., Battles, A.C., Stroud, J.T., Buffum, B., Forman, R.T.T., Losos, J.B. (2016) Determinants of spread in an urban landscape by an introduced lizard. Landscape Ecology, 31(8): 1795-1813

Perez, T.M., Stroud, J.T., Feeley, K.J. (2016) Thermal trouble in the tropics. Science, 351(6280): 1392-1393

Ljustina O, Stroud J.T. (2016) Anolis equestris (Cuban Knight Anole): Novel predator-prey interaction. Herpetological Review 47(3): 459-460

Ljustina O, Stroud J.T. (2016) Anolis cristatellus (Puerto Rican Crested Anole): Absent tympanum. Herpetological Review 47(3): 459

Stroud, J.T., Bush, M.R., Ladd, M.C., Nowicki, R.J., Shantz, A.A., and Sweatman, J. (2015) Is a community still a community? Reviewing definitions of key terms in community ecology. Ecology \& Evolution, doi: 10.1002/ece3.1651

Gillespie, G.R., Howard, S., Stroud, J.T., Ul-Hassanah, A., Campling, M., Lardner, B., Scroggie, M., Kusrini, M. (2015) Responses of a tropical herpetofauna community to anthropogenic disturbance and natural habitat variation in Sulawesi, Indonesia. Biological Conservation, 192: 161-173

Rehm, E., Olivas, P., Stroud, J.T., Feeley, K.J. (2015) Losing your edge: climate change and the conservation value of range-edge populations. Ecology \& Evolution, doi: 10.1002/ece3.1645

Stroud, J.T., and Feeley, K.J. (2015) A downside of diversity? A response to Gallagher et al. Trends in Ecology and Evolution, 30(6): 296-297

Stroud, J.T., and Feeley, K.J. (2015) Responsible academica: Optimizing conference locations to minimize greenhouse gas emissions. Ecography, 38(4): 402-404

Martin T, Guillemin M, Eudeline R, Landsmann C, Nivet-Mazerolles V, Stroud J.T. (2015) Reptiles and Amphibians of Semi deserts, Mountains, and other habitats of South Central Uzbekistan. Chicago Field Museum of Natural History

Stroud, J.T. (2015) Reptiles y amphibios de Amacayacu parque Nacional, Amazonas - Colombia (Reptiles and amphibians of Amacayacu National Park, Amazonas - Colombia). Chicago Field Museum of Natural History

Feeley, K.J., Rehm, E., Stroud, J.T. (2014) There are many barriers to species migrations. Frontiers of Biogeography 6(2): fb_22006

Stroud, J.T., Rehm E., Ladd, M., Olivas, P., Feeley, K.J. (2014) Is conservation money being spent wisely? Changing trends in conservation research priorities. Journal of Nature Conservation, 22:471-473

Stroud, J.T. (2014) An introduction to the lizards of Fairchild Tropical Botanical Gardens. The Tropical Garden 69(1): 28-29

Stroud, J.T., and Beckles, W. (2014) Anolis cristatellus (Puerto Rican Crested Anole): Abnormal dewlap color. Herpetological Review, 45(4): 693-694

Stroud, J.T. (2013) Anolis equestris (Cuban Knight Anole): Exotic intra-guild predation. Herpetological Review 44(4): 660-661

Stroud, J.T., and Giery, S. (2013) Anolis equestris (Cuban Knight Anole): Nocturnal activity. Herpetological Review 44(4): 661

Stroud, J.T., and Krysko, K.L. (2013) Ctenosaura similis (Gray’s Spiny-tailed Iguana): Nonnative diet. Herpetological Review 44(2):322 